\title{
Argonne
}

\section{Corrective Action Study for the Former CCC/USDA Facility at Agra, Kansas}

\author{
Environmental Science Division
}




\begin{abstract}
About Argonne National Laboratory
Argonne is a U.S. Department of Energy laboratory managed by UChicago Argonne, LLC under contract DE-AC02-06CH11357. The Laboratory's main facility is outside Chicago, at 9700 South Cass Avenue, Lemont, Illinois 60439. For information about Argonne and its pioneering science and technology programs, see www.anl.gov.
\end{abstract}

\title{
DOCUMENT AVAILABILITY
}

Online Access: U.S. Department of Energy (DOE) reports produced after 1991 and a growing number of pre-1991 documents are available free at OSTI.GOV (http://www.osti.gov/),

a service of the US Dept. of Energy's Office of Scientific and Technical Information.

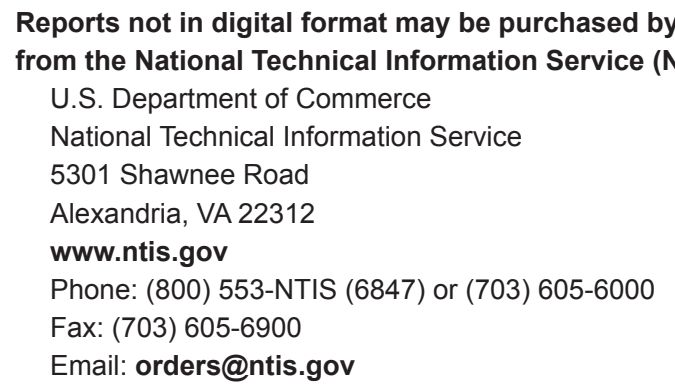

Reports not in digital format are available to DOE and DOE contractors from the Office of Scientific and Technical Information (OSTI):

U.S. Department of Energy

Office of Scientific and Technical Information

P.O. Box 62

Oak Ridge, TN 37831-0062

www.osti.gov

Phone: (865) 576-8401

Fax: (865) 576-5728

Email: reports@osti.gov

\footnotetext{
Disclaimer

This report was prepared as an account of work sponsored by an agency of the United States Government. Neither the United States Government nor any agency thereof, nor UChicago Argonne, LLC, nor any of their employees or officers, makes any warranty, express or implied, or assumes any legal liability or responsibility for the accuracy, completeness, or usefulness of any information, apparatus, product, or process disclosed, or represents that its use would not infringe privately owned rights. Reference herein to any specific commercial product, process, or service by trade name, trademark, manufacturer, or otherwise, does not necessarily constitute or imply its endorsement, recommendation, or favoring by the United States Government or any agency thereof. The views and opinions of document authors expressed herein do not necessarily state or reflect those of the United States Government or any agency thereof, Argonne National Laboratory, or UChicago Argonne, LLC.
} 


\section{Corrective Action Study for the Former CCC/USDA Facility at Agra, Kansas}

by

Applied Geosciences and Environmental Management Section

Environmental Science Division, Argonne National Laboratory

November 2018 


\section{Contents}

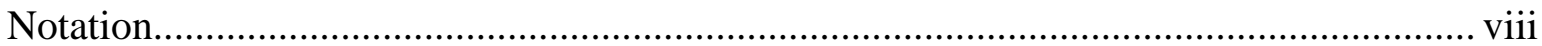

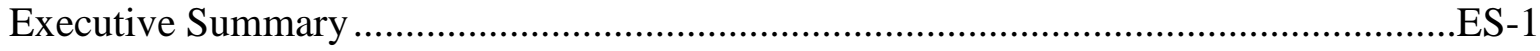

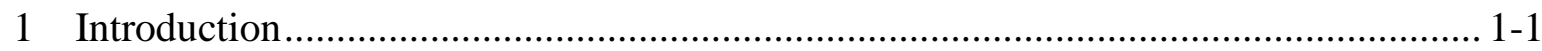

2 Site Background ............................................................................................... 2-1

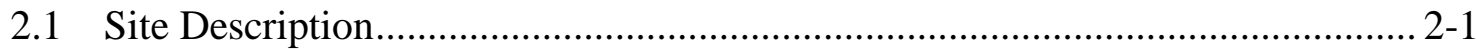

2.2 Summary of Previous Investigations ............................................................ 2-3

2.2.1 Preliminary Assessment: KDHE 1987 ........................................... 2-3

2.2.2 Site Inspection: KDHE 1987-1988 ................................................. 2-3

2.2.3 Site Assessment: KDHE 1993 …..................................................... 2-4

2.2.4 Comprehensive Investigation: KDHE 1995 ........................................ 2-4

2.2.5 Phase I Expedited Site Characterization: CCC/USDA 1995 ................... 2-4

2.2.6 Phase II Expedited Site Characterization: CCC/USDA 1995.................. 2-4

2.2.7 Feasibility Study for Remedial Action: CCC/USDA 1996 .................... 2-5

2.2.8 Phase I Corrective Action Study: KDHE 1997-1998 .............................. 2-5

2.2.9 Groundwater Monitoring: KDHE 1998-1999.................................... 2-5

2.2.10 Contaminant Source Investigation: CCC/USDA 2005 .......................... 2-5

2.2.11 Interim Measure Implementation and Monitoring: CCC/USDA 2009-present ............................................................................ 2-6

2.2.12 Interim Measure Implementation: Pro Ag 2009-2010 .......................... 2-6

2.2.13 Site-Wide Groundwater Monitoring: CCC/USDA and Pro Ag2009-

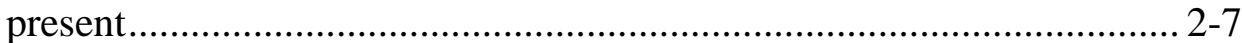

2.2.14 Water Well Survey: Pro Ag 2010 ....................................................... 2-7

2.2.15 Vapor Instrusion Assessment: Pro Ag 2012 ........................................ 2-8

2.2.16 IM Shutdown and Aquifer Testing: CCC/USDA 2016-2017 ................. 2-8

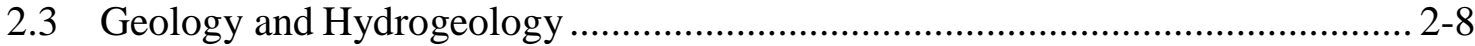

2.4 Carbon Tetrachloride Contamination in Soil .................................................... 2-10

2.4.1 Western Pro Ag Source ................................................................... 2-11

2.4.2 Eastern Pro Ag Source ................................................................... 2-12

2.4.3 CCC/USDA Source ..................................................................... 2-12

2.5 Carbon Tetrachloride Contamination in Groundwater...................................... 2-13

2.6 Evaluation of Carbon Tetrachloride Source Areas and Basis for the CAS ........ 2-15

2.6.1 Evaluation of Carbon Tetrachloride Source Areas ............................. 2-15

2.6.2 Basis for the CAS ...................................................................... 2-18

3 Evaluation of Current and Potential Future Human and Environmental Exposure

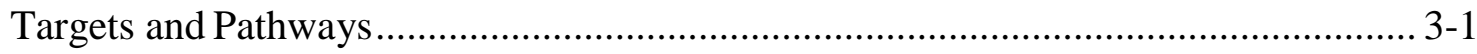

3.1 Soil Exposure Pathway .............................................................................. 3-1

3.2 Vapor Intrusion Exposure Pathway ........................................................... 3-1 


\section{Contents (Cont.)}

3.3 Soil-to-Groundwater Exposure Pathway.............................................................. 3-1

3.4 Groundwater Exposure Pathway...................................................................... 3-2

3.5 Summary .................................................................................................

4 Corrective Action Goals and Regulatory Considerations ............................................. 4-1

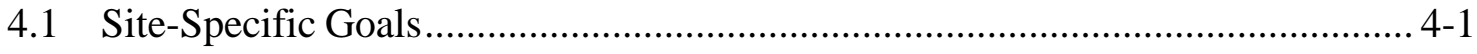

4.2 Regulatory Considerations ............................................................................ 4-1

4.2.1 ARARs and Guidance to be Considered............................................. 4-1

4.2.2 Chemical-Specific ARARs ............................................................... 4-2

4.2.3 Action-Specific ARARs...................................................................... 4-3

4.2.4 Advisories, Criteria, and Guidance ........................................................ 4-4

4.2.5 Waivers and Variances ...................................................................... 4-8

5 Identification and Screening of Technologies............................................................... 5-1

5.1 Criteria for Identifying and Screening Technologies ............................................ 5-1

5.2 Screening of Remedial Technologies............................................................... 5-3

5.2.1 No Action....................................................................................... 5-3

5.2.2 Land Use Controls ............................................................................. 5-4

5.2.3 Containment by Engineered Physical Barriers to Groundwater Flow .... 5-7

5.2.4 Extraction and Treatment of Groundwater ................................................ 5-9

5.2.5 Subsurface Removal and Treatment of VOCs by SVE, AS, or a Combination of SVE and AS ............................................................ 5-13

5.2.6 In Situ Treatment by Permeable Reactive Barriers ............................... 5-16

5.2.7 ISCR Treatment ..................................................................... 5-18

5.3 Retention of Potentially Applicable Technologies............................................ 5-20

6 Description of Alternatives ....................................................................................... 6-1

6.1 Alternative 1: No Action.................................................................................... 6-1

6.2 Alternative 2: Groundwater Extraction, Treatment with a Tray Aerator, Discharge, and Groundwater Monitoring ......................................................... 6-2

6.2.1 Installation of Three Extraction Wells, One Observation Well, and Performance of a Pump Test................................................................... 6-3

6.2.2 Preparation of a Corrective Action Plan ..................................................... 6-4

6.2.3 Installation and Operation of a Groundwater Pump and Treat System and Discharge Pipeline ............................................................... 6-4

6.2.4 SMPE-Related Monitoring and Reporting ......................................... 6-5

6.3 Alternative 3: Groundwater Extraction, Treatment with an Inclined Cascade

Aerator, Discharge, and Groundwater Monitoring ............................................ 6-7

6.3.1 Installation of Three Extraction Wells, One Observation Well, and Performance of a Pump Test..................................................................... 6-8

6.3.2 Preparation of a Corrective Action Plan .................................................. 6-9 


\section{Contents (Cont.)}

6.3.3 Installation and Operation of a Groundwater Pump and Treat System and Associated Pipelines

6.3.4 SMPE-Related Monitoring and Reporting

6.4 Alternative 4: Groundwater Extraction, Treatment, and Discharge by Spray Irrigation, and Groundwater Monitoring $6-12$

6.4.1 Installation of Three Extraction Wells, One Observation Well, and Performance of a Pump Test

6.4.2 Preparation of a Corrective Action Plan ................................................. 6-14

6.4.3 Installation and Operation of a Combined Groundwater Pumping and Spray Irrigation System and Associated Pipelines ........................ 6-15

6.4.4 SMPE-Related Monitoring and Reporting .......................................... 6-16

6.5 Alternative 5: Land Use Controls and Monitoring............................................. 6-18

6.5.1 Preparation of a Corrective Action Plan ............................................... 6-19

6.5.2 SMPE-Related Monitoring and Reporting......................................... 6-19

7 Detailed Analysis of the Corrective Action Alternatives .................................................. 7-1

7.1 Alternative 1: No Action ............................................................................... 7-2

7.1.1 Overall Protection of Human Health and the Environment..................... 7-3

7.1.2 Compliance with ARARs and TBCs .................................................... 7-3

7.1.3 Long-Term Effectiveness and Permanence …………………….............. 7-3

7.1.4 Reduction of Toxicity, Mobility, or Volume …….................................... 7-4

7.1.5 Short-Term Effectiveness ................................................................... 7-4

7.1.6 Implementability........................................................................ 7-4

7.1.7 Cost .............................................................................................. 7-4

7.2 Alternative 2: Groundwater Extraction, Treatment with a Tray Aerator, Discharge, and Groundwater Monitoring ........................................................ 7-5

7.2.1 Overall Protection of Human Health and the Environment ..................... 7-5

7.2.2 Compliance with ARARs and TBCs ..................................................... 7-6

7.2.3 Long-Term Effectiveness and Permanence .............................................. 7-6

7.2.4 Reduction of Toxicity, Mobility, or Volume ………................................ 7-6

7.2.5 Short-Term Effectiveness ..................................................................... 7-6

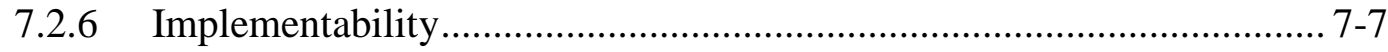

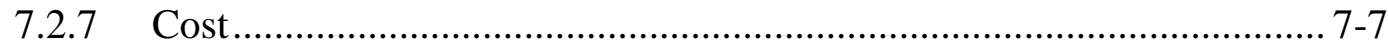

7.3 Alternative 3: Groundwater Extraction, Treatment with an Inclined Cascade

Aerator, Discharge, and Groundwater Monitoring ............................................... 7-8

7.3.1 Overall Protection of Human Health and the Environment..................... 7-8

7.3.2 Compliance with ARARs and TBCs ....................................................... 7-9

7.3.3 Long-Term Effectiveness and Permanence .......................................... 7-9

7.3.4 Reduction of Toxicity, Mobility, or Volume .......................................... 7-9

7.3.5 Short-Term Effectiveness …………………................................ 7-10

7.3.6 Implementability.................................................................

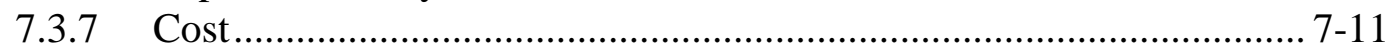




\section{Contents (Cont.)}

7.4 Alternative 4: Groundwater Extraction, Treatment and Discharge by Spray Irrigation and Groundwater Monitoring ........................................................... 7-11

7.4.1 Overall Protection of Human Health and the Environment ................... 7-11

7.4.2 Compliance with ARARs and TBCs .................................................. 7-12

7.4.3 Long-Term Effectiveness and Permanence ........................................ 7-13

7.4.4 Reduction of Toxicity, Mobility, or Volume ………………….............. 7-13

7.4.5 Short-Term Effectiveness ................................................................ 7-13

7.4.6 Implementability......................................................................... 7-13

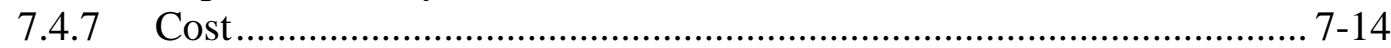

7.5 Alternative 5: Land Use Controls and Monitoring ……............................... 7-15

7.5.1 Overall Protection of Human Health and the Environment ................... 7-15

7.5.2 Compliance with ARARs .................................................................. 7-15

7.5.3 Long-Term Effectiveness and Permanence .......................................... 7-15

7.5.4 Reduction of Toxicity, Mobility, or Volume ………………................ 7-16

7.5.5 Short-Term Effectiveness ............................................................ 7-16

7.5.6 Implementability............................................................................ 7-16

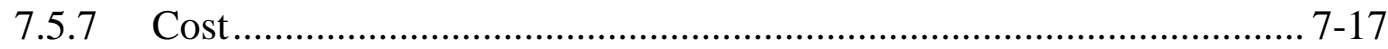

8 Comparative Analysis of Alternatives ...................................................................... 8-1

8.1 Overall Protection of Human Health and the Environment .................................. 8-1

8.2 Compliance with ARARs and TBCs........................................................... 8-2

8.3 Long-Term Effectiveness and Permanence....................................................... 8-2

8.4 Reduction of Toxicity, Mobility, or Volume ……............................................... 8-3

8.5 Short-Term Effectiveness.............................................................................. 8-3

8.6 Implementability .................................................................................... 8-3

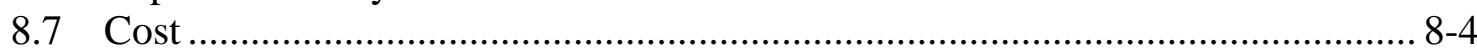

8.8 Stakeholder and State Acceptance ………………............................................. 8-4

8.9 Summary and Recommended Corrective Action.................................................. 8-5

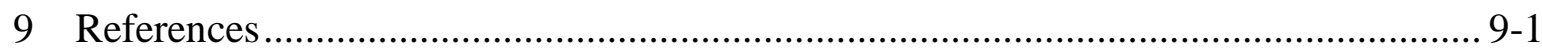

Appendix A: Pro Ag Water Well Survey Results …………............................................ A-1

Appendix B: Potential Federal and State ARARs and State Guidance Documents "To Be Considered" ........................................................................................

Appendix C: Estimation of the Operating Time Period for Groundwater Extraction in Alternatives 2, 3, and 4 ......................................................................... 


\section{Figures}

2.1 Locations of Phillips County and Agra, Kansas

2.2 City map/recent aerial with PWS wells, former CCC, and Co-op property outlines ... 2-24

2.31961 Aerial photograph with potential sources marked ............................................ 2-25

$2.4 \quad 1985$ aerial photograph with potential sources marked …………………................... 2-26

2.5 Interpreted elevation of the bedrock surface, with cross section location shown......... 2-27

2.6 North-south geologic cross section A-A' .............................................................. 2-28

2.7 Interpreted distribution of the upper sand interval....................................................... 2-29

2.8 Vertical cross section A-A', showing schematic net flow for Agra aquifer.................. 2-30

2.9 Map showing source areas and locations of cross sections ......................................... 2-31

2.10 Cross section A-A' ........................................................................................... 2-32

2.11 Cross section $\mathrm{B}-\mathrm{B}^{\prime}$........................................................................................ 2-33

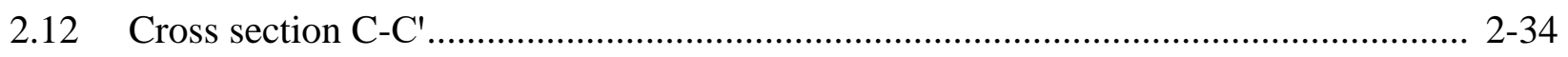

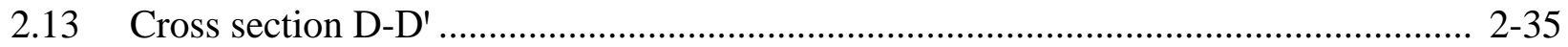

2.14 Map of LDB and IM monitoring point locations...................................................... 2-36

2.151995 plume map at Agra................................................................................... 2-37

2.162005 plume map at Agra..................................................................................... 2-38

2.172017 plume map at Agra...................................................................................... 2-39

2.18 Carbon tetrachloride time-series for the LDB area monitoring wells........................... 2-40

2.19 Location map of monitoring wells downgradient from source areas ........................... 2-41

2.20 Carbon tetrachloride time series for GW5 and MW-J ............................................. 2-42

2.21 Carbon tetrachloride time series for wells downgradient of western Pro Ag source.... 2-43

2.22 Carbon tetrachloride time-series for wells downgradient of eastern Pro Ag source .... 2-44 


\section{Figures (Cont.)}

2.23 Map of bedrock surface in source areas............................................................. 2-45

2.24 Map of upper sand interval and historic carbon tetrachloride detections ................... 2-46

2.25 Map of upper sand near source areas, with historic carbon tetrachloride detections ... 2-47

2.26 Map of maximum nitrate concentrations for wells sampled................................... 2-48

5.1 Inclined Cascade Aerator at Frankfort, Kansas ...................................................... 5-21

6.1 Location of LDB extraction wells, treatment building, ICA, power and pipelines for groundwater flow, power supply, and treated effluent.

6.2 Proposed location for spray irrigation system

C.1 Maximum carbon tetrachloride concentration in groundwater identified in SeptOct 2016, and local extent of the plume as previously identified by the CCC/USDA in 2005

C.2 Drawdown of groundwater levels, in feet from static conditions, observed after six hours of pumping at LDB2 and LBD3 on March 9, 2017

\section{Tables}

2.1 Maximum nitrate concentrations from monitoring points sampled at the Agra site .... 2-20

7.1 Comparative analysis of Agra CAS alternatives .............................................. 7-18

7.2 Cost basis for Alternatives 1-5...................................................................... 7-20

A.1 Summary of Pro Ag water well survey, 2010 .................................................... A-2

B.1 Determination of potential federal ARARs and guidance to be considered for the former CCC/USDA facility at Agra

B.2 Determination of potential state ARARs and guidance to be considered for the former CCC/USDA facility at Agra

C.1 Summary of volumetric analysis for the CCC/USDA source area........................... C-6 


\section{Notation}

AEC Allied Environmental Consultants, Inc.

AMSL above mean sea level

ARAR applicable or relevant and appropriate requirement

AS air sparging

BER Bureau of Environmental Remediation

BGL below ground level

BNSF Burlington Northern-Santa Fe

CAA Clean Air Act

CAD Corrective Action Decision

CAP Corrective Action Plan

CAS Corrective Action Study

CCC Commodity Credit Corporation

CERCLA Comprehensive Environmental Response, Compensation, and Liability Act

CFR Code of Federal Regulation

COKR Code of Kansas Regulations

CRPR Chicago, Rock Island, and Pacific Railroad

CWA Clean Water Act

EO Executive Order

EPA U.S. Environmental Protection Agency

EUC Environmental Use Control

${ }^{\circ} \mathrm{F} \quad$ degree(s) Fahrenheit

$\mathrm{ft} \quad$ foot (feet)

$\mathrm{ft}^{2} \quad$ square foot (feet)

GAC granular activated carbon

gpm gallon(s) per minute

HAP hazardous air pollutant

HDPE high-density polyethylene

hr hour(s)

ICA inclined cascade aerator

IM interim measure

in. inch(es)

ISCR in situ chemical reduction

KAR Kansas Administrative Regulations

KDA Kansas Department of Agriculture 


\section{Notation (Cont.)}

\begin{tabular}{|c|c|}
\hline KDHE & Kansas Department of Health and Environment \\
\hline $\mathrm{kg}$ & kilogram(s) \\
\hline$K_{h}$ & hydraulic conductivity \\
\hline KRC & Kyle Railroad Company \\
\hline KSA & Kansas Statutes Annotated \\
\hline $\mathrm{lb}$ & pound \\
\hline LDB & large-diameter borehole \\
\hline LUC & land use control \\
\hline$\mu g / \mathrm{kg}$ & microgram(s) per kilogram \\
\hline$\mu g / L$ & microgram(s) per liter \\
\hline $\mathrm{mg} / \mathrm{kg}$ & milligram(s) per kilogram \\
\hline $\mathrm{mg} / \mathrm{L}$ & milligram(s) per liter \\
\hline $\mathrm{mi}$ & mile(s) \\
\hline MCL & maximum contaminant level \\
\hline MSPA & Mid-States Port Authority \\
\hline NAPL & non-aqueous phase liquid \\
\hline NCP & National Oil and Hazardous Substances Pollution Contingency Plan \\
\hline NEPA & National Environmental Policy Act \\
\hline NESHAP & National Emission Standards for Hazardous Air Pollutants \\
\hline NPDES & National Pollutant Discharge Elimination System \\
\hline NPR & Nitrogen Presumptive Remedy \\
\hline NPV & net present value \\
\hline $\mathrm{O} \& \mathrm{M}$ & operation and maintenance \\
\hline OSHA & Occupational Safety and Health Administration \\
\hline OSWER & Office of Solid Waste and Emergency Response \\
\hline OTST & off-the-shelf technology \\
\hline PA & preliminary assessment \\
\hline PM & particulate matter \\
\hline POTW & publicly owned treatment works \\
\hline PRB & permeable reactive barrier \\
\hline PRC & PRC Environmental Management, Inc. \\
\hline PVC & polyvinyl chloride \\
\hline PWS & public water supply \\
\hline $\mathrm{QA} / \mathrm{QC}$ & quality assurance/quality control \\
\hline
\end{tabular}




\section{Notation (Cont.)}

RACER Remedial Action Cost Engineering and Requirements

RAO remedial action objective

RBSL risk-based screening level

RCRA Resource Conservation and Recovery Act

ROI radius-of-influence

SMCL secondary maximum contaminant level

SMPE Site Monitoring and Performance Evaluation

SVE soil vapor extraction

TBC to be considered

TSCA Toxic Substance Control Act

USC U.S. code

USDA U.S. Department of Agriculture

VI vapor intrusion

VOC volatile organic compound

yr year(s) 


\section{Corrective Action Study for the Former CCC/USDA Facility in Agra, Kansas}

\section{Executive Summary}

This Corrective Action Study (CAS), consistent with the guidance of the Kansas Department of Health and Environment (KDHE 2001a), has been prepared for the Commodity Credit Corporation of the U.S. Department of Agriculture (CCC/USDA) grain storage facility formerly located in Agra, Kansas.

Site investigations conducted by the CCC/USDA and others identified carbon tetrachloride contamination in the vadose zone and saturated soils and groundwater beneath the former CCC/USDA facility and adjacent grain storage facilities currently owned and operated by the Producers Agricultural Marketing Association, Inc. (Pro Ag; formerly known as the Kensington Cooperative Association), and in groundwater downgradient from these facilities. The carbon tetrachloride levels exceeded the KDHE Tier 2 risk-based screening level (RBSL) guideline for this contaminant in soils ( $73.4 \mu \mathrm{g} / \mathrm{kg}$, for protection of the soil-to-groundwater pathway), and the KDHE RBSL guideline and U.S. Environmental Protection Agency maximum contaminant level for this compound in drinking water $(5 \mu \mathrm{g} / \mathrm{L})$. Hydrogeologic and groundwater monitoring data compiled by the CCC/USDA show that groundwater contamination associated with the former CCC/USDA facility has historically demonstrated little to no downgradient migration, supporting the conclusion that the downgradient carbon tetrachloride distribution at Agra originated from source areas on the Pro Ag property.

In 2009, with the approval of the KDHE, the CCC/USDA implemented an interim measure (IM) employing combined air-sparging and soil vapor extraction in large-diameter boreholes (LDBs) to mitigate localized, elevated levels of carbon tetrachloride contamination in the vadose zone soils and groundwater beneath the former CCC/USDA facility (hereafter referred to as the "LDB/IM"). Since 2009, the LDB/IM has successfully remediated contamination in the vadose zone soils. Continued operation of the LDB/IM, however, does not represent a technically efficient or cost-and-time-effective mechanism for the remediation of contamination locally remaining in the groundwater (Argonne 2018). To evaluate measures that would address residual carbon tetrachloride contamination primarily remaining in groundwater at this location, this CAS compares a baseline "no action" alternative and four remedial action alternatives. The no action alternative assumes that operation of the LDB/IM systems has ceased. 
The exposure pathway from contaminated groundwater to humans via ingestion is incomplete. The exposure pathways from contaminated groundwater to surface discharge and then to human or environmental receptors are also incomplete. In addition, the site is located on an active railroad right-of-way and is subject to rigorous land use controls by the owner of the railroad. Nevertheless, for this CAS, all of these possible exposure pathways have been evaluated to define site-specific goals for corrective actions related to the former CCC/USDA property, as follows:

- Reduce the toxicity, mobility, and volume of contaminated groundwater associated with the source area at the former CCC/USDA facility.

- Mitigate potential future risks to human health via the groundwater exposure pathway, associated with the carbon tetrachloride contamination that has been linked to the former CCC/USDA facility.

Four general response actions and seven individual technologies and practices, in addition to the required no action option, were considered for their potential to meet the site-specific corrective action goals. These technologies and practices were screened against criteria outlined in the CAS guidance (KDHE 2001). On the basis of this initial review, selected technologies and practices were assembled into five candidate alternatives for further detailed evaluation, as follows:

- Alternative 1: No action (required by the KDHE)

- Alternative 2: Groundwater extraction, treatment with a tray aerator, discharge to Turner Creek, and groundwater monitoring

- Alternative 3: Groundwater extraction, treatment with an inclined cascade aerator, discharge to Turner Creek, and groundwater monitoring

- Alternative 4: Groundwater extraction, treatment and discharge by spray irrigation, and groundwater monitoring

- Alternative 5: Land use controls and monitoring 
The candidate alternatives were evaluated in accord with KDHE requirements, in the context of other site-specific contamination issues. The preferred remedial alternative is Alternative 2: Groundwater extraction, treatment with tray aeration, discharge to Turner Creek, and groundwater monitoring. Alternative 2 would accomplish the following:

1. Remove and treat a significant mass of carbon tetrachloride from the contaminated groundwater.

2. Enable closure of the site after an agreed upon period of operation.

The recommended alternative also includes periodic groundwater monitoring, reporting of treatment system and groundwater monitoring results to the KDHE, and the performance of 5-yr reviews to substantiate the protectiveness of the remedy. If an evaluation of the monitoring results indicates that groundwater contaminant concentrations are not decreasing, the CCC/USDA would review the current site conditions and historical data to determine the most appropriate approach for addressing the contamination; contingency plans would be evaluated in conjunction with the KDHE if such plans become necessary. 


\section{Corrective Action Study for the Former CCC/USDA Facility in Agra, Kansas}

\section{Introduction}

The Commodity Credit Corporation of the U.S. Department of Agriculture (CCC/USDA) directed Argonne National Laboratory to prepare this Corrective Action Study (CAS), consistent with guidance of the Kansas Department of Health and Environment (KDHE 2001a), for the CCC/USDA grain storage facility formerly located in Agra, Kansas.

Site investigations conducted by the CCC/USDA and others (discussed in Section 2) identified carbon tetrachloride contamination in the vadose zone and saturated soils and groundwater beneath the former CCC/USDA facility and adjacent grain storage facilities currently owned and operated by the Producers Agricultural Marketing Association, Inc. (Pro Ag; formerly known as the Kensington Cooperative Association), and in groundwater downgradient from these facilities. The carbon tetrachloride levels exceeded the Kansas Tier 2 risk-based screening level (RBSL) guideline for this contaminant in soils $(73.4 \mu \mathrm{g} / \mathrm{kg})$ for protection of the soil-togroundwater pathway, and the KDHE RBSL guideline and U.S. Environmental Protection Agency (EPA) maximum contaminant level (MCL) for this compound in drinking water $(5 \mu \mathrm{g} / \mathrm{L})$.

In response to these findings, and with the approval of the KDHE, the CCC/USDA implemented an Interim Measure (IM) in 2009 employing combined air-sparging and soil vapor extraction (AS/SVE) in large-diameter boreholes (LDBs) to mitigate localized, elevated levels of carbon tetrachloride contamination in the vadose zone soils and groundwater beneath the former CCC/USDA facility (hereafter referred to as the "LDB/IM"). This LDB/IM has operated since 2009 and has successfully remediated contamination in the vadose zone soils. Recently, continued operation of the LDB/IM for the remediation of contamination remaining in groundwater has been determined not to be technically efficient or cost-and-time effective (Argonne 2018a). This CAS was initiated to evaluate measures to address residual carbon tetrachloride contamination remaining primarily in the saturated zone at this location, by comparing a baseline "no-action" alternative and four remedial action alternatives. The no-action alternative assumes that operation of the LDB/IM has ceased.

The history of previous investigations and the nature of the contamination at Agra are summarized in Section 2, together with an overview of the factors controlling the distribution and movement of carbon tetrachloride in the subsurface. An evaluation of human and environmental 
targets and potential exposure pathways associated with the contamination identified at the former CCC/USDA facility is in Section 3. Section 4 describes the corrective action goals and applicable or relevant and appropriate requirements (ARARs). Section 5 identifies and screens candidate technologies for addressing the contamination; and in Section 6, selected technologies are used to develop remedial alternatives. The alternatives are evaluated in detail in Section 7 and compared in Section 8. Section 8 also presents a summary of the CAS findings and identifies the recommended corrective action alternative. Section 9 provides a list of references cited in this report. 


\section{Site Background}

\subsection{Site Description}

Agra, Kansas, is a rural community in eastern Phillips County, in the north-central portion of the state (Section 27, Township 3 south, Range 16 west), about 275 mi northwest of Topeka, Kansas (Figure 2.1). The population of Agra was identified as 267 in the 2010 Census; the current population is estimated as 244 (U.S Census Bureau; http://www.census.gov).

Agra lies within the Blue Hills-Smoky Hills physiographic region of Kansas, adjacent to the eastern border of the High Plains and beyond the western limit of continental glaciation. In this area, unconsolidated deposits of Quaternary fluvial sands and gravels overlying Cretaceous limestone (or chalk) and shale bedrock represent the only available aquifers (Frye and Leonard 1965; Reed et al. 1965).

Since 1939, Agra has obtained its water supply from a municipal distribution system (Kansas water system number 2014707), although a number of private wells are present in the town that remain in use for lawn-and-garden purposes (Pro Ag 2010a). Current average water usage from the public system is estimated at approximately 29,100 gal/day. Over the years, five public water supply (PWS) wells completed in the unconsolidated deposits have been operated by the town (PWS1-PWS5; Figure 2.2); since 1991, only wells PWS1, PWS2, and PWS5 have been in regular use (KDHE 2017a). Since 1997, the KDHE has been testing the Agra distribution system for contamination by volatile organic compounds (VOCs) once every three years; the most recent KDHE sampling event was in September, 2015. No carbon tetrachloride has been detected in the system since 1991.

Carbon tetrachloride contamination was first identified in the groundwater at Agra as a result of routine screening of the PWS conducted by the KDHE in September, 1985; levels of carbon tetrachloride below the MCL (5 $\mu \mathrm{g} / \mathrm{L}$ ) were confirmed in both PWS3 and PWS4 (KDHE 1985). In December 1985, the city discontinued regular use of PWS3 and PWS4. Additional sampling of these wells demonstrated an increase in carbon tetrachloride levels, to $12 \mu \mathrm{g} / \mathrm{L}$ at PWS3 and 3.4 $\mu \mathrm{g} / \mathrm{L}$ at PWS4 in August 1986. On the basis of these findings, the KDHE directed the city to remove PWS3 and PWS4 from service (except for emergency use), and recommended that the city take action to replace these wells (KDHE 1987). In 1988, PWS4 was disconnected from the distribution system and ownership of the well was transferred by the City to the local high school in Agra, for 
irrigation of the school's football field (PRC 1994). Until the construction of well PWS5 in 1991, wells PWS1 and PWS2 were operated routinely, with PWS3 as needed to meet maximum demands. Well PWS5 is located approximately one mile east of the Agra. Well PWS3 remains available to the City for emergency use only (KDHE 2017a).

Agra has historically hosted multiple grain storage or ag-related facilities that may have been associated with the use or storage of grain fumigants containing carbon tetrachloride, primarily on right-of-way formerly owned by the Chicago, Rock Island, and Pacific Railroad (CRPR) at the northern edge of the city (Figure 2.3). Because the railroad was not required to file property leases with the county, the exact timing and duration of the operations at several of these facilities is not known with certainty. In 1984, CRPR deeded its property to the Mid-States Port Authority (MSPA). The tracks through Agra were purchased from the MSPA by the Kyle Railroad Company (KRC) on May 27, 2009.

Information obtained from long-term residents of Agra, together with historic aerial photographs, indicate that the CCC/USDA operated a grain storage facility on CRPR property north of the existing tracks from the early 1950s to the 1970s (Figure 2.3). The facility was completely dismantled by 1985 (Figure 2.4), and the property it formerly occupied is reported to have been continuously used for agricultural purposes since the CCC/USDA operations ended.

On the south side of the railroad tracks, agricultural facilities that have been identified are as follows (Figure 2.3):

Pro Ag currently operates grain storage facilities that include multiple large circular bins, flat storage buildings, and an elevator on railroad property directly to the south and across the tracks from the former CCC/USDA facility. Historic aerial photographs document the presence of many of these structures during the timeframe in which grain storage activities also occurred at the former CCC/USDA facility (Figure 2.3).

A grain elevator that was located on the northwestern corner of Main Street and Railroad Avenue, on CRPR property, was demolished by 1985 (Figures 2.3 and 2.4). The original town plat of Agra identifies the structure as the Farmers' Union Elevator. 
An abandoned store formerly located on private property at the southeast corner of Main Street and Railroad Avenue was used for many years for chemical storage (Figure 2.3). Numerous empty containers of grain fumigants containing carbon tetrachloride were discovered in the basement of the building by the Phillips County Health Department and confirmed by the KDHE in 1986. The building was demolished in 1989 (PRC 1994).

A small former grain storage facility was located at the southwest corner of Main Street and Railroad Avenue, on privately owned property (Figure 2.3).

\subsection{Summary of Previous Investigations}

Since the discovery of carbon tetrachloride in the groundwater at Agra in 1985, numerous investigations have been conducted to document the occurrence of this contaminant in groundwater, to identify and characterize potential source areas, and to evaluate the factors influencing the distribution and movement of carbon tetrachloride in the subsurface. The chronology and scope of these activities are outlined below; the key interpretations developed on the basis of their cumulative findings are summarized in Sections 2.3-2.6.

\subsubsection{Preliminary Assessment: KDHE 1987}

The KDHE conducted a preliminary assessment (PA) of wells PWS3 and PWS4. Investigation activities documented in the PA report include the sampling for VOCs analyses of three monitoring wells installed by the KDHE, the description of an unsuccessful attempt by the City to purge PWS3 and PWS4 of carbon tetrachloride by extended pumping of the wells to waste, and a preliminary consideration of potential contaminant source areas. On the basis of these findings, KDHE recommended that a site inspection be performed, to verify potential contaminant sources and determine the extent of the contaminant plume (KDHE 1987).

\subsubsection{Site Inspection: KDHE 1987-1988}

A general site inspection conducted by the KDHE provided lithologic and construction information for the three monitoring wells previously installed and sampled as part of the PA (KDHE 1987), and included additional sampling of these wells, PWS wells, and selected private 
wells for VOCs analyses (15 locations); a soil gas survey of suspected source areas (17 locations); and the measurement of groundwater levels to investigate potential flow directions (KDHE 1988).

\subsubsection{Site Assessment: KDHE 1993}

On behalf of the KDHE, PRC Environmental Management, Inc. (PRC) conducted sampling of groundwater for VOCs analyses from the three KDHE monitoring wells and municipal wells PWS3-PWS5 as part of a site assessment (PRC 1994).

\subsubsection{Comprehensive Investigation: KDHE 1995}

PRC conducted a comprehensive investigation that included the sampling and analysis of soil gas (five locations), surface and subsurface soils (14 locations), and groundwater from existing private, PWS and monitoring wells and investigative borings (21 locations). Soil and soil gas samples were collected at the Pro Ag facility and around the location of the former store (PRC 1995).

\subsubsection{Phase I Expedited Site Characterization: CCC/USDA 1995}

At the request of the CCC/USDA, Argonne performed an initial site characterization that included the collection and analysis of groundwater samples (31 locations) and soil samples (one location) for VOCs analyses; the installation of one monitoring well and one well point; and characterization of the local hydrostratigraphy and groundwater levels. The area of investigation extended from the former CCC/USDA facility to the south, southwest, and southeast but did not include the Pro Ag property (Argonne 1995).

\subsubsection{Phase II Expedited Site Characterization: CCC/USDA 1995}

The second phase of the CCC/USDA site investigation included the collection of surface and near-surface soil samples for lithologic evaluation and VOCs analyses (54 locations); groundwater sampling for VOCs analyses (13 locations); the installation of four monitoring wells; continuous measurement and recording of groundwater levels; and a geophysical survey to 
investigate the bedrock topography. The areal extent for this stage of the CCC/USDA study was generally similar to that of Phase I, and did not address the Pro Ag property. Soil sampling focused on the locations of the former CCC/USDA facility and the abandoned store (Argonne 1996).

\subsubsection{Feasibility Study for Remedial Action: CCC/USDA 1996}

Argonne's feasibility study for the CCC/USDA included the installation of one soil boring, one temporary well, and three piezometers; two pumping tests to evaluate aquifer hydraulic properties; monitoring of groundwater levels; modeling of the fate and transport of the contaminant plume; and an examination of the human health risks associated with potential exposure to the contaminated groundwater (Argonne 1997).

\subsubsection{Phase I Corrective Action Study: KDHE 1997-1998}

On behalf of the KDHE, BE\&K/Terranext conducted field studies that included the drilling of soil borings for lithologic/stratigraphic characterization and soil and groundwater sampling for VOCs analyses (27 locations); and the installation of 18 monitoring wells. The investigation of possible contamination in soils centered on the locations of the former CCC/USDA facility and the abandoned store (BE\&K 1998a). The study was presented as the initial phase of a CAS investigation; however, no further work was conducted and a CAS was not completed in conjunction with this effort.

\subsubsection{Groundwater Monitoring: KDHE 1998-1999}

At the request of the KDHE, BE\&K/Terranext performed groundwater sampling for VOCs analyses from all existing and accessible monitoring wells, PWS wells, borings, and privatewells (37 locations) in September 1998 and April-May 1999 (BE\&K 1998b, 1999).

\subsubsection{Contaminant Source Investigation: CCC/USDA2005}

At the direction of the CCC/USDA, Argonne conducted an investigation of potential carbon tetrachloride source areas. The field program included geomechanical logging, physical 
logging, and sampling for VOCs analyses of vertical soil profiles on the former CCC/USDA property, the Pro Ag facility, and in the vicinity of the former abandoned store (20 locations); direct-push vertical-profile or selective groundwater sampling for VOCs analyses at these properties (37 locations); the installation of one new piezometer; groundwater sampling and analyses from monitoring wells, PWS wells and selected private wells (32 locations); and an inventory of private wells in the town and their usage (Argonne 2006).

\subsubsection{Interim Measure Implementation and Monitoring: CCC/USDA2009-present}

In 2009, with the approval of the KDHE, the CCC/USDA implemented an IM (KDHE Project C6-074-00002) to address localized carbon tetrachloride contamination identified in the vadose zone and saturated soils and groundwater beneath the central portion of the former CCC/USDA facility (Sections 2.4 and 2.5). The IM activities included the installation of coupled AS/SVE wells in five LDBs; treatment of contaminated soils excavated from the LDBs by landfarming; the installation of five new piezometers for groundwater sampling and the monitoring of groundwater levels; and the installation of six new points for soil gas sampling and the monitoring of soil vapor pressures (Argonne 2007a, 2008a). In conjunction with operation of the IM systems, sampling of soil vapor from the SVE wells and monitoring points and sampling of groundwater from monitoring wells in the vicinity of the LDBs (eight locations) for VOCs analyses have been conducted subsequently on a quarterly or twice-yearly basis (Argonne 2009a,b,c; 2010a,b,c,d; 2011a,b,c; 2012a,b; 2013a,b; 2014a,b; 2015a,b; 2016a,b; 2017; and 2018a).

\subsubsection{Interim Measure Implementation: Pro Ag 2009-2010}

In April 2008, Pro Ag entered into a Consent Order (No. 07-E-0028) with the KDHE for the investigation and remediation of carbon tetrachloride (and nitrate) contamination linked to the Pro Ag facility (KDHE Project C6-074-72376). As a requirement of this agreement, Pro Ag initiated IM investigation activities for the western portion of the facility in fall 2009, and for the eastern portion of the facility in spring 2010. These efforts included the performance of an aquifer pumping test in the western portion of the Pro Ag facility, and the installation of nine new monitoring wells, but presently the CCC/USDA and Argonne have access to only limited documentation for these activities. To the knowledge of the CCC/USDA, no IM remedial actions have been implemented by Pro Ag in response to the Consent Order (KDHE 2017b). 


\subsubsection{Site-Wide Groundwater Monitoring: CCC/USDA and Pro Ag2009-present}

In 2008, the KDHE requested that the CCC/USDA and Pro Ag develop a joint plan for sitewide monitoring of the carbon tetrachloride concentrations in groundwater. In response, Argonne, on behalf of the CCC/USDA, developed a Joint Work Plan for Sitewide Monitoring that was signed by the CCC/USDA and Pro Ag and approved by the KDHE in 2009. Under the Joint Work Plan, the CCC/USDA and Pro Ag share monitoring responsibilities: the CCC/USDA conducts sampling in odd-numbered years, and Pro Ag conducts the events in even-numbered years. During each annual event, groundwater samples are collected from a common suite of wells (11 locations) plus selected additional monitoring wells associated with the agency conducting the event in that year (for CCC/USDA, eight locations; for Pro Ag, 13 locations). On behalf of Pro- Ag, Allied Environmental Consultants, Inc., Topeka, Kansas (AEC), conducted site-wide sampling in 2010, 2012, and 2014, but did not perform the required event in 2016 (Pro Ag 2010a, 2012a, 2014). Annual monitoring events were performed by Argonne on behalf of the CCC/USDA in 2009, 2011, 2013, 2015, and 2017 (Argonne 2010e, 2012c, 2014c, 2016c, and 2018c, unpublished data). With the approval of the CCC/USDA, all monitoring locations required under the Joint Work Plan (for both the CCC/USDA and Pro Ag) were sampled by Argonne in 2017 (Argonne 2018a).

\subsubsection{Water Well Survey: Pro Ag 2010}

At the request of the KDHE, AEC conducted an investigation of private wells in the eastern portion of Agra on behalf of Pro Ag. The investigation proceeded in accordance with a work plan approved by the KDHE. The objective of the survey was to identify private water wells; the owners (or users) of the water wells; well construction and condition information; and water usage information (i.e., whether water was used for domestic water supply, lawn and garden irrigation, recreation, etc.). The survey was designed to maximize participation. To perform the survey, AEC enlisted a local resident to canvas residents in the target area for information on private well locations, property ownership, and well usage. A total of 108 properties were visited during the survey. Each residence in the survey was visited, in some cases more than once, by the surveyor. Of the 108 properties surveyed, a total of 11 private wells were identified. It was determined that seven of these private wells were in use for lawn and garden purposes and four were not in use. It was also determined that a total of 77 properties did not have a private well. No information could be obtained for 20 of the 108 properties in the target area. Nine of the 20 properties were vacant, but six of them were identified as occupied (Pro Ag 2010a,b). A summary of the water well survey report is included in Table A.1, Appendix A. 


\subsubsection{Vapor Instrusion Assessment: Pro Ag 2012}

At the request of the KDHE, AEC performed indoor air sampling at six residences selected, in cooperation with the KDHE, to investigate for possible VOC vapor intrusion (VI). Residences chosen for sampling overlie areas of elevated carbon tetrachloride contamination identified in groundwater, south of the western and eastern portions of the Pro Ag property (Pro Ag 2011, 2012a,b).

\subsubsection{IM Shutdown and Aquifer Testing: CCC/USDA 2016-2017}

With the approval of the KDHE, the CCC/USDA temporarily shut down the SVE and AS systems at the former CCC/USDA facility property to evaluate the residual concentrations of carbon tetrachloride in the soils and groundwater. In conjunction with this effort, Argonne conducted groundwater and soil vapor sampling for VOCs analyses, as well as single-well "slug" testing and brief, variable-rate groundwater pumping at selected locations in the IM area to determine the hydraulic characteristics of the local aquifer materials (Argonne 2018a). The experience gained during the construction, operation, and testing of the LDB/IM system is used in the effectiveness, implementability, and cost discussion in Section 5.2.5.

\subsection{Geology and Hydrogeology}

Unconsolidated clays, silts, sands, and gravels form the sedimentary sequence overlying Cretaceous limestone and/or shale bedrock in the Agra area. Site-wide investigations first conducted by the CCC/USDA (Argonne 1995, 1996) demonstrated that the topography of the local bedrock is relatively complex, and influences the distribution and thickness of these sediment types. Subsequent investigations conducted by the KDHE (1998), the CCC/USDA (Argonne 2006), and Pro Ag (2009, 2010b, 2012c, 2014) provided additional information on the depths to bedrock and the distribution of lithologies.

Figure 2.5 depicts the computer generated topography of the bedrock surface underlying Agra, as determined from all available information. A schematic cross section for this area is in Figure 2.6; the location of the cross section is in Figure 2.5. 
Approximately 40-65 ft of predominantly clayey-silt to locally silty-sandy-clay forms the uppermost lithologic unit across this area (Figure 2.6). Groundwater levels documented across the Agra area fluctuate within these fine-grained materials. These deposits overlie two bedrock highs and two paleovalleys formed in the bedrock. At the northern limit of Agra, these deposits directly overlie a northern, localized bedrock high that extends beneath the entire former CCC/USDA facility and the western portion of the Pro Ag property (Figures 2.5 and 2.6). The high is bordered to the southwest, south, and southeast by an east-west trending paleovalley that deepens both to the west and east from directly south of the former CCC/USDA facility. A southern bedrock high is located south of the east-west trending bedrock valley. Lithologic data from boring logs and cores indicate that while the more western portion of this paleovalley contains a mixture of interbedded silty-clay and sandy units, the eastern portion of the channel is predominantly filled by finer-grained materials. Public supply wells PWS1 and PWS2 are completed in the western, sandy portion of this northern bedrock valley (Figures 2.2 and 2.5).

In the southeastern portion of the mapped area and south of the southern bedrock high (Figure 2.5), the northern margin of a second, deeper bedrock low is indicated, opening to the south. The lithologies in this second channel consist of multiple interbedded intervals of silt-clay and fine-coarse sands with minor gravel. Municipal wells PWS3 and PWS4 penetrate the coarsergrained units of this southern paleovalley (Figures 2.2 and 2.5).

An interval of sandy-gravelly deposits, varying from a feather edge to approximately $30 \mathrm{ft}$ in thickness and occurring at an elevation of approximately 1,780 ft AMSL in Figure 2.6, represents the most laterally extensive coarser-grained zone identified in the Agra area; however, this interval is (1) locally absent within the eastern portion of the northern bedrock channel, and (2) is absent or thins across portions of the identified bedrock highs (Figures 2.5 and 2.6). The interpreted areal distribution of this "upper" sandy interval is illustrated in Figure 2.7.

Long-term groundwater monitoring data demonstrate that groundwater flow is predominantly to the south-southeast across Agra, generally paralleling the trends of both the upper sandy unit and the deeper, southern bedrock paleovalley. A representative illustration of the groundwater flow pattern across the site, as determined from monitoring wells completed in the upper sandy interval, is included in Figure 2.7.

Groundwater flow upgradient (northwest) of the southern bedrock valley is generally restricted to the upper sandy and overlying silt-clay intervals. Measurements of groundwater levels 
in paired shallow-and-deeper wells completed in the southern bedrock valley demonstrate that expansion of the flow into the thicker and deeper sand and silt units present in this area results in a natural downward flow of groundwater near the upgradient margin of the valley, and a local reduction in the horizontal hydraulic gradient. The downward component of flow diminishes downgradient, however, as flow within the valley again becomes predominantly horizontal. This effect is illustrated schematically in Figure 2.8. The observed relationships indicate that the siltyclay deposits in the deeper portion of the southern valley do not preclude hydraulic communication among the upper and deeper sands, suggesting that the unconsolidated silt-clay and sand units together form a single, layered aquifer (Argonne 1997).

Hydraulic testing has demonstrated that the hydraulic conductivity $\left(\mathrm{K}_{h}\right)$ of the silty-clayey deposits in the vicinity of the former CCC/USDA facility and the Pro Ag property is low, ranging from less than $0.1 \mathrm{ft} /$ day to approximately $0.5 \mathrm{ft} /$ day (Argonne 2018a). In contrast, $\mathrm{K}_{h}$ values identified for the local sandy-gravelly intervals (Figure 2.6) range from approximately 3-20 ft/day (Argonne 1997; 2018a). Historic records indicate that municipal wells PWS1 and PWS2, completed in the western, sandy arm of the northern bedrock valley (Figure 2.5) have producing capacities of approximately 20-25 gallons per minute (gpm), while PWS3 and PWS4 (completed in the southern bedrock valley) have pumping capacities of approximately 65-90 gpm (Argonne 1995).

As noted in Section 2.1, former municipal well PWS4 was disconnected from the public distribution system in 1988, and has since been used by the local high school for irrigation. Longterm groundwater monitoring has documented that, when used seasonally for this purpose, the pumping of well PWS4 generates transient drawdown of the groundwater levels in both the upper and deeper, sandy portions of the unconsolidated aquifer in the vicinity of the well. Data demonstrate, however, that the operation of PWS4, as well as PWS1-PWS3, has little or no discernible impact on the patterns of groundwater flow in the more northern, upgradient portion of the town.

\subsection{Carbon Tetrachloride Contamination in Soil}

From 1995-1998, multiple Investigations were conducted on behalf of the KDHE (KDHE 1988; PRC 1995; BE\&K 1998a) and the CCC/USDA (Argonne 1995, 1996) to evaluate the distribution and levels of carbon tetrachloride contamination in soils associated with the potential source areas identified in Section 2.1 (Figure 2.3). These individual studies were limited 
in scope and variously identified trace to elevated levels of carbon tetrachloride contamination in shallow and deeper soils (and soil gas) associated with the former CCC/USDA grain storage facility, the former abandoned store, and the property currently occupied by Pro Ag (Figure 2.3), but were relatively inconclusive. In 2005, at the request of the KDHE (2004), the CCC/USDA performed detailed, vertical-profile soil sampling and analyses for VOCs in each of these areas, which identified three specific locations - two on the Pro Ag property and one at the former CCC/USDA facility—as sources of carbon tetrachloride contamination (Argonne 2006). At each of these locations, carbon tetrachloride was documented in the subsurface at levels that exceed the current KDHE RBSL guideline for this contaminant $(73.4 \mu \mathrm{g} / \mathrm{kg})$ for protection of the soil-togroundwater pathway.

The locations of the carbon tetrachloride sources identified in 2005, and the characteristics of the contaminant distribution at each of these locations, are illustrated in Figures 2.9-2.13. The two Pro Ag sources are discussed in Sections 2.4.1 and 2.4.2 and the single contamination source associated with the former CCC/USDA site is discussed in Section 2.4.3.

\subsubsection{Western Pro Ag Source}

A source area for carbon tetrachloride contamination was identified at the Pro Ag facility, near the eastern end of a large, rectangular storage building located at the western end of the property (Figures 2.9-2.11). Carbon tetrachloride contamination ranging from trace levels to a maximum of $1,604 \mu \mathrm{g} / \mathrm{kg}$ were detected in both the shallow and deeper soils at this location, defining an apparent path of vertical contaminant migration from the surface through the underlying vadose zone. The highest concentrations (140-1,604 $\mu \mathrm{g} / \mathrm{kg})$ were identified near the onset of groundwater saturation, at depths of 40-48 ft below ground level (BGL). Lower levels of carbon tetrachloride contamination (10-52 $\mu \mathrm{g} / \mathrm{kg})$ were similarly identified in relatively shallow and deeper vadose zone soils at boring location SB53, approximately $75 \mathrm{ft}$ north of SB64, but were not detected in adjacent borings SB62, SB63, SB73, and SB52 to the west, north, and east of SB53 and SB64, thus delimiting the lateral extent of this source area (Figures 2.9-2.11).

To date, no actions have been taken by Pro Ag to address the carbon tetrachloride contamination in soils at this location. 


\subsubsection{Eastern Pro Ag Source}

Carbon tetrachloride concentrations ranging from trace levels to a maximum of $728 \mu \mathrm{g} / \mathrm{kg}$ were identified in an almost continuous vertical profile from the surface to the onset of groundwater saturation (at depths ranging from 12 to $48 \mathrm{ft}$ BGL) at boring location SB59, near the south-central margin of the Pro Ag facility (Figures 2.9, 2.10, and 2.12). Only a trace of carbon tetrachloride was detected at location SB58 to the west of SB59, and no carbon tetrachloride was identified in adjacent borings SB51, SB54, and SB61 to the north and east of this location, thus determining the areal limits of the source at this location.

To date, no actions have been taken by Pro Ag to address the carbon tetrachloride contamination in soils in this source area.

\subsubsection{CCC/USDA Source}

Sampling performed at the former CCC/USDA facility identified one source location on this property, in the east-central portion of the facility (Figure 2.9). Carbon tetrachloride concentrations ranging from $27 \mu \mathrm{g} / \mathrm{kg}$ to $2,273 \mu \mathrm{g} / \mathrm{kg}$ were identified in a continuous vertical profile at boring location SB46, from $8 \mathrm{ft} \mathrm{BGL}$ to the identified onset of groundwater saturation (at approximately $48 \mathrm{ft} \mathrm{BGL);} \mathrm{levels} \mathrm{exceeding} \mathrm{the} \mathrm{KDHE} \mathrm{RBSL} \mathrm{guideline} \mathrm{to} \mathrm{protect} \mathrm{the} \mathrm{soil} \mathrm{to}$ groundwater pathway $(73.4 \mu \mathrm{g} / \mathrm{kg})$ were detected at all sampled depths greater than $16 \mathrm{ft}$ BGL. A similar vertical distribution of carbon tetrachloride was also detected at boring location SB43 to the north-northwest of SB46 (Figure 2.13), but at trace levels only (less than the method detection limit for these analyses of $10 \mu \mathrm{g} / \mathrm{kg}$ ). No carbon tetrachloride was detected at adjacent boring SB45 to the west of SB46, and only sporadic, trace levels were detected in the vadose zone soils at borings SB68 and SB49 to the east and south, respectively, of this location, delineating the lateral extent of this source area (Figures 2.9, 2.12 and 2.13). These results were qualitatively consistent with the findings of earlier soil studies near this location (Argonne 1995, 1996; BE\&K 1998a).

Vertical-profile soil sampling conducted at multiple locations along the southern boundary of the former CCC/USDA facility and the northern boundary of the Pro Ag property (SB48, SB49, SB51, SB52, SB54, SB55, SB73; Figure 2.9) confirmed that a clear separation exists in the subsurface between (1) the soil source areas identified near the southern margin of the Pro Ag facility, and (2) the soil source identified on the former CCC/USDA property. The CCC/USDA and Pro Ag source areas are clearly distinguishable since soil samples collected from locations 
along this transect between the CCC/USDA source area and the Pro Ag source areas were nondetect for carbon tetrachloride. Soil sampling previously conducted by the CCC/USDA (Argonne 1995, 1996) and the KDHE (BE\&K 1998a) similarly provided no evidence of potential soil sources of carbon tetrachloride to groundwater in the western, or eastern, portions of the former CCC/USDA facility beyond the localized contamination identified at boring SB46.

To address the contamination in soils identified on the former CCC/USDA property, the CCC/USDA implemented an IM with the approval of the KDHE (Argonne 2007, 2008). The measures employed as part of the IM included the mass removal of contaminated soil at five locations in close proximity to soil boring SB46 and the inferred CCC/USDA contamination source when the LDBs were installed. Soil removal was followed by treatment (by land farming) of approximately 300 cubic yards of contaminated vadose zone and saturated zone soils that were excavated from the five LDBs and the installation of coupled AS and SVE wells in the LDBs for further treatment of the surrounding soils and groundwater (Figure 2.14). Performance monitoring of the IM systems has documented the subsequent removal of more than $18 \mathrm{~kg}$ of carbon tetrachloride from the vadose zone and saturated soils (and groundwater) by the AS/SVE systems since operation of the IM facilities began in May 2009 (Argonne 2009a,b,c; 2010a,b,c,d; 2011a,b,c; 2012a,b; 2013a,b; 2014a,b; 2015a,b; 2016a,b; 2017; and 2018 unpublished data).

\subsection{Carbon Tetrachloride Contamination in Groundwater}

As outlined in Section 2.2, groundwater sampling efforts at Agra span a period of over 30 years, with individual sampling events varying in both their areal coverage and sampling approach, making it difficult to assess the exact distribution and concentrations of carbon tetrachloride contamination in groundwater across the complete site through time. Figures 2.15-2.17 present selfconsistent data sets reflecting the evolution of the contaminant distribution as determined by the CCC/USDA in 1995 and 2005 (Argonne 1995, 1996, 2006). Groundwater data for samples obtained during the most recent site-wide monitoring event, conducted by the CCC/USDA in 2017, are illustrated in Figure 2.17.

The highest concentrations of carbon tetrachloride in groundwater at Agra have been detected directly beneath, or in the immediate vicinity of, the three soil source areas discussed in Section 2.4 (Figure 2.9). Concentrations ranging from approximately 1,000 $\mu \mathrm{g} / \mathrm{L}$ to in excess of $6,000 \mu \mathrm{g} / \mathrm{L}$ were identified at the western source area on the Pro Ag property, in groundwater samples collected at boring location SB64 (Figures 2.9 and 2.11). Similar levels of carbon 
tetrachloride were also identified at boring location SB46 on the former CCC/USDA property, during the 2005 investigation program and in monitoring wells subsequently installed by the CCC/USDA at this location in conjunction with the IM (Figures 2.12, and 2.17). At the eastern Pro Ag source area, carbon tetrachloride concentrations in groundwater of up to approximately 1,500 $\mu \mathrm{g} / \mathrm{L}$ were detected at boring location SB59 (Figures 2.9 and 2.12).

The identified downgradient extent of carbon tetrachloride contamination in groundwater is illustrated in Figures 2.15-2.17. The results of periodic monitoring have consistently identified the occurrence of two separate regions of elevated carbon tetrachloride concentrations in groundwater extending from the southern margin of the Pro Ag property, which possibly merge with distance; however, the distribution of control points for mapping of the downgradient plume is relatively limited.

Maximum carbon tetrachloride levels of up to approximately $400 \mu \mathrm{g} / \mathrm{L}$ have been identified in the more upgradient, western arm of the groundwater distribution, while maximum concentrations in the eastern arm have generally ranged from 100-225 $\mu \mathrm{g} / \mathrm{L}$ (Figures 2.15-2.17); the levels in both of these areas have decreased during the period of record, but remain above the MCL and KDHE risk-based target ( $5 \mu \mathrm{g} / \mathrm{L}$ ) for this contaminant in groundwater (Figure 2.17). Carbon tetrachloride concentrations at monitoring points in the more distal, downgradient portion of the groundwater distribution have variably shown slight increases and decreases with time but have generally ranged from approximately $10-60 \mu \mathrm{g} / \mathrm{L}$, and demonstrate slow, downgradient elongation of the plume during the period of record (Figures 2.15-2.17). The identified carbon tetrachloride contamination in groundwater currently extends approximately $0.5 \mathrm{mi}$ downgradient from the southern margin of the Pro Ag property (Figure 2.17).

Recent monitoring conducted by the CCC/USDA has demonstrated that elevated levels of carbon tetrachloride (up to 3,000 $\mu \mathrm{g} / \mathrm{L}$ or more) locally remain beneath and in the immediate vicinity of the source area identified on the former CCC/USDA property (Figure 2.17). Together with the results of earlier groundwater sampling, these data indicate little or no significant downgradient migration of carbon tetrachloride in groundwater beyond this source area (Argonne 2018a). Documented carbon tetrachloride concentrations in groundwater at monitoring points located directly downgradient from this source area have consistently remained at levels that typically range from not detected to approximately $20 \mu \mathrm{g} / \mathrm{L}$. The concentrations at these monitoring points have also been consistently one to two orders of magnitude less than those 
observed in the eastern arm of the groundwater plume, directly downgradient from the eastern source area on the Pro Ag property (Figures 2.16-2.17).

\subsection{Evaluation of Carbon Tetrachloride Source Areas and Basis for the CAS}

\subsubsection{Evaluation of Carbon Tetrachloride Source Areas}

The demonstrated hydraulic characteristics of the saturated, silty-clay deposits in the source area at the former CCC/USDA facility (at SB46; Figures 2.9, 2.10, and 2.12) indicate that the expected natural rates of groundwater (and contaminant) migration in this immediate area are very slow (Argonne 2018a). Because of these conditions, the contamination in groundwater beneath the CCC/USDA source area has historically demonstrated little to no downgradient migration.

Monitoring of the carbon tetrachloride concentrations in groundwater in and directly downgradient from the identified source location indicate that there has been little or no net change in the contaminant levels at these locations (wells GW1-GW4 and MW-P; Figures 2.14 and 2.18). Similarly, extended monitoring data for points slightly further downgradient from the source area have identified only non-detectable or very low levels of carbon tetrachloride contamination (wells MW5 and MW-J; Figures 2.19 and 2.20).

The identified characteristics of this area demonstrate that either (1) no net contaminant migration from the CCC/USDA source area has occurred during the observation period, or (2) that effectively steady-state conditions exist, resulting in the very slow release of carbon tetrachloride from this area at concentrations generally less than approximately $20 \mu \mathrm{g} / \mathrm{L}$, to the downgradient groundwater along a restricted migration pathway (intercepted at monitoring location MW-J; Figures 2.19 and 2.20). Similar groundwater migration patterns associated with the former CCC/USDA site have existed for 35-60 or more years, given the low permeability and persistence of high carbon tetrachloride levels in groundwater in the immediate source area only (Figure 2.18), and lack of significant changes in the factors affecting the hydraulic regime at Agra since at least 1954-1982 (corresponding to the installation of downgradient public supply wells PWS3 and PWS4, respectively). 
The contaminant migration patterns and distribution identified directly downgradient from the source area at the former CCC/USDA facility distinctly contrast with those observed atpoints downgradient from the source areas that have been identified on the adjacent Pro Ag property (at locations SB64 and SB59; Figures 2.9 and 2.19), despite general similarities in the lithologic characteristics of the vadose zone soils at each of these locations. Near the former CCC/USDA facility, only low concentrations of carbon tetrachloride have been identified at relatively short distances downgradient from the identified source area. Much higher contaminant levels have been documented in the groundwater, extending to significantly greater distances downgradient from the identified source areas on the Pro Ag property.

The results of multiple soil and groundwater studies conducted by both the KDHE and the CCC/USDA provided no evidence of a current or former source of carbon tetrachloride contamination to the groundwater in the western portion of the former CCC/USDA facility, identifying the western Pro Ag property as the sole source for groundwater contamination in this portion of Agra (Argonne 2006; KDHE 1987, 1988; PRC 1994, 1995; BE\&K 1998a). As shown in Figures 2.15-2.17 and 2.21, however, carbon tetrachloride concentrations ranging from approximately 200-450 $\mu \mathrm{g} / \mathrm{L}$ have been identified in groundwater downgradient from this source area during the documented period from 1995-2017, and suggest a progression of concentrations with distance downgradient over time that is consistent with active contaminant migration in this area. Similarly, Figures 2.15-2.17 and 2.22 demonstrate that carbon tetrachloride concentrations ranging from approximately 100-230 $\mu \mathrm{g} / \mathrm{L}$ have consistently been detected in groundwater at locations downgradient from the more eastern source area identified on the Pro Ag property. It must be noted that the concentrations of carbon tetrachloride documented in the area downgradient from the eastern Pro Ag source (at MW-M and PMW09; Figures 2.19 and 2.22) have persistently been up to an order of magnitude greater than those documented directly downgradient from the CCC/USDA source area (at GW5 and MW-J).

The contaminant relationships outlined here are consistent with greater mobility of the carbon tetrachloride contamination in groundwater downgradient from the source areas on the ProAg property, in comparison to the source area at the former CCC/USA facility. Lithologic information obtained from continuous soil coring on both the Pro Ag and former CCC/USDA properties (Argonne 2006) indicates that the silty-clayey sediments hosting the vadose and saturated zone contamination in the respective source areas are comparable, and therefore might be expected to possess similar hydraulic characteristics. Consideration of the wider hydrogeologic environment controlling the movement of groundwater (and contaminants) at Agra, however, 
presents a viable mechanism for the apparent differences in contaminant mobility downgradient from the Pro Ag versus CCC/USDA source areas.

As discussed in Section 2.3, the topography of the bedrock underlying Agra is relatively complex, and influences the occurrence and thickness of sediment types in the overlying, unconsolidated deposits.

Figure 2.5 shows the topography of the bedrock surface in the Agra area, as determined from all presently available penetrations to this depth. In Figure 2.23, the more limited area surrounding the former CCC/USDA facility and Pro Ag property is illustrated. Figures 2.5 and 2.23 show that the three identified source areas overlie the northernmost localized bedrock high that extends beneath the entire former CCC/USDA facility and the western portion of the Pro Ag property.

The lithologic data demonstrate that an interval of sandy deposits, the "upper" sandy unit, represents the most areally extensive and permeable unit across much of the study area; the area distribution of this sandy interval is illustrated in Figure 2.7. Groundwater levels documented in the study area have consistently indicated groundwater flow predominantly to the south-southeast, generally paralleling the trends of both the upper sandy unit and the deeper, southern bedrock low.

The locations of all investigation borings and monitoring wells installed by the KDHE, the CCC/USDA, and Pro Ag to determine and track the distribution of carbon tetrachloride contamination in the groundwater at Agra (independent of the "host" lithologic type) have been plotted in Figure 2.24. As Figure 2.24 illustrates, the majority of carbon tetrachloride detections in groundwater downgradient from the former CCC/USDA and Pro Ag properties, and particularly those at concentrations exceeding the $5 \mu \mathrm{g} / \mathrm{L}$ MCL for this contaminant, are associated with the presence of the upper sandy interval. The upper sandy interval unit appears to be the primary permeable conduit for lateral groundwater and contaminant migration across the study area. The majority of the permanent monitoring wells currently located at Agra were constructed to intersect the upper sandy unit.

The locations of the carbon tetrachloride source areas identified at the former CCC/USDA and Pro Ag properties are depicted in Figures 2.19 and 2.25, relative to the areal distribution of the upper sandy interval. These diagrams illustrate that the source area at the former CCC/USDA facility (at location SB46) overlies the local bedrock high (Figure 2.23) that is isolated from the 
laterally continuous deposits of the upper sandy interval to the southeast, and downgradient. In the immediate vicinity of the CCC/USDA source, both vertical and lateral groundwater and contaminant migration are therefore restricted to the low-permeability silty-clayey deposits discussed in Section 2.3, thereby constraining offsite migration from the former CCC/USDA site. In contrast, Figures 2.19 and 2.25 show that the carbon tetrachloride source areas identified on the Pro Ag property (at locations SB59 and SB64), either directly overlie or are in very close proximity to the permeable upper sandy deposits, hence providing a readily accessible pathway for more effective downgradient groundwater and contaminant migration from the Pro Ag source areas.

\subsubsection{Basis for the CAS}

The hydrogeologic data and groundwater monitoring history outlined above support the conclusion that the source area located at the former CCC/USDA facility has contributed little to no contamination to the extensive downgradient groundwater plume that has originated from the eastern and western source areas on the Pro Ag property. The CCC/USDA has operated the LDB/IM for nine years and mass removal coupled with treatment using AS/SVE has likely mitigated the carbon tetrachloride present in the vadose zone in the CCC/USDA source area. The CCC/USDA recognizes, however, that residual carbon tetrachloride concentrations in the groundwater beneath and immediately downgradient from this (remediated) soil source area remain above the MCL for groundwater $(5 \mu \mathrm{g} / \mathrm{L})$.

To address this concern, this CAS presents an evaluation of potential remedial alternatives, including a "no action" alternative, for restoration of the groundwater quality in the vicinity of the source identified at the former CCC/USDA facility, as a localized area of contamination distinct from the carbon tetrachloride contamination in soils and groundwater associated with the two source areas identified on and downgradient from the adjacent Pro Ag property. In addition, during the term of its lease, operations at the former CCC/USDA facility did not include the storage, handling, or use of nitrate or compounds that could produce nitrate contamination in groundwater. Nevertheless, nitrate contamination in groundwater (unrelated to past CCC/USDA activities) has been identified as part of previous site investigations. With the source of the information noted, Table 2.1 summarizes the maximum nitrate concentrations detected in a variety of monitoring points, including piezometers, monitoring wells, temporary direct push investigation points, and water supply wells, sampled as part of the investigations at Agra from 1988 to present. Due to space limitations, only a subset of monitoring points that have been sampled for nitrate are depicted in Figure 2.26. 
In keeping with KDHE (2001a) guidance, this CAS compares a baseline "no action" alternative and additional corrective action alternatives for addressing carbon tetrachloride. For the purposes of this CAS, the no action alternative includes termination of the LDB/IM. 
TABLE 2.1 Maximum nitrate concentrations from monitoring points sampled at the Agra site. ${ }^{1}$

\begin{tabular}{|c|c|c|c|}
\hline Location & Sample Date & Result (mg/l) & Source \\
\hline DW07 & $6 / 24 / 1988$ & 3.1 & Argonne 2006 \\
\hline KMW01 & $11 / 1 / 1993$ & 12.3 & Argonne 2006 \\
\hline PWS-4 & 11/1/1993 & 9.23 & Argonne 2006 \\
\hline DW18 & 3/23/1995 & 23.5 & Argonne 1995 \\
\hline SB03 & 6/1/1995 & 27 & Argonne 1995 \\
\hline SB11 & 6/1/1995 & 10 & Argonne 1995 \\
\hline SB01 & 6/2/1995 & 1.8 & Argonne 1995 \\
\hline DW09 & 6/3/1995 & 13 & Argonne 1995 \\
\hline PW16 & 6/4/1995 & 5.6 & Argonne 1995 \\
\hline DW17 & 6/4/1995 & 25 & Argonne 1995 \\
\hline DW08 & 6/4/1995 & 7.5 & Argonne 1995 \\
\hline SB01A & 6/5/1995 & 4.9 & Argonne 1995 \\
\hline DW10 & 6/5/1995 & 11 & Argonne 1995 \\
\hline SB04 & 6/6/1995 & 33 & Argonne 1995 \\
\hline SB07 & 6/7/1995 & 27 & Argonne 1995 \\
\hline SB12 & 6/7/1995 & 9.5 & Argonne 1995 \\
\hline SB09 & 6/7/1995 & 6.1 & Argonne 1995 \\
\hline DW20 & 6/7/1995 & 13 & Argonne 1995 \\
\hline PWS-2 & 6/8/1995 & 9.63 & Argonne 2005 \\
\hline SB14 & 6/8/1995 & 17 & Argonne 1995 \\
\hline SB05 & 6/9/1995 & 8.7 & Argonne 1995 \\
\hline DW12 & 8/26/1997 & 11.9 & Argonne 2006 \\
\hline PWS-3 & 8/26/1997 & 7.52 & Argonne 2006 \\
\hline MW-I & $3 / 21 / 1998$ & 14.3 & Argonne 2006 \\
\hline MW-P & 9/1/1998 & 18.7 & Argonne 2006 \\
\hline PWS-5 & $4 / 21 / 1999$ & 2.07 & Argonne 2005 \\
\hline MW-C & $4 / 22 / 1999$ & 54.5 & Argonne 2005 \\
\hline MW-G & $4 / 22 / 1999$ & 32.6 & Argonne 2005 \\
\hline SB15 & $4 / 22 / 1999$ & 9.21 & Argonne 2005 \\
\hline SB28 & 5/5/1999 & 15.7 & Argonne 2005 \\
\hline SB63 & $5 / 18 / 2005$ & 8.5 & Argonne 2006 \\
\hline MW01 & $5 / 19 / 2005$ & 10 & Argonne 2006 \\
\hline MW-B & $5 / 19 / 2005$ & 14 & Argonne 2006 \\
\hline SB23 & $5 / 20 / 2005$ & 3.9 & Argonne 2006 \\
\hline MW-R & $5 / 20 / 2005$ & 5.5 & Argonne 2006 \\
\hline SB53 & $5 / 20 / 2005$ & 71 & Argonne 2006 \\
\hline KMW03 & $5 / 21 / 2005$ & 6.1 & Argonne 2006 \\
\hline
\end{tabular}


TABLE 2.1 (Cont.)

\begin{tabular}{|c|c|c|c|}
\hline MW-K & $5 / 21 / 2005$ & 5.8 & Argonne 2006 \\
\hline MW-O & $5 / 22 / 2005$ & 7.7 & Argonne 2006 \\
\hline MW-Q & $5 / 24 / 2005$ & 4.5 & Argonne 2006 \\
\hline SB56 & $5 / 25 / 2005$ & 0.3 & Argonne 2006 \\
\hline DW07A & 6/2/2005 & 8.2 & Argonne 2006 \\
\hline SB36 & $6 / 2 / 2005$ & 18 & Argonne 2006 \\
\hline DW98 & $6 / 3 / 2005$ & 28 & Argonne 2006 \\
\hline SB38 & $6 / 3 / 2005$ & 11 & Argonne 2006 \\
\hline SB61 & $6 / 5 / 2005$ & 121 & Argonne 2006 \\
\hline SB65 & 6/6/2005 & 51 & Argonne 2006 \\
\hline SB59 & $6 / 7 / 2005$ & 216 & Argonne 2006 \\
\hline SB64 & 6/7/2005 & 310 & Argonne 2006 \\
\hline SB66 & 6/9/2005 & 17 & Argonne 2006 \\
\hline SB54 & 6/9/2005 & 45 & Argonne 2006 \\
\hline PWS-1 & 6/9/2005 & 11 & Argonne 2006 \\
\hline SB41 & 6/9/2005 & 16 & Argonne 2006 \\
\hline SB60 & 6/10/2005 & 9.1 & Argonne 2006 \\
\hline SB40 & $6 / 11 / 2005$ & 7.6 & Argonne 2006 \\
\hline SB71 & 6/11/2005 & 5.5 & Argonne 2006 \\
\hline SB47 & $6 / 11 / 2005$ & 2.5 & Argonne 2006 \\
\hline SB48 & $6 / 12 / 2005$ & 6.6 & Argonne 2006 \\
\hline SB73 & $6 / 12 / 2005$ & 7.1 & Argonne 2006 \\
\hline SB49 & $6 / 13 / 2005$ & 20 & Argonne 2006 \\
\hline SB46 & $7 / 6 / 2005$ & 7 & Argonne 2006 \\
\hline SB45 & $7 / 7 / 2005$ & 7.4 & Argonne 2006 \\
\hline SB69 & $7 / 8 / 2005$ & 29 & Argonne 2006 \\
\hline SB72 & $7 / 12 / 2005$ & 4.6 & Argonne 2006 \\
\hline KMW02 & 8/4/2010 & 26.1 & Pro Ag 2010b \\
\hline MW-J & $8 / 4 / 2010$ & 47.6 & Pro Ag 2010b \\
\hline PMW-01 & $8 / 4 / 2010$ & 29.2 & Pro Ag 2010b \\
\hline PMW-02 & $8 / 4 / 2010$ & 8.63 & Pro Ag 2010b \\
\hline PMW-03 & $8 / 4 / 2010$ & 10.1 & Pro Ag 2010b \\
\hline PMW-04 & $8 / 4 / 2010$ & 19.8 & Pro Ag 2010b \\
\hline PMW-05 & $8 / 4 / 2010$ & 33.7 & Pro Ag 2010b \\
\hline PMW-06 & 8/4/2010 & 12 & Pro Ag 2010b \\
\hline PMW-07 & $8 / 4 / 2010$ & 13.8 & Pro Ag 2010b \\
\hline PMW-09 & $8 / 4 / 2010$ & 44.4 & Pro Ag 2010b \\
\hline PMW-10 & $8 / 4 / 2010$ & 30.6 & Pro Ag 2010b \\
\hline SB23S & 8/5/2010 & 7.02 & Pro Ag 2010b \\
\hline $\mathrm{MW}-\mathrm{H}$ & $6 / 26 / 2012$ & 12.9 & Pro Ag 2012c \\
\hline PMW-06 Dup & $6 / 26 / 2012$ & 15.2 & Pro Ag 2012c \\
\hline MW02 & $6 / 27 / 2012$ & 9.81 & Pro Ag 2012c \\
\hline PMW-09 & 6/28/2012 & 43.4 & Pro Ag 2012c \\
\hline
\end{tabular}


TABLE 2.1 (Cont.)

\begin{tabular}{cccc}
\hline MW-M & $6 / 24 / 2014$ & 60.8 & Pro Ag 2014 \\
\hline PMW-04 & $6 / 24 / 2014$ & 63.5 & Pro Ag 2014 \\
MW-F & $6 / 25 / 2014$ & 71.6 & Pro Ag 2014 \\
MW-L & $6 / 25 / 2014$ & 95 & Pro Ag 2014 \\
PMW-01 & $6 / 26 / 2014$ & 98.6 & Pro Ag 2014 \\
PMW-05 & $6 / 26 / 2014$ & 76.9 & Pro Ag 2014 \\
PMW-07 & $6 / 27 / 2014$ & 30.4 & Pro Ag 2014 \\
GW1 & $10 / 1 / 2017$ & 17 & Argonne 2018c \\
GW2 & $10 / 1 / 2017$ & 2.8 & Argonne 2018c \\
GW3 & $10 / 1 / 2017$ & 11 & Argonne 2018c \\
GW4 & $10 / 1 / 2017$ & 4.4 & Argonne 2018c \\
GW5 & $10 / 1 / 2017$ & 77 & Argonne 2018c \\
\hline
\end{tabular}

${ }^{1}$ Only highlighted entries appear on Figure 2.26 (due to space limitations on the map). 


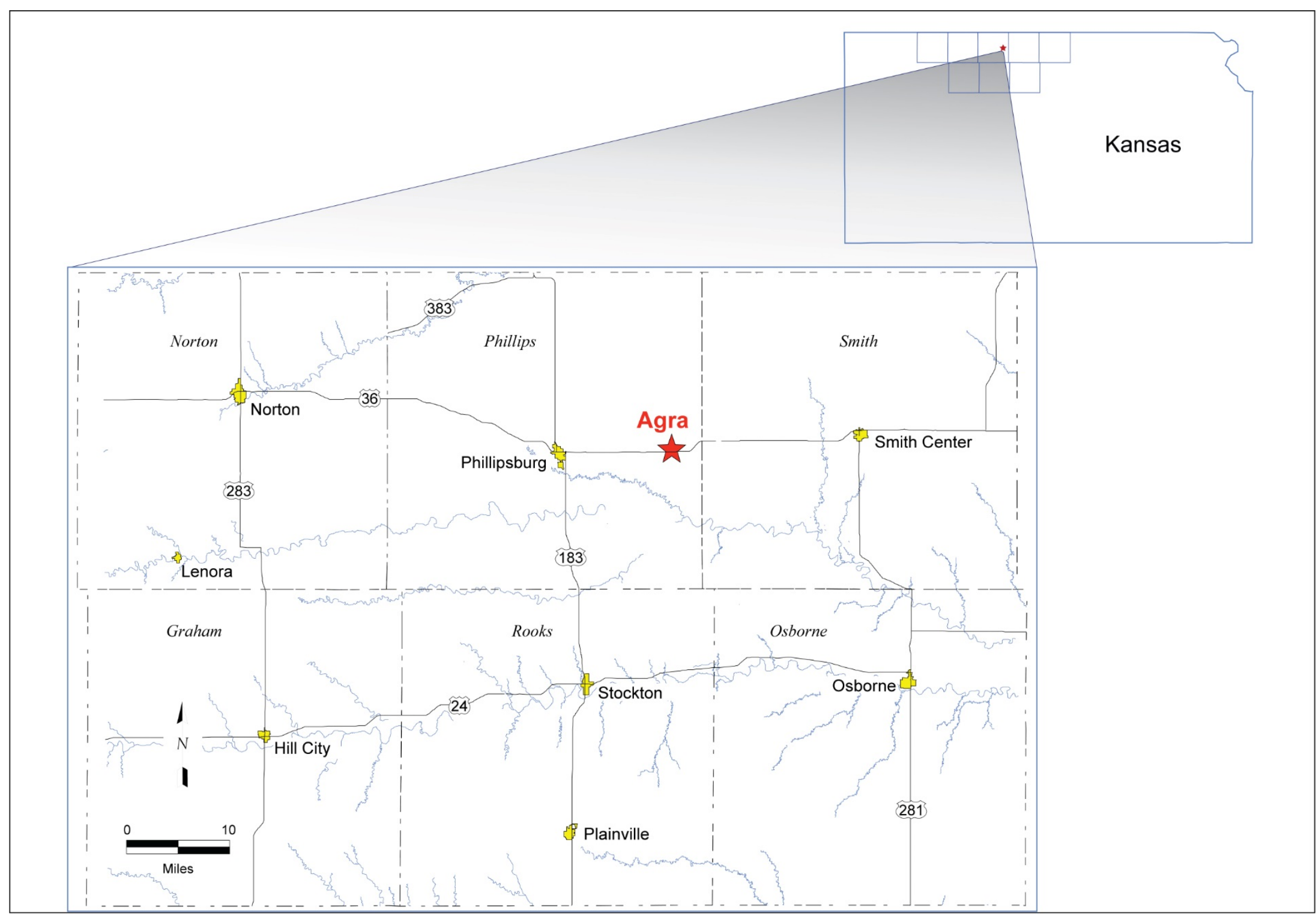

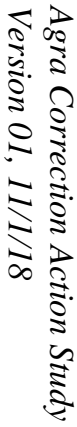

FIGURE 2.1 Locations of Phillips County and Agra, Kansas. 


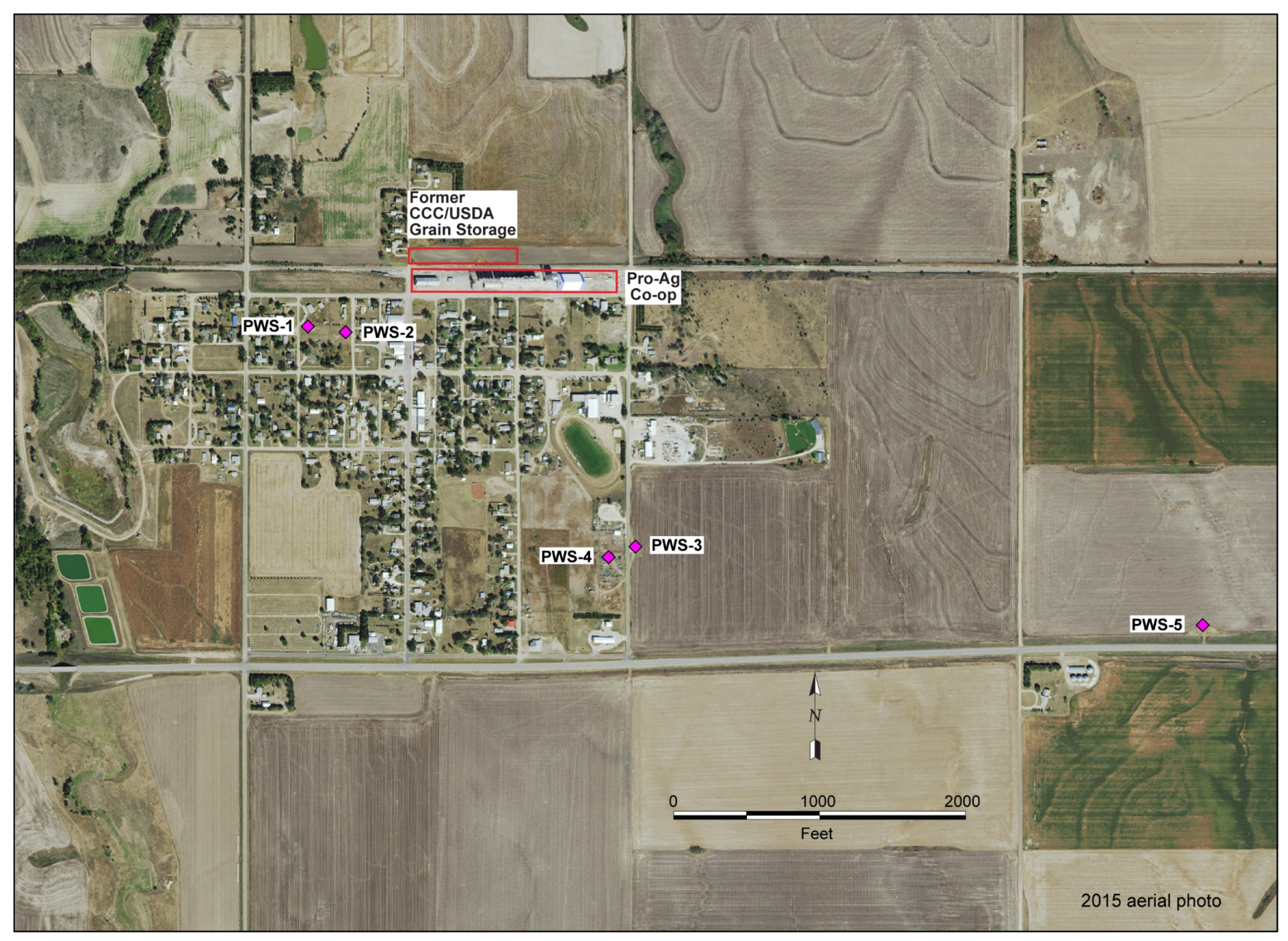

FIGURE 2.2 City map/recent aerial with PWS wells, former CCC, and Co-op property outlines. Source of photograph: NAIP (2015). 


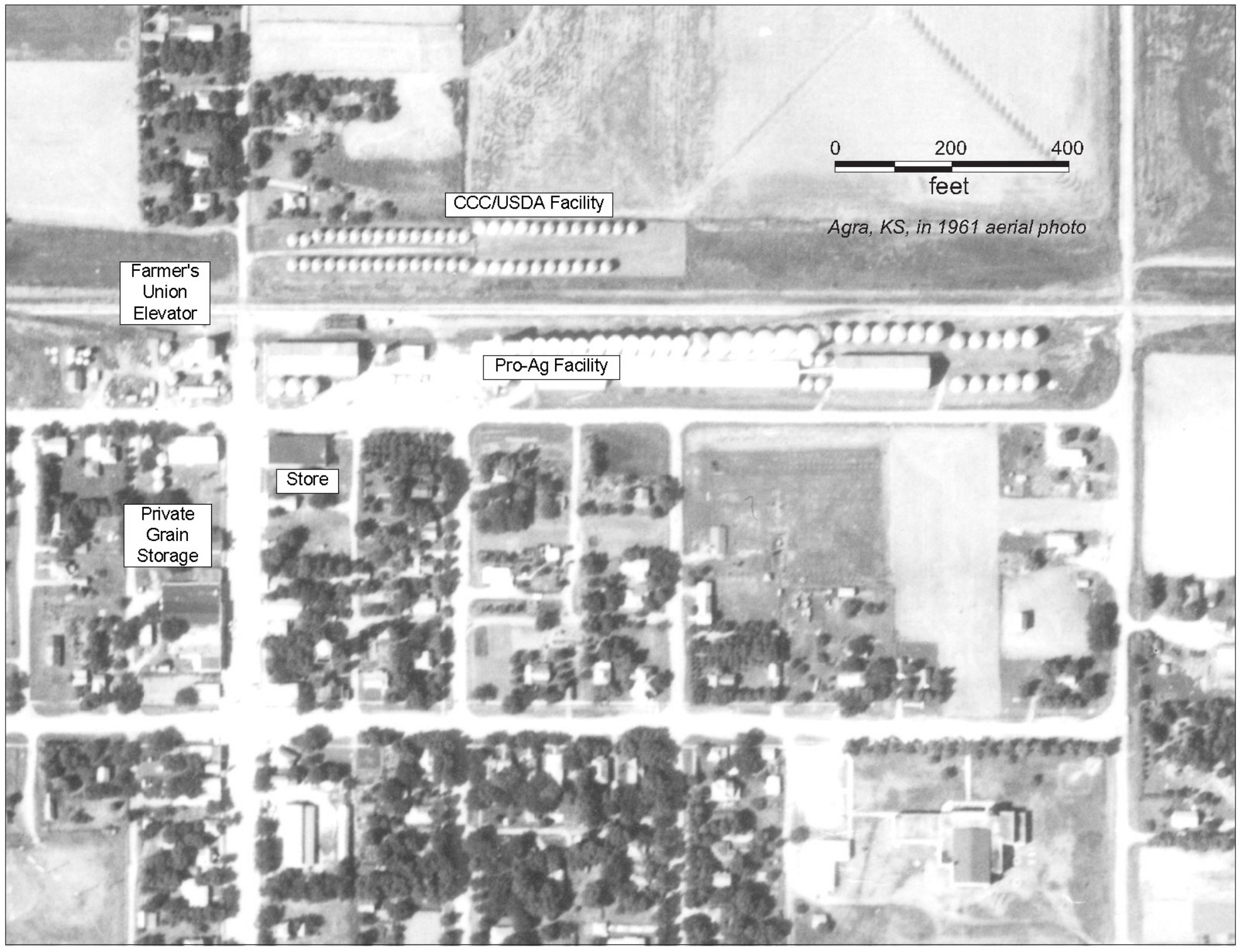

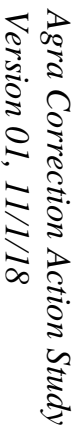

FIGURE 2.3 1961 Aerial photograph with potential sources marked. Source of photograph: NAIP (2015). 


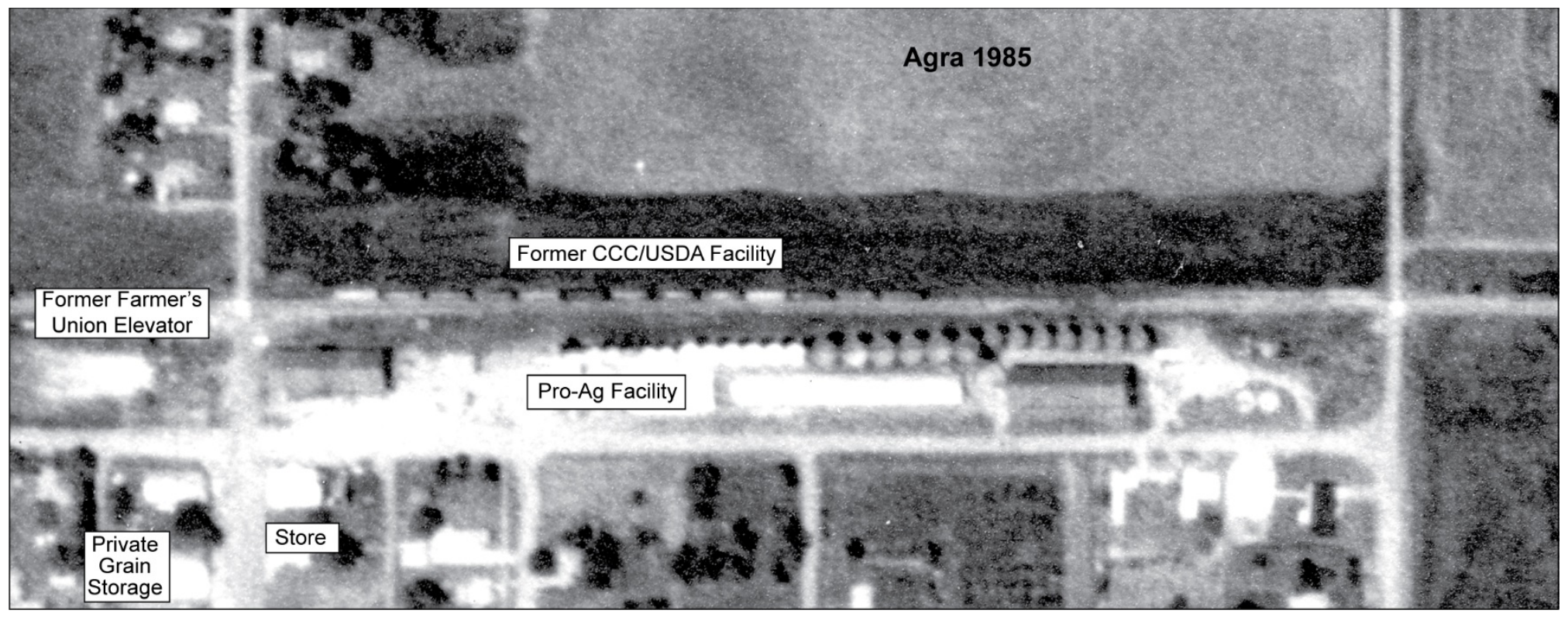

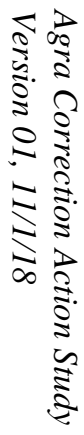

FIGURE 2.4 1985 aerial photograph with potential sources marked. Source of photograph: NAIP (2015). 


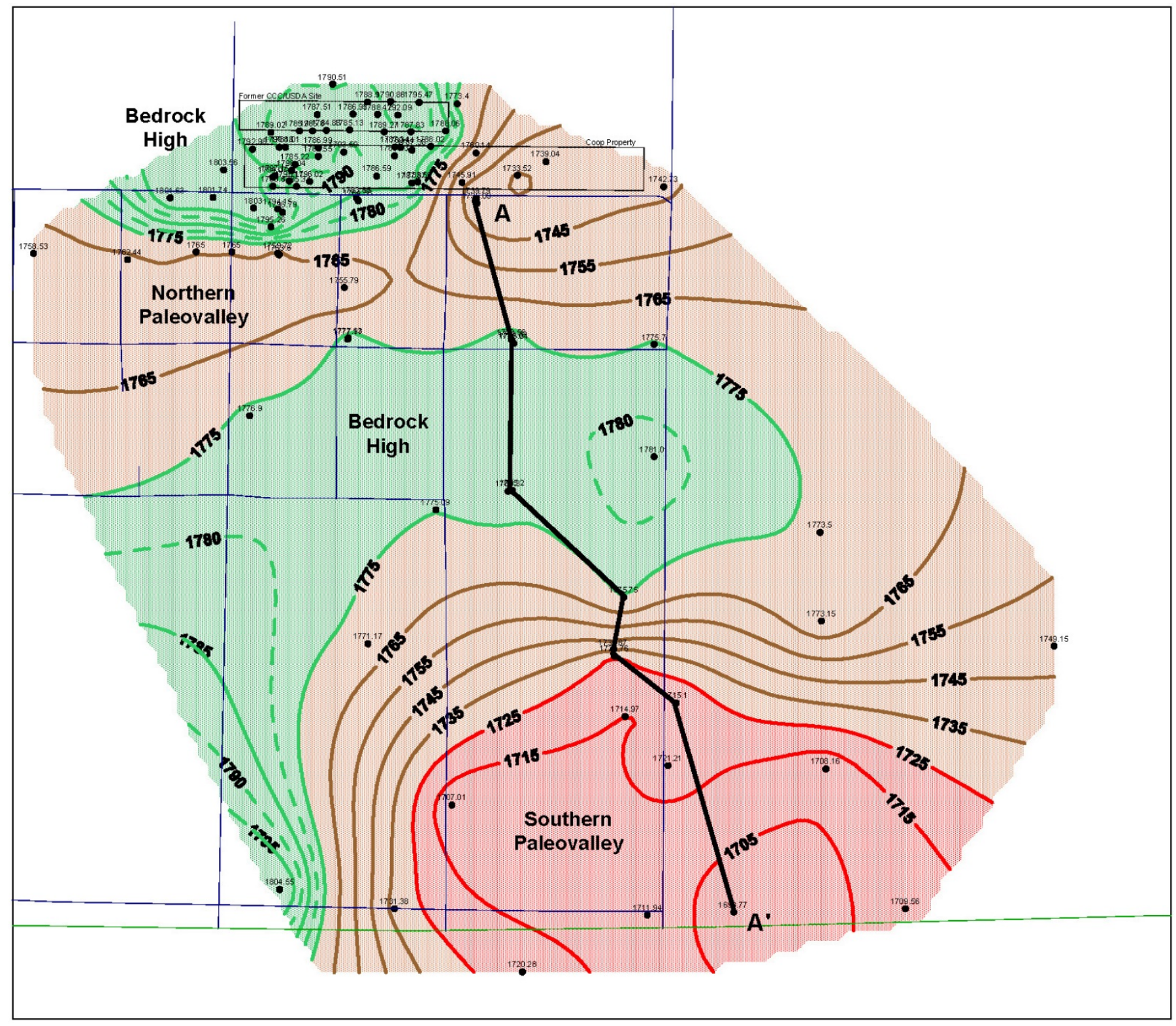

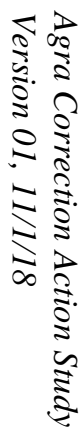

FIGURE 2.5 Interpreted elevation of the bedrock surface (ft AMSL), with cross section location shown. 


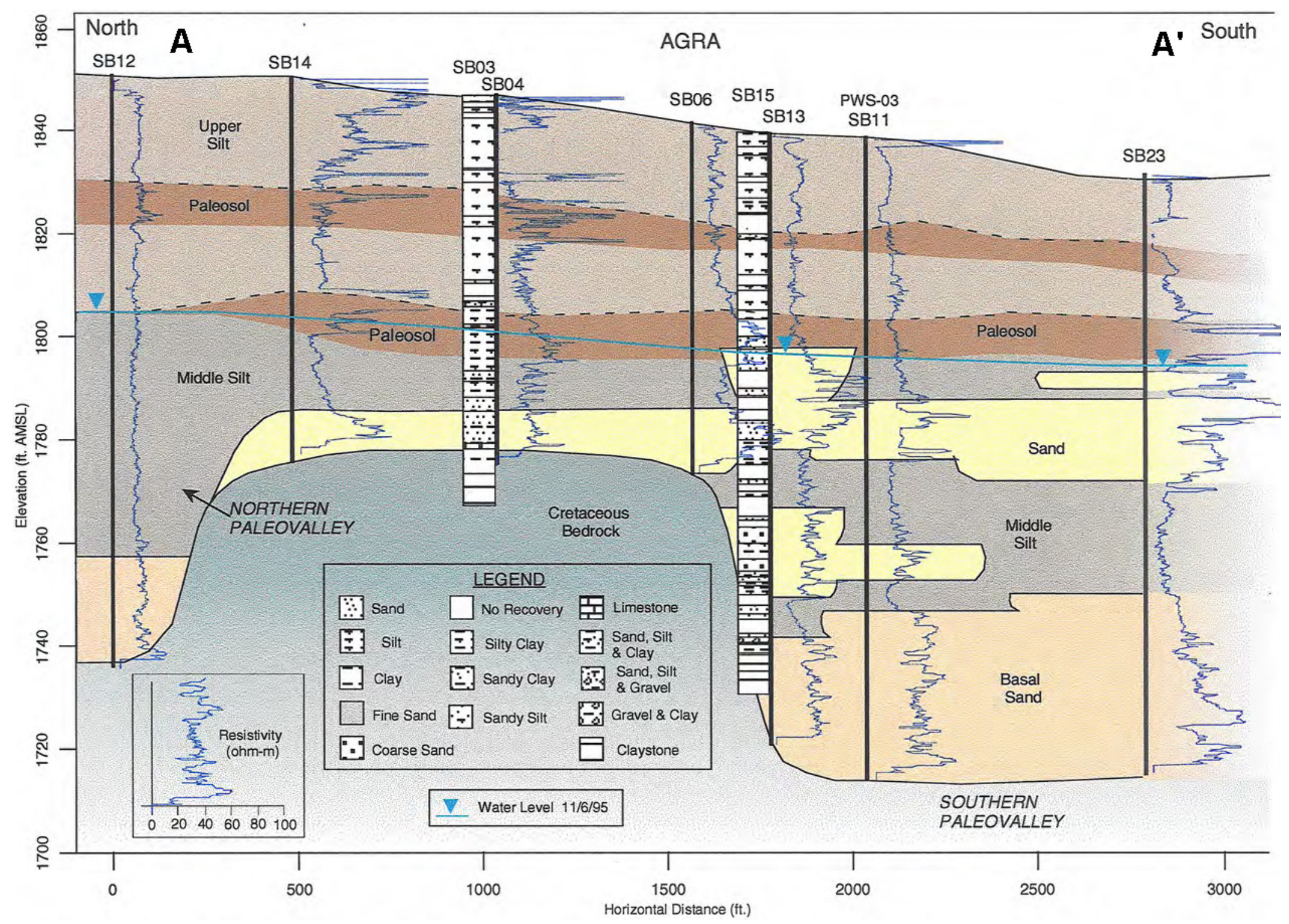

FIGURE 2.6 North-south geologic cross section A-A'. 


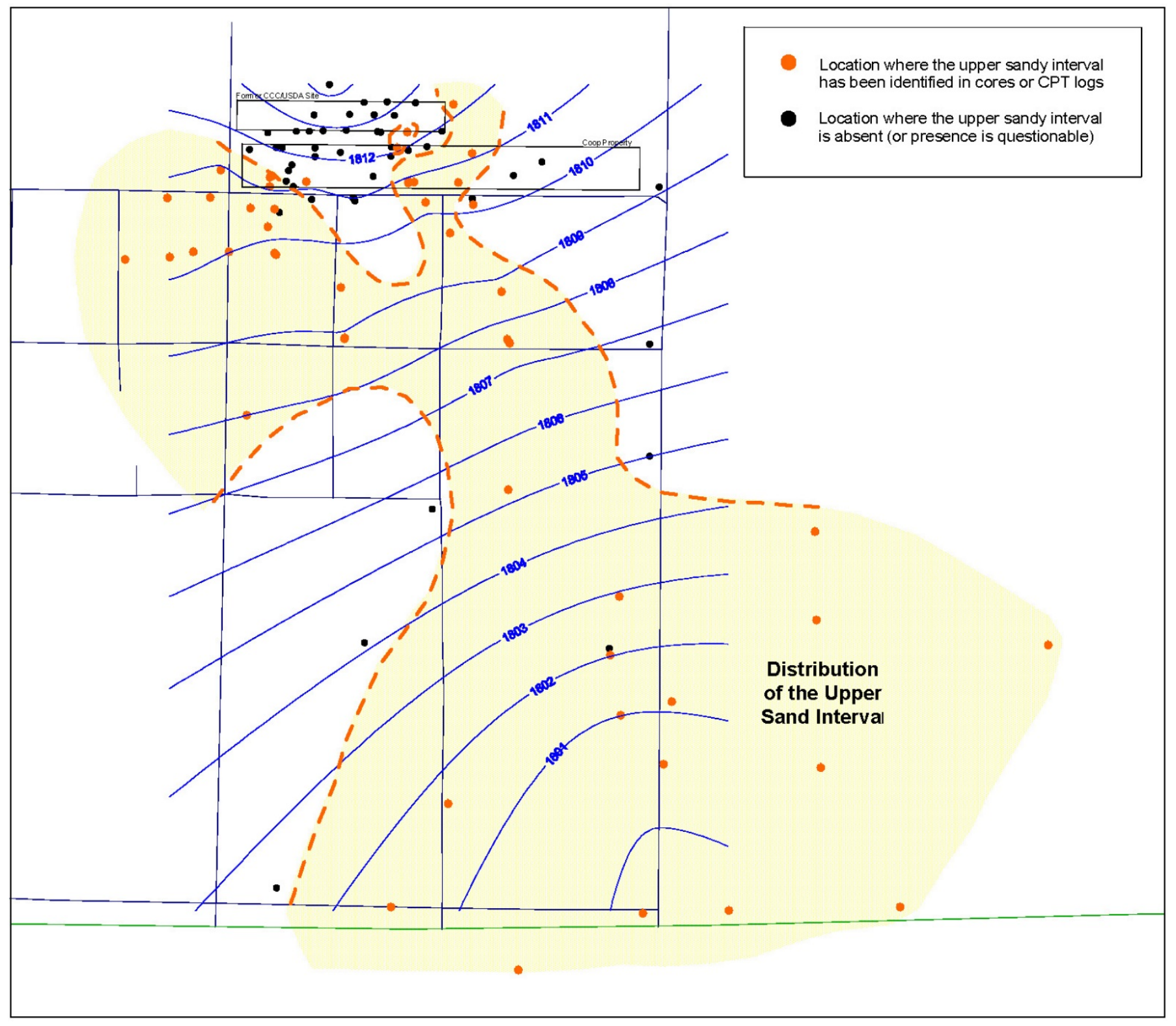

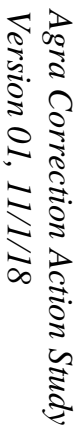

FIGURE 2.7 Interpreted distribution of the upper sand interval. 


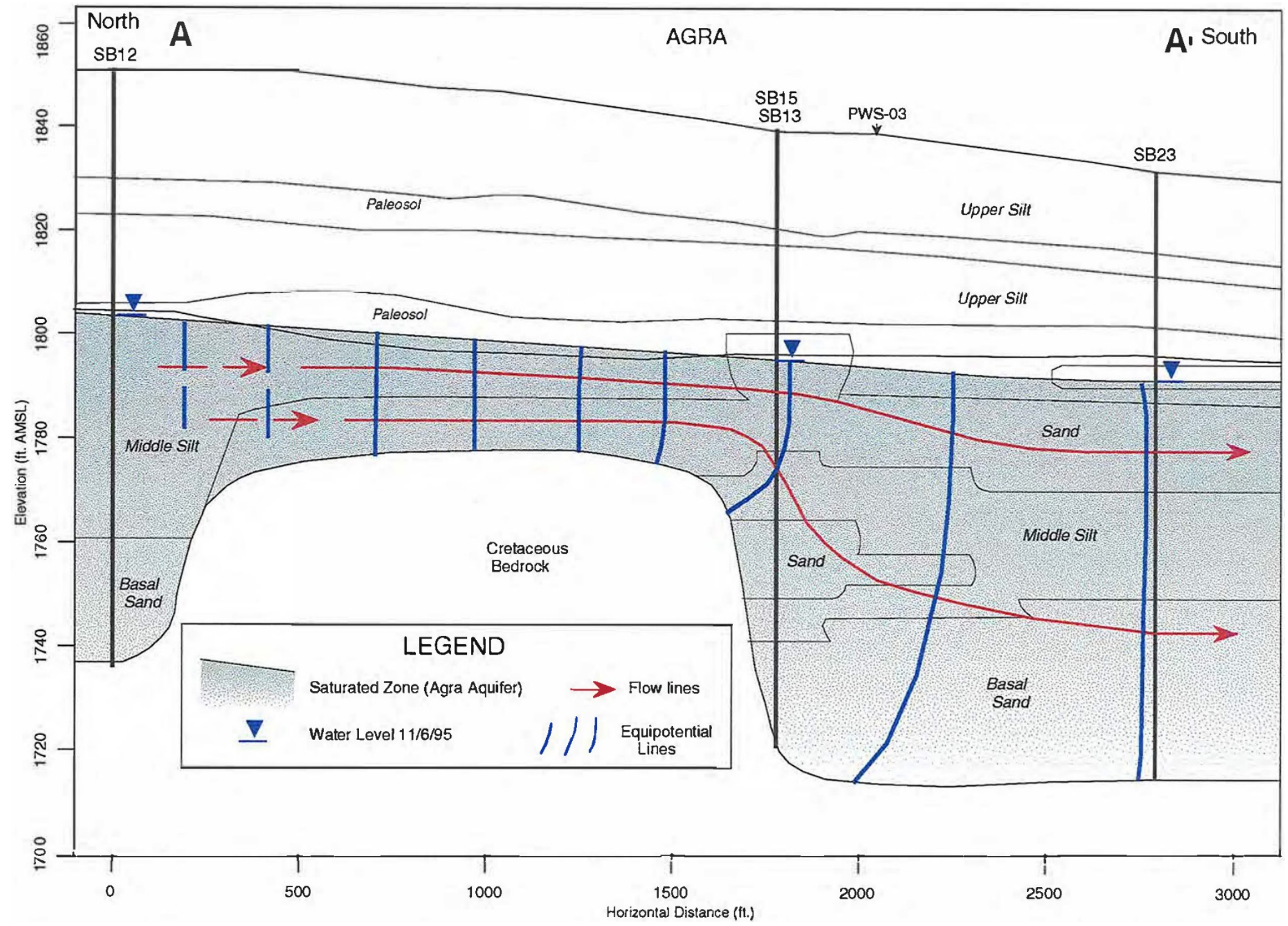

FIGURE 2.8 Vertical cross section A-A', showing schematic net flow for Agra aquifer. 


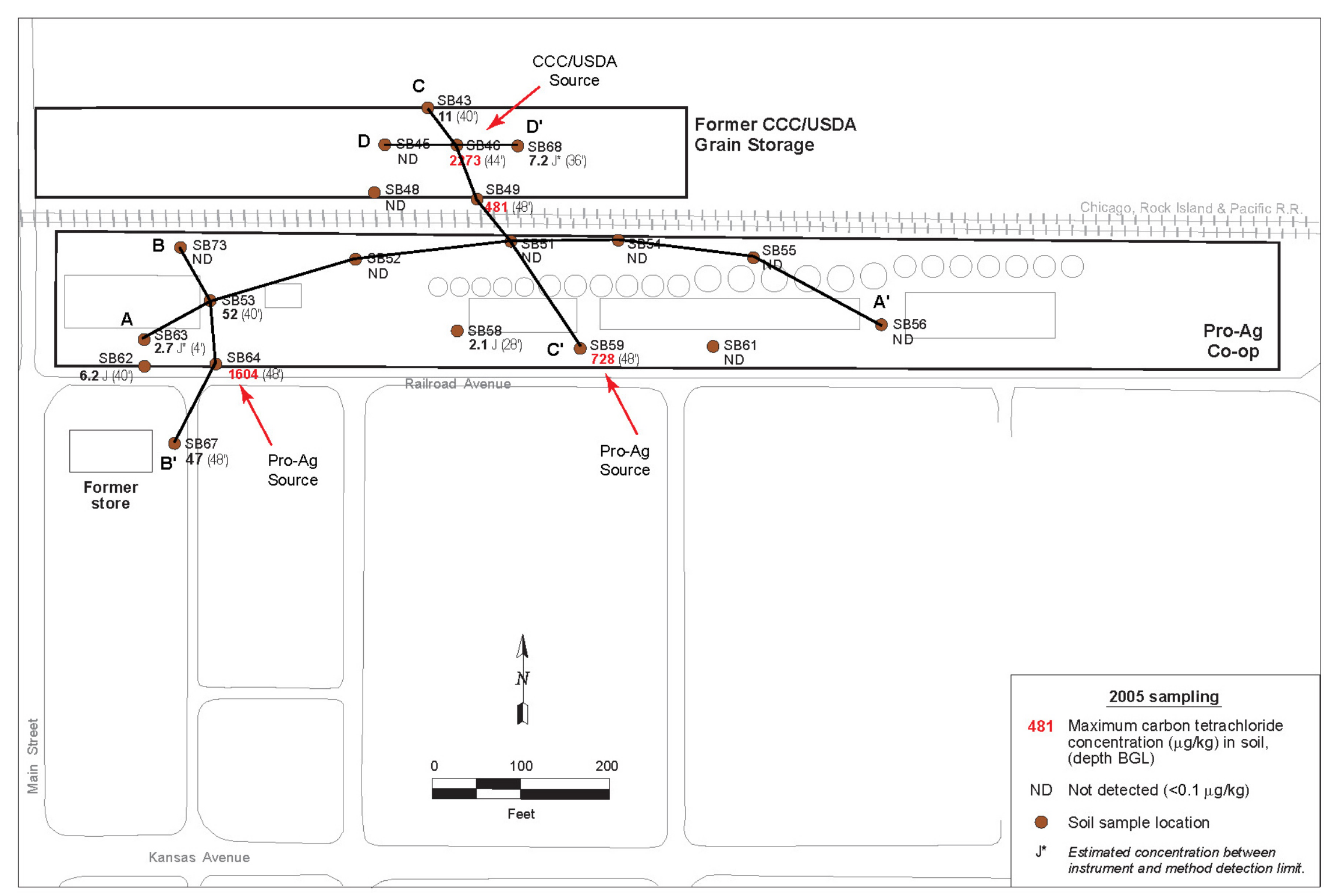

FIGURE 2.9 Map showing source areas and locations of cross sections. 


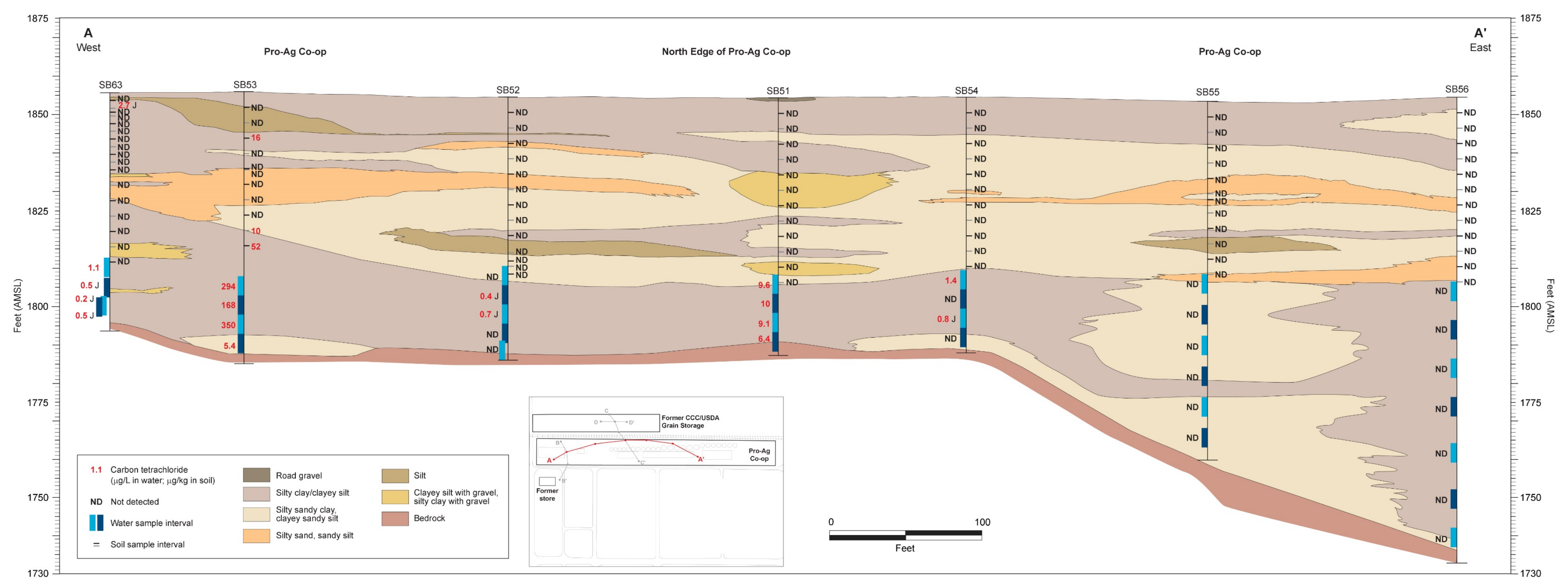

FIGURE 2.10 Cross section A-A' (see Figure 2.9 for location of cross section). 


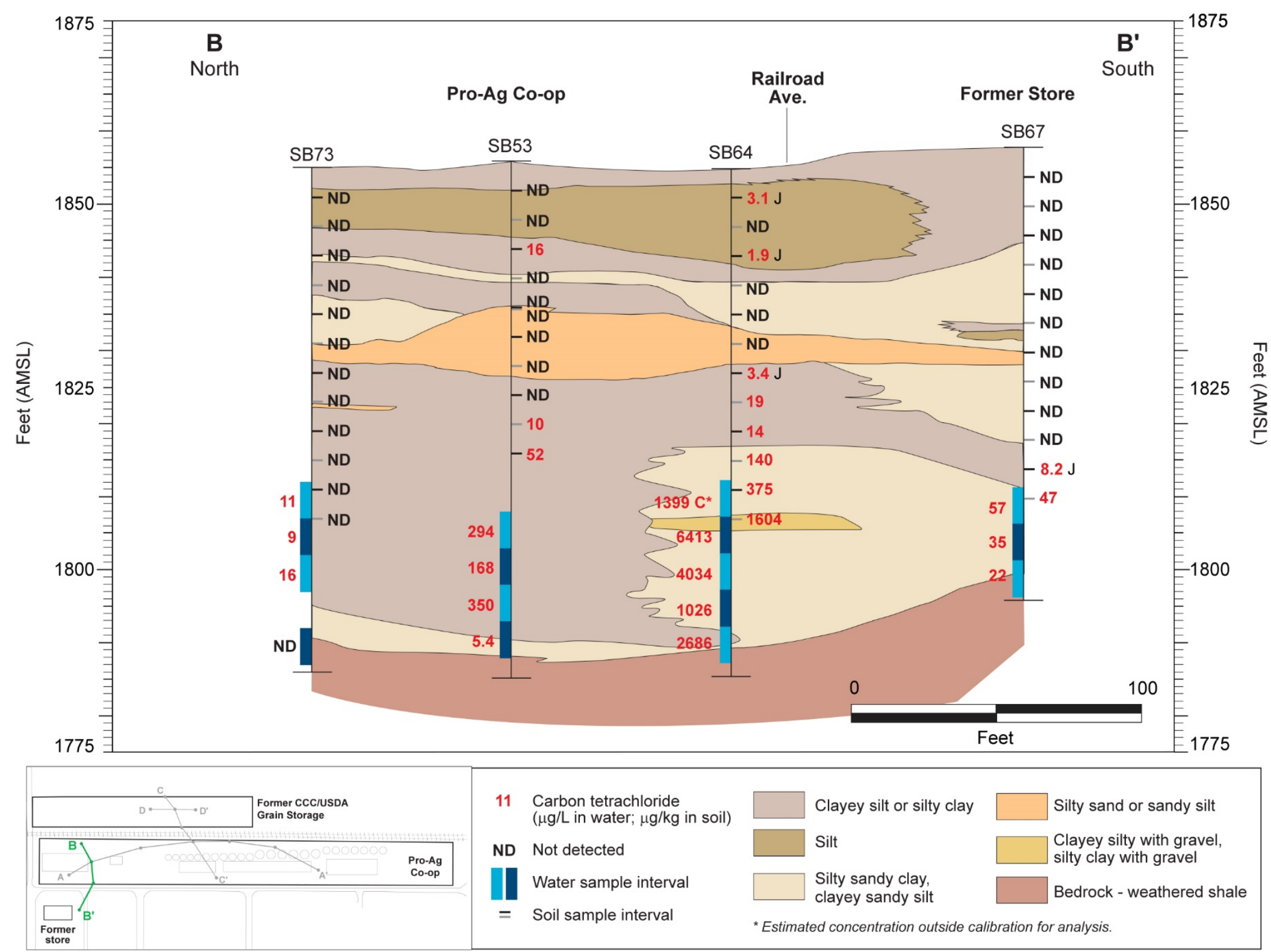




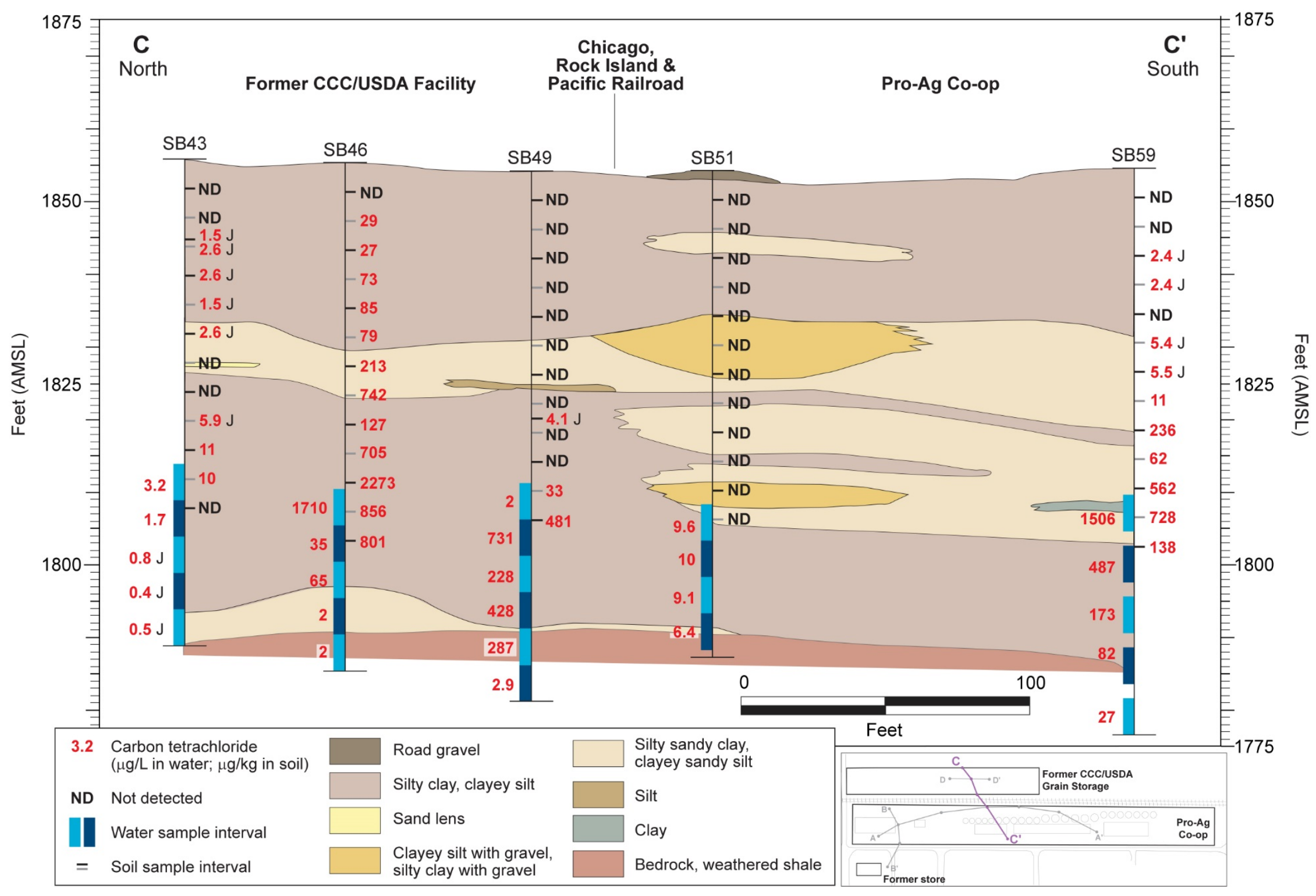

FIGURE 2.12 Cross section C-C' (see Figure 2.9 for location of cross section). 


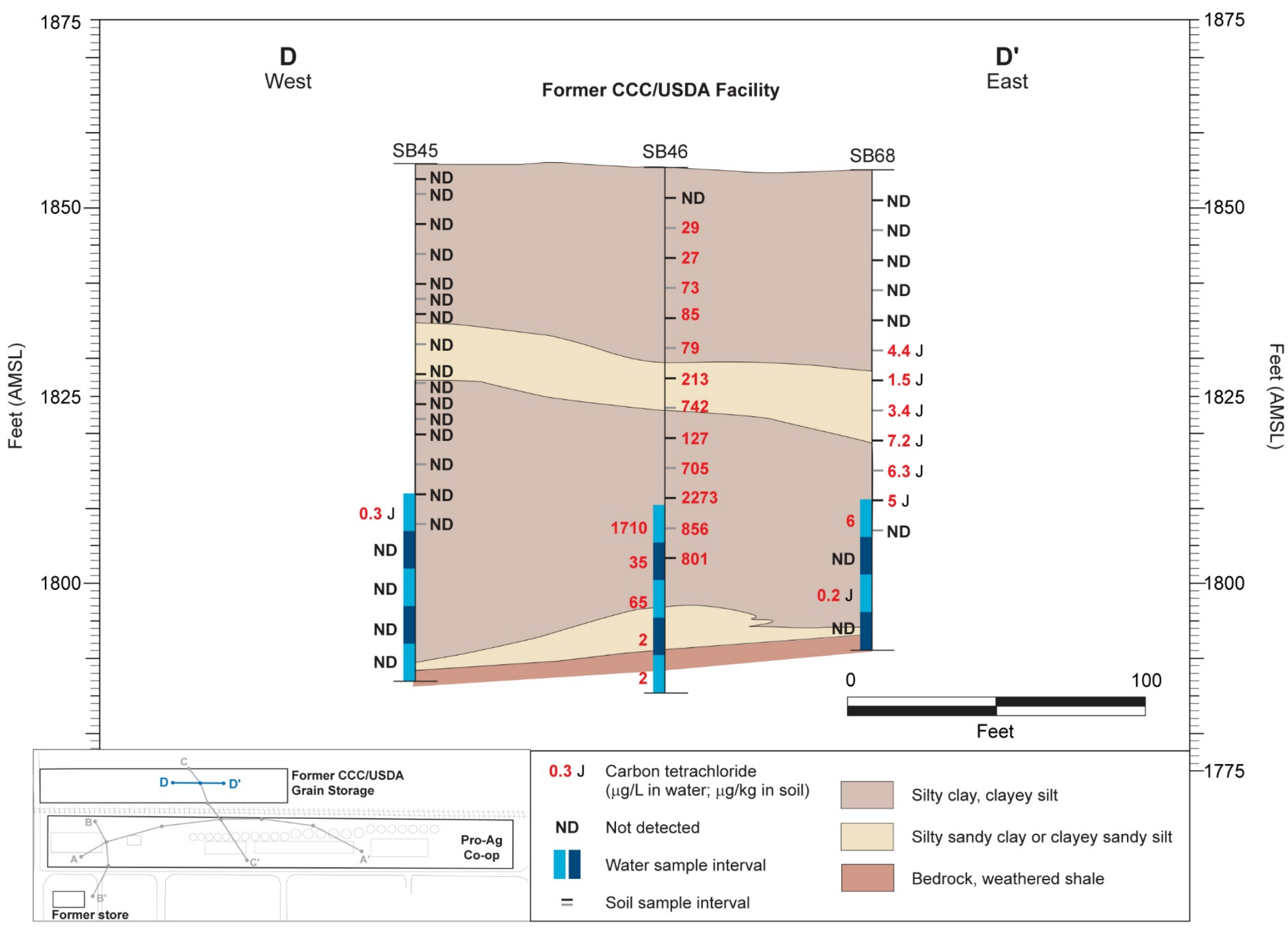

FIGURE 2.13 Cross section D-D' (see Figure 2.9 for location of cross section). 


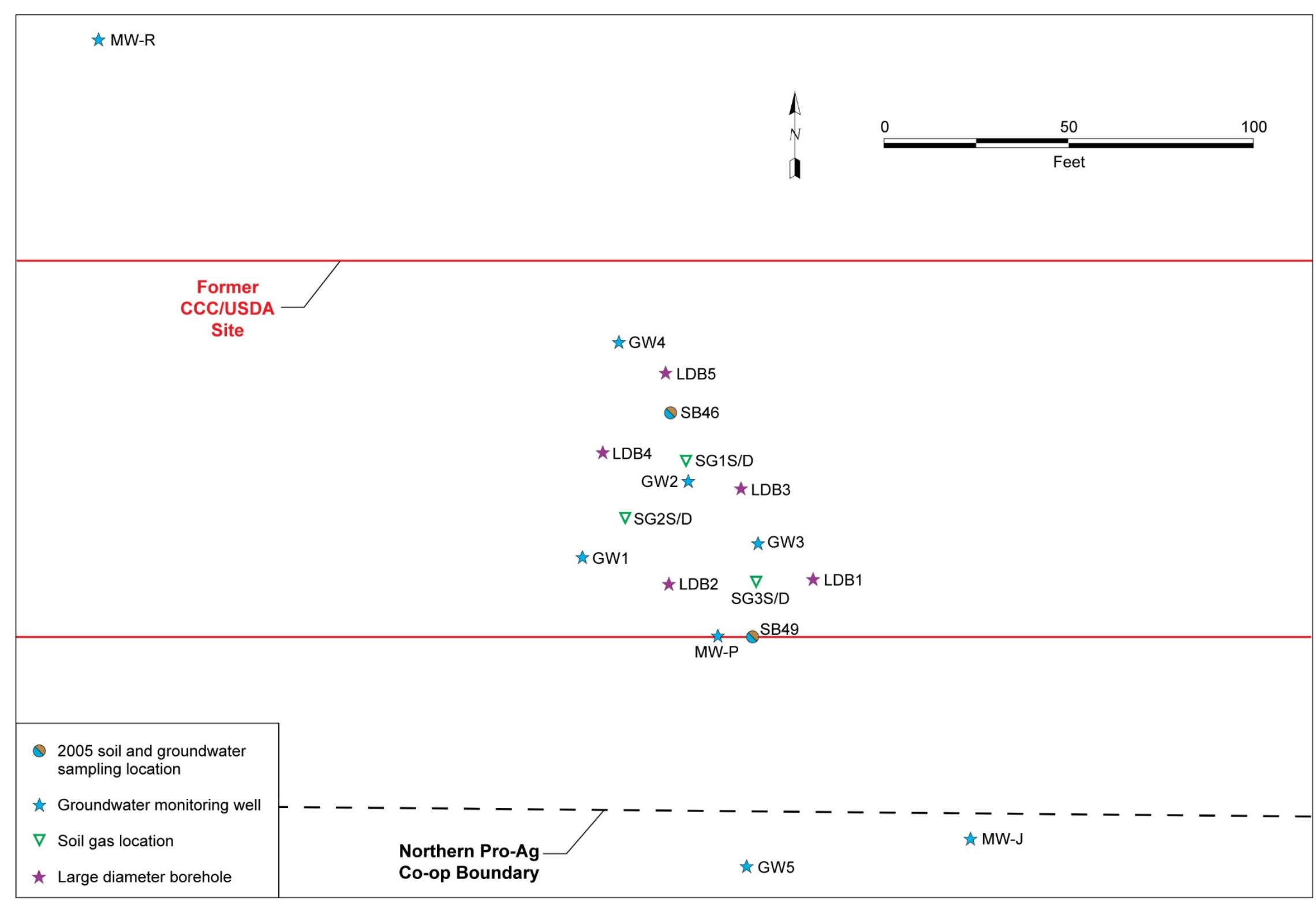

FIGURE 2.14 Map of LDB and IM monitoring point locations. 


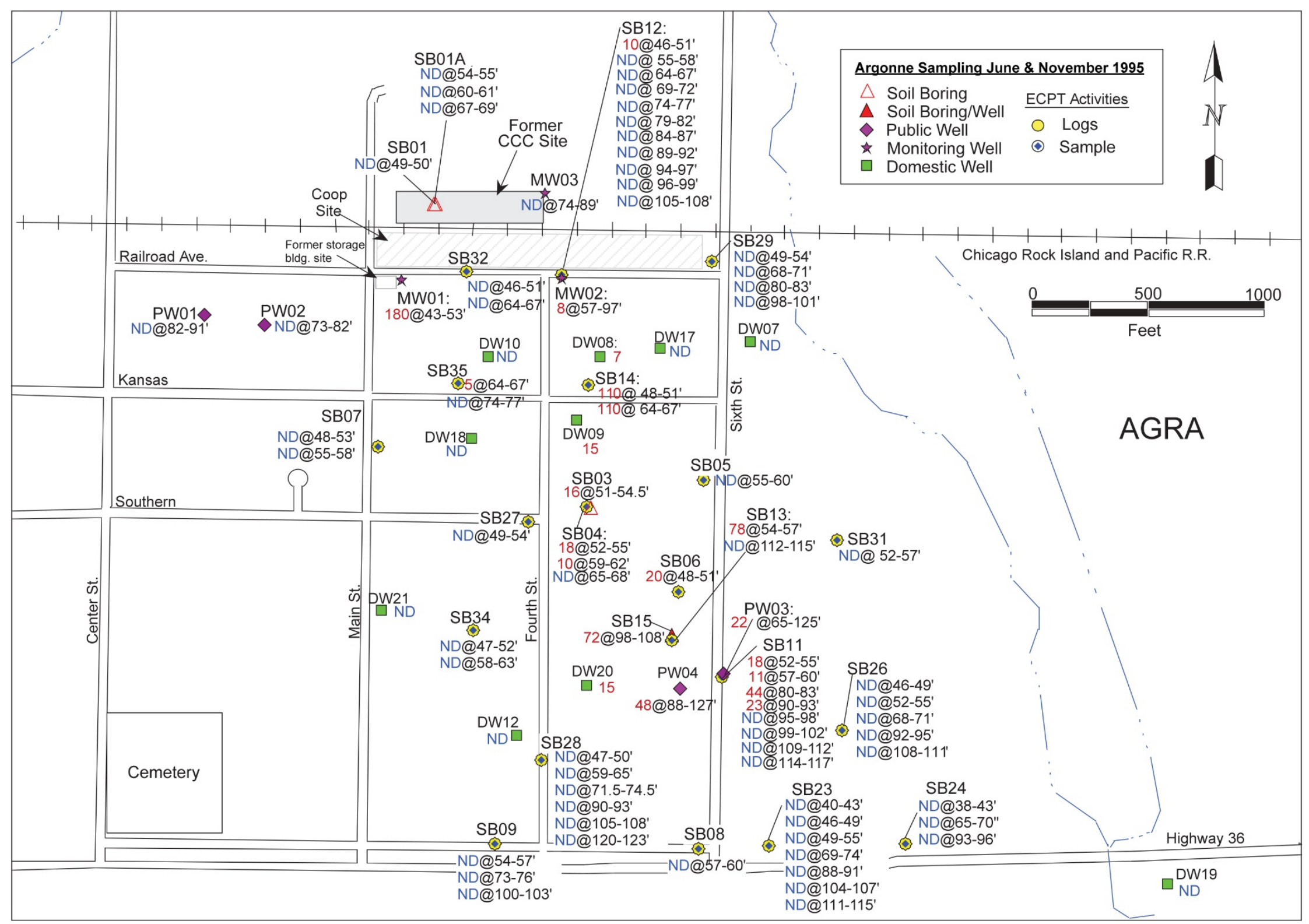

FIGURE 2.151995 plume map at Agra. 


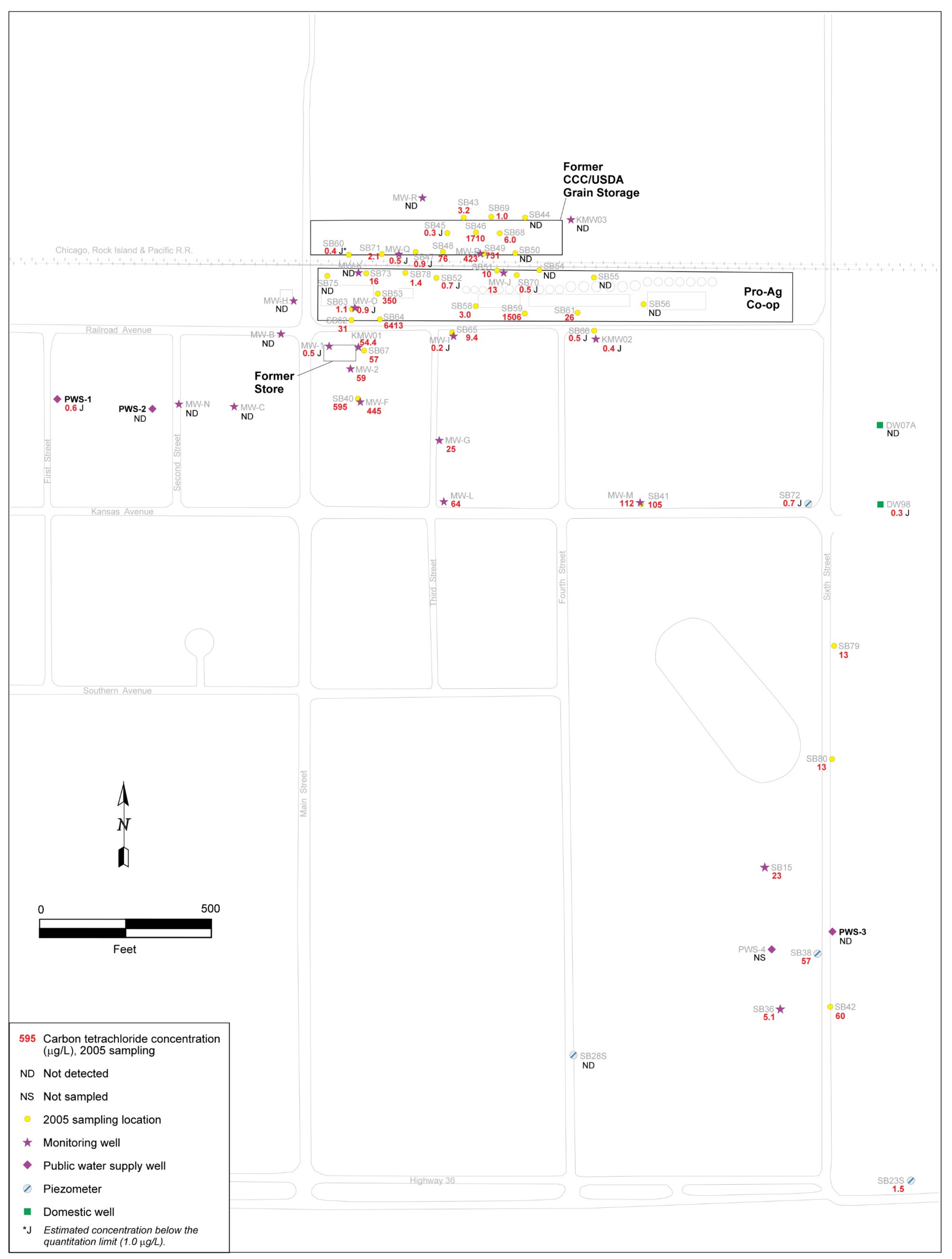

FIGURE 2.162005 plume map at Agra. 


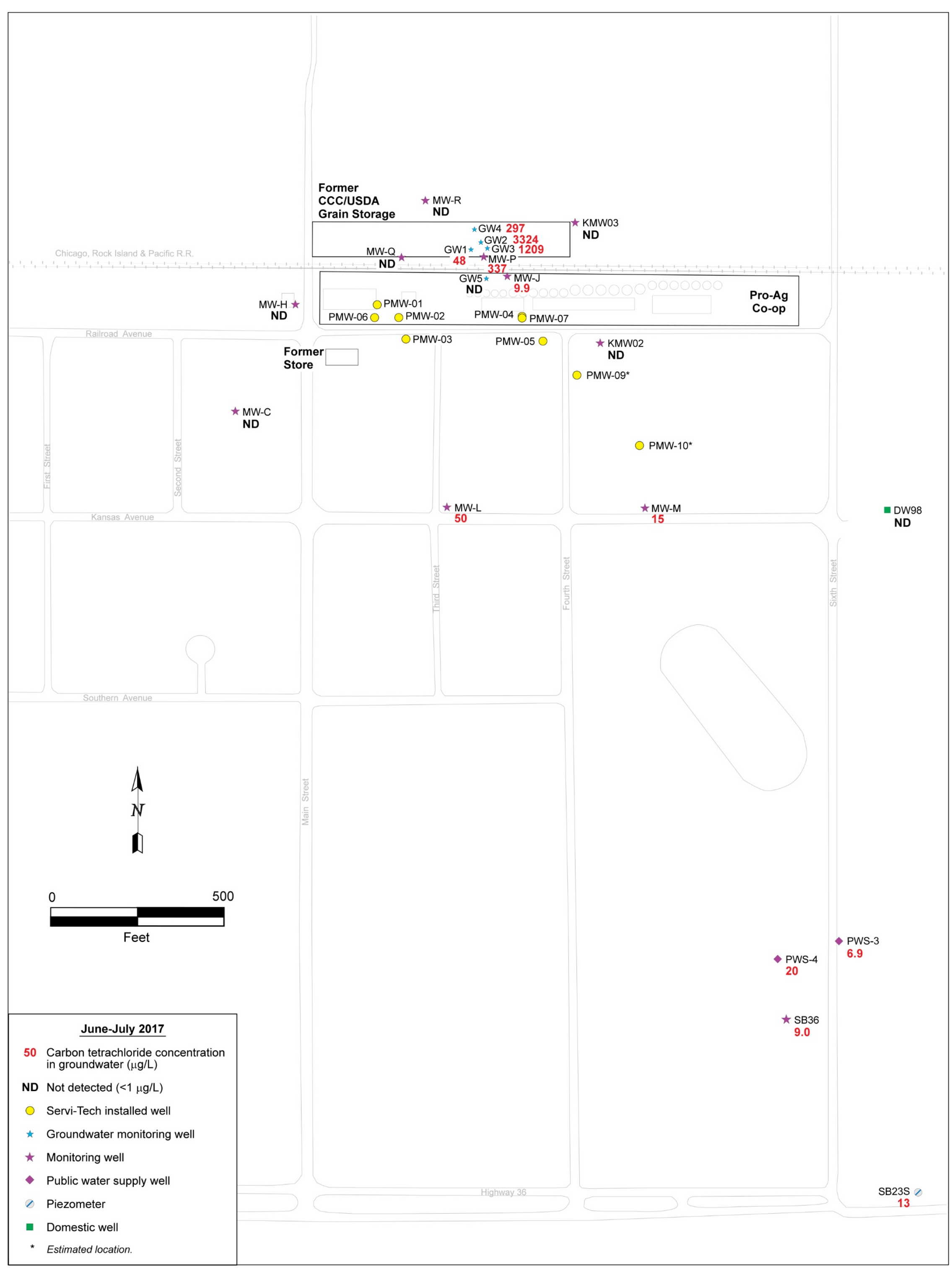

FIGURE 2.172017 plume map at Agra. 


\section{LDB Area Monitoring Wells}

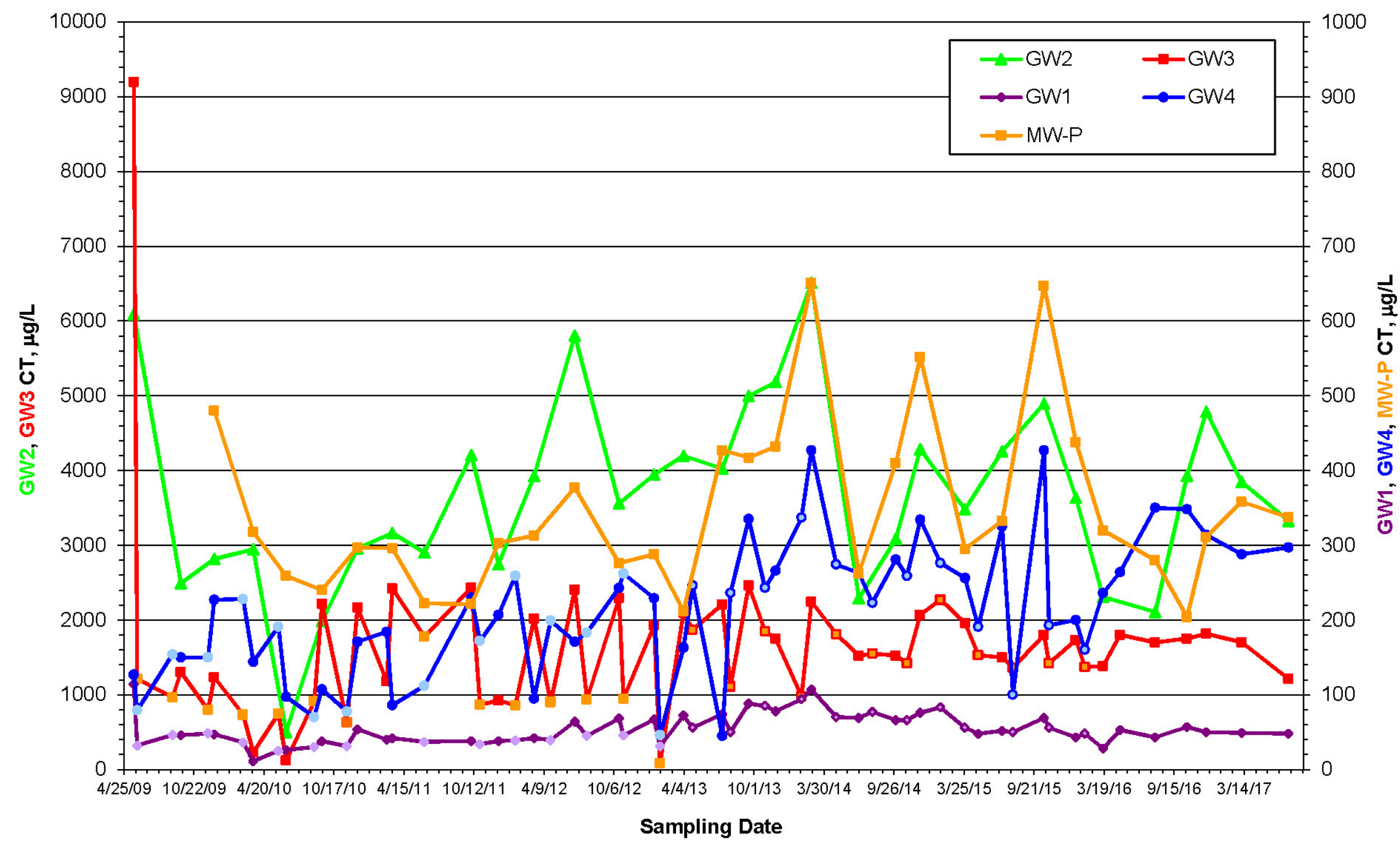

FIGURE 2.18 Carbon tetrachloride time-series for the LDB area monitoring wells (2009-2017). 


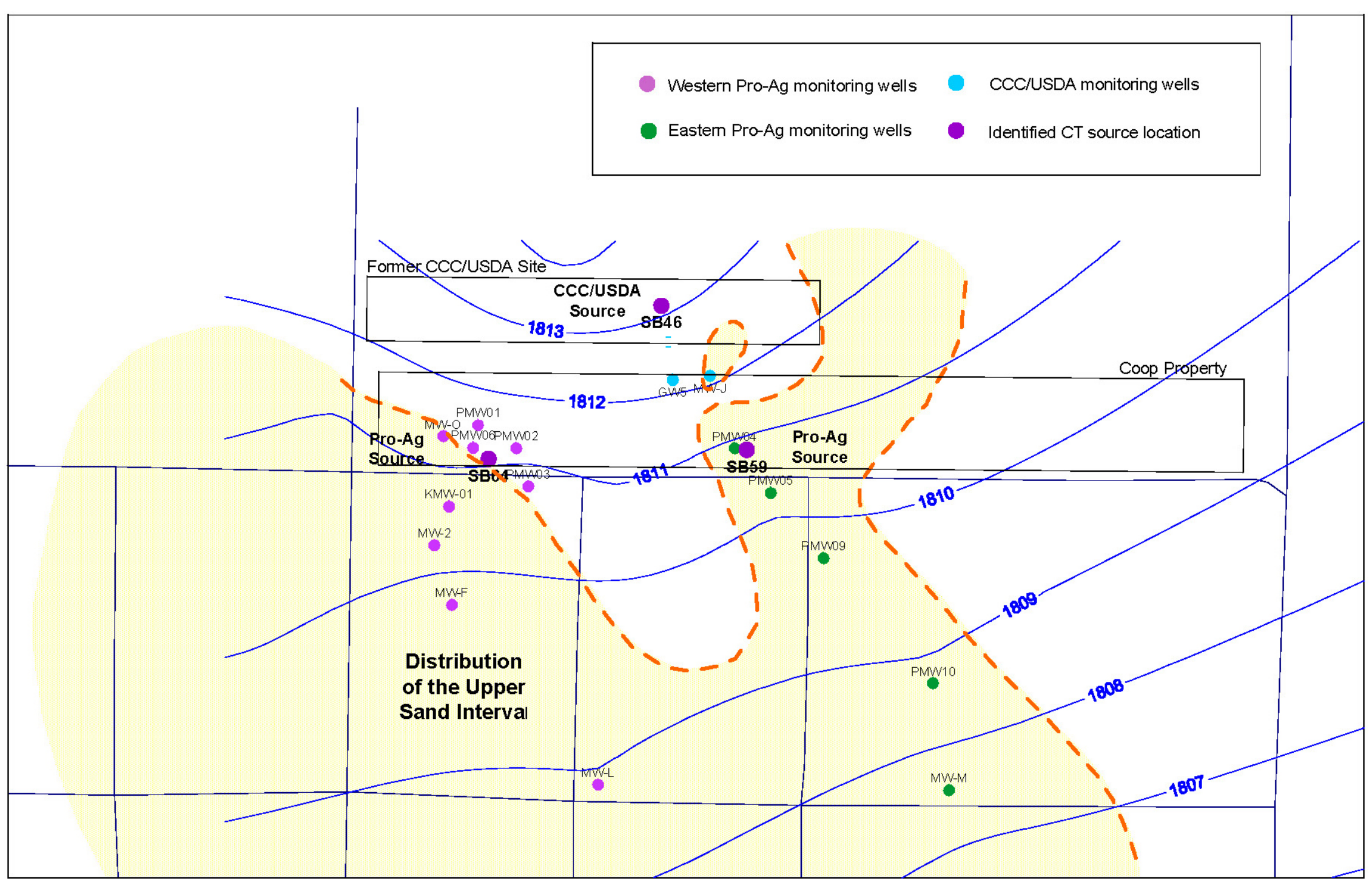

FIGURE 2.19 Location map of monitoring wells downgradient from source areas. 
CT Concentrations at Points Downgradient from the

Soil Source Location at the Former CCC/USDA Site

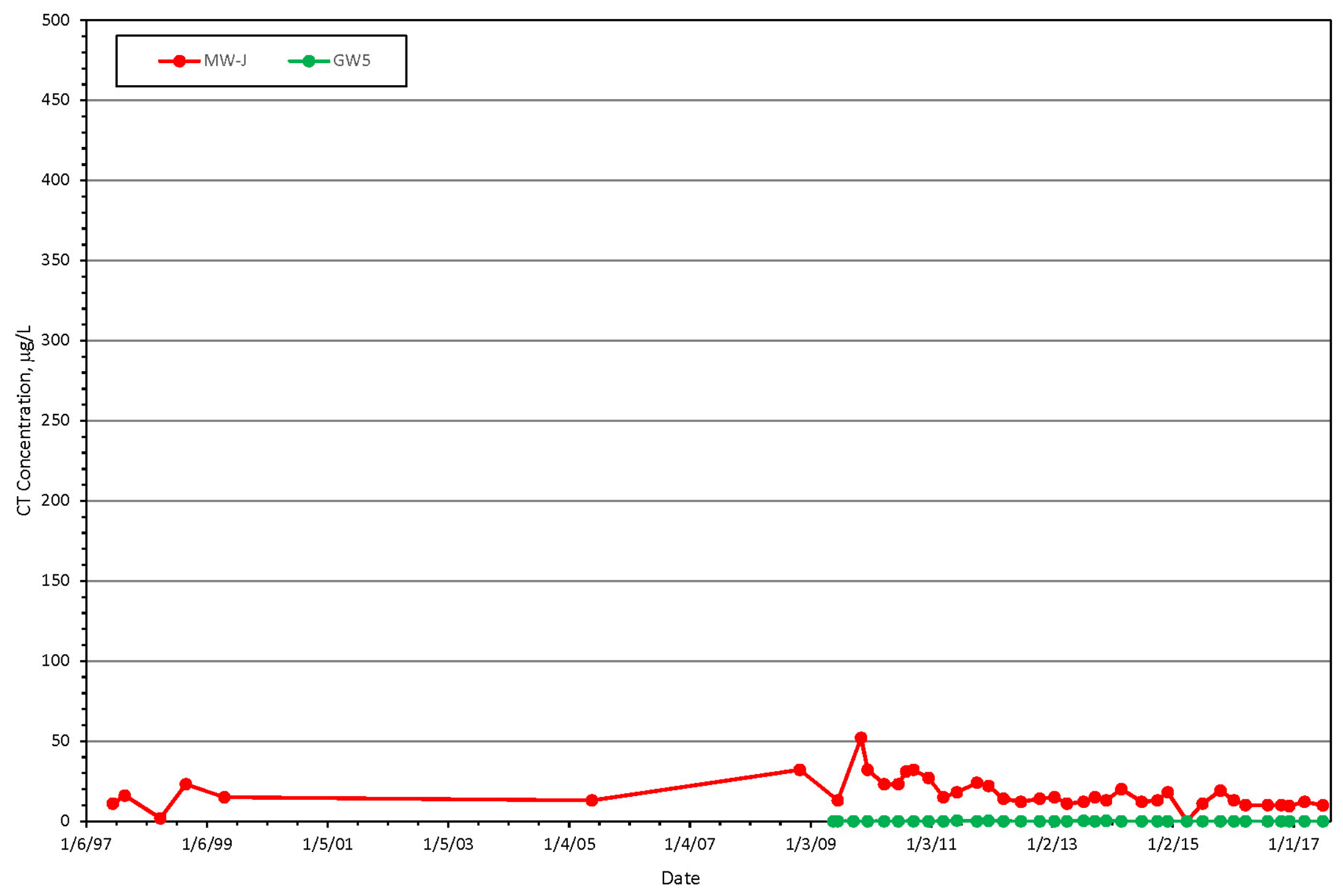

FIGURE 2.20 Carbon tetrachloride time series for GW5 and MW-J. 
CT Concentrations at Points Downgradient from the

Western Source Area on the Co-op Site

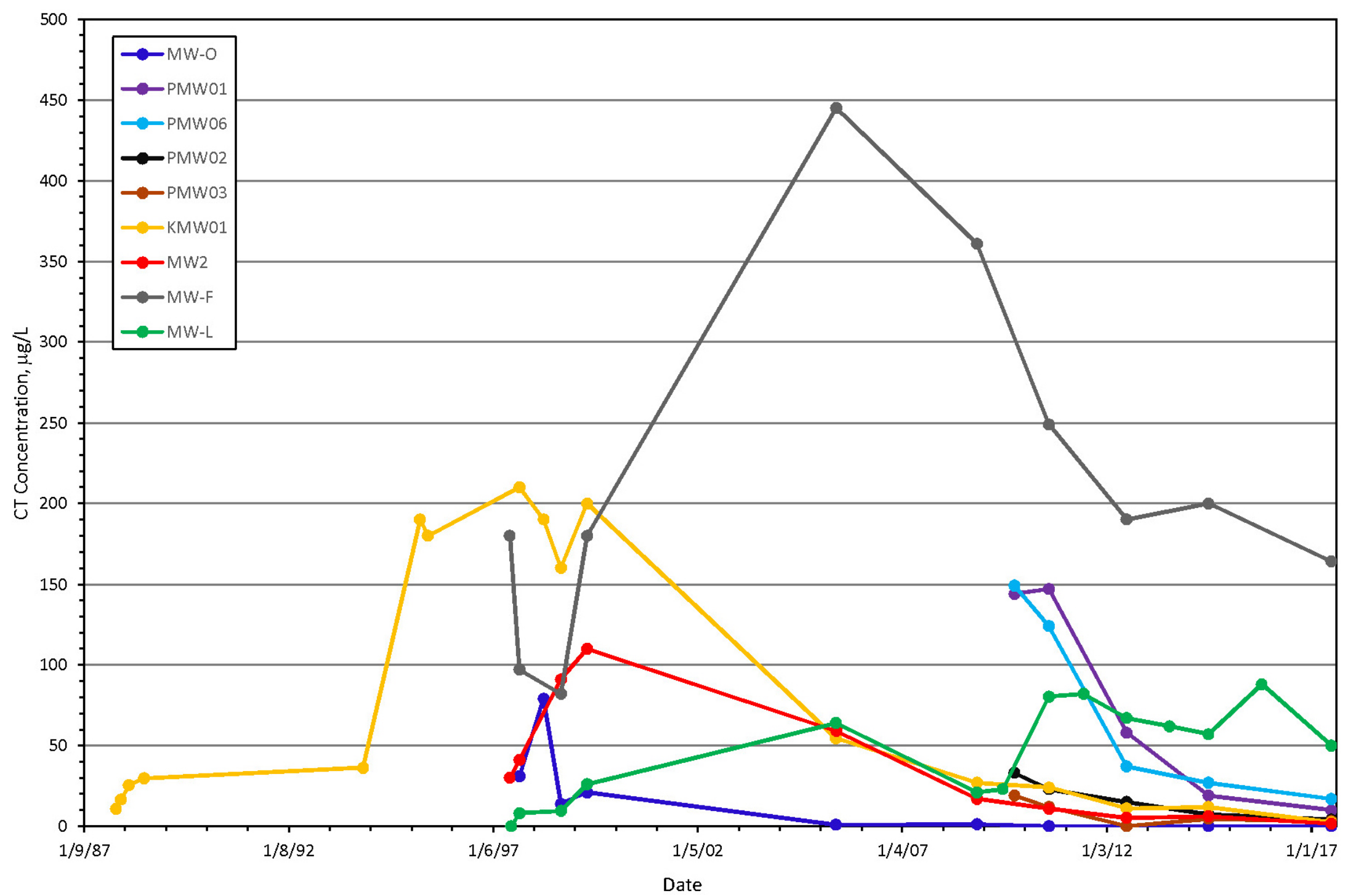

FIGURE 2.21 Carbon tetrachloride time series for wells downgradient of western Pro Ag source. 
CT Concentrations at Points Downgradient from the

Eastern Source Area on the Co-op Site

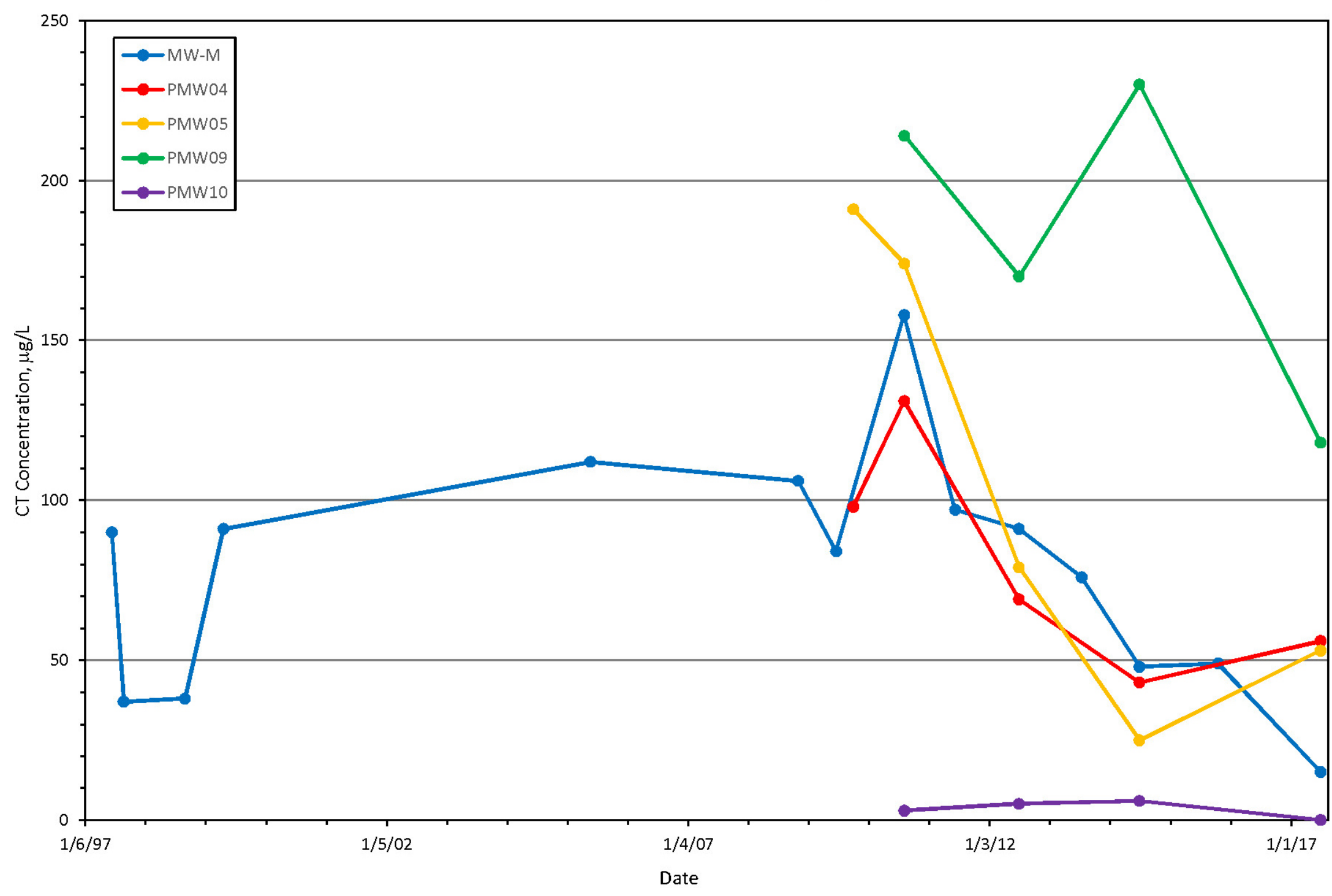

FIGURE 2.22 Carbon tetrachloride time-series for wells downgradient of eastern Pro Ag source. 


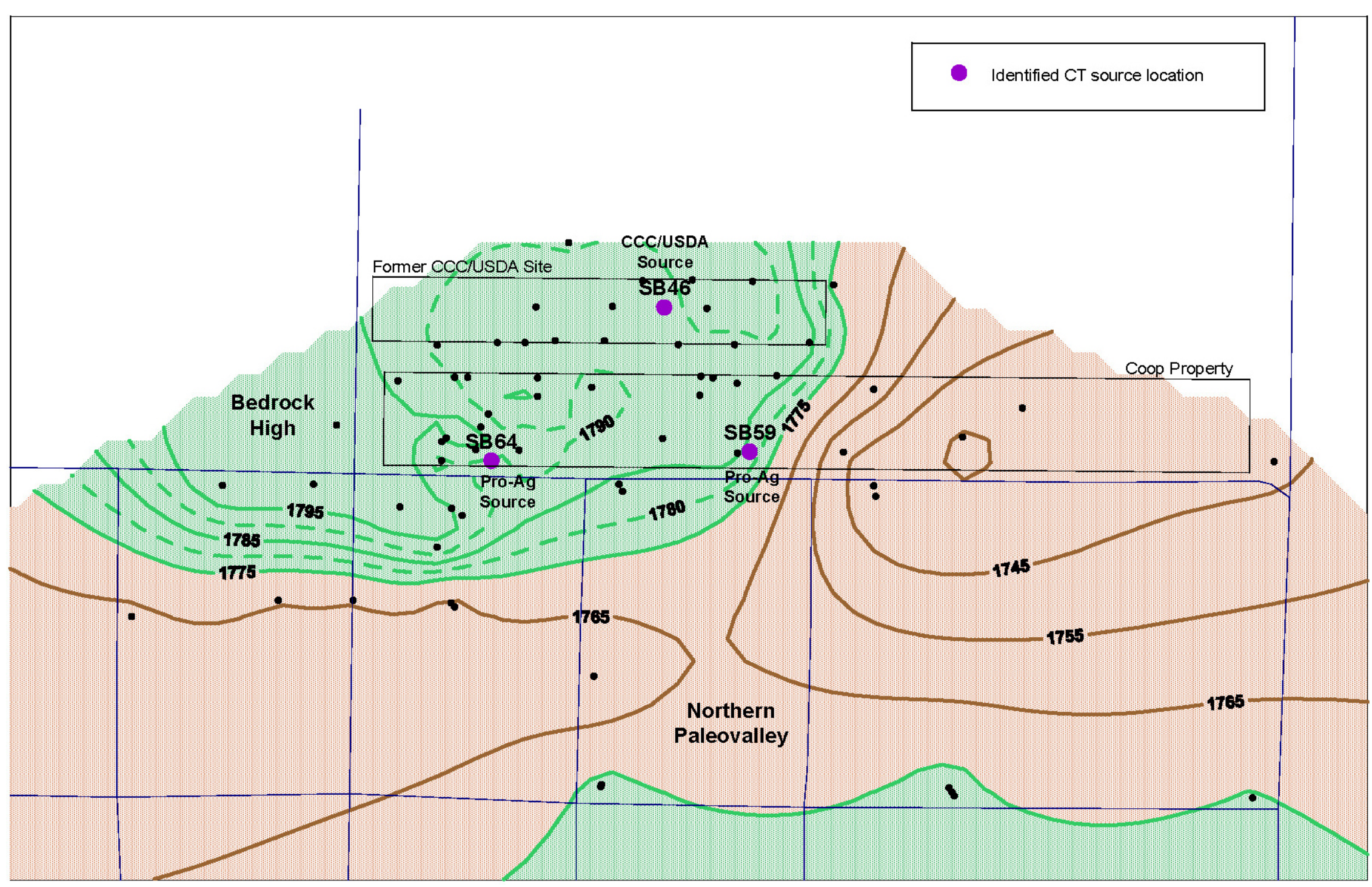

FIGURE 2.23 Map of bedrock surface in source areas. 


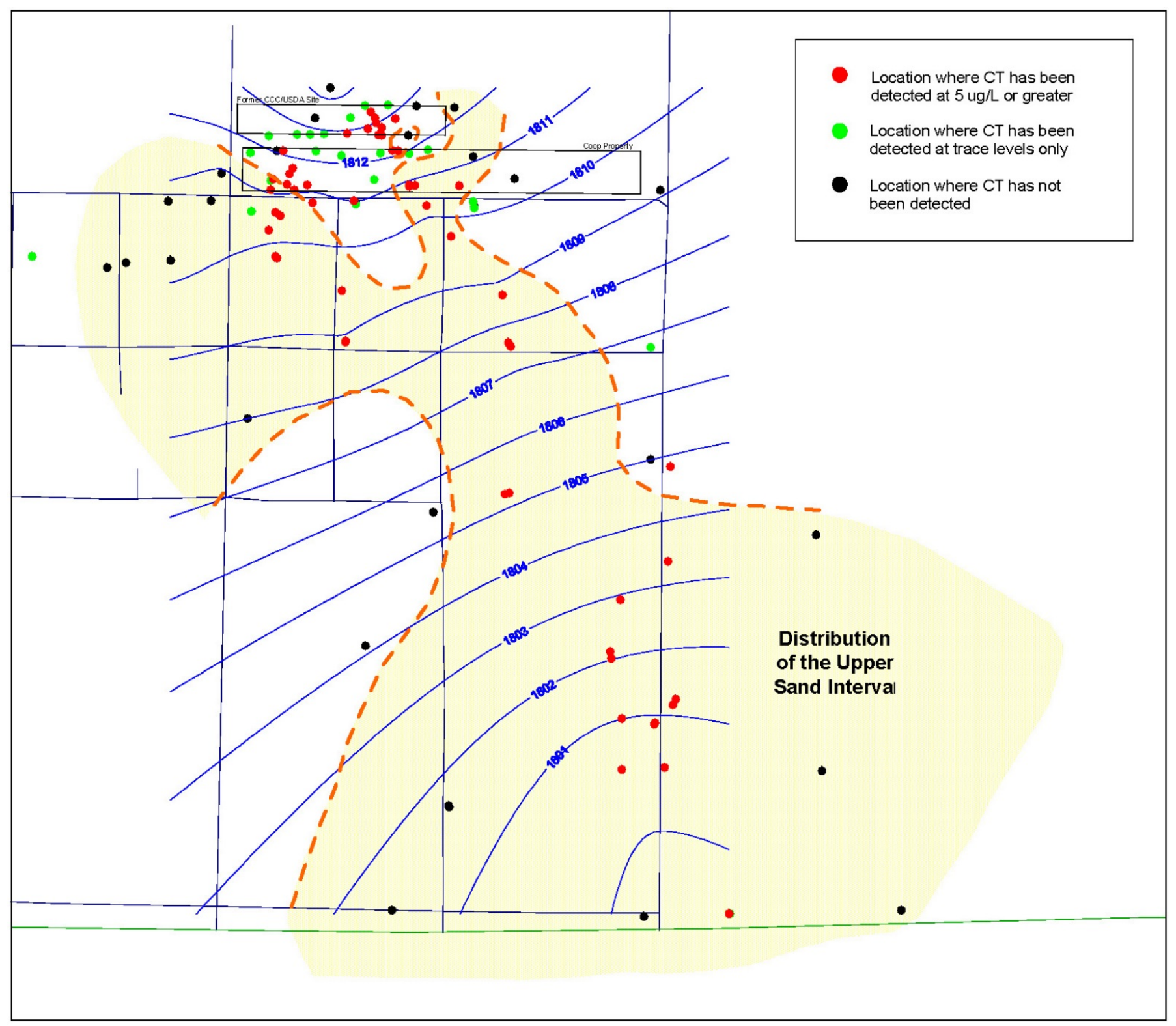




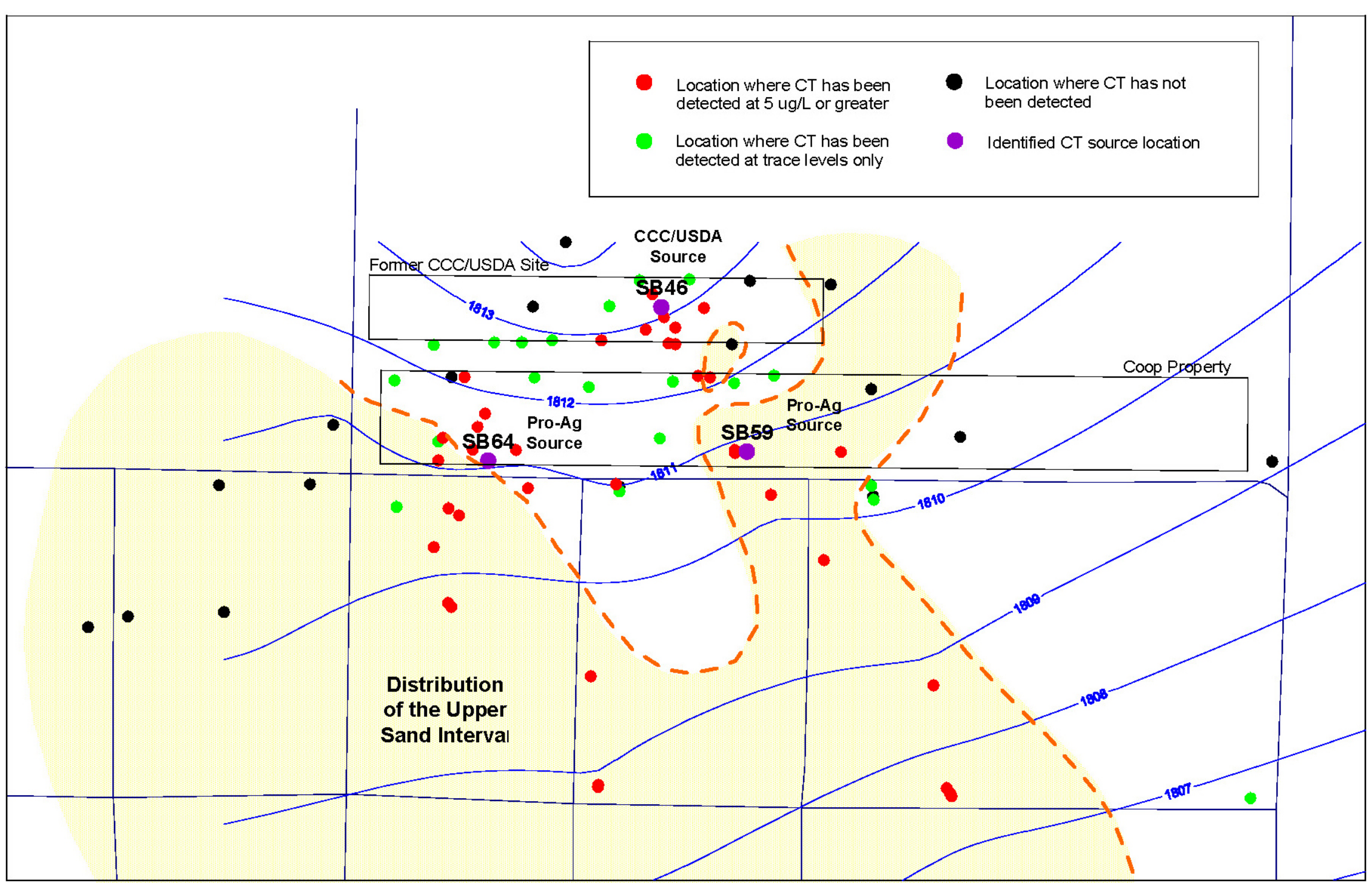

FIGURE 2.25 Map of upper sand near source areas, with historic carbon tetrachloride detections. 


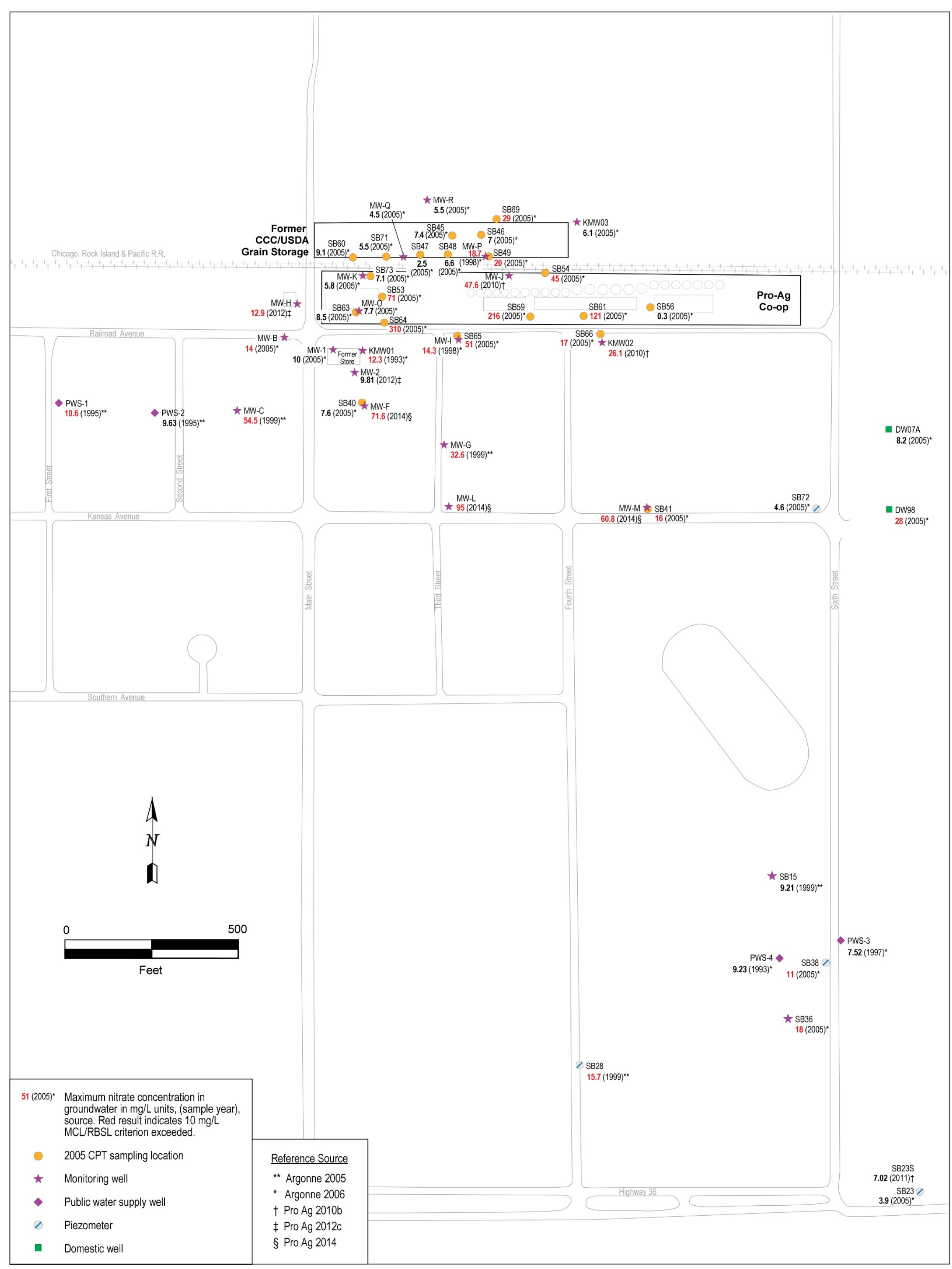

FIGURE 2.26 Map of maximum nitrate concentrations for wells sampled. 


\section{Evaluation of Current and Potential Future Human and Environmental Exposure Targets and Pathways}

\subsection{Soil Exposure Pathway}

Soils at Agra were sampled to evaluate the former CCC/USDA facility as a source of carbon tetrachloride contamination. Carbon tetrachloride was detected in soil at two locations; however, it was detected at depths that preclude exposure by direct contact.

\subsection{Vapor Intrusion Exposure Pathway}

The KDHE guideline for "buildings of concern" potentially at risk due to VI, are buildings within $40 \mathrm{ft}$ vertically or $100 \mathrm{ft}$ laterally of a contamination source. There are no residences within $100 \mathrm{ft}$ of the former CCC/USDA site. As a result there is no currently complete VI exposure pathway. Water levels in the vicinity of monitoring wells GW1-GW-5 have at times been shallower than $40 \mathrm{ft}$ BGL. As a result, although there is no current VI risk, in the unlikely event that a habitable structure would ever be built at the location of former CCC/USDA facility, the structure would be considered a building of concern.

\subsection{Soil-to-Groundwater Exposure Pathway}

Carbon tetrachloride concentrations exceeding the KDHE RBSL guideline of $73.4 \mu \mathrm{g} / \mathrm{kg}$ for protection of the soil-to-groundwater pathway were identified. Carbon tetrachloride concentrations ranging from $27-2,273 \mu \mathrm{g} / \mathrm{kg}$ were identified in a continuous vertical profile at boring location SB46, from $8 \mathrm{ft}$ BGL to the identified onset of groundwater saturation. Nevertheless, contaminated soil in proximity to boring location SB46 was remediated by the IM. The IM included the mass removal of contaminated soil by excavation, AS and SVE from groundwater within the LDBs, and SVE from the vadose zone in proximity to the LDBs. The IM has operated for more than eight years, and the AS/SVE systems have recovered more than $18 \mathrm{~kg}$ of carbon tetrachloride from the vadose zone and saturated soils and groundwater (Argonne 2009a,b,c; 2010a,b,c,d; 2011a,b,c; 2012a,b; 2013a,b; 2014a,b; 2015a,b; 2016a,b; 2017; and 2018 unpublished data). Although groundwater in the vicinity of the former CCC/USDA site remains contaminated above the KDHE RBSL guideline and MCL, vadose zone soil contamination in the 
CCC/USDA source area has been addressed and risk associated with the exposure pathway from soil to groundwater has been mitigated by the IM actions.

\subsection{Groundwater Exposure Pathway}

Although the western portion of the former CCC/USDA site is located upgradient of two of the PWS wells, PWS1 and PWS2, no contamination source has been identified in the western portion of the former CCC/USDA site. A number of private wells are present in the town that remain in use for lawn and garden purposes (Pro Ag 2010a). However, there is no pathway from the CCC/USDA source to these lawn and garden wells.

A potential groundwater exposure pathway exists in the identified source area at the former CCC/USDA facility. In this restricted area, groundwater contamination linked to the former CCC/USDA operations remains at concentrations above the MCL and KDHE RBSL (5 $\mu \mathrm{g} / \mathrm{L})$ for this contaminant. Although the identified groundwater contamination in this area (currently undeveloped farmland, on railroad property) poses no present risk to human health, human exposure could be possible in the unlikely event that groundwater from this location were to be used as a source for drinking water or other domestic purposes in the future.

On the basis of the hydrogeologic relationships and groundwater monitoring history outlined in Section 2.6, the source area located at the former CCC/USDA facility has not contributed significant contamination to the extensive downgradient groundwater plume that has originated from the eastern and western source areas on the Pro Ag property, and poses no unacceptable threat to the groundwater beneath or downgradient from these areas.

\subsection{Summary}

In reference to the former CCC/USDA site, no current or future risks are associated with direct exposure to near-surface soils or the seepage of groundwater to surface water. No current risks are associated with VI since there are no structures on this portion of the railroad right-ofway. Water levels in the vicinity of monitoring wells GW1-GW-5 have, however, occasionally been shallower than $40 \mathrm{ft}$ BGL. As a result, although there is no current VI risk, in the unlikely event that a habitable structure would ever be built on the former CCC/USDA property, the structure would be considered a building of concern. 
Because Agra residents have been served by a municipal water supply system, there are no human health risks related to the use of contaminated groundwater as a domestic (drinking) water source. However, in the absence of enforced regulations to prevent future drilling of domestic wells, future risk might exist from this exposure pathway. Risks previously associated with protection of the soil-to-groundwater pathway in the identified soil-source area at the former CCC/USDA facility have been mitigated by the implementation and long-term operation of the IM. 


\section{Corrective Action Goals and Regulatory Considerations}

\subsection{Site-Specific Goals}

The site-specific goals of any proposed remedial action at the former CCC/USDA facility concern groundwater as follows:

- Reduce the toxicity, mobility, and volume of contaminated groundwater associated with the source area at the former CCC/USDA facility.

- Mitigate potential future risks to human health via the groundwater exposure pathway, associated with the carbon tetrachloride contamination in groundwater that has been linked to the former CCC/USDA facility.

\subsection{Regulatory Considerations}

\subsubsection{ARARs and Guidance to be Considered}

The KDHE guidance for the preparation of a CAS (KDHE 2001a) lists compliance with Federal and State ARARs as one of the criteria that must be evaluated in the CAS process. The CAS guidance also refers to and adopts several regulations and guidance documents related to the Comprehensive Environmental Response, Compensation, and Liability Act (CERCLA). Section 121 of CERCLA and provisions of the National Oil and Hazardous Substances Pollution Contingency Plan (NCP; EPA 1990) require the EPA to ensure that cleanup actions implemented under CERCLA meet the specifications of ARARs.

Applicable requirements are cleanup standards, standards of control, and other substantive environmental protection requirements, criteria, or limitations promulgated under federal or state environmental or facility siting laws that specifically address a hazardous substance, pollutant, contaminant, remedial action, location, or other circumstance. Only those state standards that are identified by a state in a timely manner and that are more stringent than federal requirements may be applicable. 
Relevant and appropriate requirements are cleanup standards, standards of control, and other substantive environmental protection requirements, criteria, or limitations promulgated under federal or state environmental or facility siting laws that, while not attaining the status of being "applicable” to a hazardous substance, pollutant, contaminant, remedial action, location, or other circumstance, nevertheless address problems or situations sufficiently similar so that their use is well suited to the particular site. Only those state standards that are identified by a state in a timely manner and that are more stringent than federal requirements may be relevant and appropriate.

As described by the EPA (1990), ARARs can be placed in three categories: chemicalspecific, location-specific, and action-specific. Chemical-specific ARARs address certain chemical species or classes of contaminants and relate to the allowable limits of contaminant concentrations in various environmental media (soil, groundwater, surface water, air). These ARARs can be used to determine cleanup levels. Location-specific ARARs are based on the specific setting and nature of the site, such as proximity to wetlands, floodplains, or archaeological resources. Action-specific ARARs relate to specific response actions (e.g., excavation or treatment activities) proposed for implementation at the site.

In addition to ARARs, the NCP (EPA 1990) provides for the use of other advisories, criteria, or guidance "to be considered" (TBC). The TBCs are advisories, criteria, and standards that are issued by the federal or state regulatory body but are not legally binding because they have not been promulgated. The identification of TBCs is not mandatory; however, they are to be used, as appropriate, to complement the ARARs.

Potential ARARs for the proposed actions described in Sections 5, 6, and 7 were identified on the basis of the nature of the contamination, the site location, and the proposed activities. A comprehensive list of potential ARARs and TBCs, including both federal and Kansas requirements, is in Appendix B. Chemical-specific and action-specific ARARs are discussed below in relation to the Agra site.

\subsubsection{Chemical-Specific ARARs}

Cleanup levels are generally established on the basis of chemical-specific ARARs, which are requirements or risk-based numerical limits establishing the allowable amount or concentration 
of a hazardous substance that may exist in or be released to the environment. The contaminants of concern in this case are carbon tetrachloride and chloroform, and a potential chemical-specific ARAR would be the Kansas-administered Federal Safe Drinking Water Regulations (KDHE 2005a), which establish MCLs (applicable at the tap) pertaining to public water supplies as potential ARARs. The MCL for carbon tetrachloride is $5.0 \mu \mathrm{g} / \mathrm{L}$, as is the Kansas Tier 2 RBSL. The MCL for chloroform is $80 \mu \mathrm{g} / \mathrm{L}$, as is the Kansas Tier 2 RBSL.

Any nitrate contamination present is not from CCC/USDA operations and, therefore, is not the responsibility of CCC/USDA. The MCL for nitrate is $10 \mathrm{mg} / \mathrm{L}$; however, because the KDHE takes into account the background concentration of nitrate in groundwater, alternative cleanup goals may be considered (KDHE 2014). Any nitrate-laden waters could be targeted for beneficial reuse, such as makeup water at an operational facility, maintaining a reserve tank for fire suppression and/or augmentation of Agra Lake and/or its surroundings.

\subsubsection{Action-Specific ARARs}

\subsubsection{Well Placement and Construction Regulations}

Regulations included in the Code of Kansas Regulations (COKR) 28-30-Water Well Contractor's License and Water Well Construction-are considered applicable for this CAS. The regulations provide protective measures for the installation of new water supply wells. Included in construction regulations for wells that are not used for the PWS (and thus are applicable to the construction of private water wells and monitoring wells) are a well placement component and a well construction component. More specifically, COKR 28-30-6 (a), (b) (c), (f) and (j) specify the following:

a) Each water well shall be so located as to minimize the potential for contamination of the delivered or obtained groundwater and to protect groundwater aquifers from pollution and contamination.

b) The following requirement for grouting shall be met: each constructed water well and each reconstructed water well shall be sealed by grouting the annulus between the casing and the boring from ground level to at least $20 \mathrm{ft}$. 
c) If groundwater is encountered at a depth less than the minimum grouting requirement, the grouting requirement may be modified by the secretary to meet local conditions.

f) Casing shall meet the following requirements: (1) each water well shall have durable watertight casing from at least one foot above the finished ground surface to the top of the producing zone of the aquifer; and (2) the watertight casing shall extend at least $20 \mathrm{ft}$ below the ground level. Exceptions to either of these requirements may be granted by the secretary if warranted by local conditions.

j) Each groundwater-producing zone that is known or suspected to contain natural or man-made pollutants shall be cased and grouted in accordance with subsection (b) during construction of any water well to prevent the movement of groundwater to either overlying or underlying fresh groundwater zones.

\subsubsection{Licensing and Professional Certifications}

Regulations included in COKR 66-6-1 through 66-14-12—adopted by the Kansas Board of Technical Professions - establish requirements for the licensing of professionals such as engineers, land surveyors, and geologists. These regulations will be applicable if the services of a geologist, engineer, or land surveyor are required to implement a corrective action alternative.

\subsubsection{Water Appropriation Regulations}

Regulations included in COKR 5-1-1 through 5-10-6 and COKR 5-50-1 through 5-50-8 establish requirements for obtaining water. If water appropriations are required for the implementation of a corrective action, these regulations will be applicable.

\subsubsection{Advisories, Criteria, and Guidance}

A chemical-specific TBC is the Kansas Tier 2 RBSL guidelines for the soil-to-groundwater pathway. The values are $73.4 \mu \mathrm{g} / \mathrm{kg}$ for carbon tetrachloride and $850 \mu \mathrm{g} / \mathrm{kg}$ for chloroform. 
Contaminated soil in the vadose zone has been addressed by the IM. Since contaminated soil may still exist in the saturated zone, the RBSL guideline for the soil-to-groundwater pathway is considered TBC guidance.

The Kansas VI guidance (KDHE 2007) defines "buildings of concern" for chlorinated VOCs as those within $100 \mathrm{ft}$ laterally and $40 \mathrm{ft}$ vertically of the contamination. At Agra, there are no receptors within $100 \mathrm{ft}$ of the confirmed soil contamination source. Although water levels in the vicinity of monitoring wells GW1-GW5 can intermittently be shallower than $40 \mathrm{ft}$ BGL, there are no habitable structures in the railroad right-of-way. Consequently, the VI guidance is not considered TBC guidance.

Although any nitrate contamination present did not originate from operations at the former CCC/USDA facility, KDHE guidance on the investigation and remediation of nitrate and ammonium contamination affects the evaluation and implementation of alternatives described in this CAS. The KDHE (2014) guidance pertains to agriculture and bulk distribution-related sites that include the use, manufacture, transportation and/or distribution of chemicals resulting in nitrogen contamination (which is the case at the Agra site). The Presumptive Remedy Policy Investigation and Cleanup of Nitrogen at Agriculture-Related Sites in Kansas, KDHE Bureau of Environmental Remediation (BER) policy BER-RS-047 (KDHE 2014; hereafter referred to as the Nitrogen Presumptive Remedy [NPR]) is to be used to address nitrate contamination in soil and groundwater. This policy describes soil excavation and land application as a remedial approach for soil with nitrate contamination, and pump and irrigate or pump and the use of extracted water for mixing water at fertilizer plants as two typical groundwater-related presumptive remedies. The NPR also poses the use of land use controls (LUCs), such as Environmental Use Controls (EUCs), as a component of the cleanup strategy to manage risks.

Cleanup levels set out in the NPR guidance are $200 \mathrm{mg} / \mathrm{kg}$ total nitrogen for the upper $24 \mathrm{in}$. of soil and $40 \mathrm{mg} / \mathrm{kg}$ for soil deeper than $24 \mathrm{in}$. Cleanup levels for groundwater are $10 \mathrm{mg} / \mathrm{L}$. The guidance notes that an alternative cleanup level may be set if the background concentration of nitrate is above the $10 \mathrm{mg} / \mathrm{L}$ threshold level. Nevertheless, this CAS does not address the remediation of nitrate contamination caused by others.

The KDHE BER policy BER-RS-023, Scope of Work for a Corrective Action Plan/Corrective Action (CAP/CA) (KDHE 2013), provides TBCs guidance regarding the content of the CAP and corrective action to be used to address the remedial actions required by KDHE 
Corrective Action Decisions (CADs). The CAP documents the basis for the design and implementation of remedial actions with the level of detail commensurate with the complexity of proposed actions. The primary objectives of the CAP are as follows:

- Develop preliminary design for proposed remedial actions;

- Develop schedule identifying critical path tasks necessary to implement remedial actions;

- Collect supplemental data as necessary to support remedy design and implementation;

- Develop detailed design plans and specifications for the remedial actions;

- Develop Contingency Plans that identify alternative corrective actions to be implemented in the event of a significant remedy failure; and,

- Develop or enhance Site Monitoring and Performance Evaluation (SMPE) Plan to monitor the effectiveness of the corrective action.

As specified in the policy, work products that constitute the practice of the disciplines of geology, engineering, architecture, or surveying should be sealed, signed, and dated by a professional licensed by the Board to practice in the State of Kansas. Depending on the nature of the corrective action, a Construction Quality Assurance Plan and a Health and Safety Plan may need to be developed. Key elements of the CAP and associated documents include:

- Summary of available site information and investigation results;

- Detailed description of the proposed corrective action;

- Remedial action objectives (RAOs) and remedial goals;

- Design specifications and drawing/schematics, including figures and site system engineering layouts (e.g., process flow diagram, piping and 
instrumentation diagram, etc.) and engineering design basis prepared as, for example a preliminary (10\%), intermediate (30-50\%) followed by a pre-final/final (90-100\%) design package;

- Cost estimate; and,

- Detailed working schedule or critical path diagram.

The CAP/CA must also contain an Operations and Maintenance plan and a SMPE Plan. The SMPE Plan includes a monitoring component to be used for evaluating the effectiveness of the remedial action and a reporting component to keep KDHE apprised of the performance of the remedial action remedy. Key elements of a SMPE Plan include:

- $\quad$ RAOs and remedial goals;

- Summary of the remedial system operations that will be evaluated and identification of four criteria that will be used to evaluate system performance;

- Frequency, methods, and rationale for site monitoring;

- Description of the environmental media to be sampled (groundwater, surface water, soil, soil vapor, indoor air, etc.);

- Description of quality assurance/quality control (QA/QC) considerations;

- Identification of institutional controls that will be inspected/monitored;

- Plan for evaluating changes in land use of affected areas that may alter the effectiveness of the corrective action;

- Description of reporting methods, format, and frequency; and,

- Description of contingency trigger criteria (e.g., asymptotic mass removal/ product recovery rates, sentinel monitoring thresholds, etc.). 
An outline for the SMPE plans is included in the policy. Other Kansas action-specific TBC guidance includes several KDHE BER policies (KDHE 2001a,b; KDHE 2002; KDHE 2005b,c,d,e,f).

\subsubsection{Waivers and Variances}

Remedial alternatives that do not meet the requirements of an ARAR under CERCLA may qualify for a waiver or variance based on the criteria listed below. Waivers apply only to the attainment of the ARAR; other statutory requirements (e.g., that remedies be protective of human health and the environment) cannot be waived (CERCLA §121[d][4]).

- Interim Remedy. An interim remedial action will not attain all ARARs; it must be followed by a complete measure that will attain all ARARs.

- Equivalent Standard of Performance. Equivalent or better results can be obtained by using a design or method different from that specified in the ARAR.

- reater Risk. Compliance with an ARAR will cause greater risk to human health and the environment than noncompliance.

- Technical Impracticability. Achieving an ARAR(s) is impracticable from an engineering perspective.

- Inconsistent Application of State Requirements. The state has not consistently applied (or demonstrated the intention to apply consistently) a standard, requirement, criterion, or limitation in similar circumstances for other remedial actions.

- Fund Balancing. The costs associated with meeting an ARAR to obtain an added degree of protection or decrease in risk would jeopardize the funds for remedial actions at other sites (EPA 1990). 


\section{Identification and Screening of Technologies}

In this section, candidate remedial technologies and practices are reviewed, along with their potential applicability to the focus area for this CAS (Section 3). A list of currently available technology types and practices suitable for the mitigation of carbon tetrachloride contamination in soils and groundwater was developed first. The technology types were then screened relative to site-specific conditions, in accordance with KDHE (2001a) and EPA (1988) guidance. Technology types retained after the screening were then assembled into corrective action alternatives that are outlined in Section 6 and evaluated in detail in Sections 7 and 8 (along with the no action alternative), in accord with KDHE (2001a) guidance.

The following types of general response actions were considered for mitigation of risk, in addition to the required no action option:

- $\quad$ LUCs to restrict potential future exposure to affected groundwater.

- Containment to restrict contaminant migration. The containment technologies considered included engineered physical barriers to groundwater flow.

- Removal of the contamination or contaminated media for ex situ treatment (as needed) and discharge or disposal. Removal technologies for soil, groundwater, and VOCs were evaluated.

- In situ implementation of chemically or biologically mediated processes within or downgradient from affected areas. The in situ technologies examined were permeable reactive barriers and in situ chemical reduction (ISCR), implemented via methods other than through the use of permeable barriers.

\subsection{Criteria for Identifying and Screening Technologies}

Technologies identified here were screened on the basis of site-specific conditions and the current understanding of the former CCC/USDA facility. Section 121 of CERCLA identifies a strong statutory preference for remedial actions that are highly reliable and provide long-term protection. 
The primary requirements for a selected remedy are that it:

- Protects human health and the environment and

- Meets the objectives of the proposed action in a cost-effective manner.

Additional selection criteria include the following:

- Preferred remedies achieve permanent or significant reduction of the toxicity, mobility, or volume of hazardous substances, pollutants, or contaminants.

- Where practical treatment technologies are available, off-site transport and disposal without treatment is the least preferred alternative.

- Permanent solutions and innovative treatment technologies or resource recovery technologies are preferred whenever practicable.

These criteria were considered in identifying and screening technologies to determine the appropriate components of the corrective action alternatives presented in Section 6.

Potentially applicable technology types and process options were screened on the basis of effectiveness, implementability, and cost, defined as follows:

- Effectiveness in terms of protecting human health and the environment in both the short term and the long term. Measures of effectiveness include (1) reduction of long-term impacts to human health and the environment; (2) reduction of contaminant toxicity, mobility, or volume through treatment; (c) control of potential impacts to human health and the environment during the action period; (4) timeliness; and (5) consistency with regulatory requirements.

- Implementability in terms of technical and administrative feasibility and resource availability. Technical feasibility is related to the practicability of construction, the reliability of operation, and the ability to meet technologyspecific regulations. Technical feasibility also addresses potential constraints 
associated with the site environment. Administrative feasibility concerns the acceptability of an alternative to relevant agencies and the public, as well as the effects of limitations imposed by permits and other restrictions. Resource availability addresses physical and logistic requirements for implementing specific components.

- Cost, considered in a comparative manner (low, moderate, or high) for technologies of similar performance and/or implementability.

These screening criteria were applied, as discussed below, to the individual technologies and practices under consideration. Combinations of technologies to address site-specific contamination were evaluated after the technologies were assembled into alternatives, as presented in Section 6.

\subsection{Screening of Remedial Technologies}

The following sections document the screening of candidate remedial technologies and practices.

\subsubsection{No Action}

The KDHE requires evaluation of a no action alternative as a baseline for comparison with other actions. The no action baseline is the condition of the site upon termination of the LDB/IM. The carbon tetrachloride contamination at the former CCC/USDA facility does not affect a presently used source of drinking water. Protective regulations for the water supply, such as the Kansas well placement and construction regulations (hererafter referred to as "water supply protective measures") that are already in force, will continue to preclude exposure to the contamination (Section 4.2.3.1).

The no action alternative is discussed further in Section 6.1. 


\subsubsection{Land Use Controls}

LUCs that constrain land use can be implemented in a variety of ways and already implicitly exist for the KRC right-of-way. Land use on the right-of-way at Agra is restricted to activities authorized by the railroad; these presently are limited to railroad operations, farming, operation of the Pro Ag facilities, and the operation and monitoring of the LDB/IM by Argonne. Activities performed by Argonne for the CCC/USDA are established in an "authorization and license agreement” entered into by the CCC/USDA, the MSPA (owner of the railroad property in 2008), and Burton Van Eaton to facilitate the installation and operation of the LDB/IM and perform what was then termed "Work at the Property" (MSPA and CCC/USDA 2008). The authorization and license agreement will need to be amended to address the change in ownership and the actions required by the corrective action decision.

The Kansas EUC program (KDHE 2005a) was established by Kansas House Bill 2247 (Kansas 2003), which became law on April 21, 2003. An EUC is defined as an institutional or administrative control — a restriction, prohibition, or control—for one or more uses of, or activities on, a specific property. In most cases, the property owner seeking the EUC has caused or is otherwise responsible for the contamination being addressed. When residual contamination exceeds standards for unrestricted use, the property owner may request the EUC to allow for appropriate use of the property while ensuring the present and future protection of public health and the environment.

Obtaining an EUC involves completing an application that details property information, applicant information, the nature of the existing or potential contamination, requested restrictions, and a signature by the site owner or a designated representative. As part of the EUC, the applicant must agree to register an approved, notarized EUC agreement with the registrar of deeds in the county in which the property is located. The EUC can be removed if the contaminant concentration decreases below environmental standards.

As explained in KDHE (2015) guidance, EUC sites are classified by the KDHE in one of three categories, on the basis of property size, the toxicity and mobility of residual contamination, and necessary KDHE inspection frequency. The approval of an EUC agreement involves either a one-time payment to the KDHE or a long-term care agreement with the KDHE. Category 1 sites have a one-time payment of $\$ 2,000$, while category 2 sites have a one-time payment not to exceed 
$\$ 10,000$. The long-term care agreement required for category 3 sites can be funded at the outset or as costs are incurred by the KDHE (KDHE 2005a, 2015).

\subsubsection{Effectiveness of Land Use Controls}

Although LUCs do not actively reduce contaminant toxicity, mobility, or volume, they can be effective in reducing the potential for exposure to contaminated material. When they are implemented in a timely manner and remain in effect until contaminant concentrations reach acceptable regulatory levels, these controls can provide both short- and long-term protection of human health and the environment. In general, the effectiveness depends on monitoring and enforcement. The existing LUCs imposed by the KRC for the existing right-of-way, the terms of the authorization and license agreement between the USDA and the former owner/operator of the railroad, and The Kansas EUC program have proven records of managing risk at single properties affected by contamination. Numerous sites with EUCs in place are included in the Identified Sites List. One site on the ISL that is particularly relevant for the Agra CAS is the Burlington NorthernSanta Fe (BNSF)-Dodge City Rail Yard. The BNSF yard is an abandoned refueling area at a rail facility that became contaminated due to leaks from underground and above ground storage tanks and refueling operations. As is the case with the KRC property affected by past operations on the former CCC/USDA facility, there is contamination in the subsurface but the BNSF yard continues to function as an active railroad operation.

In effect, LUCs are already in place at the former CCC/USDA facility because the site is located within an active railroad right-of-way, a circumstance that makes land use subject to approval by the KRC. Thus, it is highly unlikely that a business or resident could inadvertently construct a well or build a structure within the railroad right-of-way on the former CCC/USDA property. As a result, an EUC could be considered an effective, but probably unnecessary, secondary LUC mechanism.

\subsubsection{Implementability of Land Use Controls}

To be protective, all of the landowners within the footprint of the contamination caused by former operations of the CCC/USDA at Agra would need to participate in the EUC program and agree to the establishment of property-specific restrictions that control certain activities on their properties, such as construction of habitable structures or installation of drinking water wells. In 
addition, in the event that an EUC is established, EUC administrative fees, such as the EUC application fee, apply for each participating landowner.

The only potentially affected property owner is the KRC, owner of the railroad tracks and railroad right-of-way. Any deed restrictions associated with an EUC would be of no foreseeable advantage to the KRC because the KRC did not cause the groundwater contamination that is the key focus of this CAS, and the identified contamination has no discernable, negative impact on KRC's usage of this property. However, land use on the former CCC/USDA facility is already tightly controlled since it is an active railroad right-of-way. In addition, land use is also controlled by the access and use agreement between the USDA and the MPSA, a predecessor owner of the railroad property. Because of the change in right-of-way ownership, the authorization and license agreement will be updated in the future. The KRC may be amenable to implementing LUCs on the former CCC/USDA facility to provide an additional layer of use control. As a result, establishing LUCs for the portion of the KRC property affected by operations at the former CCC/USDA facility at Agra is considered to be implementable.

\subsubsection{Costs of Land Use Controls}

There are no costs associated with the existing implicit LUCs. Costs to establish an updated "authorization and license agreement" for the relevant parties (the USDA, the KRC, and Burton Van Eaton) to make the implicit LUCs explicit and to allow the USDA to implement "Work at the Property" required by a future CAD is expected to be low to moderate.

The KDHE determines the category of EUCs on a case-by-case basis. In some situations, the statute authorizing the creation of EUCs can require the applicant to provide financial assurance to demonstrate a financial capability adequate to provide remedies which are protective of human health and the environment should the proposed remedial activity fail as noted in the following excerpt from the 2015 Kansas statutes:

"The department may require the applicant to provide financial assurance for category 3 property as described in subsection (c)(3) of K.S.A. 2015 Supp. 65-1,226, and amendments thereto, based on the potential for long term maintenance cost of protective structures and the potential for release or migration of environmental contamination from the property. The applicant shall provide the financial assurance by one or more methods satisfactory to the department, 
including, but not limited to, environmental insurance, guarantee, performance or other surety bond, letter of credit, qualification as a self-insurer or other demonstration of financial capability. The demonstration of financial capability must be adequate to provide remedies which are protective of human health and the environment should the proposed remedial activity fail” (COKR §65-1.244 (b)(3); KDHE 2015).

As a result, for planning purposes, the CCC/USDA assumes that the administrative fees to establish LUCs for the KRC property at Agra would be low to moderate.

\subsubsection{Land Use Controls - Retained}

There are uncertainties as to whether or not the KRC would agree to an EUC. However, it is assumed that the KRC would agree to an alternative LUC mechanism such as the existing authorization and use agreement that the USDA has used to maintain, operate, and monitor the LDB/IM. As a result, LUCs have been retained.

\subsubsection{Containment by Engineered Physical Barriers to Groundwater Flow}

Engineered physical barriers to contain groundwater flow can reduce contaminant mobility and the associated potential for exposure, but they do not reduce contaminant toxicity or volume. Examples of such barriers include cryogenic barriers designed to freeze moisture in a relatively limited, discrete area within the soil horizon and thus immobilize soluble contaminants; slurry walls installed by backfilling trenches or borings with an expanding material (e.g., bentonite) to form either a continuous or discrete wall; and sheet pilings constructed by driving interlocking steel or plastic sheets into the subsurface to the desired depth.

\subsubsection{Effectiveness of Engineered Physical Barriers}

Engineered physical barriers do not actively reduce contaminant toxicity or volume but can affect the mobility of groundwater. The potential for engineered physical barriers to achieve containment of the contamination at Agra is a possibility. 
Other than the railroad tracks and the piping and appurtenances associated with the $\mathrm{LDB} / \mathrm{IM}$, the relatively complete absence of cultural features (residences and utilities) across the area overlying the groundwater contamination at the CCC/USDA source area would allow a variety of candidate physical barriers to be deployed. One or more physical barriers might be employed to reduce horizontal contaminant mobility locally, in a preferred area or direction, but without additional groundwater control measures such as groundwater extraction (Section 5.2.4), such structures could have potentially detrimental effects, including contaminant migration around, over, or under the barrier, or localized groundwater mounding upgradient of the barrier.

\subsubsection{Implementability of Engineered Physical Barriers}

Contamination has been detected in a continuous vertical profile at boring location SB46, from $8 \mathrm{ft}$ BGL to the identified onset of groundwater saturation at approximately $48 \mathrm{ft}$ BGL. Operation of the LDB/IM was designed to reduce contamination in soil to levels below the KDHE RBSL guideline to protect the soil to groundwater pathway $(73.4 \mu \mathrm{g} / \mathrm{kg})$. However, groundwater at the former site is still contaminated. A physical barrier would need to surround the identified extent of the residual contamination at the former CCC/USDA facility. It would need to extend from the onset of groundwater saturation down and into the underlying, competent bedrock to a sufficient depth (> 65-70 ft BGL) to (1) span the interval with known contamination, and (2) ensure that vertical containment of the enclosed groundwater could be achieved. As a result, it does not appear that an engineered physical barrier would be readily implementable.

\subsubsection{Costs of Engineered Physical Barriers}

Costs for engineered physical barriers would be moderate to high.

\subsubsection{Engineered Physical Barriers - Eliminated}

Because engineered physical barriers (1) could create uncontrolled vertical and horizontal groundwater flow components, and (2) could not be tied into an impermeable layer, this technology is eliminated from further consideration. 


\subsubsection{Extraction and Treatment of Groundwater}

Groundwater extraction technologies can effectively reduce the mobility and volume of contaminants by coupling groundwater and contaminant removal with the potential for hydraulic control of the contaminant migration patterns near the extraction site. Groundwater extraction is typically accomplished by using conventional vertical wells equipped with electrically operated pumps. Extracted groundwater can be treated with treatment technologies appropriate for the contaminants present.

\subsubsection{Effectiveness of Groundwater Extraction and Treatment}

Groundwater extraction wells can be installed in a timely manner, and operation of the wells could result in permanent reduction in the mobility and volume of the dissolved carbon tetrachloride contamination. Hydraulic testing has demonstrated that the hydraulic conductivity $\left(\mathrm{K}_{h}\right)$ of the silty-clayey deposits in the vicinity of the former CCC/USDA facility and the Pro Ag property is low, ranging from less than $0.1 \mathrm{ft} /$ day to approximately $0.5 \mathrm{ft} /$ day (Argonne 2018b). Such $\mathrm{K}_{h}$ values would significantly limit the effectiveness of a conventionally designed groundwater extraction system, employing relatively small-diameter wells. In contrast, the hydraulic conductivity of the LDB backfill may be from one to more than three orders of magnitude greater than the surrounding aquifer materials. The $\mathrm{K}_{h}$ estimates for backfill materials at LDB1 and LDB4 were calculated to range from 33-111 ft/day (Argonne 2018b). The results of limited field testing conducted by Argonne have demonstrated that groundwater extraction from the LDBs, to take advantage of the large effective radius and permeable backfill present in these borings, could be effective in the CCC/USDA source area (Argonne 2018b).

The extraction of groundwater would have multiple effects on any contamination remaining after the LDB/IM, including:

- Directly addressing the high levels of carbon tetrachloride contamination remaining in groundwater near boring SB46;

- Removing contaminants from both the existing more mobile, affected groundwater as well as the saturated soils in and near the identified source area; 
- Facilitating local hydraulic containment of the groundwater contamination.

Two of the most common technologies for the treatment of extracted groundwater are adsorption by granular activated charcoal (GAC) and air stripping. The use of GAC represents an effective technology for the removal of organic contaminants from groundwater. This technology requires little energy for operation; however, periodic replacement of the GAC medium is required, as it becomes depleted during the treatment process. Air stripping involves the removal of VOCs from contaminated groundwater via exposure of the water to a high-volume forced-air flow. This process is typically conducted by using a packed tower, tray, or other form of aeration. Electric service that would be required for the operation of pump(s) and possible treatment equipment is readily accessible where the LDB/IM infrastructure is already set up. Because of the need to periodically replace the GAC medium and associated costs, air stripping is the preferred treatment technology. Of the various air stripping designs, tray aeration is preferred because it has a smaller footprint and is better suited for treating the flow rates anticipated in the LDB area (Argonne 2018).

A third active technology for the treatment of extracted groundwater contaminated with volatile organic constituents is referred to as an inclined cascade aerator (ICA). This system has been deployed at the Frankfort, Kansas, PWS\#4 site (Aquaterra 2009a,b; 2015). A cascade aerator system is an inclined plane with a transversely corrugated surface. Turbulence imparted to the water flowing down the inclined plane results in the mass transfer of VOCs from the liquid phase to the gas phase. Treated water at the bottom of the inclined plane can either be discharged or recirculated to the top of the structure to allow for additional aeration and contaminant transfer. In the case of the Frankfort, Kansas, site, the system was designed to function when air temperatures are above freezing (Figure 5.1). As a result, groundwater extraction and treatment using an ICA would be limited to three seasons (all but winter). Basic criteria for the design of an ICA have historically been derived from empirical relationships reported in the literature. Parameters to be considered in the design include the Henry's Law constant of the constituent to be treated, slope and surface texture of the inclined plane, flow rate, temperature, cascade length, influent concentration and desired effluent concentration. (Boyden et al. 1990). Surface topography in the Agra area indicates an elevation drop near the former CCC/USDA facility, along the KRC right-ofway toward Turner Creek; in concept, an ICA design could take advantage of the elevation differential to accommodate the needed cascade slope.

A fourth active technology for the treatment of extracted groundwater is spray irrigation. The remediation of VOCs by spray irrigation is dependent on the vapor pressure and solubility of 
the VOC in question, and the influence of factors such as turbulence, molecular diffusion, water temperature, and ambient temperature. Successful removal of VOCs has been demonstrated for both large capacity irrigation systems (> 1,000 gpm) or small capacity systems $(<20 \mathrm{gpm})$ at several sites in Nebraska. A conventional large capacity (center pivot) sprinkler irrigation system removed from 98.2 to $99.6 \%$ of trichloroethene, a compound that is less volatile and more difficult to treat via spray irrigation than carbon tetrachloride (Spalding et al. 1995).

At two former CCC/USDA grain storage sites in Nebraska, pilot scale studies by the CCC/USDA and Argonne were followed by long-term groundwater treatment operations using spray irrigation systems. At Utica, Nebraska, an initial research study using standard center- pivot spray irrigation equipment demonstrated that concentrations of carbon tetrachloride in groundwater as high as $326 \mu \mathrm{g} / \mathrm{L}$ could be reduced to $5 \mu \mathrm{g} / \mathrm{L}$ or less in the spray outfall reaching ground level. The experimental testing identified an optimum range of operating pressures and weather conditions for this technology (Argonne 2000). A larger spray irrigation system, operating at 375 gpm, was subsequently used to treat contaminated groundwater, with the treated discharge being used to irrigate a local natural waterfowl conservation (wetlands) habitat (CCA 2018). The treatment by spray irrigation at Utica, Nebraska, is ongoing, and supplied more than 813 million gallons of treated groundwater to the wetlands from 2004-2017.

The Utica system is operated intermittently during the year subject to weather conditions and in consultation with the wetlands administration, the Nebraska Game and Parks Commission. Typically, the system operates from March or April to October or November in order to ensure that optimum ambient temperatures $\left(>45^{\circ} \mathrm{F}\right)$ are maintained; however, operation of the system is possible throughout the year whenever temperatures are suitable. Carbon tetrachloride concentrations in the treated groundwater discharged to the wetlands by spray irrigation were consistently below $5 \mu \mathrm{g} / \mathrm{L}$ from 2004-2017; influent concentrations to the spray system were as high as $125 \mu \mathrm{g} / \mathrm{L}$. Detailed information about operating parameters, carbon tetrachloride removal rates, and the total groundwater volume treated on a monthly basis is included in 5-yr and 10-yr reviews of the operations (Argonne 2011d, 2016e).

Pilot scale studies using a small capacity spray irrigation system (30-35 gpm) were also performed at the Murdock, Nebraska, former CCC/USDA site. Groundwater contaminated with carbon tetrachloride at concentrations ranging from 131-250 $\mu \mathrm{g} / \mathrm{L}$ was remediated during the pilot scale study using standard spray irrigation equipment. The concentrations of carbon tetrachloride in individual samples collected from the spray cloud ranged from 2.6-9.3 $\mu \mathrm{g} / \mathrm{L}$, resulting in average 
concentrations for the discharged water of $<5 \mu \mathrm{g} / \mathrm{L}$ (Argonne 2004). A spray irrigation program was subsequently initiated and operated in 2005-2007, to treat contaminated groundwater and irrigate athletic fields owned by the Elmwood-Murdock Public School System (field irrigation was generally not required after 2007). The irrigation system was operated seasonally and subject to weather conditions and the needs of the school system. Concentrations of carbon tetrachloride in untreated groundwater over the 2005-2007 period of operations ranged from 72-336 $\mu \mathrm{g} / \mathrm{L}$. The average concentration of carbon tetrachloride in treated groundwater from the spray irrigation treatment system was below 3.6 $\mu \mathrm{g} / \mathrm{L}$ (Argonne 2007b, 2008b).

\subsubsection{Implementability of Groundwater Extraction and Treatment}

The installation of conventional groundwater extraction wells can be accomplished by using readily available drilling techniques, and the installation of one or several vertical wells within the existing LDB fill materials at Agra is logistically feasible. The vertical extraction wells and required piping to a preferred treatment system can be completed at or below grade, so as not to interfere with agricultural operations. It may be possible to incorporate the existing underground piping associated with the LDB/IM systems in the design of a groundwater extraction and treatment system; however, additional piping along the railroad right-of-way, and beneathseveral existing roads, may be required to provide an outfall (possibly to Turner Creek, to the west) for the treated effluent.

Access would be required to the railroad right-of-way for installation and operation of the wells and related treatment system. The CCC/USDA successfully obtained access agreements from the previous owner (MSPA) and tenant (H. Van Eaton) for the installation and operation of the LDB/IM. Similar, updated agreements would be required, however, with KRC for any additional/new facilities.

Treatment of groundwater using conventional aeration, ICA, or spray-irrigation also appears to be implementable. Preliminary inspection of the railroad right-of-way near and west of the former CCC/USDA facility indicates that (subject to specific design requirements to be determined) the installation of one or more ICA units may be possible along the right-of-way at track level, or along the naturally descending bank of Turner Creek. The installation of a spray irrigation in the naturally forested area near Turner Creek also appears to be possible. 


\subsubsection{Costs of Groundwater Extraction and Treatment}

Costs for the construction and operation of conventional groundwater extraction technologies and effluent treatment technologies for carbon tetrachloride are expected to be moderate. Costs for the construction and operation of an ICA or a spray irrigation system are expected to be low to moderate.

\subsubsection{Groundwater Extraction and Treatment - Retained}

Because it is effective in suitable locations, offers the potential to address groundwater contamination, is readily implementable, and has moderate costs, groundwater extraction and treatment to address VOCs has been retained

\subsubsection{Subsurface Removal and Treatment of VOCs by SVE, AS, or a Combination of SVE and AS}

In contrast to approaches that physically remove contaminated soil or groundwater for $e x$ situ treatment, technologies such as SVE and AS target the removal of VOCs from soil and groundwater in the subsurface environment. Employed alone, SVE is typically used to address vadose zone soil contamination in relatively permeable soils. In this application, SVE is accomplished by "pumping” vertical or horizontal wells to induce a subsurface vacuum and thus extract contaminated soil vapors. Although SVE can remove contaminant vapors arising from an underlying saturated zone, SVE alone does not represent an effective technology for remediating contaminated groundwater.

The AS technology for removal of VOCs from subsurface groundwater is typically implemented by installing one or more wells screened in the saturated zone, from which air is forced to percolate through the adjacent (contaminated) groundwater column, promoting stripping of VOCs from the groundwater. The (now contaminated) air released from an AS system is allowed to escape naturally to the surface or is collected by a coupled SVE system.

To enhance the removal of contaminants from both groundwater and vadose zone soil in certain situations, SVE can be performed in conjunction with AS in LDBs. This technology was employed in the IM implemented by the CCC/USDA, to address carbon tetrachloride in the vadose zone and saturated soils in the source area at the former CCC/USDA facility, which operated for 
eight years. The combined LDB/AS/SVE treatment operation was shown to have successfully removed contamination from the soils, but proved less effective in treatment of the underlying groundwater under the (restricted permeability) conditions encountered in the LDB/IM area.

\subsubsection{Effectiveness of SVE and AS}

Discrete zones where soil is contaminated above the soil-to-groundwater RBSL guideline were identified at the former CCC/USDA site. This area was targeted for treatment by AS/SVE. Together with the results of long-term monitoring of the Agra AS/SVE systems that have been reported over the last eight years, the data and observations acquired during the recent AS/SVE shutdown testing, slug testing, and LDB test-pumping support the following interpretations.

- Landfarming operations that were completed in October 2010 successfully treated approximately 300 cubic yards of contaminated soil that were excavated during the installation of the LDBs.

- Treatment of carbon tetrachloride contamination originally identified in the vadose zone by the SVE system is likely to have been accomplished primarily during the first several years of operation of the IM systems. The rates of this phase of the cleanup are believed to have been controlled in large measure by natural changes in the soil moisture content of the unsaturated soils, together with the flow of soil vapor induced by the operation of the SVE wells.

- An estimated $18.2 \mathrm{~kg}$ of carbon tetrachloride had been recovered by the SVE system from May 29, 2009, to April 26, 2013. Of this total, approximately $17.3 \mathrm{~kg}$ (about 95\%) can be attributed to the very high SVE effluent concentrations identified during the May 2009 (start-up) and November 2010. The results suggest that, since March 2011, continued operation of the SVE system has generated only $1-2 \%$ of the total carbon tetrachloride that has been recovered.

- In consultation with the original (Greenfield) design engineer for the AS/SVE systems, an attempt was made in May 2012 to improve the effectiveness of these systems for treatment of the contaminated groundwater by implementing 
individual, cyclic operation of three of the LDBs (LDB3-LDB5) at increased SVE vacuum levels and vapor flow rates. However, continued operation of the AS/SVE systems in this mode since that time has demonstrated limited potential for significant acceleration of the groundwater treatment via this approach (Argonne 2015a).

- Recent sampling data provide little evidence for the continued presence of a vadose zone soil source of carbon tetrachloride across much of the IM area.

- Long-term monitoring data demonstrate that the operation of the AS/SVE systems has had little to no discernable effect on the concentrations of carbon tetrachloride identified in groundwater at several monitoring wells located within approximately $20 \mathrm{ft}$ of the LDB borings.

- The continued presence of localized, highly contaminated groundwater primarily in the northeastern portion of the IM area is believed to now represent the primary contributor of carbon tetrachloride contamination to the soil vapor recovered by the SVE system.

- Significant differences between the hydraulic conductivity of the LDB backfill and that of the surrounding, natural aquifer materials in the immediate vicinity of these borings are likely to limit the effects of the AS treatment to primarily within the LDBs.

- The AS/SVE systems are capable of rapidly treating the contaminated groundwater that reaches the LDBs. However, the effectiveness of the AS/SVE systems for treatment of the groundwater is severely limited by the natural rates at which groundwater can enter these borings.

The above observations strongly suggest that continued operation of the AS/SVE systems is no longer an effective remediation approach. The results indicate that these technologies donot represent a technically efficient or cost-and-time-effective mechanism for treatment of the remaining carbon tetrachloride contamination in groundwater in the CCC/USDA source area. 


\subsubsection{Implementability of SVE and AS}

Construction and operation of the IM has shown that AS/SVE is implementable, in combination with the use of LDBs.

\subsubsection{Costs of SVE and AS}

Construction costs to install the LDB/SVE/AS systems were about \$293,000. Between 2009 and 2017, operating costs for the AS/SVE technologies ranged from \$123,000 to \$315,000 per year. Costs for carbon tetrachloride removal have ranged from $\$ 38,000 / \mathrm{kg}$ to $\$ 2,500,000 / \mathrm{kg}$ per year in 2009 and 2013, respectively. Similarly exorbitant costs (as noted for calendar year 2013) for carbon tetrachloride removal could be expected if operation of the existing systems was continued. As a result, costs for operating the LDB/SVE/AS systems going forward are considered to be high.

\subsubsection{AS and SVE - Eliminated}

The AS/SVE option has been eliminated. The presence of unacceptable concentrations of carbon tetrachloride in soil, the mass excavation benefit of LDB technology, and the anticipated radius of influence made LDB technology suitable for addressing the soil and groundwater contamination at Agra in the short term. A substantial amount of contamination was removed, primarily from the vadose zone as a result of the construction and operation of the LDB/IM. However, the existing system can no longer be operated cost-effectively. This is a primary requirement for a selected remedy, as discussed in Section 5.1. Continued operation of the LDB/SVE/AS system does not represent a technically efficient or cost-and-time effective mechanism for addressing the remaining carbon tetrachloride contamination in groundwater at the former CCC/USDA facility.

\subsubsection{In Situ Treatment by Permeable Reactive Barriers}

Permeable reactive barrier (PRB) technology has been used to treat both organic (including carbon tetrachloride) and inorganic contaminants. A permeable "wall” or barrier containing a chemically and/or biologically active treatment medium capable of interacting with the target 
groundwater contaminant(s) is constructed in the subsurface, across the groundwater migration pathway. The technology is passive in that the design relies on natural hydraulic gradients to carry groundwater through the PRB, where the treatment occurs. The thickness of the PRB must be sufficient so that groundwater passes through with adequate residence time for treatment or removal of the contaminants (EPA 2002).

Construction methods used to install PRBs include conventional excavation, continuous trenching, and slurry wall techniques; deep soil mixing; horizontal or large-diameter boring; hydraulic fracturing; and injection. The depth limit for conventional excavation and trenching techniques is typically about $40 \mathrm{ft}$ BGL (Hocking 2004).

Reactive constituents (such as zero-valent iron) are frequently used in barrier construction for the treatment of VOCs. The reactive constituents are often mixed with materials such as guar gum, sand, gravel, or native soil to increase barrier permeability, or in some cases to help promote biological activity. Other potentially reactive media include edible oil, mulch, and hydrogen- or oxygen-releasing compounds. These materials can negatively affect the potability of groundwater in the treatment area.

\subsubsection{Effectiveness of Permeable Reactive Barriers}

Where applicable, PRB technology is capable of reducing the toxicity, mobility, and volume of contaminants in groundwater. The existence of contamination within bedrock portions of the aquifer at depths of $45 \mathrm{ft}$ BGL could make the effective use of this technology difficult at Agra on a sitewide basis. One or more PRBs might possibly be employed locally to intercept the contamination in groundwater at a restricted number of locations, subject to property access. Since the PRB technology relies, however, on natural groundwater flow to transport contaminants toward and through the subsurface PRB, the relatively low permeability of the lower silty-clayey interval would result in a prolonged remediation time frame in that interval. Since contaminant reduction takes place only within the PRB itself, this passive remedial approach would have no effect on groundwater contamination upgradient of any constructed PRB. 


\subsubsection{Implementability of Permeable Reactive Barriers}

The depth to bedrock ranges up to approximately $74 \mathrm{ft} \mathrm{BGL,} \mathrm{which} \mathrm{is} \mathrm{deeper} \mathrm{than} \mathrm{braced}$ construction techniques or continuous trenching equipment can achieve, indicating that more specialized construction methods would be required (see also Section 5.2.4). Long-term access to any constructed PRB location(s) would be required for periodic renewal of the subsurface treatment medium as it becomes depleted over time.

\subsubsection{Costs of Permeable Reactive Barriers}

The costs for placement of multiple PRBs are expected to be high.

\subsubsection{Permeable Reactive Barriers - Eliminated}

On the basis of its limited effectiveness, difficulty in implementation, and high cost, PRB technology is eliminated from further consideration.

\subsubsection{ISCR Treatment}

For contaminants such as carbon tetrachloride that are amenable to abiotic and anaerobic biodegradation processes, the introduction into the subsurface (by means other than the construction of a PRB) of materials that promote either abiotic or biologically mediated ISCR can be a viable remedial approach. Existing or newly installed semi-permanent injection wells, or (in some cases) direct-push technologies, can be used to deliver the treatment chemicals to the affected zone via pressure injection or by passive placement within a borehole or casing. The applicability of ISCR is determined primarily by the nature of the contaminant(s) and the availability of suitable treatment media. Successful implementation is also strongly influenced, however, by the sitespecific geologic and hydrologic characteristics of the target treatment zone, as these parameters largely determine the potential for effective emplacement and dispersion of the treatment material. 


\subsubsection{Effectiveness of ISCR Treatment}

Where applicable, ISCR technology can reduce the toxicity, mobility, and volume of contaminants in groundwater and soil. Vendors produce a variety of additives capable of addressing chlorinated organic contamination; these can be introduced singly or in combination. In some cases, the additives need to be introduced in phases, because the initial injections create the geochemical environment needed for the follow-on amendment to function effectively.

The application strategy at the former CCC/USDA facility would involve an injection area of roughly 0.55 acres $\left(23,575 \mathrm{ft}^{2}\right)$. Based on prior CCC/USDA experience at several sites with similar contamination levels and subsurface conditions, a relatively densely packed vertical and lateral injection point spacing pattern would likely be required to be effective. For the inferred acre treatment area, 130-140 injection points would be needed to achieve a $15 \mathrm{ft}$ spacing between injection points. At each location, five vertical intervals would be needed to address contamination from the water table to the base of the saturated zone (from roughly 40-65 ft BGL). Based on the soil-to-amendment mass ratio employed by the CCC/USDA at a similar former facility (in Missouri) where carbon tetrachloride levels were also $>2,000 \mu \mathrm{g} / \mathrm{L}$ in groundwater, the mass of amendment that might be required could exceed 140,000 lbs.

\subsubsection{Implementability of ISCR Treatment}

The ISCR technology can be implemented with available equipment and materials. Directpush technology can readily be used to inject ISCR materials. Pressurized injection of the ISCR materials with specialized equipment will be required because of the thickness and generally low permeability of the silty-clayey lithologies. The ISCR placement operations are likely to cause minimal disruption to the daily activities of nearby residents. Long-term access to the ISCR placement locations might be required for renewal of the subsurface treatment medium as it becomes depleted over time.

With the approval of the KDHE, the CCC/USDA and Argonne pilot-tested the use of the $\mathrm{EHC}^{\circledR}$ material developed by the Adventus Group for the in situ treatment of carbon tetrachloride in relatively fine-grained sediments at the former CCC/USDA facilities in Centralia, Kansas, and Montgomery City, Missouri (Argonne 2009d; 2016d). The EHC ${ }^{\circledR}$ material is currently marketed by PeroxyChem (http://www.peroxychem.com) and is available in forms suitable for injection or 
for passive placement in boreholes and wells. Introduction of the ISCR chemicals can, however, result in persistent fouling of the groundwater being treated, making it unsuitable for domestic use.

\subsubsection{Costs of ISCR Treatment}

Expected costs for the ISCR treatment technology would be moderate to high for targeted treatment of the highly contaminated area; the 0.55 acre footprint mentioned above. Costs for the ISCR technology would be higher if semi-permanent injection points are required to allow the introduction of amendments periodically over time.

\subsubsection{In Situ Chemical Reduction Treatment - Eliminated}

On the basis of the potential to adversely affect groundwater quality and cost, the ISCR treatment technology is eliminated from further consideration.

\subsection{Retention of Potentially Applicable Technologies}

The screening process for potentially applicable methods for addressing the contaminated groundwater in the CCC/USDA source area resulted in retention of the following technologies and practices for further consideration:

- Groundwater extraction from the existing LDBs

- Treatment with GAC, tray aeration, ICA, or spray-irrigation

- Land use controls

The technologies and practices retained through the screening analysis were used to develop the corrective action alternatives for the site that are identified and discussed in Section 6. 


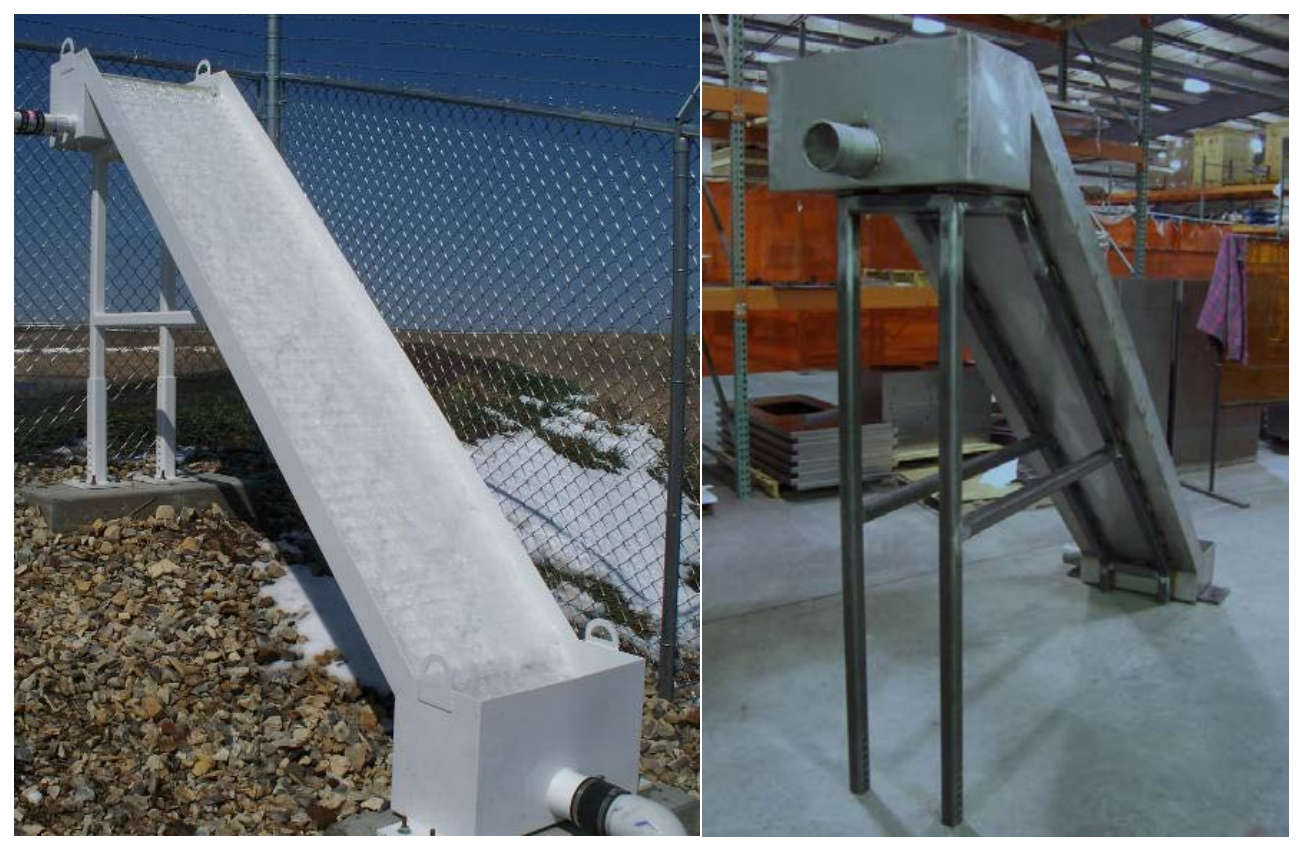

FIGURE 5.1 Inclined Cascade Aerator at Frankfort, Kansas (Source: Aquaterra 2009a,b). 


\section{Description of Alternatives}

Corrective action alternatives for the former CCC/USDA facility at Agra were developed on the basis of the remedial technologies retained after the initial screening process described in Section 5, conducted in accordance with EPA (1988) and KDHE (2001a, 2009b) guidance. The resulting candidate technologies for addressing the carbon tetrachloride contamination in groundwater on the former CCC/USDA property were combined to create four remedial action alternatives, in addition to the no-action alternative, for further consideration. This section describes the five alternatives that were evaluated in detail.

The focus of each alternative is the carbon tetrachloride contamination in groundwater associated with the former CCC/USDA facility. The CCC/USDA accepts no responsibility for nitrate contamination identified at Agra; Pro Ag has entered into a Consent Order (Case No. 07-E-0028) with the KDHE to address nitrate (as well as carbon tetrachloride) contamination that has been attributed to operations at the Pro Ag facilities (KDHE 2008). For Alternative 2 (groundwater extraction and treatment with tray aeration), Alternative 3 (groundwater extraction and treatment with ICA), and Alternative 4 (groundwater extraction and treatment by sprayirrigation), treated effluent containing de minimis concentrations of nitrate may be discharged via a National Pollutant Discharge Elimination System (NPDES) permit.

\subsection{Alternative 1: No Action}

The no action response is a required component of the CAS evaluation under KDHE (2001a) guidance, to provide a baseline for comparison. The no action response is evaluated as Alternative 1 in Sections 7 and 8.

Under Alternative 1, no further action would be taken at the former CCC/USDA facility, and the identified residual carbon tetrachloride contamination would remain in place. Further operation of the AS/SVE systems would not be included, because the LDB/IM would end under the no action alternative. It is assumed that the former CCC/USDA property would continue to be used as agricultural land, and that the existing land use constraints associated with the railroad right-of-way would remain in effect. Under the no action alternative, all existing water supply protective measures are also assumed to remain in effect. These include the KDHE regulations governing the location and construction of water supply wells (Section 4.2.3.1). 


\subsection{Alternative 2: Groundwater Extraction, Treatment with a Tray Aerator, Discharge, and Groundwater Monitoring}

Alternative 2 would involve the installation, operation, and monitoring of a groundwater extraction system to reduce carbon tetrachloride contamination to the extent practicable (mass removal to asymptotic levels in monitoring wells or for six years, whichever occurs sooner. The basis for the six year period of operation is provided in Appendix C (Estimation of the Operation Time Period for Groundwater Extraction in Alternative 2). Alternative 2 has the following components:

- Installation and testing of three extraction wells (in LDBs 2, 3 and 5); and one monitoring well (GW6), to document the viability of the proposed approach and determine specific operating parameters for the individual extraction wells in the existing LDBs (Figure 6.1).

- Contingent on the results of the pump test performed on the three extraction wells, preparation of a CAP including, but not limited to, a pre-final and final (90\% to $100 \%)$ design and cost estimate, operation and maintenance (O\&M) Plan, and SMPE Plan.

- Replacing the existing AS/SVE treatment trailer with a tray aeration system to be housed in a utility shed.

- Routing of electrical power to each of the extraction wells by utilizing the existing buried (former AS/SVE) piping.

- Establishing a force main pipeline connection within the existing AS/SVE piping, from each extraction well to the tray aerator.

- Installation of a discharge line to route treated water from the aerator to Turner Creek and operation of the groundwater extraction and treatment system for an anticipated period of up to six years.

- Preparation of a SMPE monitoring and reporting program to include (1) baseline groundwater sampling, (2) sampling and analysis of an NPDES- 
permitted, treated discharge on a quarterly basis, (3) initial and longer-term, annual sampling and analysis of groundwater and continuous measurement of water levels at selected monitoring wells, and (4) the recording of groundwater extraction volume and flow rates pursuant to requirements of the Kansas Department of Agriculture (KDA) groundwater appropriation regulations.

\subsubsection{Installation of Three Extraction Wells, One Observation Well, and Performance of a Pump Test}

As part of Alternative 2, the existing, 4-in diameter SVE wells in LDBs 2, 3 and 5 would be replaced with 8-in. diameter extraction wells. An additional observation well would also be installed. A 10-24 hr pump test would be performed using the three newly installed extraction wells. The extraction wells would be constructed using schedule $40 \mathrm{PVC}$ casing and $10 \mathrm{ft}$ of 20- mil-slot screen, extending to bedrock (at approximately $65 \mathrm{ft} \mathrm{BGL)}$ ) to improve the recovery of groundwater from the noted LDBs. Each well would be completed with a pitless adapter and a flush grade well cover (18 or 24 in.) and concrete pad. The results of previous investigations conducted by the CCC/USDA indicate that an estimated, combined extraction rate of approximately $4.3 \mathrm{gpm}$ could be sustained by pumping from the existing, 4-in. diameter SVE wells in two of the LDBs (Argonne 2018b). Under the experimental conditions used a radius-of-influence (ROI) of at least $100 \mathrm{ft}$ was documented in response to pumping at LDB2 and LBD3. The revised ROI and extraction well yields would be determined by the recommended testing using all three of the newly installed extraction wells. The inclusion of LDB5 is expected to improve the symmetry of the resulting cone of depression, and enhance the recovery of contaminated groundwater from the central, most concentrated portion of the targeted treatment area. The additional monitoring well (GW6) would be a 2-in. well screened from 55-65 ft BGL. (Figure 6.1).

The newly installed well (GW6) and existing monitoring wells would be used to evaluate the performance of the extraction wells during the test pumping and subsequently during the implementation of the remedy. Parameters to be evaluated during the pump testing would include the potentiometric surface in a subset of the existing monitoring wells and water quality parameters for groundwater from each extraction well. Water quality parameters to be determined include:

- Carbon tetrachloride

- Nitrate

- Dissolved oxygen 
- Conductivity

- Temperature

- $\mathrm{pH}$ and

- Oxidation-reduction potential

Extracted groundwater from the testing would be accumulated in a tanker truck. The produced water would be analyzed for selected contaminants in accord with KDHE requirements and disposed of as appropriate, subject to KDHE review and approval. The results of the pump test would be evaluated to substantiate the efficacy of groundwater extraction from the modified LDBs, and to guide the preparation of the CAP.

\subsubsection{Preparation of a Corrective Action Plan}

The CAP would describe the design, construction, and implementation of the remedial actions. It would also include details associated with the design, O\&M, and performance evaluation for the groundwater extraction and treatment system. The CCC/USDA would submit a pre-final/final (90-100\%) design package for approval by KDHE that would document prefinal/final design specifications/drawings and the design basis. The CAP package would also address O\&M requirements and SMPE-related activities.

\subsubsection{Installation and Operation of a Groundwater Pump and Treat System and Discharge Pipeline}

Three submersible pumps (such as a Grundfos RediFlo 4 or similar) and electric service/communication cables would be installed in the extraction wells. One 2-in. force main from each of the extraction wells would be routed, if possible in the existing but unused AS/SVE piping running from each LDB to the existing treatment trailer area, to minimize further surface disruption at the site. Electrical service from the existing electric power infrastructure at the $\mathrm{LDB} / \mathrm{IM}$ treatment trailer would also be routed via the existing unused AS/SVE piping from the treatment building to a power distribution point at the LDB cluster. Power would then be run from the distribution point to each of the three extraction wells. A control system, such as a Geotech Environmental Control Module would be mounted in a treatment building to control, monitor, and display the performance of the three pumps and the aerator. Meters would be installed to measure flow rate and total flow from each of the three wells as required by KDHE and KDA groundwater withdrawal regulations. 
Extracted groundwater would be treated by an aeration system installed within a treatment building. Using the information collected to date, and subject to change based on the results of the pump test, the use of a Lo Pro II Air Stripper TM or similar, is anticipated. Treated effluent would be pumped to a discharge point along Turner Creek, approximately 2,100 ft west of the treatment building, via a 2-in. high-density polyethylene (HDPE) pipeline to be installed in a trench between the treatment building and the outfall. The pipeline would be buried to a depth of about $3 \mathrm{ft}$ and would be routed beneath two existing road crossings. An NPDES permit would be obtained to regulate the discharge.

After the extraction wells and aerator are brought on line, the system would undergo a startup phase to establish routine operating conditions. A corrective action report would then be prepared and an O\&M manual for the site would be submitted for KDHE approval.

The groundwater extraction and treatment system is expected to operate for a period of six years or until carbon tetrachloride concentrations reach asymptotic levels in monitoring wells in the treatment area, whichever happens sooner. The basis for the operating time of the groundwater extraction system is discussed further in Appendix C.

\subsubsection{SMPE-Related Monitoring and Reporting}

Alternative 2 would include a groundwater monitoring component and a groundwater treatment system monitoring component. The alternative would also require periodic reporting of the monitoring results on either an annual basis or as part of the content of 5-yr reviews.

\subsubsection{Groundwater Monitoring}

A comprehensive groundwater monitoring program would be implemented at and near the former CCC/USDA facility to evaluate groundwater quality. The monitoring would include a baseline sampling event followed by groundwater monitoring to assess the performance of the remedy, and subsequent post-remedy groundwater monitoring. The same ten wells would be sampled to establish a baseline, assess the performance of the remedy, and assess water quality after pumping ceases. The wells would be sampled for the baseline event in Year 1, twice during Year 2, and then annually from Years 3-7 to assess the impact of the groundwater pump and treat 
system on groundwater quality. The wells are shown in Figure 6.1. The well sampling program would be evaluated continuously throughout the duration of the remedy.

The groundwater monitoring program would involve collection of groundwater samples, laboratory analysis for selected VOCs, data evaluation, and reporting. The samples would be analyzed for field parameters (dissolved oxygen, oxidation-reduction potential, $\mathrm{pH}$, temperature, and conductivity) at the wellhead, and for carbon tetrachloride, chloroform, and methylene chloride by a qualified laboratory.

\subsubsection{Groundwater Treatment Operations and System Monitoring}

Operating conditions of the groundwater extraction and aerator treatment system would be monitored during periodic visual inspections and remotely via cellular or land line communication with the well pump and aerator system control boxes. In compliance with KDA water appropriation regulations, flow rates and total flow would be tracked and recorded. In compliance with KDHE NPDES requirements, the discharge to surface waters would be sampled and analyzed as specified in the permit. Sampling frequency is yet to be determined; however, for planning purposes, it is assumed to be quarterly.

\subsubsection{SMPE-Related Reporting}

As part of the SMPE Plan reporting, a summary of the total volume of groundwater withdrawn for treatment would be sent to the KDA each year. A summary of the results of groundwater monitoring, and NPDES discharge monitoring results, would be sent to the KDHE in conjunction with each yearly groundwater well sampling event. Data analyses, evaluations, and interpretations would be delivered to the KDHE every five years as a component of the 5-yr reviews.

For sites like the former CCC/USDA source area where contamination is expected to remain at levels that do not allow for unrestricted residential use, the KDHE suggests reviews at least every five years to ensure that remedial actions remain protective of human health and the environment. The 5-yr review for this area would include document review, a site inspection, and a report. Documents to be reviewed by the CCC/USDA and Argonne include the SPME Plan and $\mathrm{CAD}$, groundwater monitoring results, and any records generated during the review period 
pertaining to groundwater use or distribution or to the investigation of contamination in groundwater or soils in the affected area. The report is expected to include a discussion of the RAOs established by the CAD, a summary of the site visit, a summary of groundwater monitoring, any areas of noncompliance, and a summary of the protectiveness of the established corrective action.

The 5-yr review would serve as a project management mechanism. Each 5-yr review would include a recommendation regarding the potential need for continued operation of the groundwater extraction wells to (or beyond) the initially planned six years, on the basis of documented system performance and the concentrations attained in the monitoring well network. Similarly, the potential for ultimate site reclassification pursuant to KDHE BER policy BER-RS-024 (KDHE 2001b) would be evaluated in conjunction with the 5-yr review process, on the basis of concentrations observed in the site monitoring wells. For cost estimating purposes, it is assumed that two 5-yr reviews would occur.

\subsection{Alternative 3: Groundwater Extraction, Treatment with an Inclined Cascade Aerator, Discharge, and Groundwater Monitoring}

Alternative 3 would involve the installation, operation, and monitoring of the same groundwater extraction system described for Alternative 2. However, an ICA rather than a tray aerator would be used to treat carbon tetrachloride before discharge to Turner Creek. As discussed for Alternative 2, the system would be operated to reduce carbon tetrachloride contamination to the extent practicable (mass removal to asymptotic levels in monitoring wells or for eight years, whichever occurs sooner). The basis for the eight year period of operation is provided in Appendix C (Estimation of the Operation Time Period for Groundwater Extraction in Alternative 2). Alternative 3 would need to be operated for eight years in order to achieve the same pore volume exchange as Alternative 2, since the ICA could only be operated seasonally, when the air temperature is above $32^{\circ} \mathrm{F}$ (estimated as nine months per year for the Agra area). Alternative 3 has the following components:

- Installation and testing of three extraction wells (in LDBs 2, 3 and 5); and one monitoring well (GW6), to document the viability of the proposed approach and determine specific operating parameters for the individual extraction wells in the existing LDBs (Figure 6.1). 
- Contingent on the results of the pump test performed on the three extraction wells, preparation of a CAP including, but not limited to, a pre-final and final (90\% to $100 \%$ ) design and cost estimate; O\&M Plan, and SMPE Plan.

- Routing of electrical power to each of the extraction wells by utilizing the existing buried (former AS/SVE) piping.

- Establishment of a force main pipeline connection within existing AS/SVE piping, from each extraction well to where the existing LDB/IM treatment trailer is located.

- Construction of a collection point to combine flows from the three extraction wells at or near the location of the existing LDB/IM treatment trailer.

- Installation of piping to convey the combined (untreated) flow to the ICA.

- Construction of an ICA system designed to receive and treat the extracted groundwater and to discharge the treated effluent to Turner Creek.

- Operation of the groundwater extraction and treatment system for an anticipated period of up to eight years.

- Preparation of a SMPE monitoring and reporting program to include (1) baseline groundwater sampling, (2) sampling and analysis of an NPDESpermitted, treated discharge on a quarterly basis, (3) initial and longer-term, annual sampling and analysis of groundwater and continuous measurement of water levels at selected monitoring wells, and (4) the recording of groundwater extraction volume and flow rates pursuant to the requirements of the KDA.

\subsubsection{Installation of Three Extraction Wells, One Observation Well, and Performance of a Pump Test}

As discussed for Alternative 2, the existing, 4-in. diameter SVE wells in LDB2, LBD3, and LBD5 would be replaced with 8-in. diameter extraction wells, an observation well would be 
installed, and a 10-24 hr pump test would be performed using the three newly installed extraction wells. The extraction wells would be constructed as described in Alternative 2. The ROI and extraction well yields for the revised pumping system would be substantiated by testing all three of the newly installed extraction wells.

The newly installed monitoring well (GW6) and existing monitoring wells would be used to evaluate the performance of the extraction wells during test pumping and subsequently during the implementation of the remedy. During the pump test, the same parameters proposed for Alternative 2 would be evaluated. Extracted groundwater would be containerized and disposed of, as outlined in Section 6.2.1. The results of the pump test would be evaluated to substantiate the efficacy of groundwater extraction from the LDBs, and to guide the preparation of the CAP.

\subsubsection{Preparation of a Corrective Action Plan}

The CAP would describe the design, construction, and implementation of the remedial actions. It would also include details associated with the design, O\&M, and performance evaluation for the ICA groundwater extraction and treatment system. The CCC/USDA would submit a pre-final/final (90-100\%) design package for approval by KDHE that would document pre-final/final design specifications/drawings and the design basis. The CAP package would also address O\&M requirements and SMPE-related activities.

\subsubsection{Installation and Operation of a Groundwater Pump and Treat System and Associated Pipelines}

Electrical /pump communication service, and a 2-in. HDPE line for each extraction well would be routed in the existing subsurface (former AS/SVE) pipe chases between each LDB and the approximate location of the current LDB/IM treatment trailer, where the separate flows would be combined into a single stream. Three submersible pumps (such as a Grundfos RediFlo 4 or similar) and electric service would be installed at the extraction wells. A control system, such as the Geotech Environmental Control Module, would be mounted in a weatherproof panel on the existing power pole to control, monitor, and display the performance of the three pumps. Meters would be installed within the weather proof panel box to measure flow rate and total flow as required by KDHE and KDA groundwater withdrawal regulations. 
As discussed for Alternative 2, a 2-in. HDPE force main would be installed in a trench to convey the combined (untreated) groundwater stream to the ICA treatment system, to be located at or near Turner Creek. The pipeline would be buried to a depth of about $3 \mathrm{ft}$ and would be routed beneath two existing road crossings.

The ICA treatment system is expected to consist of a series of cascade units. The first unit, ICA\#1 would be located at railroad grade level immediately east of Turner Creek. The second unit, ICA\#2 would be located with the upstream end of the incline at the level of the railroad grade and with the downstream (discharge) end of the incline located at or near the level of Turner Creek. Flows would be directed to the top of ICA\#1 in the influent force main line and flows between ICA\#1 and ICA\#2 would be gravity flows. Footings would be created to support each of the ICAs. An NPDES permit would be obtained to regulate the discharge.

After the extraction wells and ICA are brought on line, the system would undergo a startup phase to establish routine operating conditions. A corrective action report would be prepared and an O\&M dmanual for the site would be submitted for KDHE approval.

The required operating period for Alternative 3 would be longer than the operating time for Alternative 2 to achieve the equivalent desired pore volume exchange. Groundwater extraction would be expected to occur for approximately nine months annually (versus year round operation for Alternative 2) since air temperatures above freezing are required for this treatment approach to be effective. The groundwater extraction and treatment system is expected to operate for a period of eight years or until carbon tetrachloride concentrations reach asymptotic levels in monitoring wells, whichever happens sooner. The basis for the operating time of the groundwater extraction system is discussed further in Appendix C.

\subsubsection{SMPE-Related Monitoring and Reporting}

This alternative would include a groundwater monitoring component and a groundwater treatment system monitoring component. The alternative would also require periodic reporting of the monitoring results on either an annual basis or as part of the content of 5-yr reviews. 


\subsubsection{Groundwater Monitoring}

A comprehensive groundwater monitoring program would be implemented at and near the former CCC/USDA facility to evaluate groundwater quality. The monitoring would include a baseline sampling event followed by groundwater monitoring to assess the performance of the remedy, and subsequent post-remedy groundwater monitoring. The same ten wells would be sampled to establish a baseline, assess the performance of the remedy, and assess water quality after pumping ceases. The wells would be sampled for the baseline event in Year 1, twice during Year 2, and then annually from Years 3-9 to assess the impact of the groundwater pump and treat system on groundwater quality. The wells are shown in Figure 6.1. The well sampling program would be evaluated continuously throughout the duration of the remedy.

The groundwater monitoring program would involve collection of groundwater samples, laboratory analysis for selected VOCs, data evaluation, and reporting. The samples would be analyzed for field parameters (dissolved oxygen, oxidation-reduction potential, $\mathrm{pH}$, temperature, and conductivity) at the wellhead, and for carbon tetrachloride, chloroform, and methylene chloride by a qualified laboratory.

\subsubsection{Groundwater Treatment Operations and System Monitoring}

Operating conditions of the groundwater extraction and ICA treatment system would be monitored during periodic visual inspections and remotely via cellular or land line communication with the extraction wells. In compliance with KDA water appropriation regulations, flow rates and total flow would be tracked and recorded. In compliance with KDHE NPDES requirements, the discharge to surface waters would be sampled and analyzed as specified in the permit. Sampling frequency is yet to be determined; however, for planning purposes, it is assumed to be quarterly.

\subsubsection{SMPE-Related Reporting}

As part of the SMPE Plan reporting, a summary of the total volume of groundwater withdrawn for treatment would be sent to the KDA annually. A summary of the results of groundwater monitoring and NPDES discharge monitoring results would be sent to the KDHE in conjunction with each yearly groundwater well sampling event. Data analyses, evaluations, and 
interpretations would be delivered to the KDHE every five years as a component of the 5-yr reviews.

For sites like the former CCC/USDA source area where contamination is expected to remain at levels that do not allow for unrestricted residential use, the KDHE suggests reviews at least every five years to ensure that remedial actions remain protective of human health and the environment. The 5-yr review for this area would include document review, a site inspection, and a report. Documents to be reviewed by the CCC/USDA and Argonne include the SPME Plan and $\mathrm{CAD}$, groundwater monitoring results, and any records generated during the review period pertaining to groundwater use or distribution or to the investigation of contamination in groundwater or soils in the affected area. The report is expected to include a discussion of the RAOs established by the CAD, a summary of the site visit, a summary of groundwater monitoring, any areas of noncompliance, and a summary of the protectiveness of the established corrective action.

The 5-yr reviews would serve as a project management mechanism. Each of the two anticipated 5-yr reviews would include a recommendation regarding the potential need for continued operation of the groundwater extraction wells to (or beyond) the initially planned eight years, on the basis of documented system performance and the concentrations attained in the monitoring well network. Similarly, the potential for ultimate site reclassification pursuant to KDHE BER policy BER-RS- 024 (KDHE 2001b) would be evaluated in conjunction with the ongoing 5-yr review process, on the basis of concentrations observed in the site monitoring wells.

\subsection{Alternative 4: Groundwater Extraction, Treatment, and Discharge by Spray Irrigation, and Groundwater Monitoring}

Alternative 4 would involve the installation, operation, and monitoring of the same groundwater extraction system described for Alternatives 2 and 3. However, a spray irrigation system would be used to simultaneously treat carbon tetrachloride and disperse the resulting effluent, to foster development of the existing natural vegetation bordering Turner Creek. As discussed for Alternatives 2 and 3, the extraction well system would be operated to reduce carbon tetrachloride contamination to the extent practicable (mass removal to asymptotic levels in monitoring wells or for 10 years, whichever occurs sooner). The basis for the 10 year period of operation is provided in Appendix C (Estimation of the Operation Time Period for Groundwater Extraction in Alternative 2). Alternative 4 would need to be operated for 10 years in order to 
achieve the same pore volume exchange as Alternative 2, since the spray irrigation system could only be operated seasonally, when the air temperature is above $45^{\circ} \mathrm{F}$ (estimated as 7 to 8 months per year for the Agra area). Alternative 4 has the following components:

- Installation and testing of three extraction wells (in LDB2, LBD3, and LBD5); and one monitoring well (GW6), to document the viability of the proposed approach and determine specific operating parameters for the individual extraction wells in the existing LDBs (Figure 6.1).

- Contingent on the results of the pump test performed on the three extraction wells, preparation of a CAP including, but not limited to, a pre-final and final (90\% to $100 \%$ ) design and cost estimate; O\&M Plan, and SMPE Plan.

- Routing of electrical power to each of the extraction wells by utilizing the existing buried (former AS/SVE) piping.

- Establishment of a force main pipeline connection within existing (former AS/SVE) piping, from each extraction well to where the existing LDB/IM treatment trailer is located.

- Construction of a collection point to combine flows from the three extraction wells at or near the location of the existing LDB/IM treatment trailer.

- Installation of piping to convey the combined (untreated) flow to the spray irrigation system.

- Construction of a spray irrigation system designed to receive, treat, and disperse the extracted groundwater to irrigate vegetation already present and bordering Turner Creek.

- Operation of the groundwater extraction and spray irrigation treatment system for an anticipated period of up to 10 years.

- Preparation of an SMPE monitoring and reporting program to include (1) baseline groundwater sampling, (2) sampling and analysis of the spray 
irrigation system effluent, as specified in an NPDES permit, on a quarterly basis, (3) initial and longer-term, annual sampling and analysis of groundwater and continuous measurement of water levels at selected monitoring wells, and (4) the recording of groundwater extraction volume and flow rates pursuant to the requirements of the KDA.

\subsubsection{Installation of Three Extraction Wells, One Observation Well, and Performance of a Pump Test}

As discussed for Alternative 2, the existing, 4-in diameter SVE wells in LDB2, LBD3, and LBD5 would be replaced with 8-in. diameter extraction wells, an observation well would be installed and a 10-24 hr pump test would be performed using the three newly installed extraction wells. The extraction wells would be constructed as described in Alternative 2. The ROI and extraction well yields for the revised pumping system would be substantiated by testing all three of the newly installed extraction wells.

The newly installed well (GW6) and the existing monitoring wells would be used to evaluate the performance of the extraction wells during test pumping and subsequently during the implementation of the remedy. During the pump test, the same parameters proposed for Alternative 2 would be evaluated. Extracted groundwater would be containerized and disposed of, as outlined in Section 6.2.1. The results of the pump test would be evaluated to substantiate the assumed efficacy of groundwater extraction from the modified LDBs, and to guide the preparation of the CAP.

\subsubsection{Preparation of a Corrective Action Plan}

The CAP would describe the design, construction, and implementation of the remedial actions. It would also include details associated with the design, O\&M, and performance evaluation for the spray irrigation system. The CCC/USDA would submit a pre-final/final (90-100\%) design package for approval by KDHE that would document pre-final/final design specifications/drawings and the design basis. The CAP package would also address O\&M requirements and SMPE-related activities. 


\subsubsection{Installation and Operation of a Combined Groundwater Pumping and Spray Irrigation System and Associated Pipelines}

Electrical/pump communication service and a 2-in. HDPE line for each extraction well would be routed in the existing subsurface (former AS/SVE) pipe chases between each LDB and the approximate location of the current LDB/IM treatment trailer, where the separate flows would be combined into a single stream. Three submersible pumps (such as a Grundfos RediFlo 4 or similar) and electric service would be installed at the extraction wells. A control system, such as the Geotech Environmental Control Module, would be mounted in a weatherproof panel on the existing power pole to control, monitor, and display the performance of the three pumps. Meters would be installed within the weather proof panel box to measure flow rate and total flow as required by KDHE and KDA groundwater withdrawal regulations.

As discussed for Alternative 2, a 2-in. HDPE force main would be installed in a trench to convey the combined (untreated) groundwater stream to the ICA treatment system, to be located at or near Turner Creek. The pipeline would be buried to a depth of about $3 \mathrm{ft}$ and would be routed beneath two existing road crossings.

The spray irrigation treatment system would consist of a series of spray irrigation heads. The proposed location of the spray irrigation system is depicted in Figure 6.2. Footings would be created as needed to support the spray system. An NPDES permit would be obtained to regulate the discharge.

After the extraction wells and spray system are brought on line, the system would undergo a start-up phase to establish routine operating conditions. A corrective action report would be prepared and an operations and maintenance manual for the site would be submitted for KDHE approval.

The required operating period for Alternative 4 would be longer than the operating time for Alternatives 2 and 3, in order to achieve the equivalent desired pore volume exchange. Groundwater extraction would be expected to occur for approximately 7-8 months annually (versus year round operation for Alternative 2) since air temperatures above about $45^{\circ} \mathrm{F}$ are required for this treatment approach to be effective. The groundwater extraction and treatment system is expected to operate for a period of 10 years or until carbon tetrachloride concentrations 
reach asymptotic levels in monitoring wells, whichever happens sooner. The basis for the operating time of the groundwater extraction system is discussed further in Appendix C.

\subsubsection{SMPE-Related Monitoring and Reporting}

Alternative 4 would include a groundwater monitoring component and a groundwater treatment system monitoring component. The alternative would also require periodic reporting of the monitoring results on either an annual basis or as part of the content of 5-yr reviews.

\subsubsection{Groundwater Monitoring}

A comprehensive groundwater monitoring program would be implemented at and near the former CCC/USDA facility to evaluate groundwater quality. The monitoring would include a baseline sampling event followed by groundwater monitoring to assess the performance of the remedy, and subsequent post-remedy groundwater monitoring. The same ten wells would be sampled to establish a baseline, assess the performance of the remedy, and assess water quality after pumping ceases. The wells would be sampled for the baseline event in Year 1, twice during Year 2, and then annually from Years 3-11 to assess the impact of the groundwater pump and treat system on groundwater quality. The wells are shown in Figure 6.1. The well sampling program would be evaluated continuously throughout the duration of the remedy.

The groundwater monitoring program would involve collection of groundwater samples, laboratory analysis for selected VOCs, data evaluation, and reporting. The samples would be analyzed for field parameters (dissolved oxygen, oxidation-reduction potential, $\mathrm{pH}$, temperature, and conductivity) at the wellhead, and for carbon tetrachloride, chloroform, and methylene chloride by a qualified laboratory.

\subsubsection{Groundwater Treatment Operations and System Monitoring}

Operating conditions of the groundwater extraction and spray irrigation treatment system would be monitored during periodic visual inspections and remotely via cellular or landline communication with the extraction wells. In compliance with KDA water appropriation regulations, flow rates and total flow would be tracked and recorded. In compliance with KDHE 
NPDES requirements, the discharge to surface waters would be sampled and analyzed as specified in the permit. Sampling frequency is yet to be determined; however, for planning purposes, it is assumed to be quarterly.

\subsubsection{SMPE-Related Reporting}

As part of the SMPE Plan reporting, a summary of the total volume of groundwater withdrawn for treatment would be sent to the KDA annually. A summary of the results of groundwater monitoring, and NPDES discharge monitoring results, would be sent to the KDHE in conjunction with each yearly groundwater well sampling event. Data analyses, evaluations, and interpretations would be delivered to the KDHE every five years as a component of the 5-yr reviews.

For sites like the former CCC/USDA source area, where contamination is expected to remain at levels that do not allow for unrestricted residential use, the KDHE suggests reviews at least every five years to ensure that remedial actions remain protective of human health and the environment. The 5-yr review for this area would include document review, a site inspection, and a report. Documents to be reviewed by the CCC/USDA and Argonne include the SPME Plan and $\mathrm{CAD}$, groundwater monitoring results, and any records generated during the review period pertaining to groundwater use or distribution or to the investigation of contamination in groundwater or soils in the affected area. The report is expected to include a discussion of the RAOs established by the CAD, a summary of the site visit, a summary of groundwater monitoring, any areas of noncompliance, and a summary of the protectiveness of the established corrective action.

The 5-yr reviews would serve as a project management mechanism. Each of the two anticipated 5-yr reviews would include a recommendation regarding the potential need for continued operation of the groundwater extraction wells to (or beyond) the initially planned 10 years, on the basis of documented system performance and the concentrations attained in the monitoring well network. Similarly, the potential for ultimate site reclassification pursuant to KDHE BER policy BER-RS- 024 (KDHE 2001b) would be evaluated in conjunction with the ongoing 5-yr review process, on the basis of concentrations observed in the site monitoring wells. 


\subsection{Alternative 5: Land Use Controls and Monitoring}

Implicit LUCs relevant for the purposes of this CAS already exist for the KRC right-ofway. Relevant LUCs include prohibiting the installation of a water supply well and the construction of a habitable structure on the right-of-way. Alternative 5 assumes these implicit LUCs would be robust enough to function as an environmental use control equivalent to an ARAR such as the Kansas EUCs. Alternative 5 assumes the current land owner of the former CCC/USDA facility (KRC) would continue to prohibit construction of water supply wells, habitable structures, or any other structure that would create a hazard to life or safety or that would otherwise impact railroad operations. Barring acceptance of the adequacy of these existing implicit LUCs, the CCC/USDA would commit to establishing alternative LUCs. As a first option, the CCC/USDA would work with the KRC to enter into a legal agreement, similar to the authorization and license agreement previously established by the CCC/USDA with the MSPA and Burton Van Eaton to facilitate the LDB/IM and perform what was then termed "Work at the Property" (MSPA and CCC/USDA 2008). The CCC/USDA would require the new authorization and license agreement to make explicit the already existing LUCs, including preventing the installation of a water supply well or the construction of a habitable structure on the contaminated portion of the right-of-way formerly occupied by the CCC/USDA facility, for the full term of Alternative 5.

Alternative 5 would involve the following components:

- Monitoring of the existing well network in the immediate vicinity of the source area at the former CCC/USDA facility every five years and preparing monitoring reports to substantiate the current static condition of the contaminated groundwater present in this area.

- The authorization and license agreement would authorize the CCC/USDA to perform the CAD-related corrective actions and also formalize the existing, implicit KRC land use controls (and Kansas well siting and construction regulations), precluding the installation of water supply wells or the construction of a habitable structure within the contaminated portion of the railroad right-of-way. 
The ingestion of contaminated groundwater is a potential exposure pathway. For the purposes of this CAS, the restriction of groundwater usage for domestic or other purposes is considered appropriate. Restricting construction on the contaminated portion of the railroad rightof-way is appropriate in order to preclude upward vapor intrusion into a habitable structure as a potential exposure pathway.

\subsubsection{Preparation of a Corrective Action Plan}

The CAP would describe the LUC measures, the way they would be maintained, and all SMPE-related activities.

\subsubsection{SMPE-Related Monitoring and Reporting}

Alternative 5 would include a groundwater monitoring component. The alternative would require periodic reporting of the monitoring results.

\subsubsection{Groundwater Monitoring}

A comprehensive groundwater monitoring program would be implemented at and near the former CCC/USDA facility to evaluate groundwater quality. The monitoring would include a baseline sampling event followed by groundwater monitoring to document the static condition of the groundwater plume. The same ten wells would be sampled to establish a baseline and assess groundwater quality over time. The wells would be sampled every five years until Year 21. The wells are shown in Figure 6.1. The well sampling program would be evaluated continuously throughout the duration of the remedy.

The groundwater monitoring program would involve collection of groundwater samples, laboratory analysis for selected VOCs, data evaluation, and reporting. The samples would be analyzed for field parameters (dissolved oxygen, oxidation-reduction potential, $\mathrm{pH}$, temperature, and conductivity) at the wellhead, and for carbon tetrachloride, chloroform, and methylene chlorid by a qualified laboratory. 


\subsubsection{SMPE-Related Reporting}

For sites like the former CCC/USDA source area, where contamination is expected to remain at levels that do not allow for unrestricted residential use, the KDHE suggests reviews at least every five years to ensure that remedial actions remain protective of human health and the environment. The 5-yr reviews for this area would include document review, a site inspection, a summary of the groundwater monitoring activities, and a report. Documents to be reviewed and evaluated by the CCC/USDA and Argonne include the SPME Plan and CAD, the groundwater monitoring results, and any records generated during the review period pertaining to groundwater use or distribution or to the investigation of contamination in groundwater or soils in the affected area. The report is expected to include a discussion of the RAOs established by the CAD, a summary of the site visit, a summary of groundwater monitoring, any areas of noncompliance, and a summary of the protectiveness of the established corrective action. 


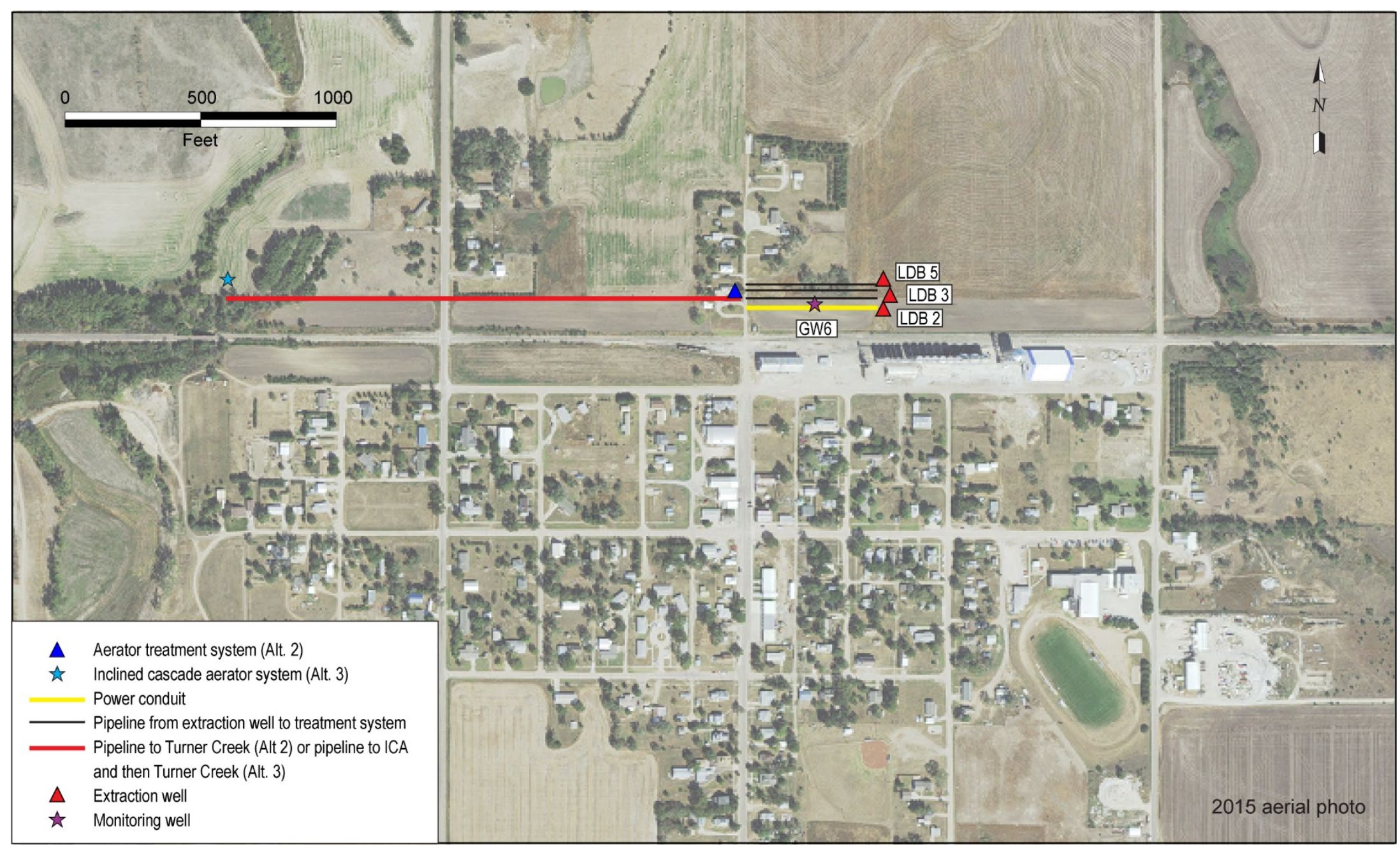

FIGURE 6.1 Location of LDB extraction wells, treatment building (Alternative 2), ICA (Alternative 3), power and pipelines for groundwater flow, power supply, and treated effluent. Note that the pipelines and collection points depicted here are also relevant for the spray irrigation system. Source of photograph: NAIP (2015). 


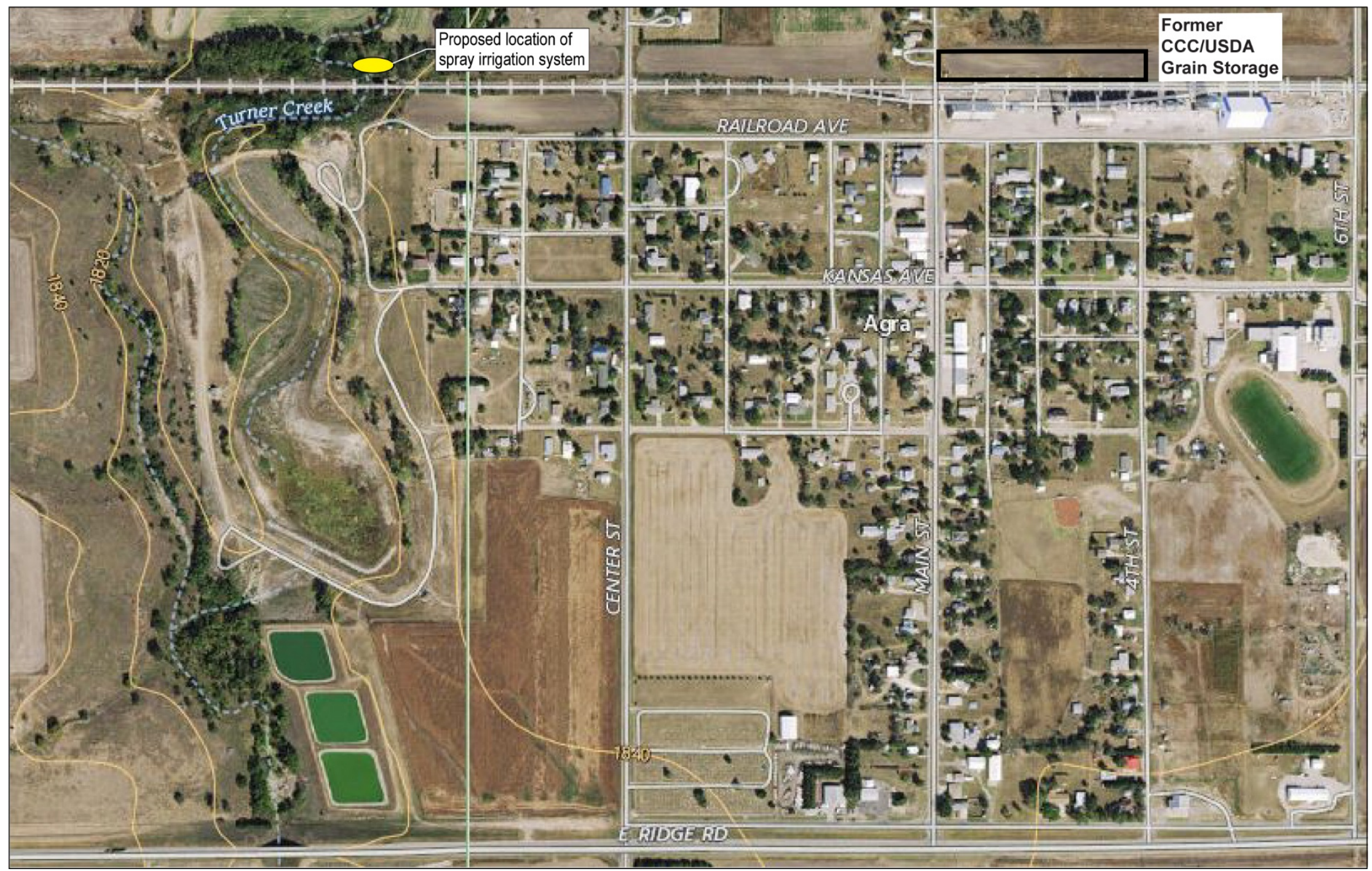

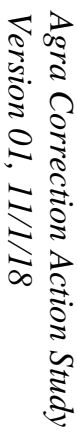

FIGURE 6.2 Proposed location for spray irrigation system. Source of photograph: NAIP (2015). 


\section{Detailed Analysis of the Corrective Action Alternatives}

The KDHE (2001a) CAS guidance adopts by reference nine EPA-defined criteria. The criteria are as follows:

1. Overall protection of human health and the environment, which addresses protection from unacceptable risks in both the short term and the long term by minimizing exposures, in accordance with the purpose and objectives of the proposed actions. Because of its broad scope, this criterion also reflects the focus of Criteria 2-5.

2 Compliance with ARARs, which addresses the attainment of federal and state environmental requirements determined to be either applicable or relevant and appropriate to the alternative, on the basis of site-specific considerations. Potential ARARs and TBCs are listed in Appendix B.

3. Long-term effectiveness and permanence, which addresses residual risks remaining after completion of a remedial action. The EPA (1991) guidance states that it is usually sufficient to indicate whether an alternative has the potential to achieve the preliminary cleanup levels and not necessary to quantify the risk that would remain after implementation.

4. Reduction of contaminant toxicity, mobility, or volume, which addresses the degree to which treatment addresses the principal threat(s) at the site; the amount of material treated; the magnitude, significance, and reversibility of the given reduction; and the nature and quantity of treatment residuals.

5. Short-term effectiveness, which addresses the potential impacts to site workers, the general public, and the environment from implementing the alternative; the effectiveness and reliability of mitigation measures; and the time required to achieve protectiveness.

6. Implementability, which addresses technical feasibility, including the availability and reliability of required resources (such as specific technologies, materials and equipment, facility capacities, and skilled 
workers); ease of implementation; and the ability to monitor effectiveness. This criterion also addresses administrative feasibility. The actual determination of administrative feasibility would not be made until after the CAS is completed.

7. Cost, which addresses both capital and annual O\&M costs. Costs for the individual components of the alternatives are also considered.

8. State acceptance, which addresses KDHE comments on the alternatives being considered. State acceptance is deferred pending issuance of this document.

9. Community acceptance, which addresses the comments made by the community on the alternatives being considered. Because these comments will not be received until this report has been issued for public review, the community acceptance criterion is deferred.

In the following sections, each of the alternatives outlined in Section 6 is evaluated in detail on the basis of Criteria 1-7 above. The state acceptance and community acceptance criteria are discussed in Section 8.8. The comparative analysis is summarized in Table 7.1.

Costs presented for the alternatives were estimated by using a combination of actual costs, costs from similar projects, conceptual cost proposals from contractors, and the Remedial Action Cost Engineering and Requirements (RACER) cost estimation model (AECOM 2009).

\subsection{Alternative 1: No Action}

In compliance with the CAS requirements, Alternative 1, the no action alternative, is included to provide a baseline for comparison with the other alternatives. Under this alternative, no action would be taken to remediate, or otherwise prevent potential exposure to, the carbon tetrachloride contamination on the former CCC/USDA property. Further operation of the SVE/AS systems would not be included, because the LDB/IM would end under the no action alternative. 


\subsubsection{Overall Protection of Human Health and the Environment}

Under the current and anticipated future use conditions, Alternative 1 is considered protective of human health and the environment. Since 1939, Agra has obtained its water supply from a municipal distribution system (Kansas water system number 2014707), although a number of private wells are present in the town that remain in use for lawn-and-garden purposes (Pro Ag 2010). Routine testing conducted by the KDHE demonstrates that the Agra municipal system is free of carbon tetrachloride contamination. Monitoring conducted by the CCC/USDA has demonstrated that locally elevated levels of carbon tetrachloride (3,000 $\mu \mathrm{g} / \mathrm{L}$ and greater) remain beneath and in the immediate vicinity of the source area identified on the former CCC/USDA property (Figure 2.17). Together with the results of earlier groundwater sampling, however, these data provide no evidence for significant downgradient migration of carbon tetrachloride in groundwater beyond this source area (Argonne 2018b). Existing water supply protective measures, including the KDHE regulations governing the location and construction of water supply wells, provide long-term mitigation of potential health risks associated with the contaminated groundwater. In addition, since the former CCC/USDA facility property is on the existing KRC railroad right-of-way, it would be extremely difficult (and unlikely) for someone to install an unauthorized drinking water supply well in the affected area. As a result, under current and future use conditions, residents will not be exposed to groundwater containing carbon tetrachloride above regulatory thresholds.

\subsubsection{Compliance with ARARs and TBCs}

Alternative 1 would not address chemical-specific ARARs for carbon tetrachloride in drinking water (the MCL and RBSL).

Because no active measures are associated with Alternative 1, there are no location- or action-specific ARARs.

\subsubsection{Long-Term Effectiveness and Permanence}

Alternative 1 involves no treatment of groundwater and thus is not considered permanent; however, the existing restrictions on land use, and water supply protective measures, outlined in Section 7.1.1 are reasonably expected to remain in effect in the long-term. Carbon tetrachloride 
levels may also be expected to decrease in the long-term through intrinsic processes. The identification of low levels of chloroform in groundwater at multiple locations indicates that some degradation of carbon tetrachloride is occurring.

Under Alternative 1, the level of contamination and risks to terrestrial biota over the long-term are similar to current levels. These risks are considered insignificant, because there would be no exposure to the affected groundwater.

\subsubsection{Reduction of Toxicity, Mobility, or Volume}

The implementation of Alternative 1 would not directly address the toxicity, mobility, or volume of carbon tetrachloride at the site.

\subsubsection{Short-Term Effectiveness}

Implementation of Alternative 1 would not impact the general public or the environment. No mitigation measures would be required.

\subsubsection{Implementability}

The property formerly occupied by the CCC/USDA facility would remain a part of the KRC railroad right-of-way. Since termination of the CCC/USDA grain storage operations (in the 1970s), the property has been used exclusively for agriculture.

\subsubsection{Cost}

There are no costs associated with Alternative 1. 


\subsection{Alternative 2: Groundwater Extraction, Treatment with a Tray Aerator, Discharge, and Groundwater Monitoring}

\subsubsection{Overall Protection of Human Health and the Environment}

Under the current and potential future use conditions, Alternative 2 is considered protective of human health and the environment. Since 1939, Agra has obtained its water supply from a municipal distribution system (Kansas water system number 2014707). Routine testing conducted by the KDHE demonstrates that the Agra municipal system is free of carbon tetrachloride contamination. Pro Ag conducted a private well study in the area in 2010 which consisted of houseto-house canvassing, and the completion of written survey forms (Pro Ag 2010). The survey results revealed that 11 private wells are present in Agra; seven of these wells are being used for landscape/irrigation purposes and four wells are not being used. The Pro Ag survey results are in Appendix A. Monitoring conducted by the CCC/USDA has demonstrated that locally elevated levels of carbon tetrachloride $(3,000 \mu \mathrm{g} / \mathrm{L}$ and greater) remain beneath and in the immediate vicinity of the source area identified on the former CCC/USDA property (Figure 2.17). Together with the results of earlier groundwater sampling, however, these data provide no evidence for significant downgradient migration of carbon tetrachloride in groundwater beyond this source area (Argonne 2018b).

Existing water supply protective measures, including the constraints established under the KDHE regulations governing the location and construction of water supply wells, provide longterm mitigation of potential health risks associated with the carbon tetrachloride contamination in groundwater. In addition, the area affected by operations of the former CCC/USDA facility is part of an active railroad right-of-way which would effectively prevent the installation of a water supply well in the contaminated area. As a result, under current and future use conditions, residents would not be exposed to groundwater containing carbon tetrachloride above regulatory thresholds.

The extraction component of Alternative 2 would result in significant carbontetrachloride mass removal from groundwater. Treatment would mitigate potential risk associated with the carbon tetrachloride in the groundwater. The groundwater monitoring and treatment system performance and compliance monitoring aspects of this alternative would verify the successful operation of the proposed treatment. 


\subsubsection{Compliance with ARARs and TBCs}

Under Alternative 2, the chemical-specific RBSL and MCL value of $5.0 \mu \mathrm{g} / \mathrm{L}$ for carbon tetrachloride in drinking water is an ARAR that would be addressed within and beyond the ROI of the extraction wells. Interception (by pumping) and treatment of the groundwater from the targeted area would reduce the concentrations, mobility, and volume of carbon tetrachloride throughout the capture zone developed during the period of active pumping.

Documentation prepared to support Alternative 2 such as the CAP, SMPE Plan, O\&M Plan, etc. would comply with the CAP/CA TBC.

\subsubsection{Long-Term Effectiveness and Permanence}

The groundwater extraction and treatment component of Alternative 2 would be protective of human health and the environment. The extraction and treatment would permanently reduce the concentrations of carbon tetrachloride in groundwater.

\subsubsection{Reduction of Toxicity, Mobility, or Volume}

Under Alternative 2, carbon tetrachloride contamination would be actively removed from groundwater continuously, resulting in a reduction of contaminant toxicity, mobility and volume.

\subsubsection{Short-Term Effectiveness}

No short-term mitigation measures are required under Alternative 2. Implementation of Alternative 2 would pose no short-term risks to the general public or the environment. Site workers involved in the construction of the groundwater extraction wells and placement of the subsurface pipeline between the aeration system and Turner Creek would be protected by adherence to a site specific health and safety plan. Installation of the required extraction wells, monitoring well and discharge pipeline are expected to have a short-term impact. There may be a short-term disruption of normal community activities in areas where the groundwater extraction and treatment system is installed. 


\subsubsection{Implementability}

Implementation of Alternative 2 is feasible. In an October 2017 meeting, Agra City officials expressed keen interest in an alternative that would result in augmented water flow to Agra Lake by way of Turner Creek. Resources and well-established construction methods are available to perform the needed installation of the three extraction wells, placement of the submersible pumps, and construction of the discharge line from the treatment system to Turner Creek. Installation of the groundwater extraction wells within the LDBs would involve the use of conventional techniques that are well within the scope of industry practice. The submersible pumps, pump controllers, and tray aerator are commercial, off-the-shelf technologies (OTST) that can be readily purchased and installed. Piping, power connections, and system controllers are also commercial OTST. The routing of power supply and control wiring to the extraction wells and the piping from the submersible pumps to the treatment building would take advantage of the existing (former AS/SVE) infrastructure and would be entirely below the surface between the LDBs and the treatment building. Either conventional trenching or directional boring techniques could be used to construct the discharge line between the treatment building and Turner Creek.

The implementability of Alternative 2 is contingent on establishing an access agreement with the KRC for the installation of the extraction wells, placement and operation of the treatment system, and construction of underground piping between the treatment building and thedischarge point on Turner Creek. Permitting for the proposed extraction of groundwater and discharge to Turner Creek would also be required from the KDA and the KDHE, respectively.

Under Alternative 2, residents would experience a short-term disruption while the extraction wells, treatment system, and discharge lines are installed. The contaminated portion of the former CCC/USDA facility would remain available for its current (agricultural) land use, as part of the railroad right-of-way. Monitoring and reporting would be performed with readily available resources.

\subsubsection{Cost}

The estimated 7-yr cost for Alternative 2 in current-year dollars is $\$ 701,000$. The net present value (NPV) cost is $\$ 638,000$ in current year dollars, and $\$ 734,000$ with a $15 \%$ contingency 
factor (Table 7.2). ${ }^{1}$ This estimate includes the costs for preparation of design documents; installation of the extraction wells, pumps, and related electrical wiring and piping; installation of one new monitoring well; purchase and installation of the treatment system building, tray aerator, and required control systems; construction of the effluent line to Turner Creek; and the performance of required monitoring and reporting.

\subsection{Alternative 3: Groundwater Extraction, Treatment with an Inclined Cascade Aerator, Discharge, and Groundwater Monitoring}

\subsubsection{Overall Protection of Human Health and the Environment}

Under the current and potential future use conditions, Alternative 3 is considered protective of human health and the environment. Since 1939, Agra has obtained its water supply from a municipal distribution system (Kansas water system number 2014707), although a number of private wells are present in the town that remain in use for lawn-and-garden purposes (Pro Ag 2010). Routine testing conducted by the KDHE demonstrates that the Agra municipal system is free of carbon tetrachloride contamination. Monitoring conducted by the CCC/USDA has demonstrated that locally elevated levels of carbon tetrachloride $(3,000 \mu \mathrm{g} / \mathrm{L}$ and greater) remain beneath and in the immediate vicinity of the source area identified on the former CCC/USDA property (Figure 2.17). Together with the results of earlier groundwater sampling, however, these data provide no evidence for significant down gradient migration of carbon tetrachloride in groundwater beyond this source area (Argonne 2018b).

Existing water supply protective measures, including the constraints established under the KDHE regulations governing the location and construction of water supply wells, provide longterm mitigation of potential health risks associated with the carbon tetrachloride contamination in groundwater. In addition, the area affected by operations of the former CCC/USDA facility is part of an active railroad right-of-way which would effectively prevent the unknown installation of a

1 Like all remedial action projects, Alternative 2 (and all of the alternatives in this CAS) involve construction costs incurred at the beginning of the project and costs in subsequent years required to maintain the remedy (e.g., sampling, analyses, and operations and maintenance costs). Present value is a way to evaluate and express expenditures which occur over different time periods. A single cost figure (the present value) can be used to compare the costs expected from different alternatives that involve different time frames. The present value is the amount of money needed to be set aside at Year 1 to assure that funds will be available in the future, assuming the funds would increase by some agreed-upon interest rate. 
water supply well in the contaminated area. As a result, under current and future use conditions, residents would not be exposed to groundwater containing carbon tetrachloride above regulatory thresholds.

The extraction component of Alternative 3 would result in significant carbontetrachloride mass removal from groundwater. Treatment would mitigate potential risk associated with the carbon tetrachloride in the groundwater. The groundwater monitoring and treatment system performance and compliance monitoring aspects of this alternative would verify the successful operation of the proposed treatment.

\subsubsection{Compliance with ARARs and TBCs}

Under Alternative 3, the chemical-specific RBSL and MCL value of $5.0 \mu \mathrm{g} / \mathrm{L}$ for carbon tetrachloride in drinking water is an ARAR that would be addressed within and beyond the ROI of the extraction wells. Interception (by pumping) and treatment of the groundwater from the targeted area would reduce the concentrations, mobility, and volume of carbon tetrachloride throughout the capture zone developed during the period of active pumping.

Documentation prepared to support Alternative 3 such as the CAP, SMPE Plan, O\&M Plan, etc. would comply with the CAP/CA TBC.

\subsubsection{Long-Term Effectiveness and Permanence}

The groundwater extraction and treatment component of Alternative 3 would be protective of human health and the environment. The extraction and treatment would permanently reduce the concentrations of carbon tetrachloride in groundwater.

\subsubsection{Reduction of Toxicity, Mobility, or Volume}

Under Alternative 3, carbon tetrachloride contamination would be actively removed from groundwater seasonally, resulting in a reduction of contaminant toxicity, mobility and volume. 


\subsubsection{Short-Term Effectiveness}

No short-term mitigation measures are required under Alternative 3. Implementation of Alternative 3 would pose no short-term risks to the general public or the environment. Site workers involved in the construction of the groundwater extraction wells and placement of the subsurface pipeline between the aeration system and Turner Creek would be protected by adherence to a site specific health and safety plan. Installation of the required extraction wells, monitoring well and discharge pipeline are expected to have a short-term impact. There may be a short-term disruption of normal community activities in areas where the groundwater extraction and treatment system is installed.

\subsubsection{Implementability}

Implementation of Alternative 3 is feasible. In an October2017 meeting, Agra City officials expressed keen interest in an alternative that would result in augmented water flow to Agra Lake by way of Turner Creek. Resources and well-established construction methods are available to perform the needed installation of the three extraction wells, placement of the submersible pumps and construction of the di scharge line from the LDBs to the ICA treatment system. Installation of the groundwater extraction wells within the LDBs would involve the use of conventional techniques that are well within the scope of industry practice. The submersible pumps and pump controllers are commercial OTST that can be readily purchased and installed. Piping, power connections and system controllers are also commercial OTST. The routing of power supply and control wiring to the extraction wells and the piping from the submersible pumps to the point where the individual flows would be merged would take advantage of the existing (former AS/SVE) infrastructure and would be entirely subsurface. Either conventional trenching or directional boring techniques could be used to construct the discharge line between the LDBs and the ICA adjacent to Turner Creek.

The ICA units would need to be custom-designed and built to meet the site-specific cleanup and installation requirements of this project; however, it is anticipated that these can be readily constructed using standard metal fabrication techniques. An ICA groundwater treatment system has been constructed, installed and successfully operated at the groundwater contamination site in Frankfort, Kansas (Aquaterra 2009a,b; 2015). 
The implementability of Alternative 3 is contingent on establishing an access agreement with the KRC for the installation of the extraction wells, construction of underground piping between the treatment building and the ICA, and installation of the ICA system along Turner Creek. Permitting for the proposed extraction of groundwater and discharge to Turner Creek will also be required from the KDA and the KDHE, respectively.

Under Alternative 3, residents would experience a short-term disruption while the extraction wells, treatment system and discharge lines are installed. The contaminated portion of the former CCC/USDA facility would remain available for its current (agricultural) land use, as part of the railroad right-of-way. Monitoring and reporting would be performed with readily available resources.

\subsubsection{Cost}

The estimated 9-yr cost for Alternative 3 in current-year dollars is $\$ 702,000$. The NPV cost is $\$ 631,000$ in current year dollars, and $\$ 726,000$ with a $15 \%$ contingency factor (Table 7.2 ). This estimate includes the costs for preparation of design documents; installation of the extraction wells, pumps, and related electrical wiring and piping; installation of one new monitoring well; fabrication and installation of the inclined cascade treatment units, construction of the influent pipeline to the ICA system; and the performance of required monitoring and reporting. Two 5-yr reviews are assumed for cost estimating purposes.

\subsection{Alternative 4: Groundwater Extraction, Treatment and Discharge by Spray Irrigation and Groundwater Monitoring}

\subsubsection{Overall Protection of Human Health and the Environment}

Under the current and potential future use conditions, Alternative 4 is considered protective of human health and the environment. Since 1939, Agra has obtained its water supply from a municipal distribution system (Kansas water system number 2014707), although a number of private wells are present in the town that remain in use for lawn-and-garden purposes (Pro Ag 2010). Routine testing conducted by the KDHE demonstrates that the Agra municipal system is free of carbon tetrachloride contamination. Monitoring conducted by the CCC/USDA 
has demonstrated that locally elevated levels of carbon tetrachloride $(3,000 \mu \mathrm{g} / \mathrm{L}$ and greater) remain beneath and in the immediate vicinity of the source area identified on the former CCC/USDA property (Figure 2.17). Together with the results of earlier groundwater sampling, however, these data provide no evidence for significant downgradient migration of carbon tetrachloride in groundwater beyond this source area (Argonne 2018b).

Existing water supply protective measures, including the constraints established under the KDHE regulations governing the location and construction of water supply wells, provide longterm mitigation of potential health risks associated with the carbon tetrachloride contamination in groundwater. In addition, the area affected by operations of the former CCC/USDA facilityis part of an active railroad right-of-way which would effectively prevent the inadvertent installation of a water supply well in the contaminated area. As a result, under current and future use conditions, residents would not be exposed to groundwater containing carbon tetrachloride above regulatory thresholds.

The extraction component of Alternative 4 would result in significant carbontetrachloride mass removal from groundwater. Treatment by spray irrigation would mitigate potential risk associated with the carbon tetrachloride in the groundwater. The groundwater monitoring and treatment system performance and compliance monitoring aspects of this alternative would verify the successful operation of the proposed treatment.

\subsubsection{Compliance with ARARs and TBCs}

Under Alternative 4, the chemical-specific RBSL and MCL value of $5.0 \mu \mathrm{g} / \mathrm{L}$ for carbon tetrachloride in drinking water is an ARAR that would be addressed within and beyond the ROI of the extraction wells. Interception (by pumping) and treatment of the groundwater from the targeted area would reduce the concentrations, mobility, and volume of carbon tetrachloride throughout the capture zone developed during the period of active pumping.

Documentation prepared to support Alternative 4 such as the CAP, SMPE Plan, O\&M Plan, etc. would comply with the CAP/CA TBC. 


\subsubsection{Long-Term Effectiveness and Permanence}

The groundwater extraction and treatment component of Alternative 4 would be protective of human health and the environment. The extraction and treatment would permanently reduce the concentrations of carbon tetrachloride in groundwater.

\subsubsection{Reduction of Toxicity, Mobility, or Volume}

Under Alternative 4, carbon tetrachloride contamination would be actively removed from groundwater seasonally, resulting in a reduction of contaminant toxicity, mobility and volume.

\subsubsection{Short-Term Effectiveness}

No short-term mitigation measures are required under Alternative 4. Implementation of Alternative 4 would pose no short-term risks to the general public or the environment. Site workers involved in the construction of the groundwater extraction wells and placement of the subsurface pipeline between the extraction wells and the spray irrigation system along Turner Creek and installation of the spray irrigation system itself would be protected by adherence to a site specific health and safety plan. Installation of the required extraction wells, monitoring well and discharge pipeline are expected to have a short-term impact. There may be a short-term disruption of normal community activities in areas where the groundwater extraction and treatment system is installed.

\subsubsection{Implementability}

Implementation of Alternative 4 is feasible. In an October 2017 meeting, Agra City officials expressed keen interest in an alternative that would result in augmented water flow to Agra Lake by way of Turner Creek. Resources and well-established construction methods are available to perform the needed installation of the three extraction wells, placement of the submersible pumps and construction of the discharge line from the extraction wells to the spray irrigation system. Installation of the groundwater extraction wells within the LDBs would involve the use of conventional techniques that are well within the scope of industry practice. The implementability of using spray irrigation as a groundwater treatment technology continues to be validated at two Nebraska sites, as discussed in Section 5.2.4.1. The submersible pumps, pump 
controllers and spray irrigation sprinkler heads are commercial OTST that can be readily purchased and installed. Piping, power connections and system controllers are also commercial OTST. The routing of power supply and control wiring to the extraction wells and the piping from the submersible pumps to the point where the individual flows would be merged would take advantage of the existing (former AS/SVE) infrastructure and would be entirely subsurface. Either conventional trenching or directional boring techniques could be used to construct the discharge line between the LDBs and the spray irrigation system adjacent to Turner Creek.

Water lines would need to be installed to connect the buried discharge line to the spray irrigation system. The spray irrigation unit(s) could be mounted on concrete footings placed within the forest bordering Turner Creek.

The implementability of Alternative 4 is contingent on establishing an access agreement with the KRC for the installation of the extraction wells, construction of underground piping between the LDBs and Turner Creek, and installation of the spray irrigation system adjacent to Turner Creek. Permitting for the proposed extraction of groundwater and discharge to Turner Creek would also be required from the KDA and the KDHE, respectively.

Under Alternative 4, residents would experience a short-term disruption while the extraction wells, treatment system and discharge lines are installed. The former CCC/USDA facility would continue to be used by the two residents. Monitoring and reporting would be performed with readily available resources.

\subsubsection{Cost}

The estimated 13-yr cost for Alternative 4 in current-year dollars is $\$ 742,000$. The NPV cost is $\$ 652,000$ in current year dollars, and $\$ 750,000$ with a $15 \%$ contingency factor (Table 7.2 ). This estimate includes the costs for preparation of design documents; installation of the extraction wells, pumps, and related electrical wiring and piping; installation of one new monitoring well; installation of the spray irrigation system; installation of the water lines to the spray irrigation system; and performance of required monitoring and reporting. Two 5-yr reviews are assumed for cost estimating purposes. 


\subsection{Alternative 5: Land Use Controls and Monitoring}

\subsubsection{Overall Protection of Human Health and the Environment}

Under current use conditions, Alternative 5 would be considered protective of human health and the environment, because there are currently no complete exposure pathways to human or ecological receptors. Under future use conditions, Alternative 5 would invoke administrative measures to eliminate the potential for exposure to contaminants in groundwater, because (1) KRC, the owner of the railroad right-of-way where the former CCC/USDA facility was located, would continue to prohibit the installation of a water supply well and the construction of structures in the area of residual contamination, or (2) similar restrictions would be implemented under a KDHE EUC.

\subsubsection{Compliance with ARARs}

Under Alternative 5, the chemical-specific RBSL and MCL value of $5 \mu \mathrm{g} / \mathrm{L}$ is an ARAR that would not be addressed directly and would not be met until natural processes eventually decreased contaminant concentrations to this level. Alternative 5 would comply with other pertinent ARARs and TBCs as appropriate. No location-specific ARARs and TBCs apply. No archeological or cultural resources are known to exist at the former CCC/USDA facility. No critical ecological habitats have been found at the facility, and activities to implement Alternative 5 (monitoring and LUCs) are not expected to impact local wetlands or wildlife.

\subsubsection{Long-Term Effectiveness and Permanence}

Alternative 5 would not involve the treatment of contaminated groundwater at the site, although contamination may decrease in the long-term through natural processes. Alternative 5 would, however, be protective of human health and the environment over the long term. The LUCs associated with this alternative would continue to eliminate potential exposure to contaminated groundwater and would remain in force as long as the railroad remains in use. 


\subsubsection{Reduction of Toxicity, Mobility, or Volume}

Implementation of Alternative 5 would not directly address the toxicity, mobility, or volume of contaminants at the site; however, intrinsic remediation may result in a decrease in the toxicity and volume of the contaminants in the long term. In the immediate vicinity of the CCC/USDA source, the vertical and lateral mobility of the groundwater, and hence contaminant migration, are naturally restricted by the low-permeability silty-clayey deposits discussed in Section 2.3, thereby limiting potential offsite migration from the former CCC/USDA site.

\subsubsection{Short-Term Effectiveness}

Implementation of Alternative 5 would not affect the general public or the environment. No mitigation measures would be required. Site workers involved in monitoring would be protected by adherence to best management practices pertaining to hazardous waste site worker health and safety.

\subsubsection{Implementability}

Alternative 5 provides an administrative mechanism for the management of risk. Alternative 5 has been shown to be feasible since the owner of the affected property (KRC) already implicitly adheres to the land use restrictions described in Section 6.5. If required by KDHE, these implicit restrictions could be made explicit in either an EUC or an access agreement between the the CCC/USDA and the KRC. The absence of active measures to decrease carbon tetrachloride concentrations in groundwater, which are currently above the RBSL and MCL values of $5 \mu \mathrm{g} / \mathrm{L}$, affects the potential for regulatory acceptance of this alternative.

Implementation of Alternative 5 would be straightforward. LUCs are already being privately imposed (by KRC) at the contaminated site. Should KDHE determine that a formal administrative mechanism linked to the LUCs is needed, the CCC/USDA has been operating under an access agreement pertaining to the affected area since 2005. That agreement could be amended to allow CCC/USDA to perform any required corrective action activities and to document the property owner's commitment to observe and maintain the existing LUCs. If an EUC is needed, the EUC program is mature in the state of Kansas, with more than 30 EUC agreements established. 
The former CCC/USDA facility would continue to be an agricultural resource. Monitoring and reporting would be performed with readily available resources.

\subsubsection{Cost}

The estimated 21 year cost of Alternative 5 is approximately $\$ 256,000$. Included are costs for sampling and analyzing water samples from nine wells for the 5, 10, 15 and 20-yr reviews, with associated 5-yr review reports to summarize the results. The estimated present worth cost for Alternative 5 is about $\$ 136,000$ in current year dollars, and \$156,000 with a 15\% contingency factor (Table 7.2). 
TABLE 7.1 Comparative analysis of Agra CAS alternatives.

Evaluation Criterion $\quad$ Alternative 1 - No Action

Protective under current use as there are no exposure pathways. Agra is served by a municipal distribution system that is ree of carbon tetrachlo protective regulations (Kansas well location and construction regulations) should also preclude exposure to contaminated groundwater

Compliance with federal Groundwater impacted by operations at the former CCC/USDA site cannot be accessed for use as a drinking water source since the site is on an active by excavation coupled with AS/SVE. Carbon tetrachloride in groundwater remains above the Kansas Tier 2 RBSL and the EPA MCL of $5 \mu \mathrm{g} / \mathrm{L}$. This

$\begin{array}{ll}\begin{array}{l}\text { Long-term effectiveness } \\ \text { and permanence }\end{array} & \begin{array}{l}\text { The long-term effectiveness of this alternative depends on continued } \\ \text { operation of the railroad and the land use controls for the ROW being }\end{array}\end{array}$ operation of the railroad and the land use controls for the ROW being enforced by the KRC

Reduction of toxicity, No reduction of toxicity, mobility, and volume occurs in this alternative CCC/USDA source, both vertical and lateral groundwater and contamin migration are restricted to the low-permeability silty-clayey deposits ccclssed in Section 2.3, thereby limiting offste migration from the former through treatment CCC/USDA site.

Short-term effectiveness

Implementation can be accomplished with no additional risk to workers, the community, or the environment.

Implementability This alternative can be implemented readily; acceptance by KDHE might be unlikely, because no active measures are taken.

Preliminary cost estimate
Protective under current use as there are no exposure pathways. Agra is served contamination. The site is located on an active railroad right-of-way, minimizing e potential for inadvertent installation of a drinking water supply well or habitable

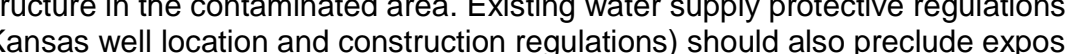
o contaminated groundwater

Groundwater impacted by operations at the former CCC/USDA site cannot be extraction and treatment has the potential to bring extraction

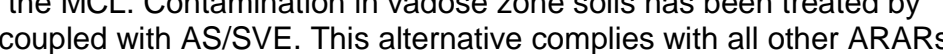

This alternative has the potential to be effective, and bring carbon tetrachloride concentrations permanently below regulatory thresholds.

Within the capture zone of the three extraction wells, reduction of carbon alternative.

Implementation can be accomplished with no additional risk to workers, the community, or the environmen

Implementation is predicated on obtaining site access to allow the installation of the extraction wells, power supply, the discharge pipeline and the tray aerator and support building. Alemalive 2 can be implemented by using standard, readly owned property.

$\$ 701,000$

$\$ 638,000(\$ 734,000)$
Protective under current use as there are no exposure pathways. Agra is served Py a muicipal distribution system that is ree or carbon tetrachlonde

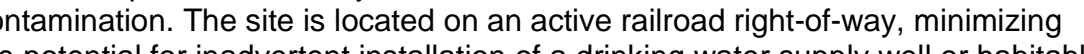
政 (Kansas well location and construction regulations) should also preclude exposure to contaminated groundwate

Groundwater impacted by operations at the former CCC/USDA site cannot be right-of-way. Groundwater extraction and treatment has the potential to bring carbon tetrachloride concentrations within the ROI of the three extraction wells below the MCL. Contamination in vadose zone soils has been treated by and TBCs.

This alternative has the potential to be effective, and bring carbon tetrachloride concentrations permanently below regulatory thresholds

Within the capture zone of the three extraction wells, reduction of carbon

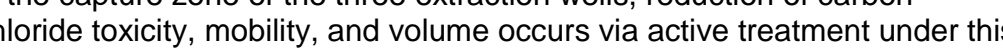
alternative.

mplementation can be accomplished with no additional risk to workers, the community,

mplementation is predicated on obtaining site access to allow the installation of the extraction wells, power supply, he discharge pipeline and the ICA treatment technologies and vendors. Contingent on gaining access to privately owned property.

$\$ 702,000$ 
Overall protection of Overall protection of environment

Protective under current use as there are no exposure pathways. Agra is served by a municipal distribution system that is free of carbon tetrach active railroad right-of-way, well or habitable structure in the contaminated area. Existing water supply protective regulations (Kansas well location and construction regulations) should also preclude exposure to contaminated groundwater

Compliance with federal Groundwater impacted by operations at the former CCC/USDA site cannot be accessed for use as a drinking water source since the site is on an active to bring carbon tetrachloride concentrations within the $\mathrm{ROI}$ of the three extraction wells below the MCL. Contanmination in vadose zone soils has

Long-term effectiveness This alternative has the potential to be effective, and bring carbon tetrachloride concentrations permanently below regulatory thresholds.

Within the capture zone of the three extraction wells, reduction of carbon

Reduction of toxicity,

Within the capture zone of the three extraction wells, reduction of carbon tetrachloride toxici
this alternative.

through treatment

Short-term effectiveness

Implementation can be accomplished with no additional risk to workers, the community, or the environmen

Implementability Implementation is predicated on obtaining site access to allow the installation of the extraction wells, power supply, the discharge pipeline and the spraystandard, readily available technologies and vendors. Contingent on gaining access to privately owned property.

Preliminary cost estimate $\quad \$ 742,000$

$\$ 652,000(\$ 750,000)$ $\$ 256,000$

Protective under current use as there are no exposure pathways. Agra is served

contamination. The site is located on an active railroad right-of-way, minimizing structure in the contaminated area. Existing water supply protective regulations (Kansas well location and construction regulations) should also preclude exposure o contaminated groundwater.

Groundwater impacted by operations at the former CCC/USDA site cannot be (nite is on an active rairoad right-of-way. Contamination in vadose zone soils has been treated by excavation coupled with AS/SVE. Carbon tetrachloride in groundwater remains above the Kansas Tier 2 RBSL and the EPA MCL of $5 \mathrm{\mu g} / \mathrm{L}$. This alternative complies with

The long-term effectiveness of this alternative depends on continued operation of the railroad and the land use controls for the right-of-way being enforced by the

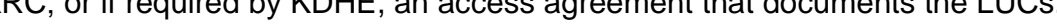
duration of 20 years has been used for developing the costs for Alternative 5 .

No reduction of toxicity, mobility, and volume occurs in this alternative, except through intrinsic remediation. In the immediate vicinity of the CCCIUSDA source, he low-permeability silty-clayey deposits discussed in Section 2.3, thereby limiting

Implementation can be accomplished with no additional risk to workers, the community, or the environment

This alternative can be implemented readily; acceptance by KDHE might be contingent upon reliance on an access agreement to formalize the LUCs.

$\$ 136,000(\$ 156,000)$

NPV cost (NPV cost
$15 \%$ contingency) 
TABLE 7.2 Cost basis for Alternatives 1-5.

Total (\$) NPV (\$)

Alternative 1: No action

Subtotal

Total cost

Alternative 2: Groundwater extraction and treatment; groundwater monitoring

Permitting and monitoring:

Third party permitting (CAP, NPDES, groundwater withdrawal) and design

107,520

Argonne permitting design effort

57,600

One year of baseline monitoring (10 wells), Year 1

11,005

Monitoring of 10 wells and NPDES sampling, twice for first year of groundwater pump and treatment operations, Year 2

22,180

Yearly sampling of 10 monitoring wells for Years 3-7, NPDES permit (one quarter per year while groundwater pump and treat is operating)

Staff and analytical costs for NPDES sampling, and analyses when wells are not sampled (twice in Year 2, three times in Years 3-7)

Pump test and remedial action:

Cascade Drilling of three extraction wells within LDBs and one new 2-in. well

72,511

Professional labor management (PLM) during drilling

16,512

Pump test (including equipment rental, Argonne's costs, support contractor costs, analytical costs, and disposal costs)

25,000

Submersible pumps with cable and cutoff level probe (three)

8,561

Power conduit to distribution point at LDBs

598

Status boxes for power and signal (three)

955

Integral control panel stand

1,909

Control panel

9,403

Excavation and installation effluent pipeline to discharge point $(2,100 \mathrm{ft})$

26,729

2-in. HDPE, 2,240 ft

4,277

Lo-Pro II aerator

11,926

Shipping

1,527

Aerator building (free delivery from Topeka Sheds)

2,864

Flow meters, miscellaneous values and fittings

6,364

Plumbing, power connection, groundwater extraction, and aerator controller installation

51,200

Argonne PLM during construction and set up

19,200

Startup costs to account for getting to routine operations

6,731

Electricity costs (6 years of continuous operation)

Reporting:

Reporting as specified in the SMPE plan $\quad 24000$

$\begin{array}{lr}\text { Five-year review (two cycles) } & 72,000\end{array}$

Subtotal

701,000

638,000

Contingency (15\%)

105,000

96,000

Total cost

807,000 


\section{Alternative 3: Groundwater extraction and treatment with ICA; groundwater monitoring}

Permitting and Monitoring:

Third party permitting (CAP, NPDES, groundwater withdrawal) and design

107,520

57,600

11,005

One year of baseline sampling (10 wells), Year 1

Yearly sampling of 10 monitoring wells and NPDES sampling (twice) for first year of groundwater pump and treat, Year 2

Yearly sampling of NPDES discharge and 10 monitoring wells (one quarter), Years 3-9

Staff, analytical costs for NPDES sampling/analyses when wells are not sampled (twice in Years 2-9 because ICA operates in three seasons only)

42,507

72,511

16,512

25,000

8,561

598

955

9,403

26,729

4,277

16,000

750

ICA delivery and set up

1,200

19,200

6,364

6,730

12,800

Electricity costs (eight years of seasonal operation)

Reporting:

Reporting as specified in SMPE plan

33,600

Five-year review (two cycles)

Subtotal

702,000

631,000

Contingency (15\%)

105,000

95,000

Total cost

807,000

726,000 
TABLE 7.2 (Cont.)

Total (\$) NPV (\$)

Alternative 4: Groundwater extraction and treatment with spray irrigation and groundwater monitoring

Permitting and Monitoring:

Third party permitting (CAP, NPDES, groundwater withdrawal) and design $\quad 107,520$

Argonne permitting design effort

57,600

One year of baseline sampling (10 wells), Year 1

11,005

Yearly sampling of 10 monitoring wells and NPDES sampling (twice) for first year

of groundwater pump and treat, Year 2

22,180

Yearly sampling of 10 monitoring wells and one quarter of NPDES discharge (3 sprinkler heads), Years 3-11

103,637

Staff, analytical costs for NPDES sampling of three sprinkler heads and analyses when wells are not sampled (twice in Year 2-11 because spray irrigation

operates in three seasons only)

59,934

Pump Test and Remedial Action:

Cascade Drilling for extraction wells within LDBs and one new 2-in. well

72,511

PLM during drilling

16,512

Pump test (including equipment rental, Argonne, support contractor, analytical, and disposal costs)

25,000

Submersible pumps with cable and cuttoff level probe (three)

8,561

Power conduit to distribution point at LDBs

598

Status boxes for power and signal (three)

955

Control Panel

9,403

Excavate and install influent pipeline to ICA $(2,100 \mathrm{ft})$

26,729

2-in. HDPE, 2,240 ft

4,277

Sprinkler head, irrigation hose purchase (1-in. HDPE, $500 \mathrm{ft}$ ) 764

Plumbing, power connection, groundwater extraction controller setup (third party)

51,200

Argonne PLM during construction and set up of irrigation system

19,200

Flow meters, miscellaneous values and fittings

6,364

Start up costs to account for getting to routine operations

6,731

Electricity costs (10 years of seasonal operation)

16,000

Reporting:

Reporting as specified in SMPE plan

43,000

Five-year review (two cycles)

72,000

Subtotal

742,000

652,000

Contigency (15\%)

112,000

98,000

Total cost

854,000

750,000 


\section{TABLE 7.2 (Cont.)}

Total (\$) NPV (\$)

Alternative 5: Land Use Controls, Monitoring and Reporting (21 year duration)

Remedial action:

Argonne permitting design effort

57,600

Sampling of nine wells once (Year 1); then every five years for 20 years

(Years 2-21)

50,000

If required, $\mathrm{CCC}$ to include LUC in authorization and license agreement (internal CCC programmatic cost)

Reporting:

Reporting as specified in SMPE plan

4,800

Five-year review (four cycles)

144,000

Subtotal

256,000

136,000

Contingency (15\%)

38,000

20,000

Total cost

294,000

156,000 


\section{Comparative Analysis of Alternatives}

This section evaluates the relative performance of the alternatives with respect to the criteria described at the beginning of Section 7. This comparative analysis of alternatives is summarized in Table 7.2.

\subsection{Overall Protection of Human Health and the Environment}

Under the realistic current-day scenario, Alternatives 1 through 5 are all protective. Although carbon tetrachloride is present in groundwater above the MCL, groundwater affected by the former CCC/USDA facility is not used as a water supply source. There are no current risks associated with direct exposure to near-surface soils or the seepage of groundwater to surface water. No current risks are associated with VI since there are no structures in the affected area on the railroad right-of-way. Transient groundwater levels in the vicinity of monitoring wells GW1GW5 have, however, occasionally been shallower than $40 \mathrm{ft}$ BGL. As a result, although there is no current VI risk, in the unlikely event that a habitable structure would ever be built on the railroad right-of-way (where the former CCC/USDA facility was located), the structure would be considered a building of concern.

Because Agra residents are served by a municipal water supply system that is free of carbon tetrachloride contamination, there are no human health risks related to the use of contaminated groundwater as a domestic (drinking) water source. However, in the absence of enforced regulations to prevent future drilling of domestic wells, future risk might exist from this exposure pathway. Risks previously associated with protection of the soil-to-groundwater pathway in the identified soil-source area at the former CCC/USDA facility have been mitigated by the implementation and long-term operation of the LDB/IM.

Under future use scenarios, Alternative 1 places no constraint beyond those already established in the existing water supply protective measures on the installation of a water supply well in the area with affected groundwater. However, under plausible future use conditions, Alternative 1 is considered protective of human health and the environment. Monitoring conducted by the CCC/USDA has demonstrated that elevated levels of carbon tetrachloride locally remain beneath and in the immediate vicinity of the source area identified on the former CCC/USDA property (Figure 2.17); however, these data provide no evidence for significant contaminant 
migration beyond this source area (Argonne 2018b). The area of residual carbon tetrachloride contamination associated with the former CCC/USDA facility lies within the right-of-way of an active railroad line, and is presently unavailable for residential or other unrestricted development; these land-use limitations are expected to continue. Furthermore, existing Kansas State water supply protective measures should preclude the installation of a drinking water well in the localized area on this property where the groundwater is contaminated, should future development of this land become possible.

Alternatives 2 through 4 are considered protective of human health and the environment under current and future use conditions. The implementation of groundwater extraction and treatment would actively reduce the carbon tetrachloride concentrations and mass in groundwater, and hydraulically restrict potential groundwater and contaminant migration beyond the presently identified limits of the affected area.

Alternative 5 is considered protective of human health and the environment under current and future use conditions. The physical location and existing limited usage of the contaminated area associated with the former CCC/USDA facility (within the active KRC railroad right-of-way) LUCs and/or either secondary option discussed for Alternative 5 (LUCs memorialized in an access agreement or an EUC) would prevent exposure to contaminated groundwater since installation of a domestic water supply well would be prohibited. Exposure via VI would be prevented since the LUCs would preclude the construction of a habitable structure on the right-of-way.

\subsection{Compliance with ARARs and TBCs}

Alternatives 1 and 5 would not actively reduce carbon tetrachloride concentrations and thus would not address concentration-related ARARs. Alternatives 2 through 4 would actively remove and/or decrease the carbon tetrachloride concentrations in groundwater. Under Alternatives 2 through 4 all measures implemented would be conducted in accordance with applicable locationand action-specific ARARs.

\subsection{Long-Term Effectiveness and Permanence}

Alternatives 1 through 5 would effectively protect human health and the environment over the long-term because, even with no action, affected groundwater is unlikely to be used as a source 
of domestic water supply. Alternatives 2 through 4 would be effective in directly addressing the carbon tetrachloride contamination in groundwater. Removal of carbon tetrachloride from the affected media under Alternatives 2 through 4 would be permanent.

\subsection{Reduction of Toxicity, Mobility, or Volume}

Alternatives 1 and 5 do not involve actions to decrease the toxicity, mobility, or volume of the existing carbon tetrachloride contamination. Alternatives 2 through 4 would reduce both the volume and mobility of the contaminated groundwater.

\subsection{Short-Term Effectiveness}

Alternatives 1 through 5 would not adversely affect the general public or the environment in the short term. The construction activities associated with Alternatives 2 through 4 might cause some temporary, local disruptions in the normal activities of residents.

\subsection{Implementability}

Alternative 1 requires no implementation actions; however, the potential for administrative acceptance of this alternative is low, because no active measures would be taken to mitigate site risks.

The implementability of Alternatives 2 through 5 is predicated on having site access to conduct the recommended remedial activities. For Alternatives 2 through 4, site access would be required from the railroad property owner (currently the KRC) for the term of the remedy to install, operate, maintain, and monitor the groundwater extraction and treatment systems. For Alternative 5, the KRC would have to agree to incorporate LUC language in the site access agreement.

The installation of groundwater extraction wells, electrical power, piping, and treatment systems (either the tray aeration, spray irrigation or ICA systems) required under Alternatives 2 through 4 can be performed with standard equipment and construction techniques. 
Alternative 2 would employ a widely proven and readily available technology (tray aeration) for treatment of the extracted, contaminated groundwater. Alternatives 3 and 4 would implement a more innovative treatment approaches. The ICA would require custom design and fabrication (using standard metal-working techniques) of the ICA units. The ICA and spray irrigation treatment approaches would likely require less preventive maintenance. All three treatment technologies are considered logistically and operationally viable.

The monitoring components of Alternatives 2 through 5 can be implemented with available techniques, materials, and equipment, subject to continued property access.

\subsection{Cost}

Alternative 1 (no action) has no costs. Alternative 2 would be the least costly of the alternatives involving an active pumping/treatment approach. Alternatives 3 and 4 would have greater costs than Alternative 2 primarily because seasonal operation of the ICA treatment system under Alternative 3 and the spray irrigation system under Alternative 4 would necessitate a longer cleanup timeframe and hence additional monitoring and reporting to achieve results comparable to those of Alternative 2. The anticipated duration of continuous pumping under Alternative 2 is six years, versus eight and 10 (calendar) years of seasonal pumping under Alternatives 3 and 4, respectively. The cost of Alternative 3 in current year dollars is only about $\$ 32,000$ more than the cost of Alternative 2 . The cost of Alternative 4 is $\$ 40,000$ more than the cost of Alternative 2 .

Alternative 5, which does not involve an active pumping/treatment approach and instead relies on administrative measures (LUCs) and monitoring to manage risks associated with potential exposure to contaminated groundwater, is the least costly of the alternatives evaluated in this CAS. Alternative 5 is $\$ 445,000$ less costly than the least expensive active pumping treatment approach, described for Alternative 2. Since Alternative 5 does not involve the active extraction and treatment of contamination however, expenses associated with Alternative 5 would likely continue beyond the 21 year time frame considered for cost comparison in this CAS.

\subsection{Stakeholder and State Acceptance}

State acceptance would be reflected in the KDHE comments on this CAS and in the final corrective action selected. Community acceptance would be affected by the content of this CAS. 
As a result, stakeholder and state acceptance cannot be determined at this time. However, Agra City officials have expressed keen interest in augmenting the natural water flows into Lake Agra by way of Turner Creek. As a result, stakeholder acceptance for Alternatives 2, 3 and 4 is considered likely.

\subsection{Summary and Recommended Corrective Action}

The CCC/USDA recommends Alternative 2 for implementation in the identified source area on the former CCC/USDA facility property at Agra. At the present time Alternative 2 is protective of human health and the environment. Alternative 3 has similar costs and may have certain advantages compared to Alternative 2, including lower power requirements and routine maintenance costs. Although the ICA is not a conventional water treatment technology, the viability of the technology has been demonstrated for a limited range of carbon tetrachloride concentrations to the KDHE during 10 years of operation at the Frankfort, Kansas, site. Alternative 2, however, addresses carbon tetrachloride contamination in groundwater in the least amount of time by employing a well-proven technology.

Alternative 2 would achieve compliance with regulatory requirements over time because of active groundwater treatment. Alternative 2 also would decrease the toxicity, mobility, and volume of carbon tetrachloride in groundwater and thus offers long-term protectiveness and permanence. 


\section{References}

AECOM, 2009, Remedial Action Cost Engineering and Requirements System, AECOM Technology Corporation, Los Angeles, California.

Aquaterra, 2009a, Construction Documentation Report: Source Area Pump and Treat Remedial System Installation Frankfort PWS\#4 Site, Frankfort, Kansas, KDHE Project Code C4-058-70122, prepared for the Kansas Department of Health and Environment, Topeka, Kansas, by Aquaterra Environmental Solutions, Inc., July.

Aquaterra, 2009b, Site Monitoring Evaluation Report Frankfort PWS\#4 Site, Frankfort, Kansas, KDHE Project Code C4-058- 70122, prepared for the Kansas Department of Health and Environment, Topeka, Kansas, by Aquaterra Environmental Solutions, Inc., November.

Aquaterra, 2015, Cascade Evaluation Report, 2014 System Operations, Frankfort PWSS \#4 Site, KDHE Project Code: C4-058-70122, memorandum prepared by SCS Aquaterra Inc., February.

Argonne National Laboratory, unpublished information, 1995.

Argonne National Laboratory, unpublished information, 1996.

Argonne National Laboratory, unpublished information, 1997.

Argonne National Laboratory, unpublished information, 2000.

Sedivy, R., Argonne National Laboratory, unpublished information, 2004.

Argonne National Laboratory, unpublished information, 2005.

Argonne, 2006, Final Report: Results of the 2005 Investigation of Contaminant Sources at Agra, Kansas, ANL/EVS/AGEM/TR-06-02, prepared for the Commodity Credit Corporation, U.S. Department of Agriculture, by Argonne National Laboratory, Argonne, Illinois, July. 
Argonne, 2007a, Interim Measure Conceptual Design for Remediation of Source Area Contamination at Agra, Kansas, ANL/EVS/AGEM/TR-07-07, prepared for the Commodity Credit Corporation, U.S. Department of Agriculture, by Argonne National Laboratory, Argonne, Illinois, July.

Argonne, 2007b, Summary of Operations and Performance of the Murdock Site Restoration Project in June 2005-December 2006, prepared for the Commodity Credit Corporation, U.S. Department of Agriculture, by Argonne National Laboratory, Argonne, Illinois, May

Argonne, 2008a, Interim Measure Work Plan/Design for Agra, Kansas, ANL/EVS/AGEM/TR08-06, prepared for the Commodity Credit Corporation, U.S. Department of Agriculture, by Argonne National Laboratory, Argonne, Illinois, November.

Argonne National Laboratory, unpublished information, $2008 \mathrm{~b}$.

Argonne, 2009a, KDHE Project C6-074-00002: Quarterly Progress in October-December 2008 for Implementation of the LDB/SVE/AS Interim Measure at the Former CCC/USDA Grain Storage Facility in Agra, Kansas, ANL/EVS/AGEM/CHRON-1229, prepared for the Commodity Credit Corporation, U.S. Department of Agriculture, by Argonne National Laboratory, Argonne, Illinois, February.

Argonne, 2009b, KDHE Project C6-074-00002: Quarterly Progress in January-March 2009 for Implementation of the LDB/SVE/AS Interim Measure at the Former CCC/USDA Grain Storage Facility in Agra, Kansas, ANL/EVS/AGEM/CHRON-1268, prepared for the Commodity Credit Corporation, U.S. Department of Agriculture, by Argonne National Laboratory, Argonne, Illinois, June.

Argonne, 2009c, KDHE Project C6-074-00002: Quarterly Progress in April-June 2009 for Implementation of the LDB/SVE/AS Interim Measure at the Former CCC/USDA Grain Storage Facility in Agra, Kansas, ANL/EVS/AGEM/CHRON-1295, prepared for the Commodity Credit Corporation, U.S. Department of Agriculture, by Argonne National Laboratory, Argonne, Illinois, October. 
Argonne, 2009d, Progress Report and Technical Evaluation of the ISCR Pilot Test Conducted at the Former CCC/USDA Grain Storage Facility in Centralia, Kansas, ANL/EVS/AGEM/TR-0818, prepared for the Commodity Credit Corporation, U.S. Department of Agriculture, Washington, D.C., by Argonne National Laboratory, Argonne, Illinois, January.

Argonne, 2010a, KDHE Project C6-074-00002: Progress and Monitoring Report for the LDB/SVE/AS Interim Measure at the Former CCC/USDA Grain Storage Facility, Agra, Kansas, in July-December 2009 (Two Quarters), ANL/EVS/AGEM/CHRON-1333, prepared for the Commodity Credit Corporation, U.S. Department of Agriculture, by Argonne National Laboratory, Argonne, Illinois, February.

Argonne, 2010b, KDHE Project C6-074-00002: Progress and Monitoring Report for the LDB/SVE/AS Interim Measure at the Former CCC/USDA Grain Storage Facility, Agra, Kansas, in January-March, 2010, ANL/EVS/AGEM/CHRON-1373, prepared for the Commodity Credit Corporation, U.S. Department of Agriculture, by Argonne National Laboratory, Argonne, Illinois, June.

Argonne, 2010c, KDHE Project C6-074-00002: Progress and Monitoring Report for the LDB/SVE/AS Interim Measure at the Former CCC/USDA Grain Storage Facility, Agra, Kansas, in April-June, 2010, ANL/EVS/AGEM/CHRON-1408, prepared for the Commodity Credit Corporation, U.S. Department of Agriculture, by Argonne National Laboratory, Argonne, Illinois, November.

Argonne, 2010d, KDHE Project C6-074-00002: Progress and Monitoring Report for the LDB/SVE/AS Interim Measure at the Former CCC/USDA Grain Storage Facility, Agra, Kansas, in July-September, 2010, ANL/EVS/AGEM/CHRON-1417, prepared for the Commodity Credit Corporation, U.S. Department of Agriculture, by Argonne National Laboratory, Argonne, Illinois, December.

Argonne, 2010e, Sitewide Monitoring at Agra, Kansas, June 2009, ANL/EVS/AGEM/TR-09-11, prepared for the Commodity Credit Corporation, U.S. Department of Agriculture, by Argonne National Laboratory, Argonne, Illinois, June.

Argonne, 2011a, KDHE Project C6-074-00002: Progress and Monitoring Report for the LDB/SVE/AS Interim Measure at the Former CCC/USDA Grain Storage Facility, Agra, Kansas, 
in October-December, 2010, ANL/EVS/AGEM/CHRON-1434, prepared for the Commodity Credit Corporation, U.S. Department of Agriculture, by Argonne National Laboratory, Argonne, Illinois, February.

Argonne, 2011b, KDHE Project C6-074-00002: Progress and Monitoring Report for the LDB/SVE/AS Interim Measure at the Former CCC/USDA Grain Storage Facility, Agra, Kansas, in January-March, 2011, ANL/EVS/AGEM/CHRON-1456, prepared for the Commodity Credit Corporation, U.S. Department of Agriculture, by Argonne National Laboratory, Argonne, Illinois, June.

Argonne, 2011c, KDHE Project C6-074-00002: Progress and Monitoring Report for the LDB/SVE/AS Interim Measure at the Former CCC/USDA Grain Storage Facility, Agra, Kansas, in April-June, 2011, ANL/EVS/AGEM/CHRON-1479, prepared for the Commodity Credit Corporation, U.S. Department of Agriculture, by Argonne National Laboratory, Argonne, Illinois, August.

Argonne, 2011d, Five Year Summary and Evaluation of Operations and Performance of the Utica Aquifer and North Lake Basin Wetlands Restoration Project in 2004-2009, ANL/EVS/AGEM/TR11-05, prepared for the Commodity Credit Corporation, U.S. Department of Agriculture, by Argonne National Laboratory, Argonne, Illinois, June.

Argonne, 2012a, KDHE Project C6-074-00002: Progress and Monitoring Report for the LDB/SVE/AS Interim Measure at the Former CCC/USDA Grain Storage Facility, Agra, Kansas, in July-December, 2011, ANL/EVS/AGEM/CHRON-1516, prepared for the Commodity Credit Corporation, U.S. Department of Agriculture, by Argonne National Laboratory, Argonne, Illinois, August.

Argonne, 2012b, KDHE Project C6-074-00002: Progress and Monitoring Report for the LDB/SVE/AS Interim Measure at the Former CCC/USDA Grain Storage Facility, Agra, Kansas, in January-June 2012, ANL/EVS/AGEM/CHRON-1555, prepared for the Commodity Credit Corporation, U.S. Department of Agriculture, by Argonne National Laboratory, Argonne, Illinois, January. 
Argonne, 2012c, Sitewide Monitoring at Agra, Kansas, June 2011, ANL/EVS/AGEM/TR-11-08, prepared for the Commodity Credit Corporation, U.S. Department of Agriculture, by Argonne National Laboratory, Argonne, Illinois, September.

Argonne, 2013a, KDHE Project C6-074-00002: Progress and Monitoring Report for the LDB/SVE/AS Interim Measure at the Former CCC/USDA Grain Storage Facility, Agra, Kansas, in July-December 2012, ANL/EVS/AGEM/CHRON-1591, prepared for the Commodity Credit Corporation, U.S. Department of Agriculture, by Argonne National Laboratory, Argonne, Illinois, February.

Argonne, 2013b, KDHE Project C6-074-00002: Progress and Monitoring Report for the LDB/SVE/AS Interim Measure at the Former CCC/USDA Grain Storage Facility, Agra, Kansas, in January-June 2013, ANL/EVS/AGEM/CHRON-1640, prepared for the Commodity Credit Corporation, U.S. Department of Agriculture, by Argonne National Laboratory, Argonne, Illinois, November.

Argonne, 2014a, KDHE Project C6-074-00002: Progress and Monitoring Report for the LDB/SVE/AS Interim Measure at the Former CCC/USDA Grain Storage Facility, Agra, Kansas, in July-December 2013, ANL/EVS/AGEM/CHRON-1681, prepared for the Commodity Credit Corporation, U.S. Department of Agriculture, by Argonne National Laboratory, Argonne, Illinois, March.

Argonne, 2014b, KDHE Project C6-074-00002: Progress and Monitoring Report for the LDB/SVE/AS Interim Measure at the Former CCC/USDA Grain Storage Facility, Agra, Kansas, in January-June 2014, ANL/EVS/AGEM/CHRON-1755, prepared for the Commodity Credit Corporation, U.S. Department of Agriculture, by Argonne National Laboratory, Argonne, Illinois, August.

Argonne, 2014c, Sitewide Monitoring at Agra, Kansas, in 2013, ANL/EVS/AGEM/TR-13-11, prepared for the Commodity Credit Corporation, U.S. Department of Agriculture, by Argonne National Laboratory, Argonne, Illinois, May.

Argonne, 2015a, KDHE Project C6-074-00002: Progress and Monitoring Report for the LDB/SVE/AS Interim Measure at the Former CCC/USDA Grain Storage Facility, Agra, Kansas, in July-December 2014, ANL/EVS/AGEM/CHRON-1847, prepared for the Commodity Credit 
Corporation, U.S. Department of Agriculture, by Argonne National Laboratory, Argonne, Illinois, May.

Argonne, 2015b, KDHE Project C6-074-00002: Progress and Monitoring Report for the LDB/SVE/AS Interim Measure at the Former CCC/USDA Grain Storage Facility, Agra, Kansas, in January-June 2015, ANL/EVS/AGEM/CHRON-1913, prepared for the Commodity Credit Corporation, U.S. Department of Agriculture, by Argonne National Laboratory, Argonne, Illinois, September.

Argonne, 2016a, KDHE Project C6-074-00002: Progress and Monitoring Report for the LDB/SVE/AS Interim Measure at the Former CCC/USDA Grain Storage Facility, Agra, Kansas, in July-December 2015, ANL/EVS/AGEM/CHRON-1959, prepared for the Commodity Credit Corporation, U.S. Department of Agriculture, by Argonne National Laboratory, Argonne, Illinois, February.

Argonne, 2016b, KDHE Project C6-074-00002: Progress and Monitoring Report for the LDB/SVE/AS Interim Measure at the Former CCC/USDA Grain Storage Facility, Agra, Kansas, in January-June 2016, ANL/EVS/AGEM/CHRON-2042, prepared for the Commodity Credit Corporation, U.S. Department of Agriculture, by Argonne National Laboratory, Argonne, Illinois, September.

Argonne, 2016c, Sitewide Monitoring at Agra, Kansas, in 2015, ANL/EVS/AGEM/TR-16-07, prepared for the Commodity Credit Corporation, U.S. Department of Agriculture, by Argonne National Laboratory, Argonne, Illinois, May.

Argonne National Laboratory, unpublished information, 2016d.

Argonne, 2016e, Utica Ten-Year Summary and Evaluation of Operations and Performance of the Utica Aquifer and North Lake Basin Wetlands Restoration Project, 2004-2014, ANL/EVS/AGEM/TR-16-09, prepared for the Commodity Credit Corporation, U.S. Department of Agriculture, by Argonne National Laboratory, Argonne, Illinois, August.

Argonne, 2017, KDHE Project C6-074-00002: Progress and Monitoring Report for the LDB/SVE/AS Interim Measure at the Former CCC/USDA Grain Storage Facility, Agra, Kansas, in July-December 2016, ANL/EVS/AGEM/CHRON-2107, prepared for the Commodity Credit 
Corporation, U.S. Department of Agriculture, by Argonne National Laboratory, Argonne, Illinois, February.

Argonne, 2018a, Results of Temporary Shutdown Testing and Groundwater Pump-Testing at Agra Kansas, February-September 2016 and March 2017, ANL/EVS/AGEM/TR-18-03, prepared for the Commodity Credit Corporation, U.S. Department of Agriculture, by Argonne National Laboratory, Argonne, Illinois, May.

Argonne, 2018b, KDHE Project C6-074-00002: Progress and Monitoring Report for the LDB/SVE/AS Interim Measure at the Former CCC/USDA Grain Storage Facility, Agra, Kansas, in January-June 2017, ANL/EVS/AGEM/CHRON-2157, prepared for the Commodity Credit Corporation, U.S. Department of Agriculture, by Argonne National Laboratory, Argonne, Illinois, March.

Argonne National Laboratory, unpublished data, 2018c.

BE\&K, 1998a, Phase I Corrective Action Study: Agra Public Water Supply, Agra, Kansas, prepared for the Kansas Department of Health and Environment, Topeka, KS by BE\&K/Terranext, July.

BE\&K, 1998b, Groundwater Monitoring Report: Agra Public Water Supply, Agra, Kansas, prepared for the Kansas Department of Health and Environment, Topeka, KS by BE\&K/Terranext, November.

BE\&K, 1999, Groundwater Monitoring Report: Agra Public Water Supply, Agra, Kansas, prepared for the Kansas Department of Health and Environment, Topeka, KS by BE\&K/Terranext, June.

Boyden, G.H., D.T. Banh, and H.K. Huckabay, 1990, Stripping Chlorinated VOCs from Drinking Water Via Inclined Cascade Aeration, 19th Australasian Chemical Engineer Conference, Chemeca 90, 27 and 30th August, Auckland New Zealand.

CCA, 2018, North Lake Basin Wetlands Restoration, published online by Cooperative Conservation America. Accessed April 2018, www.cooperativeconservation.org/ viewproject.aspx?id=517. 
EPA, 1988, Guidance for Conducting Remedial Investigations and Feasibility Studies under CERCLA, Interim Final, EPA/540/G-89/004, OSWER Directive 9355.3-01, U.S. Environmental Protection Agency, Washington, D.C., October.

EPA, 1990, National Oil and Hazardous Substances Contingency Plan: Final Rule (40 CFR Part 300), U.S. Environmental Protection Agency, Washington, D.C.

EPA, 2002, Evaluation of Permeable Reactive Barrier Performance, prepared for the Federal Remediation Technologies Roundtable by the Tri-Agency Permeable Reactive Barrier Institute, U.S. Department of Defense, U.S. Department of Energy, U.S. Environmental Protection Agency, and the Interstate Technology and Regulatory Council, December 9.

Frye, J.C., and AB. Leonard, 1965, “Quaternary of the Southern Great Plains,” pp. 203-216 in H.E. Wright, Jr., and D.C. Frey, editors, The Quaternary of the United States, Princeton University Press, Princeton, New Jersey.

Hocking, G., 2004, “Deep Permeable Reaction Barriers,” Pollution Engineering, March 1.

KDHE, 1985, letter to the Mayor and City Council of Agra from S.P. McCool, Technical Services Section, Bureau of Water Protection, Kansas Department of Health and Environment, Topeka, Kansas, reporting results of KDHE sampling of Agra public wells, December 26.

KDHE, 1987, Preliminary Assessment Report for Agra Public Water Supply Wells \#3 and \#4, KSD981710262, Agra, Kansas 67621, Kansas Department of Health and Environment, Bureau of Environmental Remediation, December.

KDHE, 1988, Final Site Inspection Report for the Agra Public Water Supply Wells \#3 and \#4, KSD981710262, Agra, Kansas, Kansas Department of Health and Environment, Bureau of Environmental Remediation, July.

KDHE, 1998, Phase I Corrective Action Study, Agra Public Water Supply, Agra, Kansas, prepared for the Kansas Department of Health and Environment, Topeka, Kansas, by BE\&K Terranext, Lenexa, Kansas, July. 
KDHE, 2001a, Scope of Work for a Corrective Action Study, Policy BER-RS-019, Remedial Section, Bureau of Environmental Remediation, Kansas Department of Health and Environment, Topeka, Kansas, March 29.

KDHE, 2001b, Reclassification Plan, Policy BER-RS-024, Remedial Section, Bureau of Environmental Remediation, Kansas Department of Health and Environment, Topeka, Kansas, December 19.

KDHE, 2002, Standards for Property Identification for Issuance of No Further Action Determinations, Policy BER-RS-VCP-003, Remedial Section, Bureau of Environmental Remediation, Kansas Department of Health and Environment, Topeka, Kansas, August 7.

KDHE, 2004, letter from L. Gotto, Bureau of Environmental Remediation, Kansas Department of Health and Environment, Topeka, Kansas, to C. Roe, Commodity Credit Corporation, U.S. Department of Agriculture, Washington, D.C., regarding completion of the feasibility study for remedial action at Agra, March 1.

KDHE, 2005a, Kansas Statutes Pertaining to Public Water Supply, Department of Water, Kansas Department of Health and Environment, Topeka, Kansas, January.

KDHE, 2005b, “KDHE’s Environmental Use Control Program,” Section 19 in Voluntary Cleanup and Property Redevelopment Program (VCPRP) Manual, Remedial Section, Bureau of Environmental Remediation, Kansas Department of Health and Environment, Topeka, Kansas, May 20.

KDHE, 2005c, Potential Applicable or Relevant and Appropriate Requirements (ARARs), Policy BER-RS-015, Remedial Section, Bureau of Environmental Remediation, Kansas Department of Health and Environment, Topeka, Kansas, August 9.

KDHE, 2005d, Evaluating Future Land Use, Policy BER-RS-005, Remedial Section, Bureau of Environmental Remediation, Kansas Department of Health and Environment, Topeka, Kansas, December 19. 
KDHE, 2005e, Consideration for Hydraulic Containment, Policy BER-RS-028, Bureau of Environmental Remediation, Kansas Department of Health and Environment, Topeka, Kansas, December 27.

KDHE, 2005e, Considerations for Remedial Standards, Policy BER-RS-033, Remedial Section, Bureau of Environmental Remediation, Kansas Department of Health and Environment, Topeka, Kansas, December 30.

KDHE, 2007, Kansas Vapor Intrusion Guidance - Chemical Vapor Intrusion and Residential Indoor Air, Remedial Section, Bureau of Environmental Remediation, Kansas Department of Health and Environment, Topeka, Kansas, June 22.

KDHE, 2008, Consent Order Case No. 07-E-0028, Pollution at Producers Agricultural Marketing Association, Inc. Site, Agra, Kansas, Kansas Department of Health and Environment, Topeka, Kansas, April 2.

KDHE, 2013, Scope of Work (SOW) for a Corrective Action Plan (CAP)/Corrective Action (CA), Policy BER-RS-023, Remedial Section, Bureau of Environmental Remediation, Kansas Department of Health and Environment, Topeka, Kansas June.

KDHE, 2014, Presumptive Remedy Policy, Investigation and Cleanup of Nitrogen at AgricultureRelated Sites in Kansas, Policy BER-RS-047, Bureau of Environmental Remediation, Kansas Department of Health and Environment, Topeka, Kansas, December 14.

KDHE, 2015, Application for an Environmental Use Control for property located in the State of Kansas, Version 8.0, May 20.

KDHE, 2017a, Drinking Water Watch (KDWW), Kansas Department of Health and Environment, Bureau of Water, Public Water Supply Section, Topeka, Kansas. Accessed October 11. (http://165.201.142.59:8080/DWW/KSindex.jsp.)

KDHE, 2017b, Pro Ag Agra - Project Code C607472376, information provided in the Identified Sites List, Kansas Department of Health and Environment, Bureau of Remediation, Topeka, Kansas. Accessed October 11. (http://kensas.kdhe.state.ks.us/plsISL/ISL_Pub_Detail?id= C607472376.) 
MSPA and CCC/USDA, 2008, Authorization and License, an agreement signed by J. Golden, Chairman of the Board of Directors, Mid-States Port Authority; B. Van Easton, a resident of the City of Agra; D. Graf, President, Producers Agricultural Marketing Association, Inc.; and J. Johnson, Deputy Administrator for Farm Programs, Farm Service Agency, and Deputy Vice President, Commodity Credit Corporation, U.S. Department of Agriculture, entered August 8.

NAIP, 2015, base map satellite images in 1961, 1985, and 2015, obtained from the National Agriculture Imagery Program, Aerial Photography Field Office, Farm Service Agency of the U.S. Department of Agriculture, Salt Lake City, Utah.

PRC, 1994, Agra Public Water Supply Site, Agra, Phillips County Final Site Assessment, prepared by PRC Environmental Management, Inc. for the Kansas Department of Health and Environment, Topeka, KS, July.

PRC, 1995, Final Comprehensive Investigation of Agra Public Water Supply Site, Agra, Phillips County, Kansas, prepared by PRC Environmental Management, Inc. for the Kansas Department of Health and Environment, Topeka, KS, November.

Pro Ag, 2009, Forms WWC-5 for monitoring wells PMW01-PMW07, filed with the Kansas Department of Health and Environment, Bureau of Water, Topeka, Kansas, August. Available online from the Kansas Geological Survey: http://www.kgs.ku.edu/Magellan/WaterWell.

Pro Ag, 2010a, Pro Ag Marketing Site, Agra, Kansas Water Well Survey Report, Consent Order \#07-E-0028, prepared by Allied Environmental Consultants, Inc., Topeka, Kansas, for Producers Agricultural Marketing Association, Inc., Kensington, Kansas, June.

Pro Ag, 2010b, Pro Ag Marketing Agra Branch 2010 Annual Monitoring Report, Consent Order \#07-E-0028, KDHE Project Code \#C607472376, prepared by Allied Environmental Consultants, Inc., Topeka, Kansas, for Producers Agricultural Marketing Association, Inc., Kensington, Kansas, October.

Pro Ag, 2011, Pro Ag Marketing, Inc. Agra, Kansas Vapor Intrusion Assessment Work Plan, KDHE File \#07-E-0028, prepared by Allied Environmental Consultants, Inc., Topeka, Kansas, for Producers Agricultural Marketing Association, Inc., Kensington, Kansas, December. 
Pro Ag, 2012a, Pro Ag Marketing Agra, Kansas Facility Addendum to Vapor Intrusion Assessment Work Plan, Consent Order \#07-E-0028, prepared by Allied Environmental Consultants, Inc., Topeka, Kansas, for Producers Agricultural Marketing Association, Inc., Kensington, Kansas, January.

Pro Ag, 2012b, Pro Ag Marketing, Inc. Agra, Kansas Vapor Intrusion Assessment Report, KDHE File \#07-E-0028, prepared by Allied Environmental Consultants, Inc., Topeka, Kansas, for Producers Agricultural Marketing Association, Inc., Kensington, Kansas, March.

Pro Ag, 2012c, Pro Ag Marketing Agra Branch 2012 Annual Monitoring Report, Consent Order \#07-E-0028, KDHE Project Code \#C607472376, prepared by Allied Environmental Consultants, Inc., Topeka, Kansas, for Producers Agricultural Marketing Association, Inc., Kensington, Kansas, September.

Pro Ag, 2014, Pro Ag Marketing Agra Branch 2014 Annual Monitoring Report, Consent Order \#07-E-0028, KDHE Project Code \#C607472376, prepared by Allied Environmental Consultants, Inc., Topeka, Kansas, for Producers Agricultural Marketing Association, Inc., Kensington, Kansas, August.

Reed, E.C., V.H. Dreeszen, C.K. Bayne, and C.B. Schultz, 1965, "The Pleistocene in Nebraska and northern Kansas,” in The Quaternary of the United States, H.E. Wright, Jr. and D.G. Frey, D., editors, Princeton Univ. Press, Princeton, N. J., pp. 187-202.

Spalding, R.F., M.E. Burbach, M.E. Exner, L. Parra-Vicary, D.R. Alexander, 1995, "Sprinkler Irrigation: A Volatile Organic Compound Remediation Alternative," University of Nebraska Water Center/Environmental Research Briefs, Volume 3, No 1, April. 


\section{Appendix A:}

Pro Ag Water Well Survey Results 
TABLE A.1 Summary of the Pro Ag water well survey, 2010

\begin{tabular}{|c|c|c|c|}
\hline Homeowner's Name & Address & $\begin{array}{c}\text { Well on } \\
\text { Premises? }\end{array}$ & Well Use ${ }^{4}$ \\
\hline Lloyd Kleinschmidt & 936 Kansas Avenue & Yes & Lawn and garden only \\
\hline Russell Rose & 148 Maine Street & Yes & Lawn and garden only \\
\hline Troy Ward & $1514^{\text {th }}$ Street & Yes & Lawn and garden only \\
\hline Lauren Holle & -1 & Yes & Lawn and garden only \\
\hline Jeanette Hakett & $1194^{\text {th }}$ Street & Yes & Lawn and garden only \\
\hline Elaine Portenier & $2204^{\text {th }}$ Street & Yes & Not in use \\
\hline Chris Atchison & $16686^{\text {th }}$ Street & Yes & Not in use \\
\hline Betty McCormack & $14606^{\text {th }}$ Street & Yes & Lawn and garden only \\
\hline Jeanette Stevens & 773 Kansas Avenue & Yes & Lawn and garden only \\
\hline Marcia Horn & $3083^{\text {rd }}$ Street & Yes & Not in use \\
\hline Daryl and Linda Dougherty & 112 Main Street & Yes & Not in use \\
\hline Jim Wilson & - & Unknown & (a) \\
\hline Jim Wilson & $2113^{\text {rd }}$ Street & Unknown & (a) \\
\hline Tony Jurey & $3316^{\text {th }}$ Street & Unknown & (b) \\
\hline Wanneta Abbott & $1354^{\text {th }}$ Street & Unknown & (c) \\
\hline Vickie Townsend & 840 Kansas Avenue & Unknown & (b) \\
\hline Wayne and Tammy Fox & 124 Main Street & Unknown & (a) \\
\hline Wayne and Tammy Fox & $2434^{\text {th }}$ Street & Unknown & (a) \\
\hline - & 790 Kansas Avenue & Unknown & (b) \\
\hline Garen Dierchs & $2664^{\text {th }}$ Street & Unknown & (a) \\
\hline Rodney Linton & 924 Kansas Avenue & Unknown & (b) \\
\hline Abbott & 175 Main Street & Unknown & (b) \\
\hline Barbara Slavens & 136 Main Street & Unknown & (d) \\
\hline Barbara Slavens & $2483^{\text {rd }}$ Street & Unknown & (d) \\
\hline Barbara Slavens & $2323^{\text {rd }}$ Street & Unknown & (d) \\
\hline Jay Atchison & - & Unknown & (b) \\
\hline Kurtis Smith & 630 Southern Avenue & Unknown & (a) \\
\hline- & 515 Kansas Avenue & Unknown & (b) \\
\hline Michael Palin & 618 Southern Avenue & Unknown & (b) \\
\hline George Russell & Main Street ${ }^{2}$ & Unknown & (b) \\
\hline Russell Simmons & 431 Southern Avenue & Unknown & - \\
\hline Gordon Bros. Construction & 319 Main Street & No & - \\
\hline City of Agra & 309 Main Street & No & (b) \\
\hline City of Agra & 311 Main Street & No & (b) \\
\hline Ali Bell & 417 and 419 Main Street & No & - \\
\hline Dean Bell & 630 Kansas Avenue & No & - \\
\hline Joanie Bass & 140 Main Street & No & - \\
\hline Frank's Radiator & 555 Frontage Road & No & - \\
\hline Frank Beach & 215 Main Street & No & - \\
\hline John Saddler & $3402^{\text {nd }}$ Street & No & - \\
\hline John Saddler & $3302^{\text {nd }}$ Street & No & - \\
\hline Betty DeRentis & $2674^{\text {th }}$ Street & No & - \\
\hline Dan Losey & $2314^{\text {th }}$ Street & No & - \\
\hline Edna Powell & 702 Southern Avenue & No & - \\
\hline BIH Plumbing \& Electric Inc. & 919 Frontage Road & No & - \\
\hline Becky Dougherty & $3544^{\text {th }}$ Street & No & - \\
\hline Micky Barnes & 121 Main Street & No & - \\
\hline Nicolas Haskett & $1034^{\text {th }}$ Street & No & - \\
\hline Farmers National Bank & 302 Main Street & No & - \\
\hline Debbie Cooper & 111 Main Street & No & - \\
\hline
\end{tabular}


TABLE A.1 (Cont.)

\begin{tabular}{|c|c|c|c|}
\hline Rejean Henry & 731 Frontage Road & No & - \\
\hline Betty Gitchel & $1134^{\text {th }}$ Street & No & - \\
\hline Charles Mott & $2484^{\text {th }}$ Street & No & - \\
\hline Charles Mott & $1434^{\text {th }}$ Street & No & - \\
\hline USD 110 & $1914^{\text {th }}$ Street & No & - \\
\hline Linda McDowell & $1744^{\text {th }}$ Street & No & - \\
\hline Linda McDowell & $2104^{\text {th }}$ Street & No & - \\
\hline Ronald Tyurell & $2764^{\text {th }}$ Street & No & - \\
\hline Carolyn Jurey & 810 Kansas Avenue & No & - \\
\hline Bonita Smith & 750 Kansas Avenue & No & - \\
\hline Tory A. Wilbur & 753 Kansas Avenue & No & - \\
\hline Connie Gordon & Main Street ${ }^{2}$ & No & - \\
\hline Lee Walker & 915 Railroad Avenue & No & - \\
\hline Scott and Kelly Bretton & $3516^{\text {th }}$ Street & No & - \\
\hline Merle Barnes & $3243^{\text {rd }}$ Street & No & - \\
\hline Agra City Mayor & 555 Southern Avenue & No & - \\
\hline Anthony Rybeck & 761 Kansas Avenue & No & - \\
\hline Arlau Johnson & $3073^{\text {rd }}$ Street & No & - \\
\hline Debbie Hill & $2293^{\text {rd }}$ Street & No & - \\
\hline Jim Wheelbargor & 747 Kansas Avenue & No & - \\
\hline Lisa H. DeLange & 245 W. $3^{\text {rd }}$ Street & No & - \\
\hline Midwest Endine and Welding & 545 Frontage Road & No & - \\
\hline John Iman & $3153^{\text {rd }}$ Street & No & - \\
\hline Ronald J.Conrad/Farr & $3403^{\text {rd }}$ Street & No & - \\
\hline Church of Christ & 406 Kansas Avenue & No & - \\
\hline Darel L. Reynolds & 145 Main Street & No & - \\
\hline Janet Devena & 151 Main Street & No & - \\
\hline Trent Giles & 160 Main Street & No & - \\
\hline Michael Nix & 154 Main Street & No & - \\
\hline Larry L. Hall & 171 Main Street & No & - \\
\hline Virginia Abbott & 221 Main Street & No & (b) \\
\hline Fineline Collision & 231 Main Street & No & - \\
\hline Wanda McKinnis & 516 Kansas Avenue & No & - \\
\hline Toby and Melissa Boyle & $3502^{\text {nd }}$ Street & No & - \\
\hline Michael Baelz & 427 Southern Avenue & No & - \\
\hline Duane Peterson & 435 Southern Avenue & No & - \\
\hline Lannie Nelson & 205 Main Street & No & - \\
\hline Virginia Munyon & 409 Southern Avenue & No & - \\
\hline Linda Diercks & 530 Southern Avenue & No & - \\
\hline Linda Stan Schmidt & $3461^{\text {st }}$ Street & No & - \\
\hline Sarah Molzahr & 408 Southern Avenue & No & - \\
\hline Patricia Walters & 178 Main Street & No & - \\
\hline Jeff Bouchard & 425 Kansas Avenue & No & (b) \\
\hline New Peoples Store & 315 Main Street & No & - \\
\hline Agra American Legion & 331 Main Street & No & - \\
\hline Burton Van Eaton & $\begin{array}{l}555 \text { Southern Avenue } \\
\text { (Apt 8) }\end{array}$ & No & - \\
\hline Judith Forell & $3512^{\text {nd }}$ Street & No & - \\
\hline Roberta Quanz and Myron & & & \\
\hline McCormack & 405 Kansas Avenue & No & - \\
\hline Mark Kaiser & 434 Kansas Avenue & No & - \\
\hline Old Library & 330 Main Street & No & (b) \\
\hline David Otis & 545 Kansas Avenue & No & - \\
\hline Kendra Cariad & Main Street & No & - \\
\hline Elaine Mooney & Main Street & No & - \\
\hline
\end{tabular}


TABLE A.1 (Cont.)

\begin{tabular}{llll}
\hline Betty Sidman & Main Street & No & - \\
Arlond Barnes & Main Street & No & - \\
Tom Heersick & Main Street & No & - \\
Kristina Shaw & 609 Frontage Road & No & - \\
Thunder Ridge Middle School & 941 Kansas Avenue & Yes $^{3}$ & Lawn and garden only \\
\hline
\end{tabular}

${ }^{1} \mathrm{~A}$ dash indicates that information was either not available or not applicable.

${ }^{2}$ The street number was not available.

${ }^{3}$ This entry is assumed to be "yes" because the table identifies a possible lawn and garden well on the property.

${ }^{4}$ Entries are defined as (a) resident was not home at the time of the survey; (b) property is vacant; (c) occupant refused to answer the door; and (d) address is a rental property.

Source: Pro Ag (2010a). 


\section{Appendix B:}

Potential Federal and State ARARs and State Guidance Documents "To Be Considered" 
TABLE B.1 Determination of potential federal ARARs and guidance to be considered for the former CCC/USDA facility at Agra.

\begin{tabular}{|c|c|c|c|c|c|}
\hline Title & Citation $^{a}$ & Description & Comment & Type $^{b}$ & Determination \\
\hline $\begin{array}{l}\text { Comprehensive Environmental } \\
\text { Response, Compensation, and } \\
\text { Liability Act (CERCLA) }\end{array}$ & $\begin{array}{l}42 \text { USC } 9601 \\
\text { et seq. }\end{array}$ & & & $A$ & $\begin{array}{l}\text { Relevant and } \\
\text { appropriate }\end{array}$ \\
\hline $\begin{array}{l}\text { National Oil and Hazardous } \\
\text { Substances Pollution } \\
\text { Contingency Plan (NCP) }\end{array}$ & 40 CFR Part 300 & $\begin{array}{l}\text { Provides the federal government's blueprint for } \\
\text { responding to both oil spills and hazardous } \\
\text { substance releases. }\end{array}$ & $\begin{array}{l}\text { Applicable to releases } \\
\text { into the environment of } \\
\text { hazardous substances } \\
\text { and pollutants or } \\
\text { contaminants that may } \\
\text { present an imminent and } \\
\text { substantial danger to } \\
\text { public health or the } \\
\text { national welfare. }\end{array}$ & $A$ & $\begin{array}{l}\text { Relevant and } \\
\text { appropriate }\end{array}$ \\
\hline Off-Site Rule & 40 CFR 300.440 & $\begin{array}{l}\text { Establishes procedures for planning and } \\
\text { implementing off-site response actions. }\end{array}$ & $\begin{array}{l}\text { Applicable to response } \\
\text { actions involving off-site } \\
\text { transfers of hazardous } \\
\text { substances, pollutants, } \\
\text { or contaminants. }\end{array}$ & A & $\begin{array}{l}\text { Relevant and } \\
\text { appropriate }\end{array}$ \\
\hline $\begin{array}{l}\text { Emergency Planning and } \\
\text { Community Right-to-Know } \\
\text { Regulations }\end{array}$ & $\begin{array}{l}49 \text { CFR } 350,355 \\
\text { and } 372\end{array}$ & $\begin{array}{l}\text { Allows state and local planning for chemical } \\
\text { emergencies, provides for notification of } \\
\text { emergency releases of chemicals, and addresses } \\
\text { communities' right to information about toxic and } \\
\text { hazardous chemicals. }\end{array}$ & $\begin{array}{l}\text { Applicable if hazardous } \\
\text { chemicals are stored or } \\
\text { otherwise used as part of } \\
\text { the corrective action. }\end{array}$ & $A$ & $\begin{array}{l}\text { Relevant and } \\
\text { appropriate }\end{array}$ \\
\hline $\begin{array}{l}\text { Safe Drinking Water Act (SDWA) } \\
\text { (Public Health Service Act) }\end{array}$ & $\begin{array}{l}42 \text { USC } 300(f) \\
\text { et seq. }\end{array}$ & & & $A$ & $\begin{array}{l}\text { Relevant and } \\
\text { appropriate }\end{array}$ \\
\hline $\begin{array}{l}\text { National Primary Drinking } \\
\text { Water Standards }\end{array}$ & $\begin{array}{l}40 \text { CFR Part 141, } \\
\text { Subparts B } \\
\text { and G }\end{array}$ & $\begin{array}{l}\text { Establishes MCLs, which are health-based } \\
\text { standards for public water systems. The MCL for } \\
\text { carbon tetrachloride is } 5 \mu \mathrm{g} / \mathrm{L} \text {. The MCL for } \\
\text { chloroform (total trihalomethanes) is } 80 \mu \mathrm{g} / \mathrm{L} \text {. }\end{array}$ & $\begin{array}{l}\text { Applicable at the tap to } \\
\text { organic groundwater } \\
\text { contamination in a sole- } \\
\text { source aquifer. }\end{array}$ & & \\
\hline
\end{tabular}




\begin{tabular}{|c|c|c|c|c|c|}
\hline Title & Citation ${ }^{a}$ & Description & Comment & Type $^{b}$ & Determination \\
\hline \multicolumn{6}{|l|}{ Safe Drinking Water Act (cont.) } \\
\hline $\begin{array}{l}\text { National Secondary Drinking } \\
\text { Water Regulations (NSDWRs) }\end{array}$ & 40 CFR Part 143 & $\begin{array}{l}\text { Establishes secondary maximum contaminant } \\
\text { levels (SMCLs) for public water systems to } \\
\text { protect the aesthetic quality of the water. The } \\
\text { SMCLs are not federally enforceable but are } \\
\text { intended as guidelines for the states. }\end{array}$ & $\begin{array}{l}\text { Applicable if } \\
\text { groundwater is a source } \\
\text { of drinking water and if } \\
\text { the NSDWRs have been } \\
\text { adopted as enforceable } \\
\text { standards by the state. }\end{array}$ & $A, C$ & $\begin{array}{l}\text { Relevant and } \\
\text { appropriate }\end{array}$ \\
\hline $\begin{array}{l}\text { Maximum Contaminant Level } \\
\text { Goals (MCLGs) }\end{array}$ & $\begin{array}{l}40 \text { CFR Part 141, } \\
\text { Subpart F }\end{array}$ & $\begin{array}{l}\text { Establishes non-enforceable drinking water } \\
\text { quality goals at levels of no known or anticipated } \\
\text { adverse health effects, with an adequate margin } \\
\text { of safety. The MCLG for carbon tetrachloride is } \\
\text { zero. }\end{array}$ & $\begin{array}{l}\text { May be relevant and } \\
\text { appropriate if a more } \\
\text { stringent standard is } \\
\text { required to protect } \\
\text { human health and the } \\
\text { environment. }\end{array}$ & C & $\begin{array}{l}\text { Relevant and } \\
\text { appropriate }\end{array}$ \\
\hline $\begin{array}{l}\text { Standards for Owners and } \\
\text { Operators of Public Water } \\
\text { Supply Systems }\end{array}$ & 40 CFR Part 141 & $\begin{array}{l}\text { Provides treatment requirements for public water } \\
\text { supply systems (i.e., systems that serve at least } \\
25 \text { people or have at least } 15 \text { connections). }\end{array}$ & $\begin{array}{l}\text { Relevant and } \\
\text { appropriate in the } \\
\text { establishment of cleanup } \\
\text { goals for groundwater } \\
\text { contamination. }\end{array}$ & $A$ & $\begin{array}{l}\text { Relevant and } \\
\text { appropriate }\end{array}$ \\
\hline $\begin{array}{l}\text { Underground Injection Control } \\
\text { Regulations }\end{array}$ & $\begin{array}{l}40 \text { CFR Parts 144- } \\
148\end{array}$ & $\begin{array}{l}\text { Provides for protection of underground sources of } \\
\text { drinking water. }\end{array}$ & $\begin{array}{l}\text { Applicable if a response } \\
\text { alternative involves } \\
\text { underground injection. }\end{array}$ & $A$ & Not an ARAR \\
\hline Sole-Source Aquifers & 40 CFR Part 149 & $\begin{array}{l}\text { Prohibits activities, including drilling, in an area } \\
\text { designated a sole-source aquifer without special } \\
\text { permission of the EPA. }\end{array}$ & $\begin{array}{l}\text { Applicable if the aquifer } \\
\text { in the area is a sole- } \\
\text { source aquifer. }\end{array}$ & $A, L$ & Not an ARAR \\
\hline
\end{tabular}

Maximum Contaminant Level Goals (MCLGs)

Standards for Owners and Operators of Public Water Supply Systems permission of the EPA. 


\begin{tabular}{|c|c|c|c|c|c|}
\hline Title & Citation ${ }^{a}$ & Description & Comment & Type ${ }^{b}$ & Determination \\
\hline $\begin{array}{l}\text { Clean Water Act (CWA) (Federal } \\
\text { Water Pollution Control Act) }\end{array}$ & $\begin{array}{l}33 \text { USC } 1251 \\
\text { et seq. }\end{array}$ & & & $A, C$ & $\begin{array}{l}\text { Relevant and } \\
\text { appropriate }\end{array}$ \\
\hline Ambient Water Quality Criteria & 40 CFR Part 131 & $\begin{array}{l}\text { Establishes ambient water quality criteria } \\
\text { (AWQCS) reflecting "the latest scientific } \\
\text { knowledge ... . on the kind and extent of all } \\
\text { identifiable effects on health and welfare } \\
\text { including, but not limited to, plankton, fish, } \\
\text { shellfish, wildlife, plant life ... which may be } \\
\text { expected from the presence of pollutants in any } \\
\text { body of water. ..." Water quality criteria are } \\
\text { based solely on data and scientific judgments on } \\
\text { the relationship between pollutant concentrations } \\
\text { and environmental and human health effects. } \\
\text { These recommended criteria provide guidance for } \\
\text { states and tribes in adopting water quality } \\
\text { standards under Section } 303 \text { (c) of the CWA [33 } \\
\text { USC } 1313(\mathrm{c})] \text {. }\end{array}$ & $\begin{array}{l}\text { Developed for some } \\
\text { organic constituents in } \\
\text { groundwater; may be } \\
\text { relevant and appropriate. }\end{array}$ & $\mathrm{C}$ & $\begin{array}{l}\text { Relevant and } \\
\text { appropriate }\end{array}$ \\
\hline $\begin{array}{l}\text { National Pollutant Discharge } \\
\text { Elimination System (NPDES) }\end{array}$ & $\begin{array}{l}40 \text { CFR Parts } \\
122-125\end{array}$ & $\begin{array}{l}\text { Establishes NPDES permit procedures, criteria, } \\
\text { and standards governing the discharge of } \\
\text { pollutants from any point source into U.S. waters } \\
\text { [Sections } 318,402 \text {, and } 405 \text { of the CWA ( } 33 \text { USC } \\
1328,1342,1345) \text { ]. Most storm water discharges } \\
\text { require coverage by an NPDES permit. }\end{array}$ & $\begin{array}{l}\text { Discharge limits will be } \\
\text { established if effluent is } \\
\text { discharged to a surface } \\
\text { water body. No permit is } \\
\text { required for on-site } \\
\text { response actions under } \\
\text { CERCLA, but the } \\
\text { substantive requirements } \\
\text { apply if a response } \\
\text { alternative involves } \\
\text { discharge into a creek or } \\
\text { other surface water on- } \\
\text { site. A permit is required } \\
\text { if the discharge is to a } \\
\text { creek or other surface } \\
\text { water off-site. }\end{array}$ & $A, C$ & $\begin{array}{l}\text { Relevant and } \\
\text { appropriate }\end{array}$ \\
\hline
\end{tabular}

body of water. ..."Water quality criteria are

These recommended criteria provide guidance for

and tribes in adopting water quality

che

Establishes NPDES permit procedures, criteria,

and standards governing the discharge of

328, 1342, 1345)]. Most storm water discharges

require coverage by an NPDES permit. ablished if effluent is required for on-site CERCLA, but the if a response water off-site. 


\begin{tabular}{ccc}
\hline Title & Citation & Description \\
\hline
\end{tabular}

\section{Clean Water Act (cont.)}

Storm Water Discharge Requirements

Water Quality Standards

National Pretreatment Standards

Dredge or Fill Requirements Protection of Wetlands
40 CFR 122.26

Establishes requirements to obtain a permit to discharge storm water under the NPDES program.

40 CFR Part 131 Defines goals for a water body by designating the water body's uses, setting criteria to protect those uses, and establishing provisions to protect water bodies from pollutants. Forms the foundation of the water-quality-based pollution control program

40 CFR Part 403 Provides general pretreatment standards and regulations for existing and new sources of pollution; establishes standards to control pollutants that pass through or interfere with treatment processes in publicly owned treatment works (POTWs) or that may contaminate sewage sludge.

40 CFR Parts 230233

[40 CFR Part

6.302(a)]

EO 11990

[40 CFR Part 6.302(a)]

Requires permits for discharge of dredged or fill material into navigable waters.

Requires federal agencies to avoid, to the extent destruction or loss of wetlands and to avoid mandated by the CWA.

Applicable if a response possible, adverse impacts associated with the support of new construction in wetlands if a practicable alternative exists.
Applicable to surface water discharges of storm water.

Applicable to surface water discharges. alternative involves discharge to POTWs.

A Relevant and appropriate

C Relevant and appropriate

A, C Not an ARAR

Applicable if a response alternative requires

discharge of dredged or fill material into navigable waters.

Applicable if a response alternative has a negative effect on wetlands.

\section{A Not an ARAR}

A, L Relevant and appropriate 


\begin{tabular}{|c|c|c|c|c|c|}
\hline Title & Citation $^{a}$ & Description & Comment & Type & Determination \\
\hline Rivers and Harbors Act of 1899 & 33 USC 401 et seq. & & & $A$ & Not an ARAR \\
\hline Section 10 Permit & $\begin{array}{l}33 \text { USC } 403 \\
33 \text { CFR Parts } 320- \\
330 \\
{[40 \text { CFR Part }} \\
6.302(a)]\end{array}$ & $\begin{array}{l}\text { Requires a permit for structures for work in or } \\
\text { affecting navigable waters. }\end{array}$ & $\begin{array}{l}\text { Applicable if a response } \\
\text { alternative affects a } \\
\text { navigable waterway. }\end{array}$ & $A, L$ & Not an ARAR \\
\hline $\begin{array}{l}\text { Executive Order on Floodplain } \\
\text { Management }\end{array}$ & $\begin{array}{l}\text { EO } 11988 \\
{[40 \text { CFR Part }} \\
6.302(b)]\end{array}$ & $\begin{array}{l}\text { Requires federal agencies to evaluate the } \\
\text { potential effects of actions in a floodplain to avoid, } \\
\text { to the extent possible, the adverse impacts } \\
\text { associated with direct and indirect development of } \\
\text { a floodplain. }\end{array}$ & $\begin{array}{l}\text { Applicable if activities } \\
\text { are located in a 100-yr } \\
\text { floodplain. }\end{array}$ & $A, L$ & Not an ARAR \\
\hline $\begin{array}{l}\text { National Environmental Policy Act } \\
\text { of } 1969 \text { (NEPA) }\end{array}$ & $\begin{array}{l}42 \text { USC } 4321- \\
4370(c)\end{array}$ & $\begin{array}{l}\text { Requires federal agencies to consider significant } \\
\text { environmental impacts arising from projects under } \\
\text { agency jurisdiction and to establish a procedure } \\
\text { giving members of the public an opportunity for } \\
\text { meaningful participation in consideration of the } \\
\text { proposed action. }\end{array}$ & $\begin{array}{l}\text { Applicable for major } \\
\text { federal actions. The } \\
\text { CERCLA-like procedures } \\
\text { in the CAS process - } \\
\text { including public } \\
\text { participation, the } \\
\text { development of } \\
\text { corrective action } \\
\text { alternatives, and the } \\
\text { corrective action } \\
\text { alternative evaluation } \\
\text { process - are } \\
\text { equivalent to the NEPA } \\
\text { process. }\end{array}$ & $A$ & $\begin{array}{l}\text { Relevant and } \\
\text { appropriate }\end{array}$ \\
\hline Clean Air Act (CAA) & $\begin{array}{l}42 \text { USC } 7401 \\
\text { et seq. }\end{array}$ & & & $A$ & Not an ARAR \\
\hline $\begin{array}{l}\text { Standards of Performance for } \\
\text { New Stationary Sources }\end{array}$ & 40 CFR 60 & $\begin{array}{l}\text { Describes standards for the performance of new } \\
\text { stationary sources of air emissions. }\end{array}$ & $\begin{array}{l}\text { Applicable if emissions } \\
\text { thresholds are } \\
\text { exceeded. }\end{array}$ & $A, C$ & Not an ARAR \\
\hline
\end{tabular}

floodplain.

Applicable for major

federal actions. The

CERCLA-like procedures

including public

participation, the

development of

corrective action

ernatives, and the

process - are

equivalent to the NEPA

process.

exceeded. 


\begin{tabular}{ccc}
\hline Title & Citation & Description \\
\hline
\end{tabular}

Clean Air Act (cont.)

National Primary and

Secondary Ambient Air Quality

Standards

National Emissions Standards for Hazardous Air Pollutants

(NESHAPS)

Solid Waste Disposal Act, as amended by the Resource

Conservation and Recovery Act

(RCRA), the Hazardous and Solid

Waste Amendments of 1984, the

Federal Facility Compliance Act of

1992, and the Land Disposal

Program Flexibility Act of 1996

40 CFR Part 50

Establishes national primary and secondary ambient air quality standards under Section 109 of the Clean Air Act (42 USC 7409) to protect public health and welfare.

\section{CFR Parts 61} and 63

Implements the federal control program for hazardous air pollutants (HAPs). Identifies emission standards for HAPs that originate from specific categories of sources, including site remediation. NESHAPs are technology based and are issued to limit the release of specified HAPs from specific industrial sectors. Federal Register notices published for carbon tetrachloride [50 FR 32621 (August 13, 1985)] and chloroform [50 FR 39626 (September 27, 1985)] included

consideration of serious health effects, such as cancer, due to ambient exposures.

40 USC 6901

et seq.

Regulates the characterization, generation,

transportation, treatment, storage, and disposal of hazardous waste and establishes a framework for the management of nonhazardous waste.
Applicable if

contaminants are discharged to the air

during treatment.

Applicable if the identified HAPs are emitted from a specific source category at amounts regulated by the program (for example, if on-site treatment units with emissions are part of response actions)
A, C Relevant and appropriate

Not an ARAR

A Applicable 


\begin{tabular}{|c|c|c|c|c|c|}
\hline Title & Citationa & Description & Comment & Type $^{b}$ & Determination \\
\hline \multicolumn{6}{|l|}{ Solid Waste Disposal Act (cont.) } \\
\hline \multirow[t]{2}{*}{$\begin{array}{l}\text { Criteria for Classification of } \\
\text { Solid Waste Disposal Facilities } \\
\text { and Practices }\end{array}$} & 40 CFR Part 257 & $\begin{array}{l}\text { Establishes classification criteria for sanitary } \\
\text { landfills and prohibits open dumps. At a minimum, } \\
\text { facilities meet the sanitary landfill classification } \\
\text { "only if there is no reasonable probability of } \\
\text { adverse effects on health or the environment ..." } \\
\text { [Section 4004(a) of RCRA (42 USC 6944(a))]. }\end{array}$ & $\begin{array}{l}\text { Applicable if a response } \\
\text { alternative involves land } \\
\text { disposal of solid waste } \\
\text { on-site. }\end{array}$ & $A$ & Not an ARAR \\
\hline & & $\begin{array}{l}\text { Provides for protection of surface water and } \\
\text { groundwater at solid waste disposal facilities } \\
\text { (40 CFR 257.3-3 and }-4 \text { ). }\end{array}$ & $\begin{array}{l}\text { Applicable if a response } \\
\text { action includes } \\
\text { provisions for an on-site } \\
\text { landfill. }\end{array}$ & & \\
\hline $\begin{array}{l}\text { Criteria for Municipal Solid } \\
\text { Waste Landfills }\end{array}$ & 40 CFR Part 258 & $\begin{array}{l}\text { Establishes minimum national criteria for } \\
\text { municipal solid waste landfill units. }\end{array}$ & $\begin{array}{l}\text { Applicable if municipal } \\
\text { solid waste is placed in a } \\
\text { municipal solid waste } \\
\text { landfill. }\end{array}$ & $A$ & Not an ARAR \\
\hline $\begin{array}{l}\text { Identification and Listing of } \\
\text { Hazardous Wastes }\end{array}$ & 40 CFR Part 261 & $\begin{array}{l}\text { Identifies solid wastes that are subject to } \\
\text { regulation as hazardous wastes under } 40 \text { CFR } \\
\text { Parts } 124,262-265,268,270 \text {, and } 271 \text {. }\end{array}$ & $\begin{array}{l}\text { Applicable if a material at } \\
\text { the site is defined as a } \\
\text { solid and hazardous } \\
\text { waste; requires handling } \\
\text { as a hazardous waste. }\end{array}$ & $A, C$ & Applicable \\
\hline $\begin{array}{l}\text { Standards Applicable to } \\
\text { Generators of Hazardous } \\
\text { Waste }\end{array}$ & 40 CFR Part 262 & $\begin{array}{l}\text { Establishes standards for generators of } \\
\text { hazardous waste. }\end{array}$ & $\begin{array}{l}\text { Applicable if hazardous } \\
\text { wastes are generated as } \\
\text { a result of on-site } \\
\text { activities. }\end{array}$ & A & Applicable \\
\hline $\begin{array}{l}\text { Standards Applicable to } \\
\text { Transporters of Hazardous } \\
\text { Waste }\end{array}$ & 40 CFR Part 263 & $\begin{array}{l}\text { Establishes standards that apply to transporters } \\
\text { of hazardous waste within the United States if the } \\
\text { transportation requires a manifest under } 40 \text { CFR } \\
\text { Part } 262 \text {. }\end{array}$ & $\begin{array}{l}\text { Applicable if a response } \\
\text { alternative involves off- } \\
\text { site transportation of } \\
\text { hazardous wastes. }\end{array}$ & $A$ & Applicable \\
\hline
\end{tabular}

is no reasonable probability of

[Section 4004(a) of RCRA (42 USC 6944(a))].

Provides for protection of surface water and groundwater at solid waste disposal facilities
Criteria for Municipal Solid Waste Landfills

Identification and Listing of

Hazardous Wastes Generators of Hazardous

Standards Applicable to Transporters of Hazardous Waste
Part 262. 


\begin{tabular}{ccc}
\hline Title & Citation & Description \\
\hline
\end{tabular}

\section{Solid Waste Disposal Act (cont.)}

Standards for Owners and Operators of Hazardous Waste

Treatment, Storage, and

Disposal Facilities
40 CFR Part 264

Establishes minimum national standards that define the acceptable management of hazardous wastes for owners and operators of facilities that treat, store, or dispose of hazardous waste.

Provides for groundwater protection standards, general monitoring requirements, corrective action requirements, and technical requirements.

Standards for Management of Specific Hazardous Wastes and Specific Types of

Hazardous Waste

Management Facilities

Land Disposal Restrictions

\section{Hazardous Waste Permit} Program

Universal Wastes
40 CFR Part 266

Establishes requirements that apply to recyclable materials.

Identifies hazardous wastes that are restricted from land disposal; defines limited circumstances under which an otherwise prohibited waste may continue to be land disposed.

40 CFR Part 270

Establishes provisions covering basic EPA permitting requirements.
Applicable or relevant

and appropriate if

hazardous waste is

disposed of on-site.

RCRA standards can be relevant and appropriate

for groundwater at a site if an on-site landfill is constructed.

No substances are expected to be present at CCC/USDA sites in quantities to warrant recycling.

Applicable or relevant and appropriate if hazardous waste is disposed of on-site.

No permit is required for on-site CERCLA

response actions.

Substantive

requirements are addressed in $40 \mathrm{CFR}$

Part 264.

Applicable if universal wastes are generated or managed on-site in the course of investigation or response operations. wastes (hazardous waste bateries, haz wastes (hazardous waste batteries, hazardous waste pesticides that are either recalled or collected in waste pesticide collection programs hazardous waste thermostats, and hazardous waste lamps).
A Not an ARAR

A Not an ARAR

A, C Not an ARAR

A Not an ARAR

A Applicable 


\begin{tabular}{|c|c|c|c|c|c|}
\hline Title & Citation ${ }^{a}$ & Description & Comment & Type ${ }^{b}$ & Determination \\
\hline \multicolumn{6}{|l|}{ Solid Waste Disposal Act (cont.) } \\
\hline $\begin{array}{l}\text { Technical Standards and } \\
\text { Corrective Action } \\
\text { Requirements for Owners and } \\
\text { Operators of Underground } \\
\text { Storage Tanks }\end{array}$ & 40 CFR Part 280 & $\begin{array}{l}\text { Establishes regulations related to underground } \\
\text { storage tanks. }\end{array}$ & $\begin{array}{l}\text { Applicable if a response } \\
\text { alternative involves use } \\
\text { of underground storage } \\
\text { tanks. }\end{array}$ & $A$ & Not an ARAR \\
\hline $\begin{array}{l}\text { Occupational Safety and Health } \\
\text { Act (OSHA) }\end{array}$ & 29 USC 651 et seq. & & & A & Applicable \\
\hline $\begin{array}{l}\text { Occupational Safety and } \\
\text { Health Standards }\end{array}$ & 29 CFR Part 1910 & $\begin{array}{l}\text { Establishes safety and health standards for } \\
\text { workers. OSHA has set a limit of } 10 \text { ppm for } \\
\text { carbon tetrachloride in workplace air for an 8-hr } \\
\text { time-weighted average ( } 29 \text { CFR } 1910.1000 \\
\text { Table Z-2). }\end{array}$ & $\begin{array}{l}\text { Under } 40 \text { CFR Section } \\
300.150 \text {, response } \\
\text { actions under the NCP } \\
\text { will comply with OSHA } \\
\text { requirements for the } \\
\text { safety and health of } \\
\text { response action workers. }\end{array}$ & $A$ & Applicable \\
\hline Regulations for Construction & 29 CFR 1926 & $\begin{array}{l}\text { Provides standards for work practices, safety } \\
\text { equipment, fall protection, equipment operation, } \\
\text { excavation, use of power tools, and other } \\
\text { activities related to construction. }\end{array}$ & $\begin{array}{l}\text { Applicable if construction } \\
\text { activities are required for } \\
\text { a corrective action. }\end{array}$ & $A$ & Applicable \\
\hline Noise Control Act of 1972 & $\begin{array}{l}42 \text { USC Sect. } 4901 \\
\text { et seq. }\end{array}$ & $\begin{array}{l}\text { Prohibits federal activities resulting in noise that } \\
\text { would jeopardize the health or welfare of the } \\
\text { public. }\end{array}$ & $\begin{array}{l}\text { Applicable for activities } \\
\text { such as drilling near a } \\
\text { public access point. }\end{array}$ & $A$ & Applicable \\
\hline $\begin{array}{l}\text { Hazardous Materials } \\
\text { Transportation Act }\end{array}$ & $\begin{array}{l}49 \text { USC } 5101 \\
\text { et seq. }\end{array}$ & & & $A$ & Not an ARAR \\
\hline
\end{tabular}

Requirements for Owners and

Operators of Underground

alternative involves use of underground storage

Establishes regulations related to underground

Under 40 CFR Sectio

licable if construction

activities are required for

equipment, fall protection, equipment operation,

excavation, use of power tools, and other

Prohibits federal activities resulting in noise that

would jeopardize the health or welfare of the

public.
Applicable for activities such as drilling near a

public access point. 


\begin{tabular}{ccc}
\hline Title & Citation & Description \\
\hline
\end{tabular}

Hazardous Materials

Transportation Act (cont.)

Hazardous Materials

Transportation Regulations

49 CFR Parts 106180

National Historic Preservation Act of 1966

Protection of Historic Properties

Protection and Enhancement of EO 11593 Cultural Environments [40 CFR 6.301(b)]
Protects against the risks to life and property inherent in the transportation of hazardous material by listing the materials deemed hazardous and describing required labeling, placarding, and training. Hazardous materials are chemicals that the U.S. Department of

Transportation has determined pose

unreasonable risks to health, safety, and property during transportation activities.

16 USC 470 et seq. Establishes criteria for the creation and management of a National Registry of Historic Places composed of districts, sites, buildings, structures, and objects significant in American history, architecture, archaeology, engineering and culture.

36 CFR Parts 800 Defines the way federal agencies meet the statutory responsibilities. Requires federa agencies to consider the effects of any federally assisted undertaking (including those carried out with federal financial assistance and those requiring a federal permit, license, or approval) on any district, site, building, structure, or object that is listed in the National Register of Historic Places or eligible for such listing; requires agencies to give the Advisory Council on Historic Preservation a reasonable opportunity to comment on those undertakings.

Requires federal agencies to preserve, restore, and maintain the nation's historic and cultural environment in their activities.
Applicable if an alternative involves transportation of hazardous materials. Does not apply to on-site response operations.

\section{Applicable if an}

alternative involves a site on the National Registry of Historic Places.

Applicable if a district, site, building, structure or object listed on or eligible for the Nationa Register is on or adjacent to the site.
Applicable if an alternative involves the disturbance of significant cultural resources. 


\begin{tabular}{llll}
\hline Title & Citation & Description & Determination \\
\hline
\end{tabular}

National Historic Preservation Act

of 1966 (cont.)

Preserve America

Historic Sites, Buildings and Antiquities Act (Historic Sites Act) and Regulations

Archaeological and Historic Preservation Act of 1974 and Regulations

Antiquities Act
EO 13287

16 USC 461 et seq. Establishes a national policy to preserve historic [40 CFR 6.301(a)] sites and objects of national significance,

including those located on refuges. Provides procedures for designation, acquisition, administration, and protection of such sites.

Requires federal agencies to consider the existence and location of landmarks on the National Registry of Natural Landmarks and avoid undesirable impacts to such landmarks.

16 USC 469 et seq. Carries out policy established by the Historic Sites [40 CFR 6.301(c)] Act. Establishes procedures for preservation of historical and archaeological data that might be lost or destroyed through alteration of terrain as a result of a federal construction project or a federally licensed activity or program. Directs federal agencies to notify the Secretary of the Interior whenever they find that a federal or federally assisted, licensed, or permitted project may cause loss or destruction of significant scientific, prehistoric, or archaeological data.

16 USC 431 et seq. Authorizes the President to designate as nationa monuments objects or areas of historic or scientific interest on lands owned or controlled by the United States. Requires a permit for examination of ruins, excavation of archaeological sites, and the gathering of objects of antiquity on lands under the jurisdiction of the Secretaries of Interior, Agriculture, and Army. Provides penalties for violations.
Applicable if an

alternative involves a

historic property.

Applicable if an entity on the National Register of

National Landmarks is on or adjacent to the site.

Applicable if historical or archaeological data are on or adjacent to the site and if construction

projects or alteration of terrain at the site could destroy historical or archaeological materials.

Applicable if an alternative involves the gathering of objects of antiquity on lands under the jurisdiction of the federal agencies noted.
A, L Not an ARAR

A, $L \quad$ Not an ARAR

\section{A, L Not an ARAR}

A, $L \quad$ Not an ARAR 


\begin{tabular}{|c|c|c|c|c|c|}
\hline Title & Citation ${ }^{a}$ & Description & Comment & Type $^{b}$ & Determination \\
\hline \multicolumn{6}{|l|}{ Antiquities Act (Cont.) } \\
\hline $\begin{array}{l}\text { Preservation of American } \\
\text { Antiquities }\end{array}$ & $\begin{array}{l}43 \text { CFR } 3 \\
\text { [40 CFR Sect. } \\
6.301(b)] \\
\text { EO } 11593\end{array}$ & $\begin{array}{l}\text { Protects all historic and prehistoric sites on } \\
\text { federal lands and prohibits excavation or } \\
\text { destruction of such antiquities without the } \\
\text { permission (Antiquities Permit) of the secretary of } \\
\text { the department that has the jurisdiction over those } \\
\text { lands; authorizes the President to declare areas } \\
\text { of public lands as national monuments and to } \\
\text { reserve or accept private lands for that purpose. }\end{array}$ & $\begin{array}{l}\text { Applicable if site } \\
\text { operations affect } \\
\text { antiquities on federal } \\
\text { lands. }\end{array}$ & $A, L$ & Not an ARAR \\
\hline $\begin{array}{l}\text { Archaeological Resources } \\
\text { Protection Act }\end{array}$ & $\begin{array}{l}16 \text { USC 470aa } \\
\text { et seq. }\end{array}$ & $\begin{array}{l}\text { Supplements the provisions of the Antiquities Act } \\
\text { of } 1906 \text {. Establishes detailed requirements for } \\
\text { issuance of permits for any excavation or for } \\
\text { removal of archaeological resources from federal } \\
\text { or Indian lands. Also establishes civil and criminal } \\
\text { penalties for the unauthorized excavation, } \\
\text { removal, or damage of such resources. }\end{array}$ & & $A, L$ & Not an ARAR \\
\hline $\begin{array}{l}\text { Protection of Archaeological } \\
\text { Resources }\end{array}$ & $\begin{array}{l}43 \text { CFR Part } 7 \text {, } \\
36 \text { CFR Part } 296 \\
\text { [40 CFR } 6.301(b)]\end{array}$ & $\begin{array}{l}\text { Establishes uniform definitions, standards, and } \\
\text { procedures to be followed by all federal land } \\
\text { managers in providing protection for } \\
\text { archaeological resources located on public or } \\
\text { Indian lands. }\end{array}$ & $\begin{array}{l}\text { Applicable if site } \\
\text { operations affect } \\
\text { archaeological resources } \\
\text { on public or Indian lands. }\end{array}$ & $A, L$ & Not an ARAR \\
\hline $\begin{array}{l}\text { American Indian Religious } \\
\text { Freedom Act }\end{array}$ & $\begin{array}{l}42 \text { USC } 1996 \\
\text { et seq. }\end{array}$ & $\begin{array}{l}\text { Protects and preserves the right of American } \\
\text { Indians to have access to their sacred places; } \\
\text { directs federal agencies to consult with Indian } \\
\text { religious practitioners if a place of religious } \\
\text { importance to American Indians may be affected } \\
\text { by an undertaking. }\end{array}$ & $\begin{array}{l}\text { Applicable if site } \\
\text { operations affect access } \\
\text { to sacred Indian sites. }\end{array}$ & $A, L$ & Not an ARAR \\
\hline
\end{tabular}

Archaeological Resources

Protection Act

16 USC 470aa

a

Establishes uniform definitions, standards, and procedures to be followed by all federal land

Indian lands.

religious practitioners if a place of religious

by an undertaking. licable if site

perations affect

antiquities on federa erations affect

archaeological resources

Applicable if site

operations affect access

to sacred Indian sites. 


\begin{tabular}{ccc}
\hline Title & Citation & Description \\
\hline
\end{tabular}

American Indian Religious

Freedom Act (cont.)

Indian Sacred Sites

EO 13007

Native American Grave Protection

and Repatriation Act

USC 3001

et seq.

Native American Graves

Protection and Repatriation

Regulations

Endangered Species Act

16 USC 1531
Requires agencies managing federal lands to accommodate access to and ceremonial use of Indian sacred sites by Indian religious

practitioners and to avoid adversely affecting the

physical integrity of such sacred sites; also

requires agencies to develop procedures for

reasonable notification of proposed actions.

Establishes the priority for ownership or control of Native American cultural items excavated or discovered on federal or tribal lands after 1990 and the procedures for repatriation of items in federal possession; allows the intentional remova or excavation of Native American cultural items from federal or tribal lands only with a permit or upon consultation with the appropriate tribe.

43 CFR Part 10

Develops a systematic process for determining the rights of linear descendants and Indian tribes to certain Native American human remains, funerary objects, sacred objects, or objects of cultural patrimony. Defines items included under the Native American Grave Protection and Repatriation Act. Describes the consultation procedure applicable to intentional excavation or inadvertent discovery of remains or objects covered. et seq.

Provides for the conservation of threatened and endangered plants and animals and the habitats
Applicable if site operations affect access to sacred Indian sites.

Applicable if site excavation or discovery of Native American

cultural items on federal or tribal lands.

Applicable if actions involve intentional excavation or inadvertent discovery of remains or objects subject to the regulations. in which they are found.
Applicable if actions involve threatened and endangered species. 


\begin{tabular}{|c|c|c|c|c|c|}
\hline Title & Citation ${ }^{\mathrm{a}}$ & Description & Comment & Type $^{b}$ & Determination \\
\hline \multicolumn{6}{|l|}{ Endangered Species Act (cont.) } \\
\hline Interagency Cooperation & $\begin{array}{l}50 \text { CFR Part } 402 \\
{[40 \text { CFR } 6.302(h)]}\end{array}$ & $\begin{array}{l}\text { Requires action to conserve threatened and } \\
\text { endangered species within critical habits upon } \\
\text { which endangered species depend, including } \\
\text { consultation and conferencing with the } \\
\text { Department of the Interior (U.S. Fisheries and } \\
\text { Wildlife Service or U.S. National Marine Fisheries } \\
\text { Service). }\end{array}$ & $\begin{array}{l}\text { Applicable if threatened } \\
\text { or endangered species } \\
\text { or critical habitats are } \\
\text { identified at the site. }\end{array}$ & A & Not an ARAR \\
\hline Migratory Bird Treaty Act & 16 USC 703 et seq. & & & $A$ & Not an ARAR \\
\hline Migratory Bird Permits & $\begin{array}{l}50 \text { CFR Parts } 10 \\
\text { and } 21\end{array}$ & $\begin{array}{l}\text { Requires a permit from the U.S. Fisheries and } \\
\text { Wildlife Service for the taking of protected } \\
\text { migratory birds. }\end{array}$ & $\begin{array}{l}\text { Applicable if a response } \\
\text { alternative will affect a } \\
\text { migratory pathway. }\end{array}$ & A & Not an ARAR \\
\hline $\begin{array}{l}\text { Responsibilities of Federal } \\
\text { Agencies to Protect Migratory } \\
\text { Birds }\end{array}$ & EO 13186 & $\begin{array}{l}\text { Directs federal agencies taking actions having or } \\
\text { likely to have a negative effect on migratory bird } \\
\text { populations to work with the U.S. Fisheries and } \\
\text { Wildlife Service to develop an agreement to } \\
\text { conserve those birds. }\end{array}$ & & $A$ & Not an ARAR \\
\hline $\begin{array}{l}\text { Bald and Golden Eagle Protection } \\
\text { Act }\end{array}$ & 16 USC 668 et seq. & & & $A$ & Not an ARAR \\
\hline Eagle Permits & $\begin{array}{l}50 \text { CFR Parts } 10 \\
\text { and } 22\end{array}$ & $\begin{array}{l}\text { Requires a permit from the U.S. Fisheries and } \\
\text { Wildlife Service to move nests because of } \\
\text { construction or operation of project facilities. }\end{array}$ & $\begin{array}{l}\text { Applicable if project } \\
\text { activities affect bald and } \\
\text { golden eagle } \\
\text { populations, including } \\
\text { construction or operation } \\
\text { of facilities that call for } \\
\text { the moving of nests. }\end{array}$ & $A, L$ & Not an ARAR \\
\hline Fish and Wildlife Conservation Act & $\begin{array}{l}16 \text { USC } 2901 \\
\text { et seq. }\end{array}$ & $\begin{array}{l}\text { Encourages states to develop conservation plans } \\
\text { for nongame fish and wildlife of ecological, } \\
\text { educational, aesthetic, cultural, recreational, } \\
\text { economic, or scientific value. }\end{array}$ & $\begin{array}{l}\text { Applicable if significant } \\
\text { populations are present } \\
\text { at a site or are affected } \\
\text { by site response } \\
\text { activities. }\end{array}$ & $A$ & Not an ARAR \\
\hline
\end{tabular}

Department of the Interior (U.S. Fisheries and

Wildlife Service or U.S. National Marine Fisheries Service).

Wuires a permit from the US. Fisheries and Wildlife Service for the taking of protected Agencies to Protect Migrato Birds

Bald and Golden Eagle Protection Eagle Permits

50 CFR Parts 10 Wildlife Service to move nests because of construction or operation of project facilities.

for nongame fish and wildlife of ecological educational, aesthetic, cultural, recreational economic, or scientific value. 


\begin{tabular}{|c|c|c|c|c|c|}
\hline Title & Citation ${ }^{\mathrm{a}}$ & Description & Comment & Type $^{b}$ & Determination \\
\hline Fish and Wildlife Coordination Act & $\begin{array}{l}16 \text { USC } 661 \text { et seq. } \\
{[40 \text { CFR } 6.302(\mathrm{~g})}\end{array}$ & $\begin{array}{l}\text { Requires consultation with the U.S. Fish and } \\
\text { Wildlife Service when a federal department or } \\
\text { agency proposes, authorizes, permits, or licenses } \\
\text { any modification of any stream or other water } \\
\text { body. Requires adequate provision for protection } \\
\text { of fish and wildlife resources. }\end{array}$ & $\begin{array}{l}\text { Applicable if a response } \\
\text { alternative will cause } \\
\text { damage to or loss of } \\
\text { wildlife by modifying a } \\
\text { stream or body of water. }\end{array}$ & $A$ & Not an ARAR \\
\hline Wilderness Act & $\begin{array}{l}16 \text { USC } 1311 \\
\text { et seq. }\end{array}$ & & & $A$ & Not an ARAR \\
\hline $\begin{array}{l}\text { Wilderness Preservation and } \\
\text { Management }\end{array}$ & 50 CFR Part 35 & $\begin{array}{l}\text { Describes the activities allowed and banned in } \\
\text { wilderness areas and uses requiring } \\
\text { authorization. }\end{array}$ & $\begin{array}{l}\text { Applicable if a } \\
\text { wilderness area exists } \\
\text { on-site or adjacent to the } \\
\text { site. }\end{array}$ & $A$ & Not an ARAR \\
\hline $\begin{array}{l}\text { Management of Designated } \\
\text { Wilderness Areas }\end{array}$ & 43 CFR Part 6300 & & $\begin{array}{l}\text { Applicable if actions } \\
\text { involve a Designated } \\
\text { Wilderness Area. }\end{array}$ & $A$ & Not an ARAR \\
\hline $\begin{array}{l}\text { National Wildlife Refuge System } \\
\text { Administration Act }\end{array}$ & 16 USC 668dd & & $\begin{array}{l}\text { Applicable if actions } \\
\text { involve a National } \\
\text { Wildlife Refuge. }\end{array}$ & A & Not an ARAR \\
\hline $\begin{array}{l}\text { Management and General } \\
\text { Public Use of the National } \\
\text { Wildlife Refuge System }\end{array}$ & EO 12996 & $\begin{array}{l}\text { Directs preservation of a national network of lands } \\
\text { and waters for the conservation and management } \\
\text { of fish, wildlife, and plant resources for the benefit } \\
\text { of present and future generations. Recognizes } \\
\text { compatible uses, while ensuring maintenance of } \\
\text { biological integrity and environmental health. }\end{array}$ & $\begin{array}{l}\text { Applicable if a wildlife } \\
\text { refuge area exists on- } \\
\text { site or adjacent to the } \\
\text { site. }\end{array}$ & $A, L$ & Not an ARAR \\
\hline Wild and Scenic Rivers Act & $\begin{array}{l}16 \text { USC } 1271 \\
\text { et seq. }\end{array}$ & $\begin{array}{l}\text { States that a federal agency may not assist, } \\
\text { through grant, loan, license, or otherwise, the } \\
\text { construction of a water resources project that } \\
\text { would have a direct and adverse effect on the } \\
\text { values for which a river in the National Wild and } \\
\text { Scenic Rivers System or a study river on the } \\
\text { National Rivers Inventory was established. }\end{array}$ & & $A, L$ & Not an ARAR \\
\hline
\end{tabular}

16 USC 131

Wilderness Preservation and Management

Management of Designated

National Wildlife Refuge System

Management and Genera

Public Use of the Nationa

Wildlife Refuge System

National Rivers Inventory was established. 


\begin{tabular}{ccc}
\hline Title & Citation & Description \\
\hline
\end{tabular}

Wild and Scenic Rivers Act (cont.)

Wild and Scenic Rivers

36 CFR Part 297

(40 CFR 6.302(e)) assisted water resource projects in any portion of a designated river.

Federal Insecticide, Fungicide and Rodenticide Act of 1972

Pesticide Management

Program Regulations

Toxic Substances Control Act (TSCA) of 1976

Guidance for Conducting Remedial Investigations and Feasibility

Studies under CERCLA, EPA 540-

G-89-004, October 1988

Office of Solid Waste and

Emergency Response Technical

guidance for Assessing and

Mitigating the Vapor Intrusion

Pathway from Subsurface Vapor

Sources to Indoor Air (Subsurface Vapor Intrusion)
16 USC 2901-2911 Establishes a pesticide regulatory program.

40 CFR 150-189 Creates a federal program for the registration control, distribution, and use of pesticides.

15 USC 2601

Authorizes the EPA to track, screen, and require reporting or testing of chemicals that might pose an environmental or human health risk.

Describes the procedures used to characterize the nature and extent of contamination and risk posed by the release of chemical constituents at a site. Also describes the procedures for evaluating potential remedial alternatives.

\section{OSWER 9200.2} 154 (June 2015)

Provides technical recommendations based on current understanding of vapor intrusion into indoor air from subsurface vapor sources. For sites with a complete pathway, guidance is provided to evaluate whether the pathway poses a potential significant risk to human health.
Applicable to on-site water resource projects located within, above,

below, or outside a wild and scenic river or study river.

Applicable if pesticides will be used as part of corrective action activities.

Applicable if site activities involve substances regulated under TSCA, such as polychlorinated biphenyls.

Suggested for use at National Priority List and Superfund Alternative Sites.

\section{A, L Not an ARAR}




\begin{tabular}{|c|c|c|c|c|c|}
\hline Title & Citation ${ }^{a}$ & Description & Comment & Type ${ }^{b}$ & Determination \\
\hline $\begin{array}{l}\text { Guidance for Quality Assurance } \\
\text { Project Plans, EPA 240-R-02-009, } \\
\text { December } 2002\end{array}$ & & $\begin{array}{l}\text { Describes the form and content of a Quality } \\
\text { Assurance Project Plan. }\end{array}$ & & $A$ & TBC \\
\hline $\begin{array}{l}\text { Use of Monitored Natural } \\
\text { Attenuation Remedies for VOCs in } \\
\text { Groundwater, April } 2004\end{array}$ & & $\begin{array}{l}\text { Describes the procedures for performing and } \\
\text { evaluating monitored natural attenuation (MNA). }\end{array}$ & & $A$ & TBC \\
\hline $\begin{array}{l}\text { Technical Protocol for Evaluating } \\
\text { Chlorinated Solvents in } \\
\text { Groundwater, October } 1998\end{array}$ & & $\begin{array}{l}\text { Describes protocols that can be used to evaluate } \\
\text { whether MNA is occurring in groundwater. }\end{array}$ & & $A$ & TBC \\
\hline $\begin{array}{l}\text { Guide to Discharging CERCLA } \\
\text { Aqueous Wastes to Publicly } \\
\text { Owned Treatment Works, EPA } \\
\text { OSWER Directive 9330.2-13 FS, } \\
\text { March } 1991\end{array}$ & & $\begin{array}{l}\text { Describes the process of discharging CERCLA } \\
\text { wastes to a POTW. }\end{array}$ & $\begin{array}{l}\text { Applicable to the } \\
\text { discharge of CERCLA } \\
\text { wastes to a POTW. }\end{array}$ & $A, C$ & Not a TBC \\
\hline
\end{tabular}

a Abbreviations for citations: CFR, Code of Federal Regulations

FR, Federal Register

Sect., Section

USC, United States Code

b Types:
A, Action-specific
C, Chemical-specific
L, Location-specific 
TABLE B.2 Determination of potential state ARARs and guidance to be considered for the former CCC/USDA facility at Agra.

\begin{tabular}{|c|c|c|}
\hline Title & Citation $^{a}$ & Description \\
\hline Radiation & $\begin{array}{l}\text { KAR 28-35-1 to } \\
28-35-363\end{array}$ & $\begin{array}{l}\text { Addresses the registration of radiation-producing } \\
\text { devices and the licensing of sources of radiation. }\end{array}$ \\
\hline Spill Reporting & $\begin{array}{l}\text { KAR } 28-48-1 \text { to } \\
28-48-2\end{array}$ & $\begin{array}{l}\text { Addresses reporting requirements for the } \\
\text { accidental releases of unpermitted discharges. }\end{array}$ \\
\hline $\begin{array}{l}\text { Emergency Planning } \\
\text { and Right-to-Know } \\
\text { Regulations }\end{array}$ & $\begin{array}{l}\text { KAR } 28-65-1 \text { to } \\
28-65-4\end{array}$ & $\begin{array}{l}\text { Requires facilities storing hazardous substances } \\
\text { above threshold quantities to report the presence } \\
\text { of the materials and any releases of the materials. } \\
\text { Creates emergency planning and response } \\
\text { procedures. }\end{array}$ \\
\hline $\begin{array}{l}\text { Kansas Air Quality } \\
\text { Control Act; Kansas } \\
\text { Air Quality } \\
\text { Regulations }\end{array}$ & $\begin{array}{l}\text { KSA, Chapter } \\
65 \text {, Article 30; } \\
\text { KAR, Title 28, } \\
\text { Article } 19\end{array}$ & $\begin{array}{l}\text { Requires permitting and preconstruction notices for } \\
\text { air contaminant sources. Provides for reporting and } \\
\text { inspections. Establishes state emission standards } \\
\text { for listed hazardous air pollutants (HAPs) and state } \\
\text { air quality standards. HAPs include carbon } \\
\text { tetrachloride and chloroform emitted above a } \\
\text { threshold (e.g., } 10 \text { tons/yr of a single HAP or } 25 \\
\text { tons/yr of any combination of HAPs). }\end{array}$ \\
\hline & & $\begin{array}{l}\text { Specifically requires the following: } \\
\text { - For emissions above threshold amounts, } \\
\text { (1) construction permits (e.g., for } 25 \text { tons/yr of } \\
\text { particulate matter [PM], } 15 \text { tons/yr of PM } 10 \text {, } \\
100 \text { tons/yr of carbon monoxide, } 40 \text { tons/yr of } \\
\text { volatile organic compounds [VOCs]) or } \\
\text { (2) preconstruction approval (e.g., for } 5 \mathrm{lb} / \mathrm{hr} \text { of } \\
\mathrm{PM}, 2 \mathrm{lb} / \mathrm{hr} \text { of PM } 10,50 \mathrm{lb} \text { of carbon } \\
\text { monoxide per } 24-\mathrm{hr} \text { period, or } 50 \mathrm{lb} \text { of VOCs } \\
\text { per } 24-\mathrm{hr} \text { period - alternatively, in a } \\
\text { nonattainment area, either } 15 \mathrm{lb} \text { per } 24-\mathrm{hr} \\
\text { period or } 3 \mathrm{lb} / \mathrm{hr} \text { (KAR } 28-19-300) \text {. } \\
\text { Operating permits for certain stationary } \\
\text { sources (28-19-500 et seq.). }\end{array}$ \\
\hline
\end{tabular}

Applicable if radiation-producing

devices are used as part of a

corrective action.

Applicable if an unpermitted

discharge occurs during the

performance of a corrective action.

Applicable if regulated hazardous chemicals are stored as part of the corrective action.

Applicable if any listed pollutants are discharged to the air during investigation or response through air stripping, thermal destruction, handling of contaminated soil, gaseous waste treatment, aeration, or disposal in a municipal solid waste landfill.
Type $^{\text {b }}$ Determination

A, C Not an ARAR

A, C Applicable

A, C, L Applicable

Not an ARAR 


\begin{tabular}{|c|c|c|c|c|c|}
\hline Title & Citation ${ }^{a}$ & Description & Comment & Type $^{b}$ & Determination \\
\hline $\begin{array}{l}\text { Kansas Air Quality } \\
\text { Control Act; Kansas } \\
\text { Air Quality } \\
\text { Regulations (cont.) }\end{array}$ & & $\begin{array}{l}\text { Prohibits open burning (28-19-645 et seq.). } \\
\text { Establishes emission standards for major source } \\
\text { HAPs (28-19-750 et seq.). }\end{array}$ & & & \\
\hline $\begin{array}{l}\text { Underground } \\
\text { Storage, } \\
\text { Disposal Wells } \\
\text { and Surface } \\
\text { Ponds }\end{array}$ & $\begin{array}{l}\text { KSA, Chapter } \\
65 \text {, Article 1; } \\
\text { KAR, Title } 28 \\
\text { Article } 13\end{array}$ & $\begin{array}{l}\text { Regulates the construction and use of } \\
\text { underground storage reservoirs, disposal wells, } \\
\text { and surface ponds for the confinement, storage, } \\
\text { and disposal of industrial fluids. Establishes } \\
\text { approval and permitting requirements. }\end{array}$ & $\begin{array}{l}\text { Applicable if a response alternative } \\
\text { involves the need for underground } \\
\text { storage reservoirs, disposal wells, } \\
\text { or surface ponds. }\end{array}$ & $\mathrm{L}, \mathrm{A}$ & Not an ARAR \\
\hline $\begin{array}{l}\text { Drinking Water } \\
\text { Regulations }\end{array}$ & $\begin{array}{l}\text { KSA, Chapter } \\
65 \text {, Article 33; } \\
\text { KAR, Title 28, } \\
\text { Article } 15\end{array}$ & $\begin{array}{l}\text { Establishes MCLs pertaining to public water } \\
\text { supplies. The MCLs for carbon tetrachloride, total } \\
\text { trihalomethanes (including chloroform), nitrate, and } \\
\text { nitrite are } 0.005 \mathrm{mg} / \mathrm{L}, 0.1 \mathrm{mg} / \mathrm{L}, 10 \mathrm{mg} / \mathrm{L} \text {, and } 1 \\
\mathrm{mg} / \mathrm{L} \text {, respectively (KAR } 28-15 \mathrm{a}-61 \text { and } 28-15 \mathrm{a}- \\
62 \text { ). }\end{array}$ & $\begin{array}{l}\text { Applicable if waste derived from an } \\
\text { investigation or response enters a } \\
\text { public water system. Not applicable } \\
\text { to investigative wells, as such, that } \\
\text { are not used for drinking water } \\
\text { supply; however, relevant for } \\
\text { establishing sampling and analysis } \\
\text { parameters and analytical } \\
\text { detection limits during investigation } \\
\text { activities. }\end{array}$ & $\mathrm{C}$ & $\begin{array}{l}\text { Relevant and } \\
\text { appropriate }\end{array}$ \\
\hline
\end{tabular}




\begin{tabular}{|c|c|c|}
\hline Title & Citation $^{a}$ & Description \\
\hline $\begin{array}{l}\text { Water Pollution } \\
\text { Control Regulations }\end{array}$ & $\begin{array}{l}\text { KSA, Chapter } \\
65 \text {, Article 33; } \\
\text { KAR, Title 28, } \\
\text { Article } 16\end{array}$ & $\begin{array}{l}\text { Protects public health and welfare and the use of } \\
\text { surface water for aquatic life; for agricultural, } \\
\text { domestic, and industrial water supply; and for } \\
\text { recreation. Controls surface water use designation. } \\
\text { Establishes surface water quality standards (KAR } \\
28-16-28 \text { et seq.). MCL is defined as "any of the } \\
\text { enforceable standards for finished drinking water } \\
\text { promulgated by the U.S. Environmental Protection } \\
\text { Agency [KAR 28-16-28b(hh)]." When the KDHE } \\
\text { finds that these criteria are underprotective or } \\
\text { overprotective for a given surface water segment, } \\
\text { the KDHE may, in accordance with KAR 28-16- } \\
28 f(f), \text { make appropriate site-specific } \\
\text { determinations [KAR } 28-16-28 \text { (a)]. Surface water } \\
\text { must be free from the harmful effects of } \\
\text { substances that produce any public health hazard; } \\
\text { hazardous substances must not occur in surface } \\
\text { water at concentrations that jeopardize public } \\
\text { health and other protected life [KAR 28-16-28e(b)]. }\end{array}$ \\
\hline
\end{tabular}

Applicable if contaminated effluent

from investigative or response

operations is discharged into

surface water; also possibly

applicable to alluvial aquifers

demonstrated to be hydraulically

connected to surface water bodies.
Type $^{\mathrm{b}}$ Determination

C

Applicable 


$\begin{array}{cccc}\text { Title } & \text { Citation } & \text { Description } & \text { Typenmentermination }\end{array}$

Water Pollution

Control Regulations

(cont.)

Groundwater

Management

Districts
Provides numeric criteria by use category for different parameters [KAR 28-16-28e(d)]. For chloroform the values are $28,900 \mu \mathrm{g} / \mathrm{L}$ for aquatic life-acute, $1,240 \mu \mathrm{g} / \mathrm{L}$ for aquatic life-chronic, $470 \mu \mathrm{g} / \mathrm{L}$ for public health-food procurement, and $100 \mu \mathrm{g} / \mathrm{L}$ for public health-domestic water supply. (No values are specified for agriculture-livestock and agriculture-irrigation.) For carbon tetrachloride the values are $35,200 \mu \mathrm{g} / \mathrm{L}$ for aquatic life-acute, $6.94 \mu \mathrm{g} / \mathrm{L}$ for public health-food procurement, and $5 \mu \mathrm{g} / \mathrm{L}$ for public health-domestic water supply. (No values are specified for aquatic life-chronic, agriculture-livestock, and agriculture-irrigation.) The State's overall water quality program also implements an anti-degradation policy to limit discharges and other activities that will negatively impact water quality.

Establishes procedures relating to the discharge of wastewaters under the NPDES program (KAR 2816-57 et seq.). National effluent standards are adopted by reference.

Provides for the establishment and administration of critical water quality management areas (KAR 28-16-69 et seq.).

Limits the types of wastes that can be discharged to POTWs and governs pollutants from

nondomestic sources that are subject to one or more pretreatment standards and that are indirectly discharged into POTWs or are otherwise introduced by any means (KAR 28-16-83 et seq.).

Establishes requirements for the creation of special districts for the proper management of the groundwater resources of the state.
Applicable if the following result

frem an investigation or response:

- Discharges into "waters of the state."

- Discharges into a designated critical water quality management area

- Discharges of contaminated groundwater to POTWs.

- Discharges into a designated critical water quality management area.
L Relevant and appropriate 


\begin{tabular}{|c|c|c|}
\hline Title & Citation $^{a}$ & Description \\
\hline $\begin{array}{l}\text { Kansas Drycleaner } \\
\text { Environmental } \\
\text { Response Act }\end{array}$ & $\begin{array}{l}\text { KSA 65-34, } \\
141\end{array}$ & $\begin{array}{l}\text { Authorizes creation of a drycleaner site } \\
\text { management program; funds assessment and } \\
\text { corrective action activities at former and existing } \\
\text { drycleaner facilities. }\end{array}$ \\
\hline $\begin{array}{l}\text { Kansas } \\
\text { Drycleaner } \\
\text { Environmental } \\
\text { Response } \\
\text { Regulations }\end{array}$ & $\begin{array}{l}\text { KAR 28-68-1 to } \\
28-68-9\end{array}$ & $\begin{array}{l}\text { Regulations created pursuant to the Kansas } \\
\text { Drycleaner Environmental Response Act. }\end{array}$ \\
\hline $\begin{array}{l}\text { Kansas } \\
\text { Environmental Use } \\
\text { Controls }\end{array}$ & $\begin{array}{l}\text { KSA, chapter } \\
65-1221 \text { to } 65- \\
1235\end{array}$ & $\begin{array}{l}\text { Defines the EUC as a legal mechanism for } \\
\text { applying restrictions, prohibitions, and conditions } \\
\text { on land use for a property that has environmental } \\
\text { contamination at levels prohibiting unrestricted use } \\
\text { (i.e., exceeding residential standards). An EUC can } \\
\text { be voluntarily applied to a property by the } \\
\text { landowner as part of a corrective action to assure } \\
\text { adequate protection of public health and the } \\
\text { environment from contamination on the subject } \\
\text { property. The protection offered by an EUC can } \\
\text { provide a landowner relief from environmental } \\
\text { liability concerns, making property more attractive } \\
\text { for redevelopment or to prospective buyers. }\end{array}$ \\
\hline $\begin{array}{l}\text { Kansas Water Well } \\
\text { Contractor's License } \\
\text { Regulations; Water } \\
\text { Well Construction } \\
\text { and Abandonment } \\
\text { Regulations }\end{array}$ & $\begin{array}{l}\text { KSA, Chapter } \\
82 \mathrm{a} \text {, Article } 12 \text {; } \\
\text { KAR, Title } 28 \text {, } \\
\text { Article } 30\end{array}$ & $\begin{array}{l}\text { Establishes requirements for licensing of well } \\
\text { drillers and standards for construction, operation, } \\
\text { and abandonment of wells (KAR 28-30-3 et seq.). }\end{array}$ \\
\hline $\begin{array}{l}\text { Underground } \\
\text { Injection Control } \\
\text { Regulations }\end{array}$ & $\begin{array}{l}\text { KSA, Chapter } \\
65 \text {, Article 1; } \\
\text { KAR, Title 28, } \\
\text { Article } 46\end{array}$ & $\begin{array}{l}\text { Governs discharges into underground injection } \\
\text { wells (KAR 28-46-1 et seq.). In general, federal } \\
\text { Safe Drinking Water Act regulations are adopted } \\
\text { by reference. }\end{array}$ \\
\hline
\end{tabular}

May be applicable if a drycleaner operated at the site of the former CCC/USDA facility.

Applicable if corrective action

includes an EUC.

Applicable if investigation o response involves drilling and installing wells that intercept the water table.

Applicable if investigative or response wastes are introduced into wells for discharge or disposal.
Type $^{\mathrm{b}}$ Determination

L $\quad$ Not an ARAR

A, C Not an ARAR

L Applicable

A Applicable

A, C Not an ARAR 


\begin{tabular}{|c|c|c|c|c|c|}
\hline Title & Citation ${ }^{a}$ & Description & Comment & Type $^{b}$ & Determination \\
\hline \multirow[t]{2}{*}{$\begin{array}{l}\text { Solid Waste Act and } \\
\text { Regulations }\end{array}$} & $\begin{array}{l}\text { KSA, Chapter } \\
65 \text {, Article } 34 \\
\text { KAR, Title } 28 \\
\text { Article } 29\end{array}$ & $\begin{array}{l}\text { Establishes standards for management activities } \\
\text { and facilities relative to solid wastes (KAR 28-29-1 } \\
\text { et seq.). }\end{array}$ & $\begin{array}{l}\text { Applicable if nonhazardous } \\
\text { materials discarded as a result of } \\
\text { an investigation or response are } \\
\text { landfilled on-site. }\end{array}$ & A, C, L & Not an ARAR \\
\hline & & $\begin{array}{l}\text { Establishes location restrictions, design standards, } \\
\text { operating standards, groundwater monitoring, } \\
\text { corrective action, and financial assurance for } \\
\text { municipal solid waste landfill units, during and after } \\
\text { closure (KAR 28-29-100 et seq.). }\end{array}$ & $\begin{array}{l}\text { Applicable if a municipal solid } \\
\text { waste landfill is used. }\end{array}$ & & \\
\hline \multirow[t]{2}{*}{$\begin{array}{l}\text { Hazardous Waste } \\
\text { Management } \\
\text { Standards and } \\
\text { Regulations }\end{array}$} & $\begin{array}{l}\text { KSA, Chapter } \\
65 \text {, Article } 34 \\
\text { KAR, Title 28, } \\
\text { Article } 31\end{array}$ & $\begin{array}{l}\text { Requires generators of solid waste to make a } \\
\text { hazardous waste determination. For a waste that is } \\
\text { not excluded from hazardous waste regulations } \\
\text { and not listed as a hazardous waste, the } \\
\text { determination is generally made through testing by } \\
\text { a laboratory certified for such analyses by the } \\
\text { KDHE [KAR 28-31-4(b)]. }\end{array}$ & $\begin{array}{l}\text { Applicable if investigation or } \\
\text { response operations generate solid } \\
\text { wastes. }\end{array}$ & $A, C$ & $\begin{array}{l}\text { Relevant and } \\
\text { appropriate }\end{array}$ \\
\hline & & $\begin{array}{l}\text { Establishes standards for hazardous waste } \\
\text { generators and transporters and for facilities that } \\
\text { treat, store, or dispose of hazardous waste (KAR } \\
\text { 28-31-4 et seq.). } \\
\text { Adopts by reference federal regulations governing } \\
\text { universal wastes (KAR 28-31-15). }\end{array}$ & $\begin{array}{l}\text { Applicable to response-generated } \\
\text { wastes that are determined to be } \\
\text { hazardous and that are managed } \\
\text { on-site through treatment, storage, } \\
\text { and disposal or are transported. } \\
\text { Applicable if universal wastes are } \\
\text { generated or managed on-site in } \\
\text { the course of an investigation or } \\
\text { response operation. }\end{array}$ & & \\
\hline $\begin{array}{l}\text { Kansas Board of } \\
\text { Technical } \\
\text { Professions }\end{array}$ & $\begin{array}{l}\text { KAR } 66-6-1 \\
\text { through } 66-14- \\
12\end{array}$ & $\begin{array}{l}\text { Establishes requirements for the licensing of } \\
\text { surveyors, geologists, and architects. }\end{array}$ & $\begin{array}{l}\text { Applicable if these professionals } \\
\text { are required for implementation of } \\
\text { the selected corrective action. }\end{array}$ & $A$ & Applicable \\
\hline
\end{tabular}




\begin{tabular}{|c|c|c|c|c|c|}
\hline Title & Citation $^{a}$ & Description & Comment & Type ${ }^{b}$ & Determination \\
\hline $\begin{array}{l}\text { Kansas Storage } \\
\text { Tanks Act }\end{array}$ & $\begin{array}{l}\text { KSA Chapter } \\
65, \text { Article } 34\end{array}$ & $\begin{array}{l}\text { Establishes standards for the registration and } \\
\text { permitting of nonexempt aboveground tanks used } \\
\text { to store a regulated substance (KAR 28-44-29). }\end{array}$ & $\begin{array}{l}\text { Applicable if a response alternative } \\
\text { involves use of storage tanks to } \\
\text { contain an accumulation of } \\
\text { regulated substances, associated } \\
\text { piping and ancillary equipment, } \\
\text { and a containment system. }\end{array}$ & $A, L$ & Not an ARAR \\
\hline $\begin{array}{l}\text { Petroleum } \\
\text { Products Storage } \\
\text { Tanks }\end{array}$ & $\begin{array}{l}\text { KAR } 28-44-1 \text { to } \\
28-44-29\end{array}$ & $\begin{array}{l}\text { Provides requirements for permitting, installing and } \\
\text { testing underground storage tanks and for } \\
\text { licensing installation contractors. }\end{array}$ & & $A, L$ & Not an ARAR \\
\hline $\begin{array}{l}\text { Kansas Water } \\
\text { Appropriations Act }\end{array}$ & $\begin{array}{l}\text { KSA } 82 a-701 \\
\text { et seq. }\end{array}$ & $\begin{array}{l}\text { Addresses the appropriation and distribution of } \\
\text { water. }\end{array}$ & & $A, L$ & Applicable \\
\hline $\begin{array}{l}\text { Kansas Water } \\
\text { Appropriations } \\
\text { Act Rules and } \\
\text { Regulations }\end{array}$ & $\begin{array}{l}\text { K.A.R. 5-1-1 } \\
\text { through 5-10-6 } \\
\text { and KAR 5-50-1 } \\
\text { through 5-50-8 }\end{array}$ & $\begin{array}{l}\text { Establishes a framework for the control, } \\
\text { conservation, regulation, allotment, and distribution } \\
\text { of water resources. }\end{array}$ & $\begin{array}{l}\text { Applicable if water appropriations } \\
\text { are required for a corrective action. }\end{array}$ & $A, L$ & Applicable \\
\hline $\begin{array}{l}\text { Kansas Nongame } \\
\text { and Endangered } \\
\text { Species } \\
\text { Conservation Act; } \\
\text { Kansas Nongame } \\
\text { and Endangered } \\
\text { Species } \\
\text { Conservation } \\
\text { Regulations }\end{array}$ & $\begin{array}{l}\text { KSA, Chapter } \\
\text { 32, Article 9; } \\
\text { KAR, Title 115, } \\
\text { Article } 15\end{array}$ & $\begin{array}{l}\text { Designates endangered and threatened species, } \\
\text { as well as nongame species in need of } \\
\text { conservation. Requires consultation with the } \\
\text { Kansas Department of Wildlife and Parks } \\
\text { pertaining to actions that might affect listed species } \\
\text { and their critical habitats. Projects that affect listed } \\
\text { species or their habitats and that are publicly } \\
\text { funded, state or federally assisted, or require a } \\
\text { permit from another state or federal agency require } \\
\text { review and action permits (KSA 32-957 } \\
\text { through -963, 32-1009 through } 32-1012 \text {, and 32- } \\
\text { 1033; KAR 115-15-1, }-2,-3 \text {, and -4). }\end{array}$ & $\begin{array}{l}\text { Applicable if threatened or } \\
\text { endangered species are identified } \\
\text { at or near the site. }\end{array}$ & A & Not an ARAR \\
\hline
\end{tabular}

\section{Petroleum}

Products Storage

KAR 28-44-1 to

KSA 82a-701

seq.

KAR, Title 115

pertaining to actions that might affect listed species

permit from another state or federal agency require

through -963, 32-1009 through 32-1012, and 32

regulated substances, associated

piping and ancillary equipment

and a containment system.

A, L Not an ARAR 


\begin{tabular}{|c|c|c|c|c|c|}
\hline Title & Citation ${ }^{\mathrm{a}}$ & Description & Comment & Type $^{b}$ & Determination \\
\hline $\begin{array}{l}\text { Kansas Levee Law } \\
\text { and Regulations }\end{array}$ & $\begin{array}{l}\text { KSA, Chapter } \\
\text { 24, Article 1; } \\
\text { KAR, Title 5, } \\
\text { Article } 45\end{array}$ & $\begin{array}{l}\text { Requires prior approval of chief engineer before } \\
\text { construction of floodplain fills and levees (KSA 24- } \\
\text { 126). "Floodplain fill" means material, usually soil, } \\
\text { rock, or rubble, placed in a floodplain to an } \\
\text { average height of more than } 1 \mathrm{ft} \text { above the existing } \\
\text { ground, which has the effect of diverting, } \\
\text { restricting, or raising the level of floodwaters on a } \\
\text { stream (KAR 5-45-1). }\end{array}$ & $\begin{array}{l}\text { Applicable if site activities involve } \\
\text { construction of floodplain fills. }\end{array}$ & $A$ & Not an ARAR \\
\hline $\begin{array}{l}\text { Kansas Historic } \\
\text { Preservation Act and } \\
\text { Regulations }\end{array}$ & $\begin{array}{l}\text { KSA, Chapter } \\
75 \text {, Article } 27 \\
\text { KAR, Title } 118 \\
\text { Article } 3\end{array}$ & $\begin{array}{l}\text { Provides for protection and preservation of sites } \\
\text { and buildings listed on state or federal historic } \\
\text { registries (KSA 75-2715 through 75-2726; KAR } \\
\text { 118-3-1 through 118-3-16). }\end{array}$ & $\begin{array}{l}\text { Applicable if the investigation or } \\
\text { response site is a listed state or } \\
\text { federal historic site or is adjacent to } \\
\text { such a site and if activities } \\
\text { requiring permitting are initiated at } \\
\text { the site. }\end{array}$ & $A$ & Not an ARAR \\
\hline $\begin{array}{l}\text { Kansas Unmarked } \\
\text { Burial Sites } \\
\text { Preservation Act }\end{array}$ & $\begin{array}{l}\text { KSA Chapter } \\
75 \text {, Article } 27 \\
\text { KAR Title } 126 \\
\text { Article } 1\end{array}$ & $\begin{array}{l}\text { Establishes the Burial Sites Preservation Board; } \\
\text { prohibits unauthorized disturbance; requires } \\
\text { permits for excavation of any unmarked burial site, } \\
\text { registered or unregistered (KSA 75-2741 through } \\
\text { 75-2754; KAR 126-1-1 through 126-1-2). }\end{array}$ & $\begin{array}{l}\text { Applicable if investigation or } \\
\text { remediation activities encounter a } \\
\text { burial site. }\end{array}$ & $L, A$ & Not an ARAR \\
\hline $\begin{array}{l}\text { Agricultural and } \\
\text { Specialty } \\
\text { Remediation Act }\end{array}$ & $\begin{array}{l}\text { KSA Chapter } 2 \text {, } \\
\text { Article } 37 \\
\text { KAR Title } 124 \\
\text { Article } 1\end{array}$ & $\begin{array}{l}\text { Provides for the reimbursement of corrective action } \\
\text { costs resulting from an incident involving a rupture, } \\
\text { leak, spill, emission, discharge, disposal, or any } \\
\text { other event that releases an agricultural or } \\
\text { specialty chemical accidentally or otherwise into } \\
\text { the environment. Releases resulting from the } \\
\text { normal use of a product or practice in accordance } \\
\text { with the law are not covered. }\end{array}$ & $\begin{array}{l}\text { Applicable if remediation activities } \\
\text { involve the release of an } \\
\text { agricultural or specialty chemical. } \\
\text { Costs to the federal government } \\
\text { are considered ineligible. }\end{array}$ & $C, A$ & $\begin{array}{l}\text { Relevant and } \\
\text { appropriate }\end{array}$ \\
\hline $\begin{array}{l}\text { Guidelines for } \\
\text { Obtaining an } \\
\text { Alternative Public } \\
\text { Drinking Water } \\
\text { Source }\end{array}$ & BER-032 & - & Formerly BER-RS-032. 2005. & $A$ & $\mathrm{TBC}^{\mathrm{C}}$ \\
\hline
\end{tabular}

Kansas Historic Preservation Act and , Article 27 KAR, Title 118 Article 3

SA Chapter 75 , Article 27 KAR Title 126

KSA Chapter 2, Article 37 KAR Title 124, ak, spill, emission, discharge, disposal, or any cicicultural or normal use of a product or practice in accordance with the law are not covered.

\section{rohibits unauthorized disturbance; requires}

registered (KSA 75-2741 through

costs to the federal government

Formerly BER-RS-032. 2005. 
TABLE B.2 (Cont.)

\begin{tabular}{|c|c|c|c|c|c|}
\hline Title & Citation ${ }^{a}$ & Description & Comment & Type ${ }^{b}$ & Determination \\
\hline $\begin{array}{l}\text { Kansas Vapor } \\
\text { Intrusion Guidance } \\
\text { Chemical Vapor } \\
\text { Intrusion and } \\
\text { Residential Indoor } \\
\text { Air }\end{array}$ & & - & No number provided. 2007. & $A$ & TBC \\
\hline $\begin{array}{l}\text { Public Information } \\
\text { Program }\end{array}$ & BER-RS-002 & - & Adopted 1993. & $A$ & TBC \\
\hline $\begin{array}{l}\text { Characterization and } \\
\text { Management of } \\
\text { Contaminated Soil } \\
\text { Cuttings }\end{array}$ & BER-RS-003 & - & Revised 1996. & $A, C$ & TBC \\
\hline $\begin{array}{l}\text { Cost Recovery of } \\
\text { EPA's Past Costs }\end{array}$ & BER-RS-004 & - & Revised 2005. & $A$ & Not a TBC \\
\hline $\begin{array}{l}\text { Evaluating Future } \\
\text { Land Use }\end{array}$ & BER-RS-005 & - & Revised 2005. & $A$ & TBC \\
\hline $\begin{array}{l}\text { Final Guidance for } \\
\text { Verification Sampling } \\
\text { of Non-Hazardous } \\
\text { Industrial } \\
\text { Wastewater Ponds }\end{array}$ & BER-RS-006 & - & Revised 1996. & $A, C$ & Not a TBC \\
\hline $\begin{array}{l}\text { Minimum Standards } \\
\text { for Model Use }\end{array}$ & BER-RS-007 & - & Revised 2005. & $A$ & TBC \\
\hline $\begin{array}{l}\text { Development of Draft } \\
\text { CADs }\end{array}$ & BER-RS-009 & - & Revised 2005. & $A$ & TBC \\
\hline $\begin{array}{l}\text { Utilization of Funding } \\
\text { Through the State } \\
\text { Water Plan }\end{array}$ & BER-RS-011 & - & Revised 2001. & $A$ & TBC \\
\hline
\end{tabular}




\begin{tabular}{|c|c|c|c|c|c|}
\hline Title & Citation $^{a}$ & Description & Comment & Type $^{b}$ & Determination \\
\hline $\begin{array}{l}\text { Recommended } \\
\text { Remedial Levels for } \\
\text { Nitrate and Ammonia } \\
\text { in Soils }\end{array}$ & BER-RS-012 & - & Revised 2002. & $A, C$ & TBC \\
\hline $\begin{array}{l}\text { Investigation and } \\
\text { Remediation of Salt } \\
\text { (Chloride)-Impacted } \\
\text { Soil and } \\
\text { Groundwater }\end{array}$ & BER-RS-013A & - & Revised 2005. & $A, C$ & TBC \\
\hline $\begin{array}{l}\text { Potential Applicable } \\
\text { or Relevant and } \\
\text { Appropriate } \\
\text { Requirements } \\
\text { ARARs }\end{array}$ & BER-RS-015 & - & Revised 2005. & $A$ & TBC \\
\hline $\begin{array}{l}\text { Scope of Work } \\
\text { (SOW) for a } \\
\text { Preliminary } \\
\text { Investigation }\end{array}$ & BER-RS-017 & - & Revised 2005. & $A$ & TBC \\
\hline $\begin{array}{l}\text { Scope of Work } \\
\text { (SOW) for a } \\
\text { Comprehensive } \\
\text { Investigation }\end{array}$ & BER-RS-018 & - & Revised 2005. & $A$ & TBC \\
\hline $\begin{array}{l}\text { Scope of Work } \\
\text { (SOW) for a } \\
\text { Corrective Action } \\
\text { Study }\end{array}$ & BER-RS-019 & - & Revised 3-29-01. & $A$ & TBC \\
\hline $\begin{array}{l}\text { Scope of Work } \\
\text { (SOW) for a } \\
\text { Comprehensive } \\
\text { Investigation } \\
\text { (CI)/Corrective } \\
\text { Action Study (CAS) }\end{array}$ & BER-RS-020 & - & Revised 2005. & $A$ & TBC \\
\hline
\end{tabular}

Groundwater

or Relevant and

Appropriate

Requirements

mprehensive

Scope of Work

Investigation

Action Study (CAS) 
TABLE B.2 (Cont.)

\begin{tabular}{|c|c|c|c|c|c|}
\hline Title & Citation ${ }^{a}$ & Description & Comment & Type & Determination \\
\hline $\begin{array}{l}\text { Scope of Work } \\
\text { (SOW) for a } \\
\text { Corrective Action } \\
\text { Plan } \\
\text { (CAP)/Corrective } \\
\text { Action (CA) }\end{array}$ & BER-RS-023 & - & Revised 2005. & $A$ & TBC \\
\hline Reclassification Plan & BER-RS-024 & - & Revised 2001. & $A$ & TBC \\
\hline $\begin{array}{l}\text { Scope of Work } \\
\text { (SOW) for a } \\
\text { Remedial } \\
\text { Investigation } \\
\text { (RI)/Feasibility Study } \\
\text { (FS) }\end{array}$ & BER-RS-025 & - & Revised 2005. & $A$ & TBC \\
\hline $\begin{array}{l}\text { Scope of Work } \\
\text { (SOW) for a } \\
\text { Remedial Design } \\
\text { (RD)/Remedial } \\
\text { Action (RA) }\end{array}$ & BER-RS-026 & - & Revised 2005. & $A$ & TBC \\
\hline $\begin{array}{l}\text { Reimbursement of } \\
\text { Costs for use of } \\
\text { KDHE Direct-Push } \\
\text { and Mobile } \\
\text { Laboratory }\end{array}$ & BER-RS-027 & - & Revised 2005. & $A$ & TBC \\
\hline $\begin{array}{l}\text { Consideration for } \\
\text { Hydraulic } \\
\text { Containment }\end{array}$ & BER-RS-028 & - & Revised 2005. & $A$ & TBC \\
\hline $\begin{array}{l}\text { Removal Site } \\
\text { Evaluation } \\
\text { (RSE)/Removal } \\
\text { Action Design } \\
\text { (RAD)/Removal } \\
\text { Action (RA) }\end{array}$ & BER-RS-031 & - & Revised 1996. & $A$ & TBC \\
\hline
\end{tabular}

Action (CA)

Scope of Work

(SOW) for

(RI)/Feasibility Study

Action (RA)

Consideration for

Hydraulic

RSE)/Remova 


\begin{tabular}{|c|c|c|c|c|c|}
\hline Title & Citation ${ }^{a}$ & Description & Comment & Type $^{b}$ & Determination \\
\hline $\begin{array}{l}\text { Guidelines for } \\
\text { Obtaining an } \\
\text { Alternative Public } \\
\text { Drinking Water } \\
\text { Source (changed to } \\
\text { BER-032, 2005) }\end{array}$ & BER-RS-032 & - & Adopted 1995. & $A$ & TBC \\
\hline $\begin{array}{l}\text { Considerations for } \\
\text { Remedial Standards }\end{array}$ & BER-RS-033 & - & Revised 2005. & $A, C$ & TBC \\
\hline $\begin{array}{l}\text { Mercury } \\
\text { Contamination } \\
\text { Characterization at } \\
\text { Gas Pipeline Sites }\end{array}$ & BER-RS-034 & - & Revised 2005. & $A, C$ & Not a TBC \\
\hline $\begin{array}{l}\text { Mercury } \\
\text { Contamination } \\
\text { Remediation at Gas } \\
\text { Pipeline Sites }\end{array}$ & BER-RS-035 & - & Revised 2005. & $A, C$ & Not a TBC \\
\hline $\begin{array}{l}\text { Scope of Work for } \\
\text { Site Monitoring }\end{array}$ & BER-RS-036 & - & Revised 2005. & $A$ & TBC \\
\hline $\begin{array}{l}\text { State Cooperative } \\
\text { Program }\end{array}$ & BER-RS-037 & - & Adopted 2005. & $A$ & TBC \\
\hline $\begin{array}{l}\text { Scope of Work for a } \\
\text { Qualitative Risk } \\
\text { Assessment }\end{array}$ & BER-RS-039 & - & Revised 2005. & $A$ & TBC \\
\hline $\begin{array}{l}\text { Clean-up Levels for } \\
\text { Total Petroleum } \\
\text { Hydrocarbons }\end{array}$ & BER-RS-041 & - & Adopted 2000. & $A, C$ & TBC \\
\hline Addendum & BER-RS-041 & - & Adopted 2001. & $A, C$ & TBC \\
\hline $\begin{array}{l}\text { Monitored Natural } \\
\text { Attenuation }\end{array}$ & BER-RS-042 & - & Revised 2005. & $A, C$ & TBC \\
\hline
\end{tabular}

Considerations fo

Characterization at

Gas Pipeline Sites

Remediation at Gas

State Cooperative

Scope of Work for a

Qualitative Risk

Clean-up Levels fo

otal Petroleum

Addendum

Attenuation
BER-RS-042 
TABLE B.2 (Cont.)

\begin{tabular}{|c|c|c|c|c|c|}
\hline Title & Citation $^{a}$ & Description & Comment & Type $^{b}$ & Determination \\
\hline $\begin{array}{l}\text { Considerations for } \\
\text { Groundwater Use } \\
\text { and Applying RSK } \\
\text { Standards to } \\
\text { Contaminated } \\
\text { Groundwater }\end{array}$ & BER-RS-045 & - & Adopted 2004 & A, C & TBC \\
\hline $\begin{array}{l}\text { Filtering Water } \\
\text { Samples Collected } \\
\text { for Metal Analysis }\end{array}$ & BER-RS-046 & - & Adopted 2006. & A & TBC \\
\hline $\begin{array}{l}\text { Scope of Work } \\
\text { (SOW) For a Nitrate } \\
\text { Presumptive } \\
\text { Remedy }\end{array}$ & BER-RS-047 & - & Adopted 2003. & A, C & TBC \\
\hline $\begin{array}{l}\text { Consideration and } \\
\text { Selection of Borrow } \\
\text { Sites }\end{array}$ & BER-RS-048 & - & Adopted 2007. & A & TBC \\
\hline $\begin{array}{l}\text { Cost Recovery } \\
\text { Guidance for } \\
\text { KDHE/BER Activities } \\
\text { at Sites Determined } \\
\text { to have Responsible } \\
\text { Parties }\end{array}$ & BER-RS-049 & - & Adopted 2007. & A & TBC \\
\hline $\begin{array}{l}\text { Remediating Soil } \\
\text { From Agricultural } \\
\text { Chemical Incidents } \\
\text { by Excavation \& } \\
\text { Land Applications } \\
\text { Interim Measures }\end{array}$ & BER-RS-050 & - & Adopted 2007. & A, C & TBC \\
\hline $\begin{array}{l}\text { VCPRP Initial } \\
\text { Deposits For } \\
\text { Grouped Properties }\end{array}$ & $\begin{array}{l}\text { BER-RS-VCP- } \\
001\end{array}$ & - & Adopted 2004 & A & TBC \\
\hline
\end{tabular}

\section{Filtering Wate}

Remedy

Consideration and

Selection of Borrow

Cost Recovery

KDHE/BER Activities

at Sites Determined

to have Responsible

Remediating Soil

From Agricultural

by Excavation \&

Land Applications

VCPRP Initia

Grouped Properties

$$
001
$$


TABLE B.2 (Cont.)

\begin{tabular}{|c|c|c|c|c|c|}
\hline Title & Citation $^{\mathrm{a}}$ & Description & Comment & Type $^{b}$ & Determination \\
\hline $\begin{array}{l}\text { Eligibility } \\
\text { Determinations } \\
\text { Concerning Public or } \\
\text { Private Drinking } \\
\text { Water Well } \\
\text { Situations }\end{array}$ & $\begin{array}{l}\text { BER-RS-VCP- } \\
002\end{array}$ & - & Adopted 2000. & A & TBC \\
\hline $\begin{array}{l}\text { Standards for } \\
\text { Property } \\
\text { Identification For } \\
\text { Issuance of NFA } \\
\text { Determinations }\end{array}$ & $\begin{array}{l}\text { BER-RS-VCP- } \\
003\end{array}$ & - & Adopted 2002. & A & TBC \\
\hline $\begin{array}{l}\text { Transfer of } \\
\text { Contaminated Sites } \\
\text { From the State } \\
\text { Cooperative Program } \\
\text { to the Voluntary } \\
\text { Cleanup and } \\
\text { Property } \\
\text { Redevelopment } \\
\text { Program }\end{array}$ & $\begin{array}{l}\text { BER-RS-VCP- } \\
004\end{array}$ & - & Adopted 2003. & A & TBC \\
\hline $\begin{array}{l}\text { Property Eligibility for } \\
\text { Assessments } \\
\text { Conducted by the } \\
\text { Brownfields Program }\end{array}$ & $\begin{array}{l}\text { BER-RS-BF- } \\
001\end{array}$ & - & Adopted 2004. & A & TBC \\
\hline $\begin{array}{l}\text { Natural Resource } \\
\text { Damage } \\
\text { Assessments }\end{array}$ & BER-ARS-044 & - & Adopted 2002. & A & TBC \\
\hline Sediment Policy & BER-ARS-045 & - & Adopted 2004. & A & TBC \\
\hline $\begin{array}{l}\text { Kansas Petroleum } \\
\text { Storage Tank } \\
\text { Release Trust Fund } \\
\text { Policy and } \\
\text { Procedures Manual }\end{array}$ & - & - & - & A & Not a TBC \\
\hline
\end{tabular}

Standards for

BER-RS-VCP

Issuance of NFA

R-RS-VCP-

From the State

to the Voluntary

Cleanup and

Program

perty Eligibility for 00

Conducted by the

wnfields Program

Damage

Assessments 


\begin{tabular}{|c|c|c|c|c|c|}
\hline Title & Citation $^{a}$ & Description & Comment & Type $^{b}$ & Determination \\
\hline $\begin{array}{l}\text { Kansas Storage } \\
\text { Tank Program } \\
\text { Aboveground } \\
\text { Storage Tank } \\
\text { Overview }\end{array}$ & - & - & - & $A$ & Not a TBC \\
\hline $\begin{array}{l}\text { Updated Policy and } \\
\text { Procedures Manual } \\
\text { for the } \\
\text { Preventative/UST } \\
\text { Unit Storage Tank } \\
\text { Section }\end{array}$ & - & - & - & $A$ & TBC \\
\hline $\begin{array}{l}\text { Kansas Geological } \\
\text { Survey Public } \\
\text { Information } \\
\text { Circular } 23 \text { - Drilling } \\
\text { a Water Well on Your } \\
\text { Land; What You } \\
\text { Should Know }\end{array}$ & $\begin{array}{l}\text { Suchy et al. } \\
2011\end{array}$ & $\begin{array}{l}\text { Includes a primer on groundwater systems; } \\
\text { describes how to evaluate the potential for a water } \\
\text { well; advises that a yield of } 4-5 \text { gpm is considered } \\
\text { the minimum amount necessary for domestic } \\
\text { household use; references the need to select a } \\
\text { reputable and responsible driller, and points out } \\
\text { the need to check with local and state regulatory } \\
\text { agencies for permitting and construction } \\
\text { regulations. }\end{array}$ & Adopted in 2005; amended in 2011 & $A$ & TBC \\
\hline $\begin{array}{l}\text { Presumptive } \\
\text { Remedy Policy } \\
\text { Investigation and } \\
\text { Cleanup of Nitrogen } \\
\text { at Agriculture- } \\
\text { Related Sites in } \\
\text { Kansas }\end{array}$ & $\begin{array}{l}\text { BER-RS-047. } \\
2014\end{array}$ & $\begin{array}{l}\text { The KDHE guidance on the investigation and } \\
\text { remediation of nitrate and ammonium } \\
\text { contamination at agriculture and bulk distribution- } \\
\text { related sites that includes the use, manufacture, } \\
\text { transportation and/or distribution of chemicals } \\
\text { resulting in nitrogen contamination. }\end{array}$ & - & $A$ & TBC \\
\hline
\end{tabular}

ransportation and/or distribution of chemicals

Related Sites in resulting in nitrogen contamination. 
TABLE B.2 (Cont.)

\begin{tabular}{|c|c|c|c|c|c|}
\hline Title & Citation ${ }^{a}$ & Description & Comment & Type ${ }^{b}$ & Determination \\
\hline $\begin{array}{l}\text { Guidelines for } \\
\text { Investigating and } \\
\text { Remediating } \\
\text { Nitrate/Ammonia } \\
\text { Contamination from } \\
\text { Agricultural Chemical } \\
\text { Releases }\end{array}$ & $\begin{array}{l}\text { BER-RS-050, } \\
\text { June } 2010\end{array}$ & $\begin{array}{l}\text { Addresses nitrate contamination in soil and } \\
\text { groundwater. }\end{array}$ & Rescinded & $A$ & Not a TBC \\
\hline
\end{tabular}

a Abbreviations for citations:

KAR, Kansas Administrative Regulations

KSA, Kansas Statutes Annotated

b Types:

A, action-specific

C, chemical-specific

L, location-specific

c TBC, To-be-considered 


\section{Appendix C:}

Estimation of the Operating Time Period for Groundwater Extraction in Alternatives 2, 3, and 4 


\section{Appendix C: \\ Estimation of the Operating Time Period for Groundwater Extraction in Alternatives 2, 3, and 4}

\section{C.1 Estimation Method}

A component of Alternatives 2, 3, and 4 is groundwater extraction by three wells, to be installed within existing large-diameter boreholes LDB2, LDB3, and LDB5 (Figure C.1). The construction method proposed is designed to take advantage of the large subsurface contact area that the LDBs provide with the saturated, contaminated silty-clayey sediments and groundwater in the immediate vicinity of the source area identified at the former CCC/USDA facility. The characteristics of the saturated soils in the source area, the nature of the contamination, and results of previous studies indicate that residual carbon tetrachloride concentrations in the groundwater are likely to decrease to asymptotic levels after the contaminated interval has been flushed with several pore volumes ${ }^{1}$ of water. For purposes of cost estimation, a simplified volumetric method (described here) was used to estimate the extraction well operation time required for the carbon tetrachloride concentration to reach asymptotic levels in the targeted source area. Estimation by numerical modeling was not attempted, in light of the relatively small lateral extent of the source area and the availability of test pumping data for two (LBS 2 and LBD3) of the three proposed extraction locations (Argonne 2018).

Pumping of the extraction wells will induce a cone of depression ${ }^{2}$ within the radius-ofinfluence (ROI) ${ }^{3}$ of the wells, and will remove a significant amount of carbon tetrachloride from the groundwater (and saturated soils) in the target area on the former CCC/USDA property.

1 Pore volume is the aggregate volume of the air spaces between soil grains.

2 Cone of depression is the natural depression in the water table around a well during pumping.

3 For remedial alternatives involving pumping, the ROI is the radial distance from the center of a wellbore to the point where no lowering of the water table or potentiometric surface occurs (i.e., the edge of the cone of depression). For other alternatives, the ROI is the area influenced by the treatment. 


\section{C.2 Characteristics of the Saturated Zone and Anticipated Response to Groundwater Pumping}

The operating time estimate for the extraction well is in part based on (1) the anticipated pumping rates of the extraction wells, and (2) their combined ROI, and hence the volume of the contaminated groundwater contained within the cone of depression induced by the pumping.

In March 2017, with the approval of the CCC/USDA, Argonne conducted a short-term pumping test at the LDB2 and LDB3 locations, to evaluate the viability of groundwater extraction from the large-diameter borings. For this experiment, a submersible pump was installed in the existing, 4-in. diameter SVE well in each of these LDBs and flow rates were progressively adjusted to determine a sustainable flow from each boring. The SVE well in each of the borings only partially penetrates the available saturated interval, which extends from the water table at a typical depth of approximately $43 \mathrm{ft}$ BGL to bedrock at approximately $65 \mathrm{ft}$ BGL, limiting the maximum drawdown that could be attained during the experiment.

The results of this investigation indicated that an estimated, combined extraction rate of approximately $4.3 \mathrm{gpm}$ could be sustained from the two LDBs in their present configuration (Argonne 2018). Under the experimental conditions a ROI of at least $100 \mathrm{ft}$ was documented in response to the pumping at LDB2 and LDB3, in association with a somewhat irregularly shaped cone of depression (Figure C.2). Figures C.1 and C.2 therefore indicate that capture and removal of carbon tetrachloride from the targeted area of groundwater contamination at the former CCC/USDA facility can be expected under Alternatives 2, 3, and 4.

As noted above, groundwater extraction from borings LDB2, LDB3, and LDB5 is proposed under Alternatives 2, 3, and 4; the inclusion of LDB5 is expected to improve the symmetry of the resulting cone of depression, and enhance the recovery of contaminated groundwater from the central, most concentrated portion of the targeted treatment area (Figures C.1 and C.2). As part of this alternative, the existing, 4-in. diameter (SVE) well in each LDB will be replaced by a larger (8-in. diameter) casing and screen extending to bedrock, to further improve the recovery of groundwater from each LDB.

On the basis of these findings and recommended modifications to the pumping configuration in the target area, sustainable (combined) pumping rates ranging from 5 gpm to $7 \mathrm{gpm}$ have been conservatively estimated for the three-well extraction system proposed in 
Alternatives 2, 3, and 4. Similarly, a conservative ROI of approximately $100 \mathrm{ft}$ from the center of the pumping-well cluster is estimated for the extraction system at Agra, yielding an estimated pore volume within the associated cone of depression of approximately 138,230 $\mathrm{ft}^{3}$ to $207,345 \mathrm{ft}^{3}$ (or 1,033,961 to 1,550,941 gallons, assuming effective porosities of $20 \%$ to $30 \%$, Table C.1).

\section{C.3 Estimated Operating Time for the Extraction Well}

In general, the performance of groundwater extraction in removing contaminants is influenced by known factors, such as non-aqueous phase liquid (NAPL) dissolution, contaminant sorption and desorption, matrix diffusion, and variations in groundwater velocity (Cohen et al. 1994). These factors typically contribute to a "tailing" effect (Boulding 1996) that results in persistent low-level (asymptotic) concentrations of the target contaminants. The operation time required to reach an asymptotic concentration of carbon tetrachloride in the source area at the former CCC/USDA facility was estimated through the following evaluation:

- The results from the KDHE, CCC/USDA, and Pro Ag investigations (see Section 2) indicate that no carbon tetrachloride is present in the form of NAPL.

- Palmer and Fish (1992) found that, in the absence of free product (NAPL), the number of pore volumes required to remove an organic contaminant from a homogeneous aquifer is approximately equal to the retardation factor. ${ }^{4}$ The retardation factor reflects the overall processes by which contaminants from groundwater tend to be adsorbed onto the solid phase of the water-bearing unit, thus retarding contaminant migration.

- In work conducted in 2003, Argonne estimated carbon tetrachloride retardation factors ranging from 1.5 to 1.8 for soil samples collected from sites in Nebraska and Kansas. In another study, Pacific Northwest National Laboratory identified a carbon tetrachloride retardation factor of 1.71 to 3.44 for soil samples collected from the aquifer unit at the U.S. Department of Energy Hanford site (Riley et al. 2005).

4 Retardation factor: The ratio of the groundwater flow rate to the contaminant migration rate, which is an indicator of sorption of groundwater contaminants onto the solid phase of the water-bearing unit. 
- Variations in migration time along different path lines will delay contaminant removal (Cohen et al. 1994). Groundwater flowing along path lines at the edge of the capture zone travels a greater distance and has a longer migration time than groundwater that flows along the center of the capture zone.

- A "tailing" effect is typically observed after initial flushing in laboratory soil column tests and field studies (Boulding 1996), even when initial flushing of the contaminated water-bearing unit with a number of pore volumes equal to the retardation factor reduces contamination significantly.

- The persistent low level (asymptotic level) of contamination remaining after a reasonable period of flushing appears to result from (1) diffusion and desorption from less permeable porous media and/or dead spots, and (2) variations in groundwater velocities due to variable permeability of the porous matrix (Keely 1989; Palmer and Fish 1992; Cohen et al. 1994), in the absence of NAPL. The mechanisms causing the tailing effect will be enhanced by the identified low permeability and fine-grained character of the saturated sediments in the targeted treatment area.

The assessment above indicates that 10 pore volumes is a conservative estimate of the flushing required to remove a significant amount of carbon tetrachloride from the impacted groundwater (and fine-grained, saturated soils) in the target area at the former CCC/USDA facility. On the basis of the highest reported carbon tetrachloride retardation factor of 3.44 for Hanover soils (Riley et al. 2005) and the finding of Palmer and Fish (1992) that the retardation factor is approximately equal to the number of pore volumes required to remove an organic compound from a homogeneous aquifer, extraction of approximately 3.5 pore volumes may be sufficient to bring the carbon tetrachloride concentration to an asymptotic level in the target area at Agra. The value of 10 pore volumes used for the operating time estimates for Alternatives 2, 3, and 4 is, however, greater by approximately a factor of three than the inferred baseline adequate recovery volume, to compensate for the potentially slower removal of carbon tetrachloride from the predominantly fine-grained sediments in the target area.

The operation time for the extraction well cluster was estimated by using a volumetric analysis based on the estimated volume of groundwater within the treatment area (within the cone 
of depression) targeted by the pumping wells, and the assumption of flushing with 10 pore volumes. The results of this evaluation are summarized in Table C.1.

TABLE C.1 Summary of volumetric analyses for the CCC/USDA source area.

\begin{tabular}{|c|c|c|c|c|c|c|c|}
\hline $\begin{array}{c}\text { Area of } \\
\text { Cone of } \\
\text { Depression } \\
\left(\mathrm{ft}^{2}\right)\end{array}$ & $\begin{array}{c}\text { Water- } \\
\text { Bearing } \\
\text { Zone } \\
\text { Thickness } \\
\text { (ft) }\end{array}$ & Porosity & $\begin{array}{l}\text { One Pore } \\
\text { Volume }\left(\mathrm{ft}^{3}\right)\end{array}$ & $\begin{array}{l}\text { One Pore } \\
\text { Volume } \\
\text { (gallons) }\end{array}$ & $\begin{array}{l}\text { Pumping } \\
\text { Rate, Q } \\
\text { (gpm) }\end{array}$ & $\begin{array}{l}\text { Time to } \\
\text { Flush One } \\
\text { Pore } \\
\text { Volume } \\
\text { (day) }\end{array}$ & $\begin{array}{c}\text { Time to } \\
\text { Flush Ten } \\
\text { Pore } \\
\text { Volumes } \\
(y r)\end{array}$ \\
\hline 31,416 & 22 & 0.2 & 138,230 & $1,033,961$ & 5 & 144 & 4.0 \\
\hline 31,416 & 22 & 0.2 & 138,230 & $1,033,961$ & 7 & 96 & 2.6 \\
\hline 31,416 & 22 & 0.3 & 207,345 & $1,550,941$ & 5 & 215 & 5.9 \\
\hline 31,416 & 22 & 0.3 & 207,345 & $1,550,941$ & 7 & 144 & 4.0 \\
\hline
\end{tabular}

The results suggest that operation of the proposed group of three extraction wells for a period of roughly 3-6 years may be sufficient to reduce the concentrations of carbon tetrachloride to asymptotic levels in the targeted source area at the former CCC/USDA facility. 


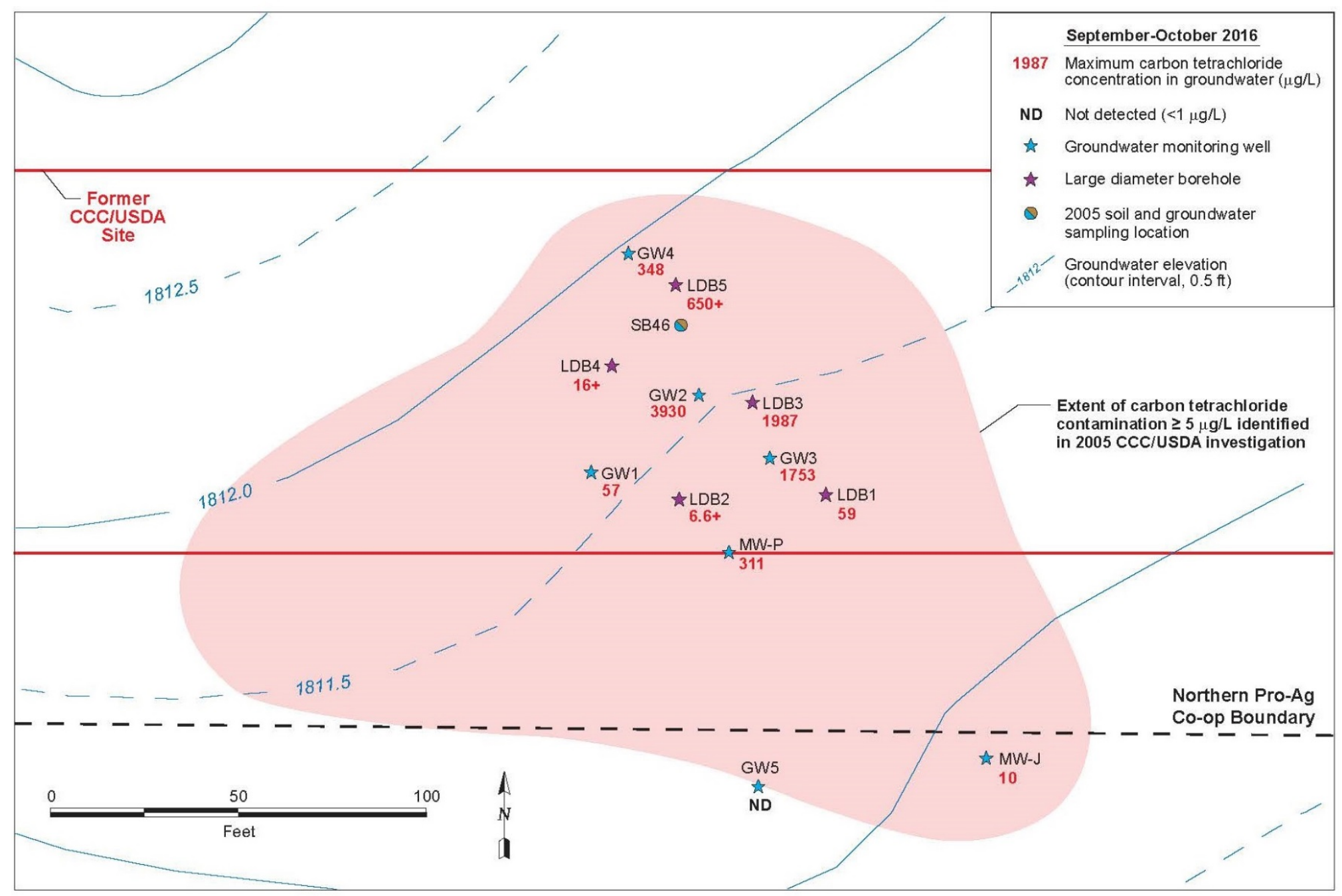

Figure C.1 Maximum carbon tetrachloride concentration $(\mu \mathrm{g} / \mathrm{L})$ in groundwater identified in Sept-Oct 2016, and local extent of the plume as previously identified by the CCC/USDA in 2005 (Argonne 2006). Water level contours constructed with data measured manually on December 6-7, 2016. 


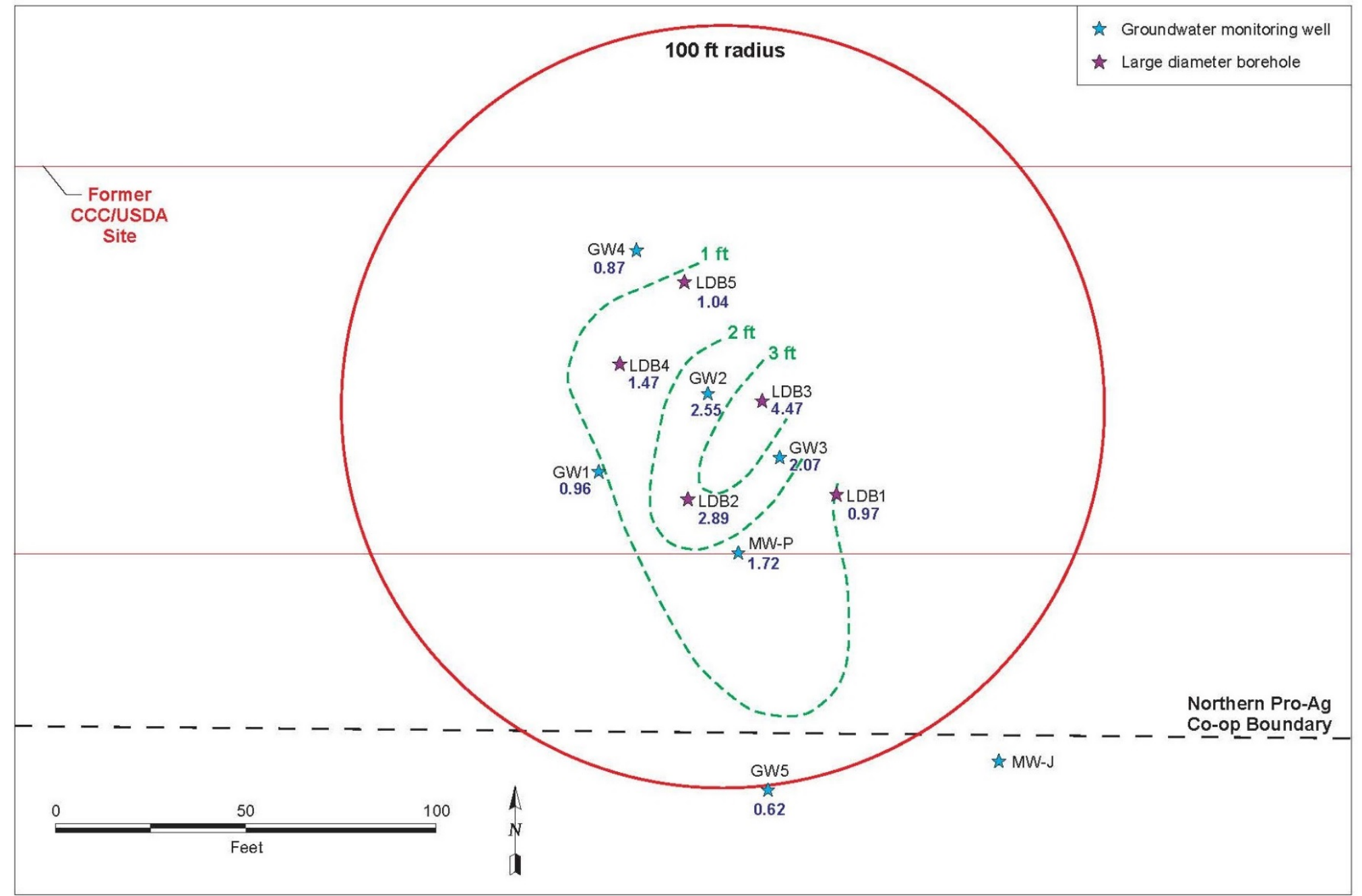

Figure C.2 Drawdown of groundwater levels, in feet from static conditions, observed after six hours of pumping at LDB2 and LDB3 on March 9, 2017. Red circle shows an arbitrary $100 \mathrm{ft}$ radius around the LDB area. 


\section{C.4 References}

Argonne, 2018, Results of Temporary Shutdown Testing and Groundwater Pump-Testing at Agra Kansas, February-September 2016 and March 2017, ANL/EVS/AGEM/TR-18-03, prepared for the Commodity Credit Corporation, U.S. Department of Agriculture, by Argonne National Laboratory, Argonne, Illinois, May.

Boulding, R., 1996, EPA Environmental Engineering Sourcebook, Ann Arbor Press, Inc., Chelsea, Michigan.

Cohen, R.M., A.H. Vincent, J.W. Mercer, C.R. Faust, and C.P. Spalding, 1994, Methods for Monitoring Pump-and-Treat Performance, EPA/600/R-94/123, Robert S. Kerr Environmental Research Laboratory, Office of Research and Development, U.S. Environmental Protection Agency, Ada, Oklahoma.

Keely, J.F., 1989, Performance Evaluations of Pump-and-Treat Remediation, EPA/540/4-89/005, Robert S. Kerr Environmental Research Laboratory, Office of Research and Development, U.S. Environmental Protection Agency, Ada, Oklahoma.

Palmer, C.D., and W. Fish, 1992, Chemical Enhancements to Pump-and-Treat Remediation, Ground Water Issue Paper EPA/540/S-92/001, Robert S. Kerr Environmental Research Laboratory, Office of Research and Development, U.S. Environmental Protection Agency, Ada, Oklahoma.

Riley, R.G., J. E. Szecsody, D.S. Sklarew, A.V. Mitroshkov, C.F. Brown, C.J. Thompson, and P.M. Gent, 2005, Carbon Tetrachloride and Chloroform Partition Coefficients Derived from Aqueous Desorption of Contaminated Hanford Sediments, PNNL-15239, prepared for the U.S. Department of Energy, Washington, D.C., by Pacific Northwest National Laboratory, Richland, Washington, July. 
Lorraine M. LaFreniere, Ph.D.

Principal Geological Engineer

Program Manager

Jorge S. Alvarado, Ph.D.

Chemist

Laboratory Manager and Analyst

Esther E. Bowen, M.S.

Quality Assurance/Quality Control Analyst and

Data Management Specialist

Records Manager

Laurel A. Culbert, B.A.

Graphic Artist/Designer

Report Graphics and Geographic Information System (GIS) Specialist

James Hansen, B.A.

Program Coordinator/Manager

Site Reconnaissance and Community Relations

Louis E. Martino, M.S.

Environmental Systems Engineer/Program

Manager

Technical Lead/Remediation Specialist (Cost Engineering)

Terri Patton, M.S.

Principal Geologist

Technical Editor

Robert A. Sedivy, M.S.

Hydrogeologist

Technical Lead/Hydrogeologist

Eugene Y. Yan, Ph.D.

Earth Scientist

Technical Lead/Hydrogeologist 


\section{Argonne}

\section{Environmental Science Division}

Argonne National Laboratory

9700 South Cass Avenue, Bldg. 203

Lemont, IL 60439-4843

www.anl.gov 